\title{
QUESTIONING IN ENGLISH AS A FOREIGN LANGUAGE UNIVERSITY CLASSES
}

BY

\section{THI VAN ANH PHAN}

A thesis submitted to Victoria University of Wellington

in fulfilment of the requirements for the degree of Doctor of Philosophy in Education 


\begin{abstract}
Vietnam has experienced many changes in education and in teaching and learning English as a foreign language since 1986 (Hoang, 2010). There are ongoing concerns about how to best develop English proficiency in EFL classes, especially how to promote students' English communicative competency in this context.

Questioning is an essential tool to help EFL teachers fulfil instructional goals (Boyd, 2015). Questioning particularly plays an important role in creating interactions to promote student's English language proficiency in EFL classroom (Tuan \& Nhu, 2010). Therefore, my study investigated how teachers and students perceived and used questioning to promote English teaching and learning in tertiary EFL classrooms in Vietnam. This also shed light on the implementation of communicative language teaching (CLT) in Vietnam.
\end{abstract}

My study uses a sociocultural lens, with a qualitative multiple case design (Creswell, 2015; Johnson \& Christensen, 2014). The two cases investigate questioning in classes where English was taught as a non-major subject, and questioning in classes where English was taught as a major. Data were triangulated through semi-structured and stimulated recall interviews with eight teachers, focus groups with eight groups of students, and observations of eight EFL classes. Thematic analysis was conducted to analyse data to find out the themes, the "important idea that occurs multiple times" in the data (Johnson \& Christensen, 2014, p. 600)

Three themes about questioning arose from studying these Vietnamese EFL classes. Firstly, questioning involved communicative interaction, which created opportunities for participants to communicate in the target language. This interaction also empowered students to engage in the lesson. Secondly, using questioning teachers orchestrated learning, diagnosed learning needs, and facilitated classroom relationships. The third theme, "My home, my rules" indicates that questioning was contextually situated. Questioning within these EFL classrooms in Vietnam reflected cultural features, such as the traditional roles of teacher and student, the concern for face or status, and the use of Vietnamese in English classes. 
My data show that both teachers and students can use questioning to promote language learning through critical thinking and collaborative learning. These are central interactive and communicative skills in tertiary EFL teaching and learning in Vietnam. The effectiveness of questioning in my study depended on teachers' skills. It was a commonly used technique to develop English language learning.

This study proposes an adapted model of learning and teaching to capture EFL learning. The model captures how teachers apply CLT and teach English for different purposes. It also emphasises the contextual features influencing questioning and therefore teaching and learning the target language. In this model, questioning is at the centre, promoting learning relationships among the teacher and students. The study contributes to an understanding of using questioning to promote language learning in EFL classroom in an Asian context, and may be relevant to CLT application for language learning classrooms in a wider international context. 


\section{ACKNOWLEDGEMENTS}

I would like to express my sincere thanks to all the people who have supported me, academically and personally, and trusted me in this task throughout my PhD journey

First and foremost, I would like to express my deepest gratitude to my supervisors, Dr Margaret Gleeson and Dr Carolyn Tait. Their careful reading, academic critiques, friendly communication and endless encouragement built up my confidence and further developed my argument and writing skills. Thank you a lot for caring about various aspects of my life in the past four years. I am indebted to them for their kindness and their meticulous attention to my work. This thesis mission would not have been possible without their wonderful supervision.

I would like to thank the scholarship providers - the Vietnamese government and Victoria University of Wellington (VUW) - for providing the financial support for my study and living in New Zealand. My sincere thanks go to the staff in the School of Education at VUW, who have always provided me with necessary advice and support in various fields when I needed.

My thanks also go to other peer PhD students in office Number 3 Waiteata Road. Thanks a lot for useful experiences, suggestions, and encouragement to improve my work. Thanks a lot for their company during the four years' study. They made me realise that friendship and peer support are so important in my life.

I am grateful to all the participants, who were so friendly and supportive during my data collection period. I would also like to thank my colleagues in Vietnam, who keep communicating and encouraging me in my task. Knowing that you are always welcoming me makes me feel so warm.

Last but not least, my special thanks to my family: to my parents for their unconditional love and encouragement; to my husband for following me in this academic pursuit in another country, sharing life and supporting me; and to my son and my new-born baby for always being my strength and love. I am deeply grateful to them for their understanding, support, and love, making my life complete. 


\section{TABLE OF CONTENTS}

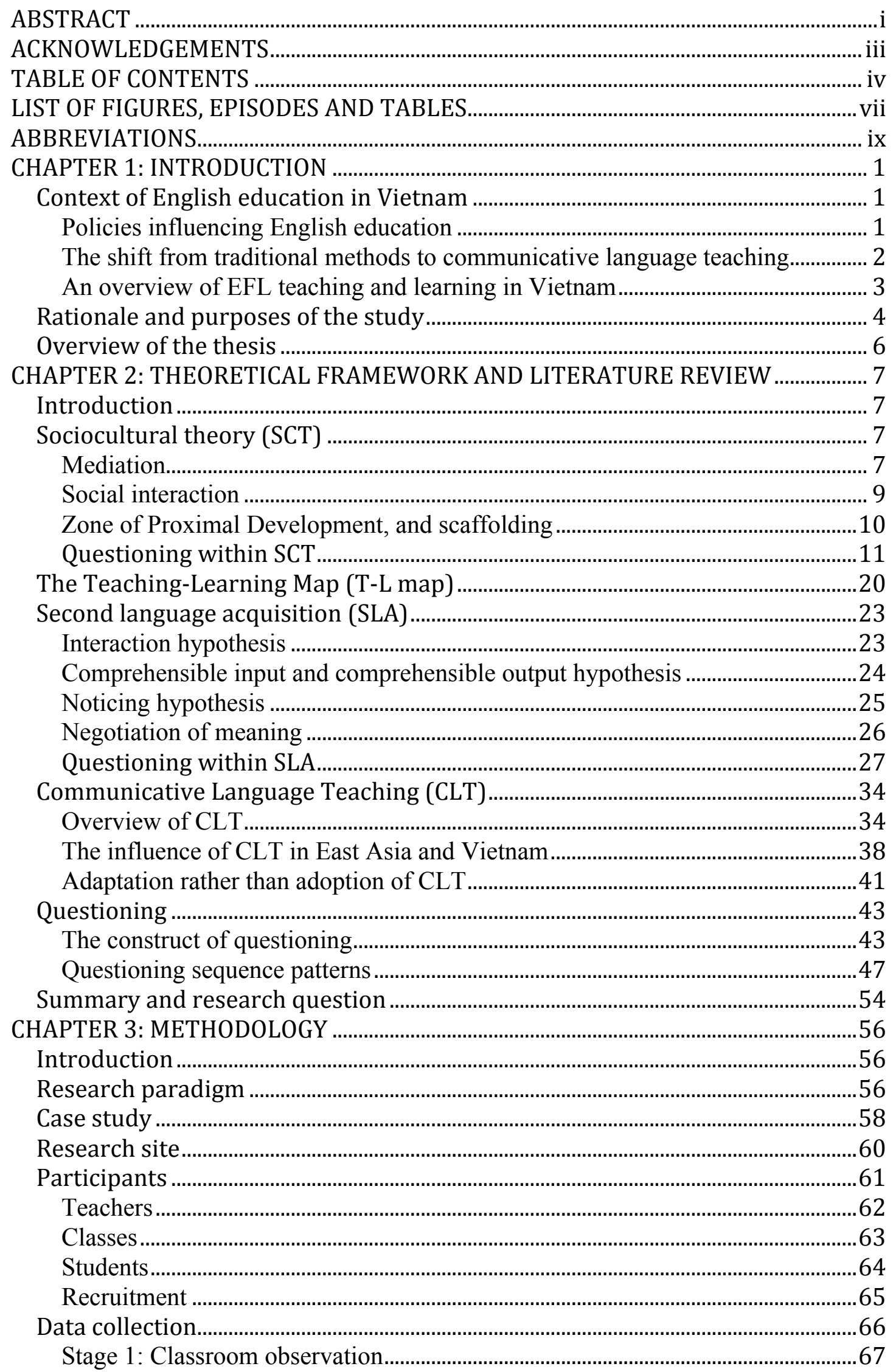


Stage 2: Semi-structured and stimulated interviews with teachers .68

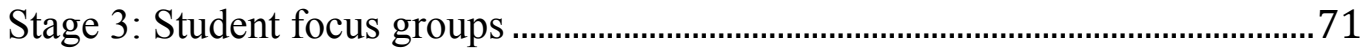

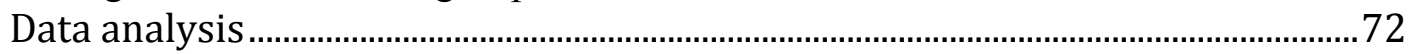

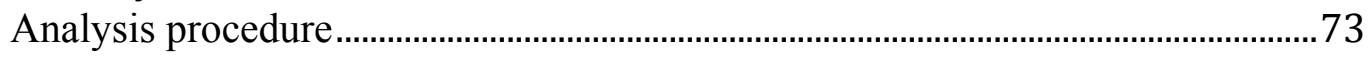

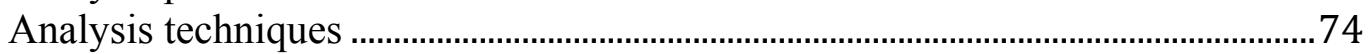

Using Vietnamese or English during data collection and data analysis...............80

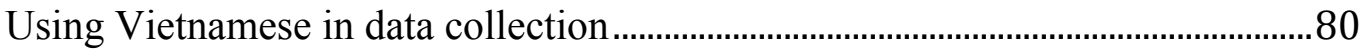

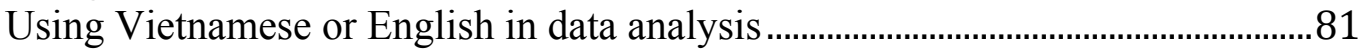

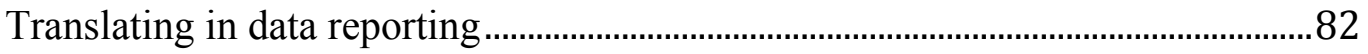

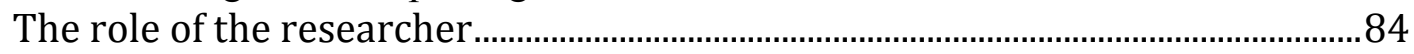

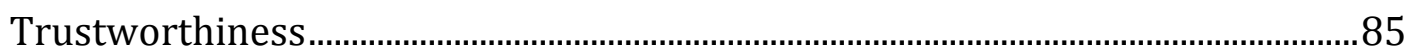

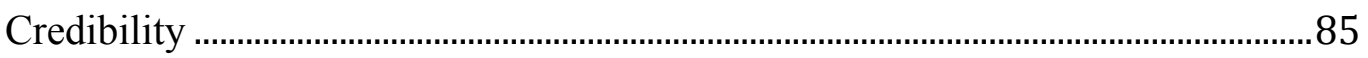

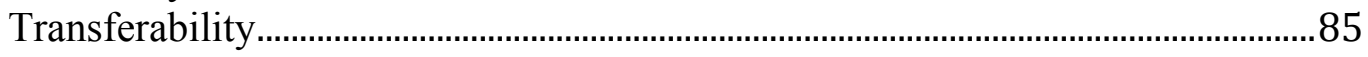

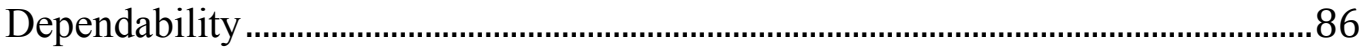

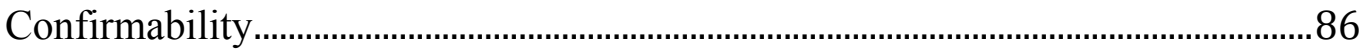

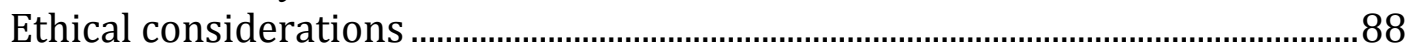

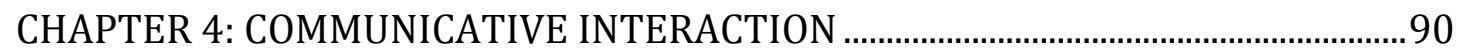

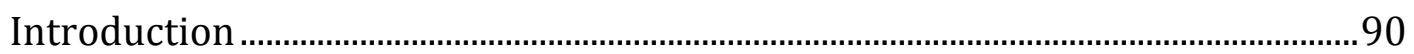

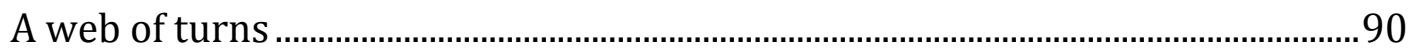

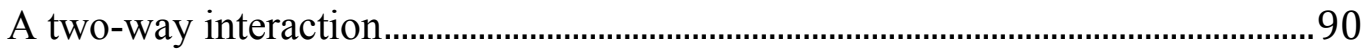

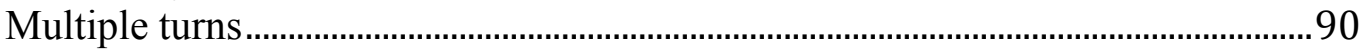

Practice makes improvement..............................................................................93

Communicating meaningfully in English................................................................93

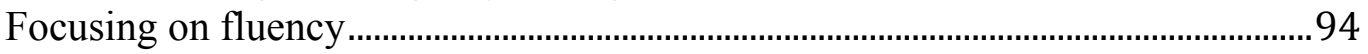

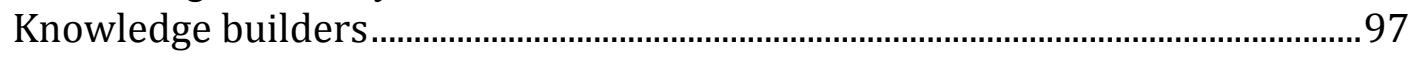

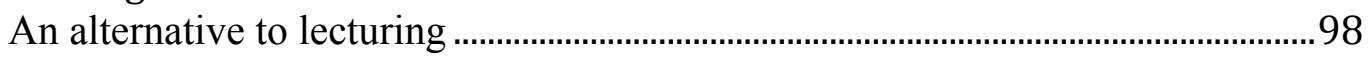

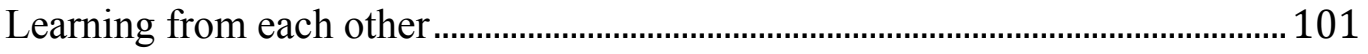

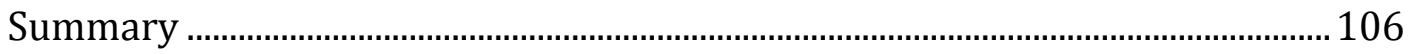

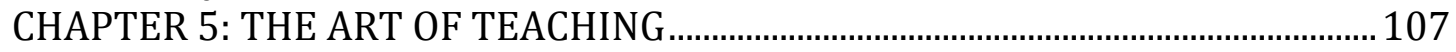

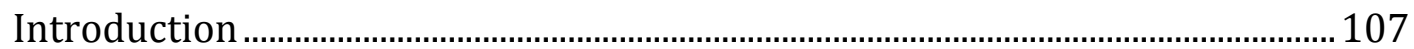

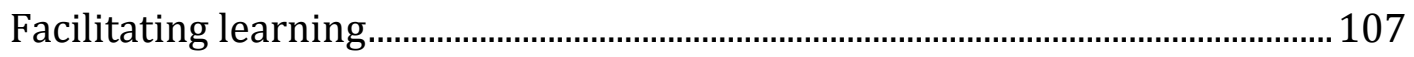

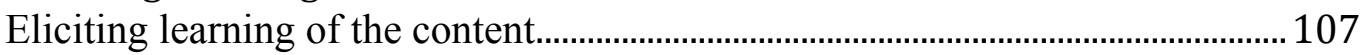

Promoting higher level thinking .......................................................................... 114

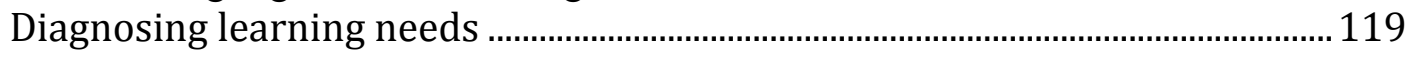

Tailoring teaching ......................................................................................... 119

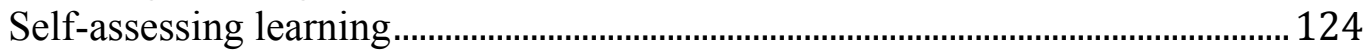

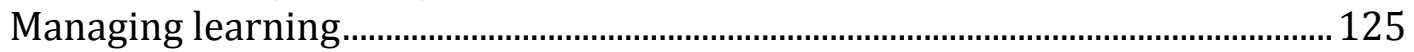

Organising classroom activities ..............................................................................126

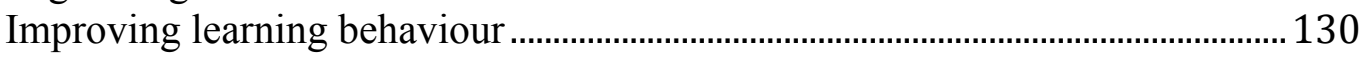

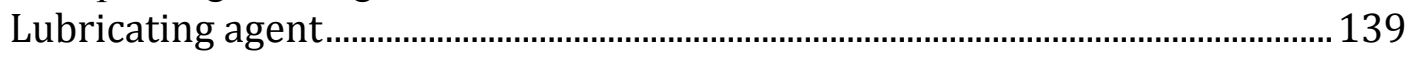

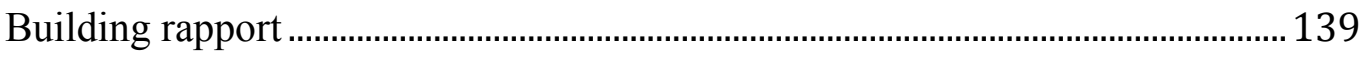

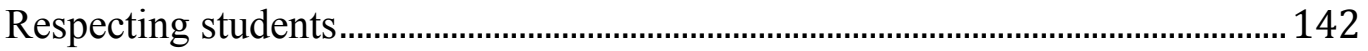

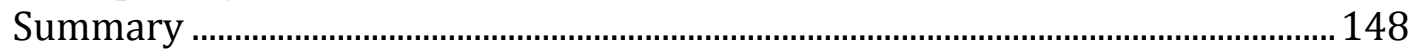

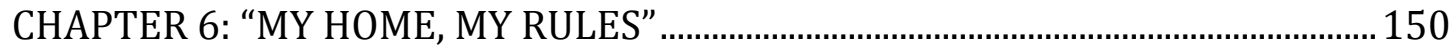

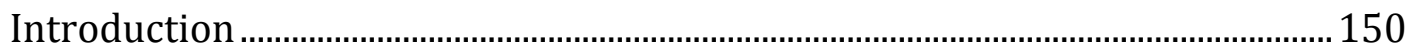

"Without the teacher, students cannot learn" ........................................................ 150

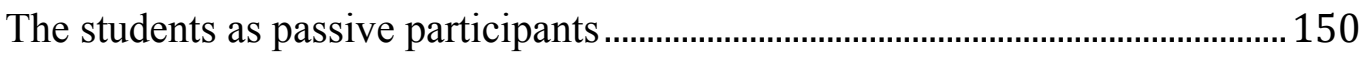

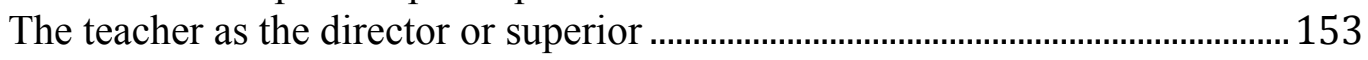

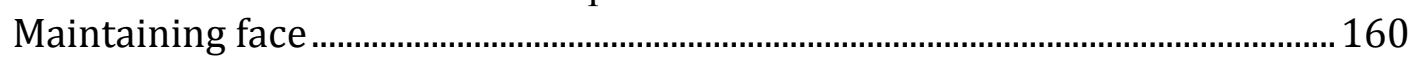


Making a good impression

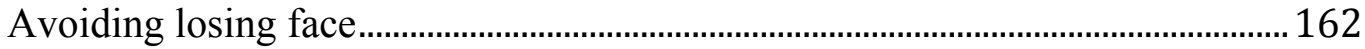

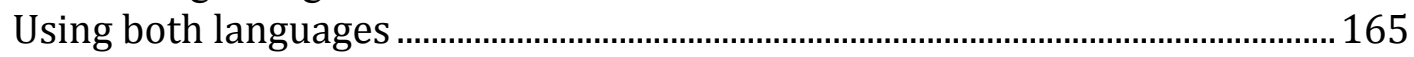

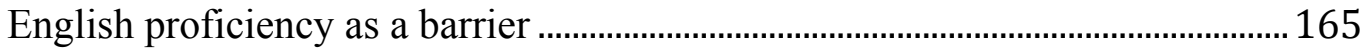

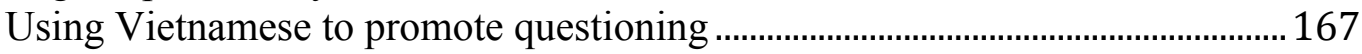

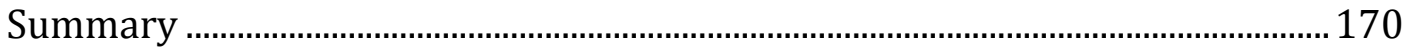

CHAPTER 7: DISCUSSION AND CONCLUSION ……................................................. 173

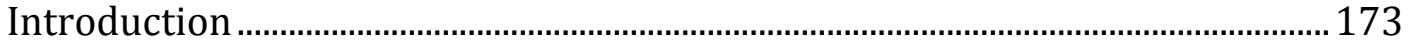

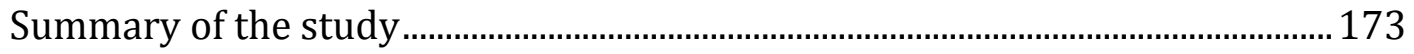

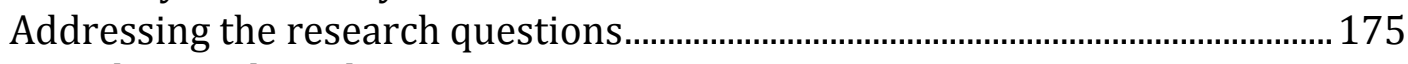

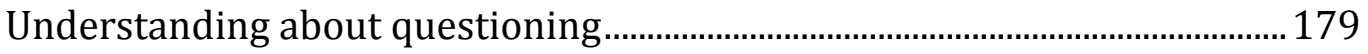

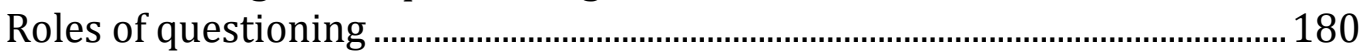

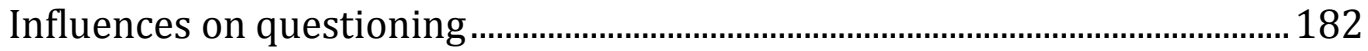

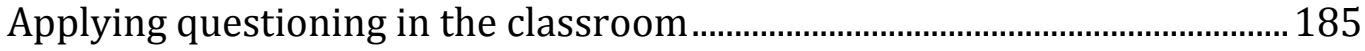

Contrasting questioning between English-major and English non-major

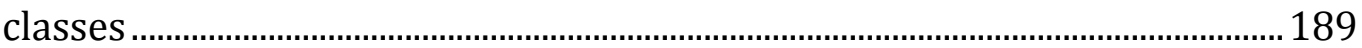

Summary........................................................................................................ 190

An adapted T-L model: Teaching and Learning in Vietnamese Tertiary EFL

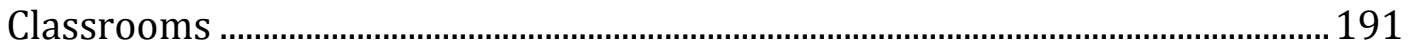

The community contexts: Commitments and tensions in applying the

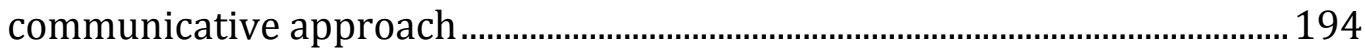

The institutional context and sub-context: English for different purposes.....201

The teaching and learning context: Questioning as a new element...............203

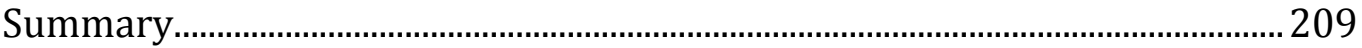

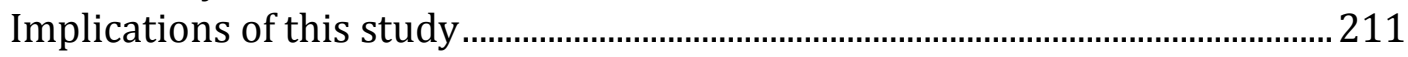

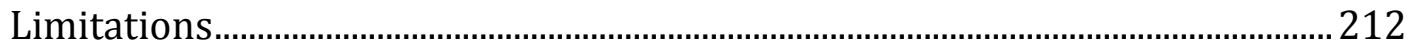

Recommendation for further research ............................................................. 213

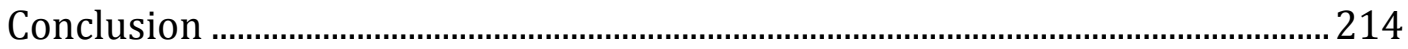

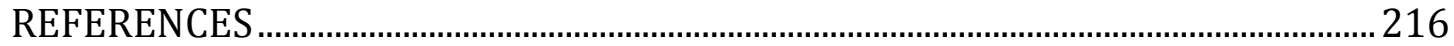

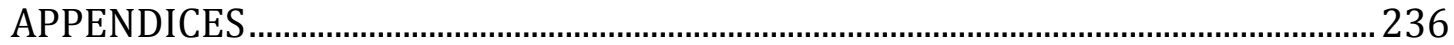

APPENDIX A: INFORMATION SHEET AND CONSENT FOR THE PRESIDENT OF

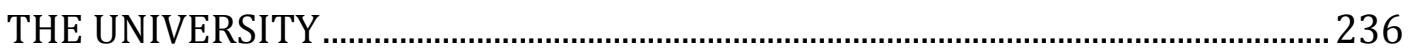

APPENDIX B: INFORMATION SHEET AND CONSENT FOR THE DEANS OF THE

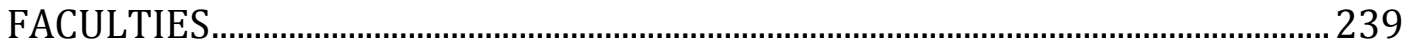

APPENDIX C: INFORMATION SHEET AND CONSENT FOR TEACHER

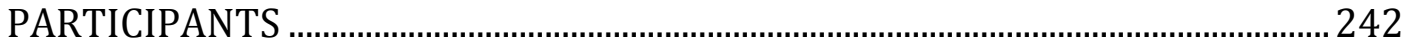

APPENDIX D: INFORMATION SHEET AND CONSENT FOR STUDENTS (CLASS

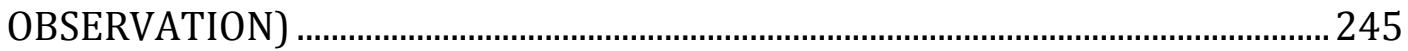

APPENDIX E: INFORMATION SHEET AND CONSENT FOR STUDENT GROUP

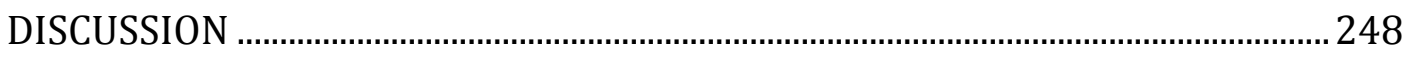

APPENDIX F: INFORMATION AND SUGGESTED GROUND RULES FOR FOCUS

GROUP INTERVIEW ON TEACHER QUESTIONING IN ENGLISH CLASS............. 251

APPENDIX G: INDICATIVE QUESTION PROMPTS FOR TEACHER INTERVIEW

253

APPENDIX H: INDICATIVE QUESTION PROMPTS FOR STUDENT FOCUS GROUP

APPENDIX I: TRANSLATOR CONFIDENTIALITY AGREEMENT ............................ 256 


\section{LIST OF FIGURES, EPISODES AND TABLES}

Figure 1. Teaching-learning map (T-L map) (Hall \& Kidman, 2004).............................20

Figure 2. Embedded-multiple case design of the study, adapted from Yin $(2013$, p.50)

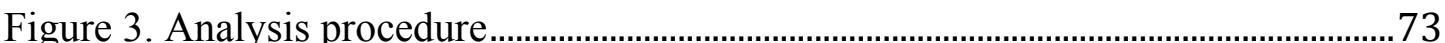

Figure 4. Thematic analysis of the study, adapted from Braun \& Clarke (2006) .........75

Figure 5. An example of theming and how themes were reported ...................................78

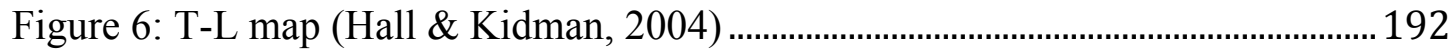

Figure 7: Modified T-L map for teaching and learning in Vietnamese tertiary EFL classrooms.

Figure 8: Modified T-L map for teaching and learning in Vietnamese tertiary EFL classrooms (repeated).

Episode 1: An example of an IRF sequence (adaped by Miao \& Heining-Boynton, 2011, p.69)

Episode 2: An example of a modified version of the IRF sequence (adapted by Marzban et al. 2010, p.131). . .50

Episode 3: An example of how discourse analysis was used in observations ...............76

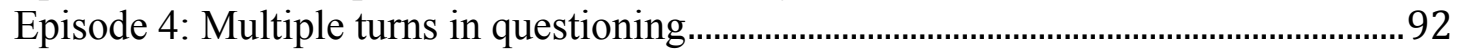

Episode 5: Focusing on fluency in questioning............................................................97

Episode 6: Using questioning as an alternative to lecturing .......................................... 100

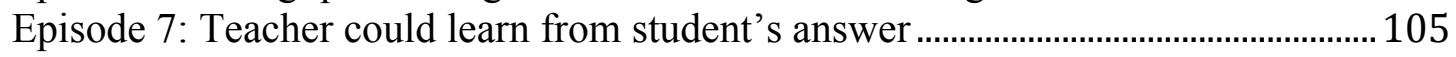

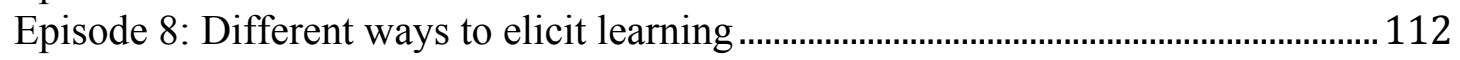

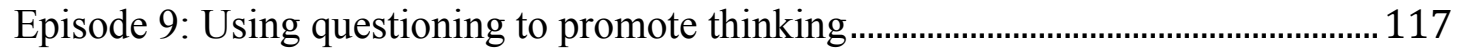

Episode 10: Using questioning to check students' preparation/readiness.................... 122

Episode 11: Using questioning according to students' competence................................124

Episode 12: Using questioning to check and direct group work …….............................127

Episode 13: Using questioning to organise group members.......................................... 128

Episode 14: Questioning to manage classroom activities...............................................129

Episode 15: Using questioning as direction or instruction ............................................. 129

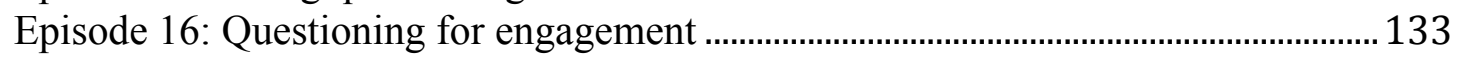

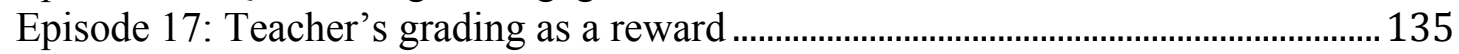

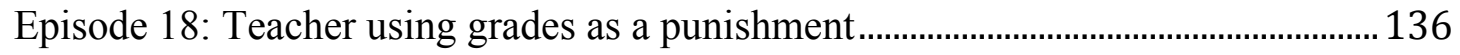

Episode 19: Questioning to build rapport........................................................................ 140

Episode 20: Teacher welcomed new idea from student .................................................. 144

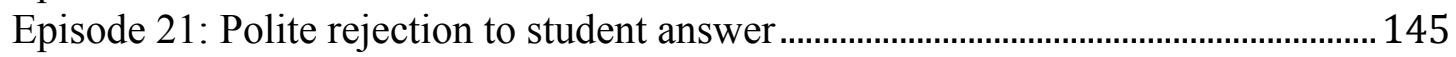

Episode 22: Student questions for permission................................................................. 152

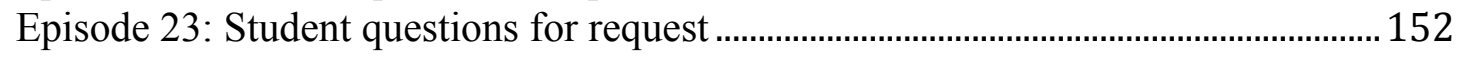

Episode 24: Teacher's directing roles in questioning ..................................................... 159

Episode 25: Questioning using Vietnamese for new word...............................................168

Episode 26: Questioning using Vietnamese to facilitate understanding ...................... 169 


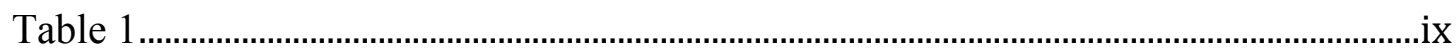

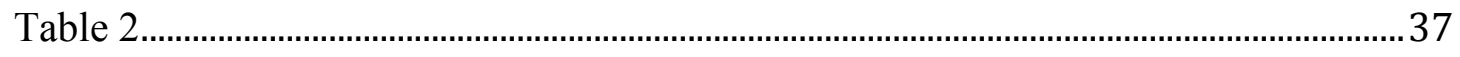

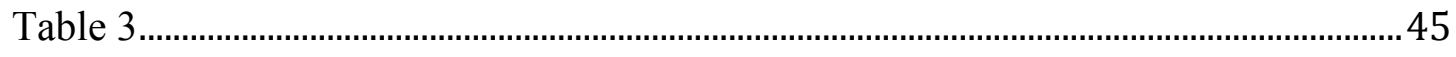

Table 4

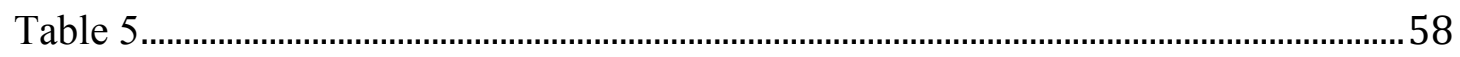

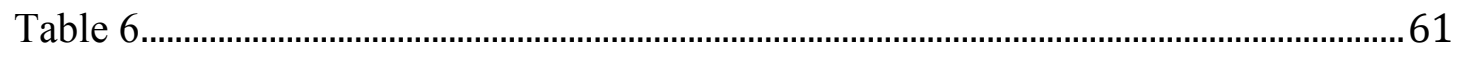

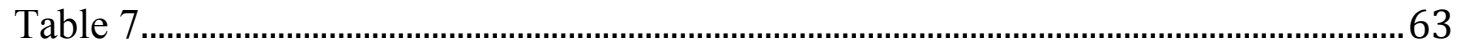

Table 8

Table 9

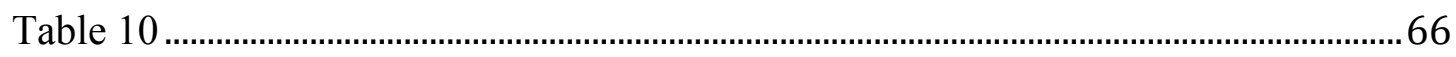

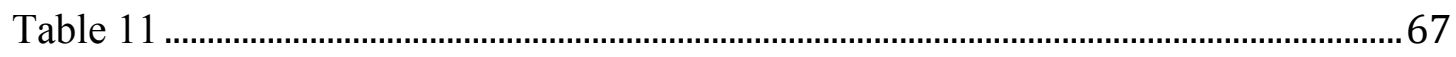

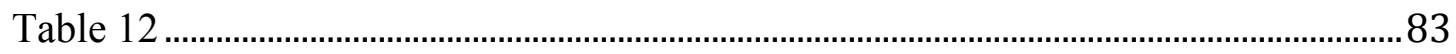

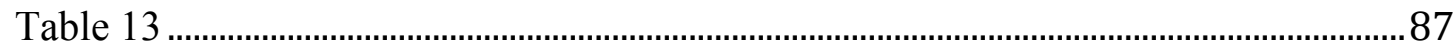

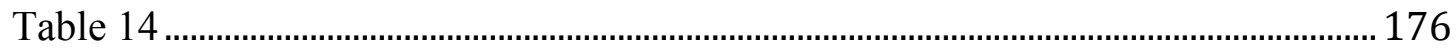




\section{ABBREVIATIONS}

Table 1

Abbreviations of the terms used in the thesis

\begin{tabular}{|c|c|c|}
\hline Abbreviation & Full term & Definition \\
\hline CLT & $\begin{array}{l}\text { Communicative Language } \\
\text { Teaching }\end{array}$ & $\begin{array}{l}\text { A framework for foreign language } \\
\text { teaching programmes that focuses } \\
\text { on the learner's ability to produce } \\
\text { and understand the target language } \\
\text { in authentic settings (Littlewood, } \\
\text { 2014). }\end{array}$ \\
\hline EM & English major & English is taught as a major subject \\
\hline ENM & English non-major & $\begin{array}{l}\text { English is taught as non major } \\
\text { subject }\end{array}$ \\
\hline IRF & $\begin{array}{l}\text { Initiation-Response- } \\
\text { Feedback }\end{array}$ & $\begin{array}{l}\text { The three-part structure Initiation- } \\
\text { Response-Feedback (IRF) is the } \\
\text { most typical discourse sequence } \\
\text { used in an EFL classroom to } \\
\text { stimulate the interaction between } \\
\text { teacher and student(s) or among } \\
\text { students (Tuan \& Nhu, 2010). }\end{array}$ \\
\hline HCQ & $\begin{array}{l}\text { Higher Cognitive } \\
\text { Question }\end{array}$ & $\begin{array}{l}\text { Questions place high cognitive } \\
\text { demands on the person who } \\
\text { answers, and require critical } \\
\text { thinking (Cotton, 2001). }\end{array}$ \\
\hline LCQ & $\begin{array}{l}\text { Lower Cognitive } \\
\text { Questions }\end{array}$ & $\begin{array}{l}\text { Lower Cognitive Questions contrast } \\
\text { with High Cognitive questions. } \\
\text { Lower Cognitive questions place }\end{array}$ \\
\hline
\end{tabular}


limited cognitive demands on the person who answers, and require factual recall of known information. (Cotton, 2001).

DQ Display Question

RQ

SCT

SLA

Second Language

Acquisition

T-L map Teaching and Learning Map
A display question is an example of a Lower Cognitive Question, and asks for information known by the questioner (Long \& Sato, 1983).

A referential question contrasts with display question. A referential question is an example of a Higher Cognitive Question, and asks for information unknown by the questioner (Long \& Sato, 1983).

Sociocultural Theory Sociocultural theory is one of the frameworks of my study, which views human mental activities as mediated, especially by language and learning as both cognitive and social activity (Lantolf \& Thorne, 2006; Vygotsky, 1978).

Another theoretical framework, which emphasises how individuals acquire a language in addition to their first language (Gass, 2013; Krashen, 1985; Long, 1983; Swain, 1985).

A way of looking at educational contexts that influence classroom teaching and learning, designed by 
Hall and Kidman (2004).

ZPD

The Zone of Proximal

This conceptualises the distance

Development

between the actual developmental

level (what an individual has

achieved) and the level of potential development (what they would be able to achieve with another learner or teacher's guidance) (Vygotsky, 1978). 


\section{CHAPTER 1: INTRODUCTION}

This thesis investigates how teachers and students used questioning to promote English language learning in tertiary classrooms in Vietnam. This chapter contextualises the study by presenting some background information about English education in Vietnam. This is followed by the aims and the purposes of the study. The chapter concludes by providing an overview of the thesis structure.

\section{Context of English education in Vietnam}

This section will provide an overview of EFL education in Vietnam, including the way that government policies influence English education and the process of implementing CLT. An overview of EFL teaching and learning is then presented.

\section{Policies influencing English education}

In 1986, the Vietnamese government adopted an open-door policy, "doi moi" (renovation), which has led to rapid economic growth and social development. The socialist-oriented market mechanism, globalisation, information technology developments, and the government's desire to industrialise Vietnam by 2020 have priortised reforms to the education system.

A series of events where Vietnam joined international organisations - ASEAN (Association of Southeast Asian Nations) in 1995, and AFTA (ASEAN Free Trade Area) in 1995, APEC (Asia-Pacific Economic Cooperation) in 1998 and WTO (World Trade Organization) in 2007- enhanced the status of English language asa "world language" in Vietnam (Brutt-Griffler, 2002). English is now considered a passport for participation in an expanding number of international social and economic activities. Therefore, English has become the preferred foreign language in Vietnam. Planning and policies have been initiated in the last few decades, and English has emerged as the main foreign language which has in turn led to the promotion of English language communicative competency (Ngoc \& Iwashita, 2012).

In the context of economic renovation and the open-door policy, English has become 
the dominant foreign language taught in schools, universities, and at evening language centres across the country. Students have to pass the national English examination if they want to graduate with the Secondary School Education Certificate. English is the compulsory foreign language in the curriculum for both undergraduates and graduates at tertiary level (MOET, 2007).

In September 2008 the Vietnamese Ministry of Education and Training issued the 'National Foreign Language 2020 Project', which emphasised English language education as a key factor in national development. The goal of this government policy is that by 2020 all undergraduates graduating from the university will be able to successfully communicate with speakers from English language communities. According to this education policy, teaching methods must promote learners' communicative ability. In other words, teaching is expected to highlight the learners' use of the target language (Vietnamese Prime Minister, 2008). In particular, it requires teachers in EFL classes to shift from teacher-centred approaches (such as grammar-translation and audio-lingualism) to learner-centred approaches, which promote the development of learners' communicative language skills.

\section{The shift from traditional methods to communicative language teaching}

The grammar-translation method of ELT that focuses on structure and form is losing its popularity internationally. Communicative language teaching (CLT) was introduced to promote learners' communicative language ability in contrast to practising grammatical forms in isolation. CLT has been gradually taking the place of grammar-translation and gaining in status since the 1990s (Nguyen, 2007). The application of CLT has received positive support from Vietnamese policymakers and educators (Lewis \& McCook, 2002; Ngoc \& Iwashita, 2012; Pham, 2004, 2007; Thanh, 2011).

Policymakers in Vietnam also believe that CLT has a positive impact on learning English when teachers add "communicative activities in their repertoire of teaching skills and [give] learners the opportunities in class to practise the language skills taught" (Ho \& Wong, 2004, p. 26). In 2002 a new set of textbooks and new national curriculum were introduced at secondary level. Unlike the previous textbooks, these emphasised the development of communicative skills rather than teaching formal 
knowledge of the language (MOET, 2006). In order to build Vietnamese teachers' skills in communicative teaching, many teachers, especially at university level, have been sent to English-speaking countries to study. ELT workshops and seminars have been organised by educational agencies for university and school teachers throughout Vietnam to equip them with new teaching strategies so they can apply CLT in their EFL classes (Lewis \& McCook, 2002).

However, there has been little discussion about whether the learners feel favourable towards CLT implementation (Ngoc \& Iwashita, 2012; Savignon \& Wang, 2003). Also, although teachers espouse communicative theory, there is often a mismatch between teachers' perceptions and their actual practice of CLT in the classroom (Pham 2004, 2007). Teachers' classroom practices often deviate considerably from the principles of CLT; for example, teachers find it challenging to act as a facilitator of knowledge (one of the important principles of CLT) while perform traditional teaching duties as monitors of behavioural and moral guides (Ngoc \& Iwashita, 2012; Phan, 2004).

\section{An overview of EFL teaching and learning in Vietnam}

Although the importance of English has been widely and publicly recognised, the quality of English education in Vietnam is still a concern. After 12 years of secondary education following four years of tertiary education, university students have at least 11 years of learning English. However, many of these students struggle to communicate in English because of shyness, inadequate vocabulary, or because they still lack the necessary communicative skills (Le, 2011; Giang, 2011; Ngoc \& Iwashita, 2012). The causes for this may include a knowledge-focused curriculum, grammar-based examinations, over-sized mixed-ability classes, the lack of an authentic English language environment for practice, and lack of motivation to communicate in English (Do, 2006; Nguyen, 2013; Thanh, 2011). Teaching methods appear to be a factor, such as many classrooms may remain teacher-centred and teachers' low language proficiency (Sullivan, 2000; Ngoc \& Iwashita, 2012). Beside these practical constraints, there are additional underlying issues; many English classrooms may still depend on traditional practices and passive Confucian learning styles, rather than adopting a western CLT approach (Nguyen, Terlouw, \& Pilot, 2005b). The following literature chapter will address CLT as an approach in Vietnam. 
To sum up, this part has focused on English education in Vietnam, including current trends in English instruction, the application of CLT, the approaches to English teaching and learning, and Vietnamese traditional values that influence English education. The following section will provide the reasons and purposes of this study.

\section{Rationale and purposes of the study}

As an EFL teacher in a Vietnamese university for seven years, I have noticed how my questions greatly impact on the learning in my English language classroom. I was aware that teacher questioning is one of the most familiar forms of teacher talk (Boyd, 2015; Cundale, 2001; Sharpe, 2008), and can serve a variety of teaching purposes (Ur, 2000), especially in creating interactions in classrooms to promote learning the target language (Mercer, 2007; Tuan \& Nhu, 2010). I was motivated to investigate how the interaction prompted by questions was important for second language teaching within the specific context of Vietnam, and how questioning was viewed by teachers and students.

Questioning is an element of communicative interaction. As such, questioning provokes learner response and learner engagement. Engagement in interaction leads to opportunities to learn the language through the use of the learners and of the others (Mcdonough, 2005; McNeil, 2012). However, research records indicates that ineffective questioning may discourage learners from engaging in their learning (Tan, 2007). Limited engagement may lead to insufficient opportunities for learners to practise speaking in the target language. Ko (2014) remarks that: "there continues to be a general lack of empirical evidence on how language classroom interaction actually contributes to L2 learning occurring moment-by-moment through social interaction" (p. 60). This suggested to me that there was a need for more research into teacher questioning that encourages interaction and English language learning processes.

Furthermore, teacher questioning in tertiary EFL classes has been a popular reseach topic in many contexts but not in Vietnam (Farahian \& Rezaee, 2012; Jiang, 2014; Shen \& Yodkhumlue, 2012; Wang \& Wang, 2013). One issue arises in EFL contexts like Vietnam when teachers try to use questioning to promote CLT, which is the dominant and recommended approach for English language learning and teaching in 
my country. For example, while in many English language classrooms, as a second language (ESL) teachers may use questioning to encourage students' communicative competence (Cundale, 2001; Jiang, 2014; Lee, 2006), EFL teachers' beliefs about questioning and CLT do not automatically translate into practice in every context, including Vietnam (Farahian \& Rezaee, 2012; Pham \& Hamid, 2013). This suggests a need for further investigation of how teacher questioning is applied to promote a communicative approach in EFL classrooms in the Vietnamese cultural context.

In addition, in Vietnam the use of teacher questioning has received little attention, especially at tertiary level. There is only one study of teacher questioning in tertiary EFL in Vietnam (Pham \& Hamid, 2013). The findings from this study focused on the relationship between beliefs and practices of beginning teachers about questioning. This was a small-scale investigation and strongly recommends further research on the topic. Therefore, there is potential for further investigation into the topic from the perspectives of teachers and students, and in different educational contexts, for example, in classes where English is taught as a major and classes where English is taught as a non-major. My study addresses this gap by studying questioning from these perspectives and in these contexts.

Previous research about questioning in L2 learning and teaching internationally and in Vietnam (Pham \& Hamid, 2013) (my own country) motivated me to investigate this topic myself. My objectives are to analyse the roles of EFL teachers' questioning in promoting English language learning and communicative language use, and to examine the challenges and facilitators influencing teacher questioning in the Vietnamese cultural context. Furthermore, this study will explore the connections between perceptions and practices, according to the perspectives of teachers, students, and classroom observations.

This study investigates teacher questioning promoting language learning in Vietnamese cultural contexts. Research in this context requires an understanding of the culture and context that fits with investigation through the lens of sociocultural theory. Therefore, this study takes a sociocultural perspective and aims to answer the question, "How do Vietnamese tertiary educators use questioning to promote language teaching and learning in EFL classes?" 


\section{Overview of the thesis}

This thesis is organised into seven chapters, including this introductory chapter. Chapter 2 develops the conceptual framework for the study through reviewing literature in five relevant areas: sociocultural theory, teaching and learning map (Hall and Kidman, 2004), second language acquisition, communicative language teaching, and questioning. The chapter concludes by identifying some issues in the field of question-answer interaction and with the research questions of the current study.

Chapter 3 explains the methodological decisions made for the study, including the methodological choice for a qualitative case study, the research site, the participants, the methods and procedures of data collection and data analysis procedures.

Chapters 4, 5 and 6 report three key themes arising from the findings: communicative interaction; the art of teaching; and My home, my rules.

Finally, Chapter 7 provides the discussion and conclusion. It answers the research questions about how questioning promoted English language teaching and learning, and argues the phenomenon of questioning in the contexts, from wider international context to classroom context, and presenting the implications for further research. 


\section{CHAPTER 2: THEORETICAL FRAMEWORK AND LITERATURE REVIEW}

\section{Introduction}

This study was undertaken in Vietnam, where English is taught as a foreign language. As outlined in the introduction, teachers in Vietnam have been encouraged to use CLT in their classrooms. In this chapter, I describe and justify the use of two relevant theories that frame this study. They are (1) sociocultural theory, and (2) the teaching and learning map by Hall and Kidman (2004). After that, the chapter reviews literature on (3) second language acquisition and (4) CLT. The chapter concludes by focusing on (5) questioning as the key phenomenon investigated in this study. Literature drawn from these main areas helps address the issues and shape the research questions.

\section{Sociocultural theory (SCT)}

Sociocultural theory originated from the work of Vygotsky (1978). Vygotsky theorised that human mental activities, distinguishing people from other living beings, are the evolutionary capability to consciously and intentionally control thinking by using "higher-level cultural tools" such as language, literacy, numeracy, categorisation, rationality, and logic. These tools enable advanced mental activities of humans such as decision-making and problem-solving (Lantolf \& Thorne, 2006 p. 198).

SCT views learning as both a cognitive and social activity. It emphasises that human mental activities are mediated, especially by language. Social interaction is a fundamental aspect of learning, providing opportunities for the process of regulation and internalisation, which facilitate cognitive development. Learning happens in the zone of proximal development (ZPD), with the scaffolding of others. In this section, I discuss three key concepts of SCT: meditation, social interaction, and the ZPD.

\section{Mediation}

Mediation is the fundamental construct of SCT. This theory claims that the human mind is mediated (Lantolf, 2000). Lantolf and Thorne (2006) define mediation as "the process through which humans deploy culturally constructed artifacts, concepts, and 
activities to regulate (i.e., gain voluntary control over and transform) the material world of their own and each other's social and mental activity" (p. 79). Mediation takes place through the use of certain tools, whether physical tools (such as machines or technology devices) or symbolic tools (such as language or signs), to change or act on the world. Within this framework, language is the most important mediational tool for thought development. Language, one of the most pervasive and powerful symbolic tools, serves as an aid to "free humans from the circumstances of their immediate environment and enables them to talk and think about entities and events that are displaced in both time and space, including those events and entities that do not yet exist in the real world" (Lantolf \& Thorne, 2006, p. 202). Language is a primary tool used to mediate between social activity and thought.

According to Vygotsky, regulation is another form of mediation, as children learn to control their own activity by engaging in mental or physical activities. Children are regulated either by objects, others, or themselves, to interact with others, to internalise the process, and to use or perform it independently in the future. The sociocultural environment exposes the child to a variety of tasks and demands. This activates the child to think and use the tools available in his world (the object-regulation stage in the child's mind). Because the child at first is completely dependent on other people, regulation or the scaffolding of others is needed to help the child fulfil new tasks (other-regulation stage). For example, the parents or teachers guide by instructing the child what and how to do it, as well as what not to do. The child acquires this knowledge through social interactions with others, then later can internalise this knowledge by imitating, remodelling, and applying their own mental capabilities. This transformation/internalisation from the social to the personal domain helps the child to develop cognition and manage their own activity, accomplishing future tasks without help (self-regulation stage).

In Vygotsky's view (1978), mediation engages the child to use culturally constructed artefacts, activate self-regulation and develop internalisation; this is the foundation of learning. Though SCT was originally constructed to explain child development, including first language learning, it has been extended and applied to the process of learning through interaction with more knowledgeable others in second language learning. 
SCT and its theories are useful in analysing second language learning (Gass, 2013; Lantolf, 2000; Lantolf \& Thorne, 2006). Within the framework of SCT, learning is viewed as "participation rather than acquisition", which means language learning originates from the engagement in the language environment rather than happening in learner's mind (Sheen \& Ellis, 2011, p. 597). Therefore, according to SCT, second language learners are required to think and speak in the target language; and language and thought are closely connected with each other. The root of this connection lies in social interaction.

\section{Social interaction}

Social interaction is a key construct of SCT, and refers to the process of using language to communicate to share experience and construct knowledge. Social interaction from a sociocultural standpoint is the communication between teachers and learners, or between learners and peers, who are together engaged in the learning process.

Sociocultural theory proposed that learning happens within social and cultural practices, and learning is a co-constructed activity, where learners develop understanding while communicating about their experience. According to McNeil (2012), social interaction enables learners to develop understanding by doing a task together, receiving support from others, and later completing the task independently. In other words, the cognitive and linguistic development of an individual can be achieved through social interaction with assistance from others. Therefore, learning is co-constructed, and occurs in social interaction.

Walqui (2006) notes that "Social interaction is the basis of learning and development. Learning is a process of apprenticeship and internalization in which skills and knowledge are transformed from the social into the cognitive plane" (p. 160). Working in language-learning situations (including foreign and second language classroom contexts), Gibbons (2007) claims that language acquisition within SCT is a joint activity between learners, and language learning and language use are situated in social and cultural situations. The role of interaction is crucial for second language learning, because it provides learners opportunities to use and comprehend the target 
language. In conclusion, learning originates in interaction, and interaction creates an environment for learning language and learning though language (Wells, 1999).

\section{Zone of Proximal Development, and scaffolding}

SCT proposes that learning, including language learning, happens within interactions and with assisstance from interlocutors. Two further key concepts are involved in this principle: the Zone of Proximal Development (ZPD), and scaffolding.

The ZPD conceptualises the "distance between the actual developmental level (what an individual has achieved) and the level of potential development (what they would be able to achieve with another learner or teacher's guidance)" (Vygotsky, 1978, p. 86). For instance, when doing a task, a student can accomplish it to a certain degree, which demonstrates his/her existing understanding. In interaction with a more proficient peer and/or a teacher, the student can perform the task to a higher level. The assistance of others helps the student to develop further learning. The ZPD is the learning space or difference between the unassisted and the later potential degree of understanding.

The supportive process that the peer or teacher, who are often more competent, help or assist the student through the steps to solve a problem or do a task, is called scaffolding. This term was developed through Bruner's work (1985). It originally referred to the process by which assistance was offered to children to carry out a task and gradually removed until the children could do it themselves.

To further explain the nature of scaffolding, Sharpe (2008) identifies key properties: scaffolding is support offered "at the point of need" in "the moment to moment interaction within lesson". This support from the teacher or more competent peer is gradually removed so that the student can take more control of his or her own learning; and this support can enable "the learner to develop competence that can be applied in other contexts or future tasks" (p. 134). Scaffolding is, therefore, "an interactive process of handing over" by the more proficient instructor or peer, and taking over by the student, in which the support provided to the students should be "only just enough and just in time" so as to give the students a chance to take charge of their learning (p. 134). 
In summary, the theory emphasises the integration of social, cultural and biological elements in learning processes, and stresses the central role of sociocultural influences in human cognitive development. Higher mental functioning occurs when people internalise or regulate what they learn from social interaction with others through the mediation of symbolic tools within their ZPD.

Sociocultural theory provides a useful framework to analyse classroom interaction because it proposes that cognitive development, and thus learning, has its genesis in a social context (such as the language classroom). My study focuses on teacher questioning (as a form of interaction) in language classrooms. A number of pedagogical concepts from SCT can be applied in my study of second language learning, such as cognitive development, social interaction and cultural influences. In the following section about questioning, there will be further illustration of how these concepts from SCT are relevant to questioning-asking interaction.

\section{Questioning within SCT}

The literature indicates three aspects of questioning from the perspective of SCT: questioning promotes cognitive development, questioning enhances social interaction, and questioning operates within a cultural context.

\section{Questioning and cognitive development}

The relationship between questioning and cognitive development has been extensively discussed by researchers and educators (Boyd, 2015; DeWaelsche, 2015; Li, 2011a; Jiang, 2014; Wang \& Wang 2013). Teachers' use of questioning to promote cognition will be reviewed from two points of view: how teachers manipulate questions to evoke critical thinking, and how students' answers reveal their developing levels of cognition. Cognitive development is one dimension of language learning.

\section{Manipulating questions to promote cognition}

There are different manifestations of how teachers use questions to promote cognitive development reported in research. Li (2011a), through a sociocultural lens, explored how a teacher facilitated and obstructed opportunities to develop learners' thinking 
skills. The study found that teachers created space for developing thinking skills (by allowing more time after higher-cognitive questions, which demand critical thinking), provided space for developing thinking skills (by following-up learners' input to encourage further elaboration and constructive feedback), managed space for developing thinking skills (by initiating and directing turns) and navigated space for developing thinking skills (by seeking clarification and providing confirmation).

Wang and Wang (2013) explored how teachers promoted cognition at different stages of the lesson. For example, to open the lesson and introduce the topic, the teacher used lower order cognitive levels of questions (such as yes/no questions or questions for known knowledge), to scaffold students' thinking. The teacher used questions as a formative assessment technique to enhance thinking levels. To move students' thinking towards a higher level, teachers chose to deliberately throw the responsibility of questioning and therefore thinking back to students, or directed students to conduct peer evaluation.

The feedback turn has been found to be particularly important in promoting thinking skills. In Jiang (2014), teacher feedback in Chinese Tertiary EFL classrooms appeared on three levels: the teacher's positive attitude towards responses; identifying the weakness of the answer and repeated calling for further ideas; finally encouraging learners to think critically by considering different perspectives and dimensions. With this strategy the teacher was able to encourage classroom engagement, help students to formulate quality ideas, and sharpen students' critical thinking.

These studies reported how teachers used different strategies within questioning to promote learners' thinking. The following part focuses on how students' answers reflected the development of their thinking.

\section{Students' responses revealing cognitive development}

Studies also reveal how cognition is reflected in student responses to teacher questions in EFL classes (Boyd, 2015; DeWaelsche, 2015; Jiang, 2014). Boyd (2015) noticed that when questions resulted in extended student answers that were structurally coherent, this was evidence of good communicative competence, engagement and levels of comprehension. Jiang (2014) also argued that different 
student responses (such as answering individually or not answering) could reveal different levels of cognitive development. For instance, individual responses could illustrate critical thinking and this, especially after discussion, seemed to represent both personal and collective thoughts. Whereas instances where students could not answer the teacher's questions appeared to reflect gaps in students' knowledge (DeWaelsche, 2015; Jiang, 2014).

In EFL classes, the primary goal was learning the target language, which fostered cognitive development (Rezaei, Derakhshan, \& Bagherkazemi, 2011). Thinking skills refers to students' abilities to analyze, evaluate information and solve problems. This process was demonstrated when students could produce and respond to teacher questions in the target language (Shen \& Yodkhumlue, 2012). The development of thinking could impact on how students shared opinions and engaged in questioning (DeWaelsche, 2015). In other words, research suggests that cognitive development is important for communicative competence, one of the components of language learning.

In summary, asking and answering questions can be a means of promoting thinking development. Research in the EFL context documents firstly how, to stimulate cognitive development, teachers use different strategies for deeper thinking. These may include offering more wait-time before answering, encouraging student clarification and elaboration, and providing constructive feedback. Secondly, students' responses, including answering individually, answering after a discussion, or not answering, could reveal the students' language development and learning. Thinking development is an essential part of language learning, especially promoting communicative competence.

Vygotsky (1978) claimed that a core mechanism for individual cognitive development is social interaction. The following section focuses on how questioning is positioned in social interaction.

\section{Questioning and social interaction}

In SCT, learning occurs in a social context in which scaffolding is applied in the zone of proximal development. Research reports that teachers in language learning classes 
use questioning as a means to scaffold learners (Heritage \& Heritage, 2013; Ko, 2014; Lee, 2006; Yaqubi \& Mozaffari, 2011).

\section{Questioning to scaffold students}

Teacher scaffolding during question-answer interactions is well-researched in literature. This can be summarised as follows: "By looking at teacher-learner interaction from a sociocultural perspective, we can improve our understanding of the functions served by the communicative moves used by teachers to provide learners with effective scaffolded help within the ZPD" (Antón, 1999, p. 315). An investigation of interaction during questioning and answering in a classroom must thus also involve the ideas of ZPD and scaffolding, whereby teachers and peers may provide effective assistance (scaffolds) to enable learners to answer questions at a higher level than they would otherwise manage.

EFL teachers help students to answer difficult questions in many different ways (Fagan, 2014; McNeil, 2012), such as to promote more interaction (Heritage \& Heritage, 2013; Lee, 2006;), or by devising different types of questions to prompt students' language production (Engin, 2013; McCormick \& Donato, 2000; Yaqubi \& Mozaffari, 2011).

Fagan (2014) and McNeil (2012) examined how teachers restructured initiating questions to assist students when they struggled to answer difficult questions. McNeil (2012) illustrated how teachers provided communicative moves such as reformulating, repeating or elaborating on the responses. These strategies scaffolded students to answer referential questions, which were important for learning but students found difficult to understand and answer.

Adopting a sociocultural lens, a number of investigations showed how teachers used questioning to assist students to perform a task individually and at a higher level. For example, Heritage and Heritage (2013) observed how teachers asked questions at the next learning level $(\mathrm{i}+1)$ to encourage the learner to produce target output at a highthinking level. These teachers offered students the chance to correct him/herself and move forwards to keep the conversation in progress. 
In an ESL classroom of international students in the US, Lee (2006) argued that even display questions (questions for known information), which are often perceived as low-level questions, could be used to build upon student talk to increase interaction by involving negotiating of meaning and multiple IRF sequences. Some scaffolding techniques were observed: making display questions answerable, using common sense knowledge, negotiating what is being asked.

Some studies proposed the categorisation of questions according to their scaffolding function. For instance, Engin (2013), studying pre-service English teacher trainees in Turkey, proposed that questions had natural scaffolding functions because questioning involved the support of more competent individuals (such as the teacher) in the learning context. The study suggested a framework for scaffolding questions. The framework consisted of four types: telling-functioned questions, "fill-in-slot" questions, hypothetical questions, and recall questions ranging from the highly controlled scaffolding to the least intervention.

Another study, Yaqubi \& Mozaffari (2011) used conversational analysis within SCT. This study explored how questioning contributed to scaffolding learning processes in EFL classrooms in Iran. It identified four question types that provided scaffolding assistance: simplifying questions, marking questions, prompting questions and asking-for-agreement questions. It argues that teacher questions were more than elicitation techniques; they were mediational interactional tools to assist participation and comprehensibility.

In summary, studies about questioning in EFL classes demonstrate that questioning functions as scaffolding, in which the teacher (as the more competent speaker) assists students to complete the task that learners may not able to fulfil without assistance. Another SCT principle discussed in literature is how questioning promotes collaborative construction of knowledge.

Questioning promotes collaborative construction of knowledge with peers and teachers

In SCT research about questioning, the co-construction of knowledge takes place mostly between teacher and students, because the teacher often takes the control 
position in the question-ask interaction; but sometimes collaborative construction happens among students.

Ko (2014) investigated how, in the course of multiple responses, learners interacted with each other to collectively work on language learning tasks in English language classrooms in Korea and Australia. This collaboration allowed learners to share their strengths with one another, together producing a performance that was of a higher level than that of any individual involved. He acknowledged that "Because no learners have the same strengths and weaknesses, such shared activity (i.e., active involvement in learning) has the potential of allowing learners to share their strengths with one another, together producing performance that is of a higher level than that of any individual involved" (p. 60). Therefore, he concluded that effective teacher questioning had the power to increase collaborative work among students. Ko's study shows the value of interactive learning that enables different students to learn from each other. This aligns with SCT that the learner develops further learning with the support of more proficient peers or the teacher.

Good teacher questioning can provoke learners' autonomy and collaboration. In Jiang (2014), when tertiary learners in China could not answer, their teacher advised them "to search for relevant information independently after class and work collaboratively in class" (p. 13). The learners were put in the position of actively and independently engaging in self-learning, rather than relying on the teacher.

Similarly, Chinese teachers observed by Wang and Wang (2013) used questioning to put EFL tertiary students in the central position of learning and teaching. By throwing the questions back to students or encouraging peer assessment, the teacher was successful in promoting the learner's responsibility to think and co-construct knowledge rather than counting on their teachers (Wang \& Wang, 2013). This suggests how teacher questioning can be formulated to shift the authority for evaluating answers to students and encouraging students to respond directly to each other. This is likely to support the development of learner autonomy.

In summary, a number of studies have employed sociocultural theory to examine questioning within social interaction. Two key principles have been discussed: how 
teachers use questioning to scaffold learners; and how questioning may promote collaboration. The following section illustrates questioning within a cultural context.

\section{Questioning within cultural contexts}

SCT proposes that learners are dependent on their institutions, settings and cultural artefacts in the social environment to acquire new mental functions and patterns of thought via the mediational assistance of tools (Edwards, 2005). This section will describe the influence of cultural contexts of second language learning, with empirical studies about questioning in particular cultural contexts.

In their report on intercultural language learning for the Australian Department of Education, Science and Training, Liddicoat, Papademetre, Scarino, and Kohler (2003) defined culture as "a complex system of concepts, attitudes, values, beliefs, conventions, behaviours, practices, rituals, and lifestyle of the people who make up a cultural group" (p. 45). Bodley (1994) referred to culture more simply as "what people think, make, and do" (p. 22). He saw culture as a socially transmitted, symbolic set of beliefs that serve as a model to guide human behaviour in society (Frank, 2013).

The connection between language and culture is a concern of L2 teachers and educators. The following studies consider how cultural factors and settings influence the practice of teacher and students questioning: DeWaelsche (2015), Sano (2014) and Tan (2007). These studies, investigating cases in the East Asian context, reveal Confucian influences on learning such as teacher-driven instruction, a desire to save face, reluctance to challenge the teacher, and reliance on rote learning. The studies identify sociocultural influences that govern language learning in EFL classrooms and disclose some differences between Asian and Western countries.

DeWaelsche (2015) explores the use of higher-level questioning in student-centred activities to elevate critical thinking and increase student engagement among Korean university English majors. The findings reveal limitations, ascribed to Korean students' cultural reluctance to speak or share opinions in class. Other institutional and sociocultural factors such as exam-driven content, teacher-dominance, and the Confucian heritage prohibition on students challenging the teacher's authority, 
appeared to inhibit the display of students' critical thinking, questioning, and engagement. According to this study, this long-established cultural tradition made students reluctant to take an active role at the university level.

The learning culture (in the first language) also appears to affect second language learning and occasionally results in misunderstandings in cross-cultural communication. Tan's (2007) study explored Chinese students' learning behaviours such as keeping silent during teacher questioning, never venturing a question in class but reserving questions to after-class time, or responding simply by repeating the text. He noted that while these are expected behaviours in Chinese culture, in the eyes of teachers from non-Confucian cultures they may be viewed as strange.

Tan's study highlighted some differences between Asian and Western cultural expectations about learning. For example, Chinese teachers and Chinese students thought it was important to have "an exact answer" and "once that answer was obtained, that was all" (p. 93). In contrast, the American teacher did not expect one exact answer, but aimed to explore the question in depth. The teacher would ask a series of questions to establish how the student arrived at that answer and prompted the student to justify the answer. This made the Chinese students in the foreign teacher's class feel "embarrassed", and they reported finding it "hard to think in depth in front of class" (p. 93). The study raised a concern that these Chinese learners avoided difficult questions or showing disagreement with the teacher. These were habits formed from long-term practice, which influenced questioning in practice.

Furthermore, Chinese teachers chose to ask challenging questions to establish authority and showed off their expertise by providing students with perfect explanations after students failed to give an adequate answer. These questioning behaviours were designed to win admiration/respect from students, rather than to promote learning. This teacher role contrasted with the Western viewpoint that establishing a superior position "is not 'earned' but culturally embedded in the teaching post" (Tan, 2007, p. 99).

The cultural domain also affects critical thinking in non-Western contexts. Sano (2014) explored critical thinking and teachers' questioning behaviour in an EFL context in a Japanese university. The study found that teaching critical thinking skills 
was too often based on Western perspectives and thus it was challenging to apply in Asian culture/contexts. The study emphasises that Japan recognises the importance of critical thinking and Japanese students often engage successfully in critical thinking in their EFL classes. In Sano's study, both teachers and students were aware of critical thinking in their questioning behaviour. There were instances when students did not respond to questions. However, reasons offered by the participants for not responding included the students' limited English competence, their desire to give turns to others to answer, and being afraid of making a mistake. The findings reveal that the majority of questions were lower-order questions. However, higher-order questions were also frequent and students in the study stated they valued questions requiring reasoning, justifying or inferring. The somewhat contradictory findings in this study prompted Sano to argue against overgeneralising or formulating stereotypes of particular cultures. It suggested that critical thinking is highly valued in Japanese culture, and this was reflected in the language classroom. Sano's study illustrates that sociocultural considerations mediate what people think and do.

These studies explore how the institutional and cultural setting influence the way teacher and students engage in questioning. However, cultural understandings of teaching and learning play a part in target language learning.

In summary, this part has presented how principal theories from SCT have been adopted in studies about questioning in EFL contexts. These studies indicate three important principles of SCT.

Firstly, in SCT, learning language facilitates cognition. Research reveals that questioning promotes cognitive development. Secondly, language learning happens within interactions and with support from interlocutors. Questioning is the most popular interaction in EFL classrooms, as teachers scaffold students or students assist each other to co-construct knowledge. Thirdly, cultural contexts mediate language learning. Studies about questioning in Asian language classrooms reveal that L1 culture influences English language learning.

Consistent with SCT, my investigation concerns contextal factors, such as the cultural context. To discuss contextual influences in teaching and learning further, the 
following section will focus on the teaching and learning map proposed by Hall and Kidman (2004).

\section{The Teaching-Learning Map (T-L map)}

Literature argues that human development is affected by a range of contextual factors (Bronfenbrenner, 1979; Horsburgh, 1999). My study used the teaching and learning map proposed by Hall and Kidman (2004), which reflects the structure of Bronfenbrenner's (1979) ecological theory to identify contexts around teaching and learning activities. Hall and Kidman (2004) developed the teaching and learning map (T-L map), which classified elements of the educational environment (the wider international and national setting, the institutional setting, and the immediate environment of teaching and learning in the classroom) (see figure 1 below).

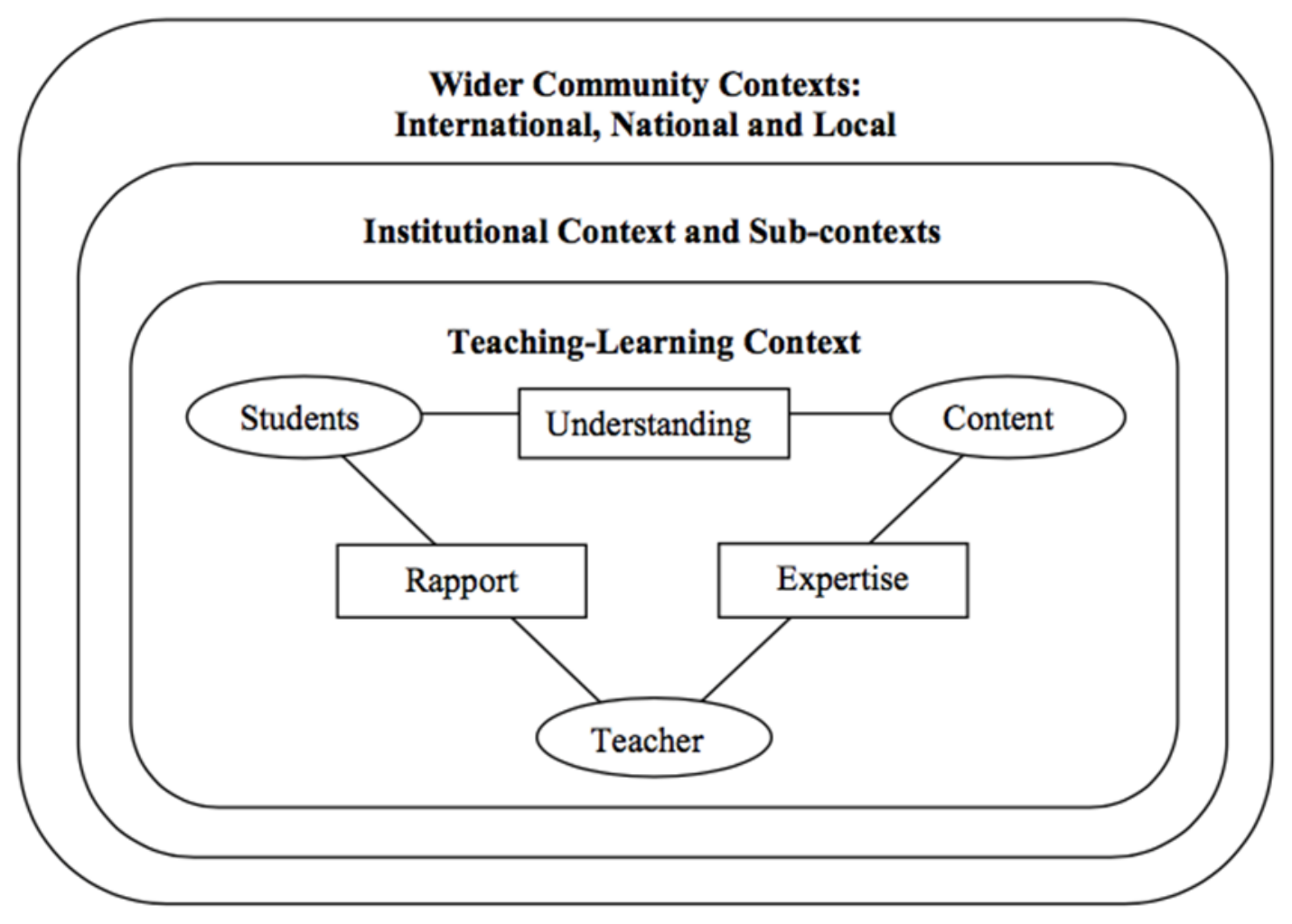

Figure 1. Teaching-learning map (T-L map) (Hall \& Kidman, 2004)

The T-L map identifies at least three layers of context in which teachers and students participate: the direct teaching-learning context of the course, including the processes and activities of teaching and learning that the teacher and students engage in; the institutional context, which involves sub-contexts (e.g. department, faculty, and wider 
institutional parameters); and the wider community context (local, national and international).

The teaching and learning context is at the heart of the map and involves three key components: the students, the teacher, and the content. The concept content refers to the knowledge, skills, and values that are included in the course. The map highlights the relationships that link these three components:

Expertise (the link between teacher and content): this is essential for any effective teaching. The teacher's expertise consists of both subject matter and teaching skills. Teacher expertise can be enhanced by keeping abreast of the subject, networking with other teachers, conducting research, and applying latest research findings into teaching.

Rapport (the link between student and teacher): a good relationship between student and teacher can motivate students to perform to higher levels. Hall and Kidman also suggest that rapport is derived from "Mutual respect, clarity of communication, organization of teaching, constructive feedback, teacher enthusiasm, intellectual challenge and approachability" (Hall \& Kidman, 2004, p. 336).

Understanding (the link between student and content) describes how students are active to build understanding of the content. The notion not only means students' understanding of the content, but also how the students perform a skill they learned and how they demonstrate their understanding through behaviour of an intellectual or ethical value. The teacher has an essential role to promote the students' understanding of the content by teaching, providing expertise and resources, engaging students to do research, and encouraging students' self-learning.

The T-L map draws on SCT because contextual factors are significant in examining learning. While SCT argues how cultural contexts mediate language and cognitive development, the T-L map identifies specific levels of contexts existing around teaching and learning activities.

The T-L map of Hall and Kidman has been used as a framework for research in education including master's and doctoral studies (Astuti, 2015 Doan, 2012; Joskin, 
2013; Tait, Horsley \& Tait, 2018). The use of the T-L map allows a deep understanding of cultural and social features as important contextual factors that may influence academic success (Astuti, 2015; Tait, Horsley \& Tait, 2018). The map provides a framework for studies about the interaction among three key components of learning-learner, teacher, and content. For example, Doan (2012) used the T-L map to study how Cambodian and Laotian international students in a Vietnamese university experienced good teacher-student relationships that facilitated cultural adaption and participation in classroom activities. In Joskin's (2013) study, the T-L map helped to evaluate the effectiveness of the implementation of the curriculum in English as a foreign language (EFL) secondary schools in Papua New Guinea by examining the three key components of teacher, student, and content.

The T-L map is appropriate for my study since the map was developed for understanding tertiary education. T-L map was originally used for understanding how teaching and learning happens within a university course. My study will apply the map to examine teaching and learning activities in two different classes in EFL courses.

The map stresses the nature of and the links between the key elements of teachers, learners, and content, in the teaching and learning process. It provides a focus to discuss how these elements interact and influence each other. Therefore, I used the map to examine questioning, as a dominant form of interaction between teacher and students to create learning.

The use of the T-L map also allowed me to explore the influences of social, cultural and institutional contexts, to understand the complexity of the influences on questioning interactions in language teaching and learning. My study investigates the classroom activities in a specific setting, Vietnamese tertiary EFL classrooms. Therefore, the map contributes a framework to systematically and explicitly describe the three different layers of the contexts. In my study, the university and two faculties provide the institutional context and sub-context. The differences between Western concepts and traditional values of Vietnam are in the wider context. The discussion chapter will develop these issues further.

To conclude, both SCT and T-L map theories suggest that understanding teaching and 
learning activities usually involves acknowledgement of the contexts around the teaching and learning process. In my study, teaching and learning takes place in second language classrooms. The next sections explore the concepts of second language acquisition (SLA) as the broad context, and CLT as the specific context of my study.

\section{Second language acquisition (SLA)}

SLA theorises how individuals acquire a language in addition to their first language. Over time SLA research has come to identify the central role of interaction in second language learning (Gass, 2013; Gass \& Mackey, 2007; Larsen-Freeman \& Long, 2014; Long, 1996; Pica, 1994). My study focuses on how EFL teaching and learning happens through questioning-based interactions. Some second language acquisition theories that precede the sociocultural turn in linguistics (Johnson, 2006) help explain why interaction can mediate learning and development. These theories involve the interaction hypothesis, the comprehensible input hypothesis, the comprehensible output hypothesis, the noticing hypothesis, and the concept of negotiation of meaning.

\section{Interaction hypothesis}

The interaction hypothesis (Long, 1983) proposes that interaction offers chances for second language learners to ask questions or clarify requests to promote one another to understand and make themselves understood. Furthermore, interacting with one another enables these learners to understand language input (what their interlocutors say or write) and ensure that output (language that the learners themselves produce) can be understood by others. The process of interacting encourages learners to notice something new from the interlocutor, such as new lexical items or structures. It also pushes learners to decide and organise what to say in their interactions with others. In brief, having to understand or produce the target language encourages learners to test out new forms.

As Gass (2003) notes, "language learning is stimulated by communicative pressure and examines the relationship between communication and acquisition and the mechanisms (e.g., noticing, attention) that mediate between them" (p. 224). The social pressure to communicate with others pushes learners to internalise and learn new 
things from the language use of others (comprehensible input). The learners are forced to produce the language and make themselves understood (comprehensible output). Interaction also promotes the development of L2 because it prompts learners to notice when what they say differs from what a native speaker says, or notice they cannot express what they want to express (noticing the gap hypothesis). Through interaction, learners have to use strategies they have developed to understand the input they need (negotiation of meaning) (Gass \& Mackey, 2007). These are the ways that interaction brings about the development of the L2. The following parts further explain the relevant theories, and the links between them and second language learning.

\section{Comprehensible input and comprehensible output hypothesis}

The comprehensible input hypothesis was first proposed by Krashen (1985). This hypothesis proposes that language learning only takes place if the input (from oral or written utterances) is at the optimal level $(i+1)$, or one step above the learner's current proficiency. If the input is comprehensible, the learner will be able to absorb new language features naturally from others, and apply these in future (Krashen, 1991).

The idea of an optimal level of input here is reminiscent of the concept of ZPD in SCT, which suggests the distance between actual and potential levels of learner. The ZPD is different from the $i+1$ notion in Krashen's input hypothesis because the former underscores the role of the learner as active agent and co-constructor, whereas in the latter input is received by a relatively passive learner (Lantolf, 2000). The ZPD highlights the interaction between the expert and novice, and its purpose is to assist the novice to move toward better self-regulation through the new language. Krashen's concept, on the other hand, focuses on language acquisition that results from learners comprehending input.

Accessing input at the appropriate level is, for Krashen, the one essential condition for acquisition (Krashen, 1991). However, according to Long (1983, 1996) and subsequent researchers like Swain (1985), comprehensible input is certainly necessary, but not sufficient, for ensuring language learning. 
In contrast, comprehensible output is achieved when learners manage to use the language to communicate with others orally or in writing. In other words, to produce comprehensible output, learners have to create meaning using the linguistic repertoire available to them at their current proficiency to communicate with a listener (Swain, 1985, 1993, 1995, 2000). The interactionist approach takes a particular perspective on output, and highly values pushed or modified output, or that output which involves a learner attempting to go beyond the learner's current level of knowledge. To make themselves understood, learners have to try out new forms or modify their output (Swain, 1995). Through interaction, learners try out their hypotheses about the language, and have chances to get feedback from the interlocutor, pushing learners to modify their output to produce more comprehensible language.

\section{Noticing hypothesis}

The noticing hypothesis suggests that learning takes place when learners are aware of the gap between what they want to say and what they can say, or the gap between the input, they obtain from a more competent L2 speaker and their own arrangement of the target language. "This leads them to recognize what they do not know or know only partially" (Swain, 1995, pp. 125-126). Noticing "may trigger cognitive processes which might generate new linguistic knowledge or consolidate existing knowledge" (Swain \& Lapkin, 1995). In other words, noticing is essential for learning to take place.

Gass (2013) further developed a cognitive view of noticing. She proposed that initial steps in second language learning happen when the learners notice the mismatches between the input they receive and the language they are producing. Gass and Mackey (2007) suggest awareness and attention as two stages of noticing. They explain how noticing can promote learning but that "the learner must be consciously aware of linguistic input in order for it to become internalized", and "attention to input is a consequence of encoding in working memory, and only input encoded in working memory may be subsequently transferred to long-term memory" (p. 191). Learning occurs when the learner notices and absorbs new input.

Being aware of a linguistic problem can push learners to modify and make their output more comprehensible to others, by searching their own linguistic resources for 
information or paying attention to the relevant input. The process of moving from encountering a linguistic problem to striving to produce understandable output is part of the process of second language learning (Swain \& Lapkin, 1995).

The noticing hypothesis is a cognitive explanation for the learning occurring inside a learner's mind when the learner recognises the difference between the learner's language knowledge, the partners' language use, and the system of the target language. In contrast, the theory about negotiation of meaning addresses how learners organise the language to make communication comprehensible.

\section{Negotiation of meaning}

The interaction hypothesis sees SLA as depending on face-to-face communication and interaction. The hypothesis explores the concept of negotiation of meaning and claims that negotiated interaction contributes second language learning (Long, 1996).

In interaction, meaning being negotiated plays an important role in SLA (Gass, 2003; Long, 1983, 1996; Pica, 1994). Long (1996) defined negotiation as conversation with a teacher containing linguistic features such as repetitions, extensions, reformulations, corrections, or modification. He also proposed that "negotiation for meaning, and especially negotiation work that triggers interactional adjustments ... facilitates acquisition because it connects input, internal learner capacities, particularly selective attention, and output in productive ways.” (pp. 452, 453).

The act of negotiation can, for example, push learners to pay attention to linguistic problems or form-meaning relationships. Through the act of rephrasing, repeating or reorganising linguistic units to aid comprehension, learners may have opportunities to notice features of the target language. For instance, Pica (1994) explained how learners perceived new syntactic features through meaning negotiation when a teacher emphasised these features by using stress, intonation, and foregrounding repetition, rewording, and elaboration. The teachers employed these emphasising strategies to encourage learners to notice and rephrase or correct their own utterances. Therefore, negotiation of meaning can lead learners to notice and ultimately internalise linguistic knowledge. 
According to Krashen (1985), negotiation of meaning can promote language learning when teachers (or others) modify their utterances to provide learners with comprehensible input. Negotiation offers learners opportunities to seek and gain clarification from the other. It requires the other to adapt the input into manageable or understandable chunks, and the learners can process language that, at first, they do not understand. Therefore, it is through interaction and by negotiating meaning that learners are provided with the opportunity to obtain comprehensible input.

In this way, when meaning is negotiated, learners pay attention to prominent linguistic features, and input is likely to become comprehensible to them.

To conclude, interaction plays a crucial role in language learning. Language learning occurs when a learner can understand the target language pitched a little in advance of their current proficiency, and when learners are pushed to think and try out new forms to produce comprehensible language. To succeed in communicating with others, learners are directed to pay specific attention (notice) to the gap in their language knowledge, and strive to produce understandable output. Through interaction, learners have opportunities to gain clarification by using the conversational and linguistic modifications (negotiation of meaning). In other words, interaction to communicate creates the conditions necessary for second language development. Theories from SLA provide a framework for my study, because these can be used to explain how questioning-based interaction promotes teaching and learning in EFL classes. The following sections illustrate how theories from SLA are relevant to studies about question-answer interactions.

\section{Questioning within SLA}

Research has used input, output and interaction hypotheses as frameworks for understanding the role of questioning.

\section{Questioning promotes input}

Two aspects of input are highlighted in previous studies about questioning: firstly, interaction during questioning involves the participants taking turns and this process 
can facilitate chances for the learner to access input. Secondly, different types of questions stimulate input differently.

\section{Questioning provides chances for learners to access input}

Questioning involves participants taking turns in asking, answering and feedback giving, and these turns can provide opportunities for learners to access input. For example, teachers could use questions to model appropriate language use. Mackey (1999) and Kao et. al. (2011) proposed that teacher talk could be a model of targetlike forms and give opportunities for students to notice structures (sociolinguistic) and apply them in different contexts (pragmatics) (Mackey, 1999). In an EFL classroom in a Taiwanese college, teachers used pseudo (saying aha rather than saying yes), confirming, and clarifying questions to remodel the students' segmental, inaudible or ungrammatical utterances (Kao et al., 2011). Kao et al. also found that appropriate questioning could help students to focus on the content and linguistic elements required to carry out natural interaction.

Input can also be contained in the teacher's answer. McNeil (2012) investigated how teachers' answering functioned as promoting input when a teacher offered a model of an answer, or modelled how to negotiate meaning. He found that such models helped students learn how to communicate effectively.

The teacher's feedback is another source of input. McDonough (2005) explored how negative teacher feedback enabled learners to notice the comprehensibility of their utterances. The teacher feedback drew learners' attention to language forms they produced and helped them to detect gaps or holes in their L2 knowledge or assess specific linguistic forms in the subsequent input.

\section{Question types and input}

Other researchers (Farahian \& Rezaee, 2012; Shomoossi, 2004) suggest that additional kinds of questions provide input to different students. Shomoossi (2004) explored types of question that could facilitate input. This mixed-methods study examined the use of referential questions (RQ, questions for unknown information) and display questions (DQ, questions for known information) in reading 
comprehension classes. Shomoossi (2004) found that DQs provided students some basic but important pieces of information concerning textual information, such as "comprehension checks, a summary of paragraph, meaning of words, idiom, position of stress and the right way of pronouncing certain word" (p. 101). These sorts of knowledge provided the necessary preparation for later and more complex questions (such as RQ). Farahian and Rezaee (2012) also note that DQ may not result in students' critical thinking but may "pave the way for their participation, and this participation may lead to acquisition. DQ is particularly important in providing comprehensible input for beginning level students" (Shomoossi, 2004, p. 102), who could find RQ are far beyond their competence. This may support Krashen's (1985) theory that the comprehensible input should be just at the next level of the current level of the learner. Therefore, these lower level students are more likely to engage in interaction when the teacher asks DQ.

In brief, language learning is the goal of an EFL class, so a teacher's role is to plan chances for students to access input in the target language (McDonough, 2005). Therefore, teachers use their turns, asking questions, modelling answers or giving feedback, to promote various aspects of acquisition. These questioning roles relate to second language learning goals such as linguistic form, language use, subject content, and skills. Furthermore, teachers can use different question types to promote learning through input adjusted for different learners' levels or teachers' purposes.

\section{Questioning promotes output}

In second language classrooms, the output is students' talk/answers to the teacher or to other students. In question-answer interactions, students are asked to respond; and this offers opportunities to produce language (output). Literature illustrates that different types of question promote different levels of output, and questioning may help learners notice the gaps and modify output.

\section{Question types and output}

Question types promote input but also promote output in a language class. Questions require responses and thus serve as a means of obliging learners to contribute to classroom interactions (Ellis, 1996). However, research reveals conflicting findings 
regarding teacher use of and student responses to display questions (DQ) and referential questions (RQ).

A number of studies contend that RQ can lead to longer interactions and encourage the amount of learner output and hence promote second language development. (Farahian \& Rezaee, 2012; Yang, 2006; Zohrabi, Yaghoubi-Notash, \& Khiabani, 2014; Wright, 2016). For example, these studies indicate that RQ might promote extended/enhanced contributions from students. Because RQs call for opinions, evaluation, or analysis, the responses are likely to be significantly longer and syntactically more complex. According to Wright (2016), RQs can push learners to engage more in negotiation for meaning than DQs, therefore, RQs should be more beneficial for language learning.

However, some studies argue that second language learners are not always able to answer RQs (David, 2007; Lee, 2006; McNeil, 2012; Suk-a-nake, Heaton, Dhanan, \& Rorex, 2003). Teachers may fail to elicit responses from students when using RQs if students struggle to answer RQ (Yang, 2010). David (2007), Shomoossi (2004), and Ozcan (2010) even argue that DQ tend to stimulate interest and promote more active participation among lower-level students. Similarly, Lee (2006), using sequential analysis, claims that "display questions are central resources whereby language teachers and students organize their lessons and produce language pedagogy" (p. 691).

The relationship between question types and student talk has been extensively explored. It is dangerous to generalise which question types are more useful (Shomoossi, 2004). However, it is likely that classroom questions of whatever sort may have the effect of prompting learners to produce language, which can promote language acquisition.

\section{Negative feedback helps students notice gaps and modify output}

Being aware of gaps in their understanding allows learners to modify their answers. Modifying answers means engaging in output producing, which facilitates language development (Gass, 2013; Long, 1996). One way that the teacher can encourage students to notice these gaps is through the use of feedback, using negative feedback 
(Long, 1996) or corrective feedback (McDonough, 2005) or constructive feedback (Li, 2011a).

McDonough (2005) conducted an empirical research study using the interaction hypothesis framework. This study demonstrated that interaction pushes learners to stretch their linguistic resources through negative feedback. Interaction could provide opportunities for learners to modify their output in response to the teacher's feedback appeared to facilitate L2 development. In response to negative feedback, learners modified their previous utterances by reformulating the previous utterance, adding more lexical items, such as relative clauses. In contrast, students who did not receive negative feedback rarely modified their utterances and if they modified them, the modifications did not involve developmentally advanced language. McDonough (2005) suggested that learning opportunities were created by both the provision of corrective feedback and the production of modified output in response to the negative feedback.

\section{Questioning and interactional hypothesis}

Questioning-answering creates interaction. Therefore, questioning interaction involves attributes of the interaction hypothesis, for instance, negotiation for meaning promotes responses. Also, more than one learner can benefit from the questioning interaction.

Negotiation for meaning promotes students' responses

Both teacher and students, when participating in questioning, negotiate meaning. Lee (2006) demonstrates how negotiating what is being asked can encourage students to elaborate on, revise or justify their talk. These were evident in the students' efforts to make sense and appeared to benefit their communicative competence in Lee's study. Teachers, in Lee's study, supported their students by developing strategies to promote student negotiation for meaning. For instance, the teachers gave negative feedback, such as open-ended classification requests: "sorry?", "what?", "pardon” or "huh?", and paused to allow the learners opportunities to modify their output. This appeared to encourage students to modify their output (Wright, 2016). 
This negotiation of meaning appeared to lead to an increase in input and a resultant increase in opportunities for student output, as suggested by Swain $(1985,1995)$. Supporting this idea, Nassaji \& Wells (2000) and Wright (2016) suggest that questions, especially RQ, may also create a variety of student output.

Nassaji and Wells (2000) previously called RQ “negotiatory questions" (p. 33). This question type is often used by the teacher in follow-up turns and can encourage more negotiation. These negotiatory questions often avoid evaluations but request justifications, connections or counter-arguments, and allow students to self-select in making their contribution. Negotiating in the follow-up turn encouraged more interaction and extended student participation.

Wright (2016) explores instances of negotiation for meaning such as repetition, echoing, reformulation, self- and other-initiated correction. The study illustrates how students attempted to produce more target vocabulary to describe facial features. These negotiatory features were used to describe exact details and added to the comprehensibility of the students' utterances, thereby making longer and more complicated responses. The study also points out that RQ have the potential to encourage negotiation of meaning because students "tried harder and harder to describe" when the teacher did not know the answers to the referential questions (p. 181).

\section{Questioning stimulates both participating and observing learners}

Studies about questioning suggest some interaction patterns that can create opportunities for students to produce more output and negotiation (Ko, 2014; Wang \& Wang, 2013). For example, teachers could use the extended pattern, teacher questionstudent response-teacher feedback and question-student response-teacher feedback and question-student response (Wang \& Wang, 2013), to promote learners' participation. Another one is the sequence teacher question-student discussionstudent answer (Ko, 2014), which can enable forums for peer discussion, which might be in pairs or in groups of students, multiplying interactions among students. This takes place as students formulate an answer to share with the teacher. These two patterns are productive because they give students chances to speak in depth about the topic with either teachers or peers. By initiating these patterns, the teacher can create 
time and turns for students to develop, articulate and challenge their opinions. Consequently, more than one student has the opportunity to work with the target language. This encourages more students to acquire and practise the new language through communication than would occur in a lecture-based classroom (Long, 1983).

Through interaction more than one student can engage with the language. Swain (1995) proposed that not only the learners actively participating in the interaction, but also others who are observing, learn through the interaction. In watching an interaction, the observers have an opportunity to hear the output of others and learn from this output. This means the output of the student who is answering can also become input for the other students who are observing the question-answer interaction.

There have been some arguments about whether learners who observe an interaction can be considered to take part in the interaction. Pica (1992), and Ellis, Tanaka, and Yamazaki (1994) claim that there is no significant difference between observers and speakers in terms of comprehension and vocabulary acquisition in EFL classroom in Asian countries. However, Mackey (1999) in an investigation about how learners learn advanced structures, disagrees in ESL classroom in Australia. In the study, Mackey observed that the group of learners who were taking part in the interactions had the opportunity to produce questions and receive feedback through the answers. The students engaging in the interaction could produce more advanced structures than the students observing the interaction. Although they could not take part in the interaction, the observer group did have the opportunity to hear the forms negotiated, segmented, repeated, and recast in the interaction. However, learners who actively participated in the interaction received the most benefit, and learners who observed the interaction without taking part in it appeared to receive less benefit.

In summary, viewing questioning interaction within interactionist theories of SLA, teacher questions can provide input, student responses are the output, and this output is followed by teacher feedback, which could be negative or corrective feedback (providing another layer of input). This feedback then can encourage further responses from students, which are modified output. In this process of questioning and answering, both teacher and students negotiate language features to ensure further comprehensibility. 
Studies about questioning also explore how interaction facilitates conditions necessary for second language development. Questions of different types can facilitate student responses differently. Referential questions (RQ), to which the teacher does not know the answer, can provoke language production. Besides, questioning can provoke negotiation for meaning and lead students to notice the gap. Finally, questioning may stimulate language development in both participating and observing learners.

In conclusion, questioning is a crucial aspect of sociocultural theory and second language acquisition. Both perspectives agree that questioning is a form of interaction and questioning interaction promotes language learning. The following section draws on theories and practices of communicative language teaching, an approach that is now widely promoted in second language teaching in Vietnam.

\section{Communicative Language Teaching (CLT)}

This section will address more specifically the research context. It focuses on the communicative approach to language teaching applied in many EFL contexts. To begin with, I will present some background information about communicative language teaching (CLT), and how CLT is understood. The later parts outline the application of CLT in general and then particularly in East Asia and in Vietnam, where my study took place.

\section{Overview of CLT}

CLT prevails in foreign language learning and provides a framework for teaching and for constructing programmes that prioritize learners' communicative competence (Littlewood, 2014). Communicative competence refers to the ability of learners to use and understand the difference purposes or functions of the target language in meaningful settings. Learners can manage to communicate with other users despite limited language competency. Thus, according to CLT, learning and teaching the target language is most effective through communication in the target language.

Littlewood (2014) and Richards (2006) outline three stages of CLT development: traditional approaches before the late 1960s, classic communicative language teaching 
between the 1970s and 1990s, and current communicative language teaching from the late 1990 s to the present.

The traditional approaches of the 1960s (such as grammar translation method, audiolingual method, and direct method) considered grammatical competence as the priority of language proficiency (Demirezen, 2011; Lightbown \& Spada, 2006). In particular, traditional language classes focused on teaching form and seriously practising using rules for accurate grammatical sentences.

In the 1970s, CLT originated in the BANA countries (Britain-America-New Zealand-Australia) in EFL classes for adult learners (Holliday, 1994). It was quickly applied to other countries, in response to a growing need for communicative competence in English. Under the influence of CLT theory, grammar-based approaches have given way to "functional and skills-based teaching, and accuracy activities such as drill and grammar practice have been replaced by fluency activities based on interactive small-group work" (Richards, 2006, p. 8). CLT developed to address the global need for learners with communicative competence.

From the 1990s to the present, CLT has been applied in a variety of different settings. According to Richards (2006), CLT has been adapted to particular teaching contexts, learners' ages and proficiency, and to achieve different learning goals. As a result, there has been no unified or single version of CLT. Littlewood (2014) emphasises that even now CLT still is the dominant model for language teaching policies and practice in EFL classes, even though there have been different applications of CLT. These differences are especially visible in Asian countries, where educational traditions often contrast strongly with those where CLT originated.

The shift to CLT led to the changes in the principles and focus of second language education (Jacobs \& Farrell, 2003). This section will review CLT frameworks and analyse how this communicative approach to teaching and learning has been managed in Vietnam.

I considered two possible frameworks to analyse the role of questioning in CLT; those theorised by Littlewood (2007) and Richards (2006). 
Littlewood (2007, p. 247) proposes a five-category framework, which gradually moves learners from a non-communicative teaching classroom to a communicative teaching classroom:

"Category 1: Non-communicative teaching is mostly form-focused, including grammar, substitution and pronunciation exercises.

Category 2: Pre-communicative language practice with the primary focus on language structures but also oriented towards meaning.

Category 3: Communicative language teaching provides activities with a predictable range of language but uses it to convey a message.

Category 4: Structured communication mainly focuses on the communication of meanings. The teacher structures activities that enable learners to work with their existing language resources and what they have recently used in more form-focused work.

Category 5: The most meaning-oriented practice involving authentic communication has the strongest focus on communication and language forms are correspondingly unpredictable. Typical activities are discussion, problem-solving, content-based tasks, and larger scale projects."

The second framework, proposed by Richards (2006), views the CLT application from a different angle. He suggests that there are eight major components of CLT that promote language teaching. These are presented below: 
Table 2

Eight Components for Applying CLT (adapted from Richards, 2006, p.25-26)

\begin{tabular}{|c|c|}
\hline Components & Description \\
\hline 1. Learner autonomy & $\begin{array}{l}\text { Giving learners greater choice over their own learning, both in terms } \\
\text { of the content of learning as well as processes they might employ. } \\
\text { The use of small groups is one example of this, as well as the use of } \\
\text { self-assessment. }\end{array}$ \\
\hline $\begin{array}{l}\text { 2. The social nature of } \\
\text { learning }\end{array}$ & $\begin{array}{l}\text { Learning is not an individual, private activity, but a social one that } \\
\text { depends upon interaction with others. The movement known as } \\
\text { cooperative learning reflects this viewpoint. }\end{array}$ \\
\hline 3. Curricular integration & $\begin{array}{l}\text { The connection between different strands of the curriculum is } \\
\text { emphasized, so that English is not seen as a stand-alone subject but is } \\
\text { linked to other subjects in the curriculum. Text-based learning } \\
\text { reflects this approach, and seeks to develop fluency in text types that } \\
\text { can be used across the curriculum. Project work in language teaching } \\
\text { also requires students to explore issues outside of the language } \\
\text { classroom. }\end{array}$ \\
\hline 4. Focus on meaning & $\begin{array}{l}\text { Meaning is viewed as the driving force of learning. Content-based } \\
\text { teaching reflects this view and seeks to make the exploration of } \\
\text { meaning through content the core of language learning activities }\end{array}$ \\
\hline 5. Diversity & $\begin{array}{l}\text { Learners learn in different ways and have different strengths. } \\
\text { Teaching needs to take these differences into account rather than try } \\
\text { to force students into a single mold. In language teaching, this has } \\
\text { led to an emphasis on developing students' use and awareness of } \\
\text { learning strategies. }\end{array}$ \\
\hline 6. Thinking skills & $\begin{array}{l}\text { Language should serve as a means of developing higher-order } \\
\text { thinking skills, also known as critical and creative thinking. In } \\
\text { language teaching, this means that students do not learn language for } \\
\text { its own sake but in order to develop and apply their thinking skills in } \\
\text { situations that go beyond the language classroom. }\end{array}$ \\
\hline 7. Alternative assessment & $\begin{array}{l}\text { New forms of assessment are needed to replace traditional multiple- } \\
\text { choice and other items that test lower-order skills. Multiple forms of } \\
\text { assessment (e.g., observation, interviews, journals, portfolios) can be } \\
\text { used to build a comprehensive picture of what students can do in a } \\
\text { second language }\end{array}$ \\
\hline 8. Teachers as co-learners & $\begin{array}{l}\text { The teacher is viewed as a facilitator who is constantly trying out } \\
\text { different alternatives, i.e., learning through doing. In language } \\
\text { teaching, this has led to an interest in action research and other } \\
\text { forms of classroom investigation }\end{array}$ \\
\hline
\end{tabular}

Both Littlewood's and Richards' proposals outline how teachers might implement

CLT in EFL teaching practice. However, they have distinctive focal points. While Littlewood (2007) proposes steps to manage a shift from non-communicative to communicative teaching, Richards' (2006) framework explores prominent attributes of CLT teaching, the nature of learning, teacher and learner roles, as well as integration of language and diversity across the curriculum. While there is no unified 
model of CLT that is officially agreed, Richards' principles of CLT provide the most usable and comprehensive CLT framework for my study. The core components, suggested by Richards, such as learning through interaction, the integration between language learning and other subjects, and critical thinking in the target language are explicit in my thesis. (These will be analyzed and discussed in the findings and discussion chapters). Therefore, I use Richards' principles to examine how features of CLT are included in teaching and learning activities in my study.

\section{The influence of CLT in East Asia and Vietnam}

CLT is applied differently in language learning classrooms as its implementation varies from culture to culture (Littlewood, 2014). Though CLT is accepted as the dominant approach in many East Asian settings; it is challenging in practice implement (Ho \& Wong, 2004; Nunan, 2004). In order to teach using a CLT approach, teachers must use skills and techniques that may contrast with traditional Asian teaching pedagogy. It may challenge EFL teachers used to a Confucian approach to education to introduce "communicative activities (or 'tasks') in which learners are expected to negotiate meaning without the direct control or intervention of the teacher" (Littlewood, 2007, p. 244). Regardless of the upheaval involved in changing from a familiar, teacher-focused approach to teaching, policymakers believe CLT as advantageous for Asian teachers to add "communicative activities in their repertoire of teaching skills and [give] learners the opportunities in class to practise the language skills taught" (Ho \& Wong, 2004, p. 26).

However, there is concern about the unquestioning acceptance and uneven application of CLT techniques in East Asian settings. For example, some EFL teachers have quietly dropped CLT practices and returned to traditional teaching methods in Malaysian classrooms (Pandian, 2002). In China, too, teachers may either ignore or refuse to implement CLT techniques proposed by policy-makers ( $\mathrm{Hu}, 2004)$. This appears to result from a mismatch between teacher's beliefs and their practice, which may reflect teachers' misconceptions about CLT and shows their adherence to traditional approaches (Lixin, 2011). In Korea, "teachers have no choice than to write up reports that comply with government recommendations while continuing to practise examination-oriented classroom instruction" (Shim \& Baik, 2003 p. 246). In South Korea, Moon (2014) also reported that EFL teachers' understanding of CLT 
was limited, especially in teaching speaking skills. In Indonesia, CLT has not been used commonly because of the inadequacy of theoretical knowledge of teachers about CLT, the perceived limited English competence of students, and the unfamiliar expectation of English communication practice that, while commonly used in Western contexts, was not familiar to Indonesian educators (Jigme, 2017; Farsia, 2016).

As a member of East Asia, Vietnam has had similar experiences when applying CLT. Even though CLT has become the dominant approach for teaching EFL in Vietnam, there are lingering concerns about how to apply CLT and develop English proficiency in practice. CLT originated in Western-based educational approaches. Yet Confucian Heritage nations may be challenged to accommodate Western concepts about the roles of teacher and student, individualism versus collectivism, and time orientations. The following parts will focus on these clashes in applying CLT in EFL in Vietnam.

The Confucian Heritage Culture (CHC) greatly influences the application of CLT in Vietnam (Ngoc \& Iwashita, 2012; Phan, 2015; O’Dwyer, 2017). In Vietnam, English classrooms still depend on traditional practices and Confucian learning roles. In other words, CHC greatly shapes Vietnamese students' perceptions about and behaviours toward teachers' and learners' roles, as well as teaching and learning styles (Ngoc \& Iwashita, 2012).

The CHC classroom is based on the teacher's position of authority. Teachers are not only moral examples for learners to follow, but also masters of subjects whose knowledge should be accepted without debate. Students are expected to be passive and expected to listen and absorb the teacher's every word. The positioning of teacher and learners in this way creates a power distance that may lead Vietnamese EFL teachers to feel conflicted between the CLT role of facilitator and the traditional role of importer of knowledge (Phan, 2004).

Classrooms in Vietnam are traditionally collectivist, in which students feel secure and comfortable when they know they belong to groups (Le, 2013). However, this is not a synonym for a preference for cooperative learning (Nguyen, Terlouw, \& Pilot, 2005a). Collectivism in Vietnam means that the value of harmony dominates; confrontations and conflicts should be avoided (Hofstede \& Hofstede, 2005). Collectivism influences behaviours in the classroom. Students may try to avoid 
offering personal ideas and criticising others in public. They might use acts of "avoiding losing face/protecting face", "saving face", "giving face", "gaining face" (Nguyen, Terlouw, \& Pilot, 2005b; Le, 2013), and they are likely to remain silent rather than voice something that may make others feel humiliated or silly.

Another conflict between Western and $\mathrm{CHC}$ nations is their different orientations towards long- and short-term goals. According to Hofstede and Hofstede (2005), short-term time orientation is more appropriate within Western cultures, where it is deemed important to follow clock time and schedules promptly, and to keep appointments. In contrast, $\mathrm{CHC}$ countries, including Vietnam, prefer long-term time orientation, "valuing the past and present, especially respect for traditions, preservation of 'face' and fulfilling social obligations" (Nguyen, Terlouw, \& Pilot, 2006, p.10). The concept of long-term orientation contributes to explaining the highly valued exams in Vietnamese education (Le, 2013). Many parents, students and even teachers consider the exams (for example, final exams and university entrance exams) to be the best measure of a learner's ability and effort. Passing the exams is the route to higher education to guarantee 'future rewards', i.e., a socially and economically better life in the future (Le, 2013).

Littlewood (2007) describes Vietnam and other East Asian countries as strong traditional examination-oriented educational systems. In these countries, teaching and learning quality is ranked according to the number of students passing the national examination, rather than by how effectively the students learn. Students and parents worry about students achieving high grades for public examinations, which are held nationally and institutionally all year round. In addition, most examinations focus largely on text structure, grammar, vocabulary and reading comprehension and lack listening and speaking components. In other words, the tests focus on examining linguistic knowledge rather than communicative competence, making the application of CLT a big challenge (Pham, 2004, 2007).

EFL teachers also face additional challenges such as the average class size in tertiary level being 40-65 students (Bock, 2000). A regular EFL class in Vietnam of 40-65 is not ideal for conducting effective group learning and can make classroom management difficult. In contrast, the Western class-size norm is 1:15 (Nguyen, Terlouw, \& Pilot, 2005b). Another challenge is the demand to include all the items in 
the curriculum despite limited time allocated to each lesson (Ngoc \& Iwashita, 2012). Due to oversized classes, limited time and an overloaded curriculum, Vietnamese teachers of English often complain about managing learning in their classrooms (Nguyen, 2010). Teachers may struggle to promote collaborative work among students, which is an important principle of CLT application.

It is challenging to create authentic communication in an EFL classroom. While ESL learners are exposed in the target language and primary communicate it in daily activities to survive in the target culture, Vietnamese EFL learners generally have limited access to the target language outside the classroom and can only usually practise what they have learned within the classroom (Campbell, 2004). Students lack opportunities for genuine communicative interactions with competent speakers of the language. Teachers and textbooks serve as the predominant source for communication needs. This inhibits the motivation of many learners to communicate in English outside the classroom (Le, 1999).

In conclusion, the assimilation of CLT in East Asian countries, including Vietnam, faces various challenges. Reasons for the difficulties in applying communicative approaches generally include: different conceptions about the value of CLT between policy-makers and teachers, misconceptions about CLT, and loyalty to the traditional approach. A noticeable barrier to applying CLT in Vietnam is the clash between Western and Vietnamese traditional values and expectations. This indicates that Western approaches to teaching English, such as applying CLT techniques, may not transfer easily to the Vietnamese context, with its Confucian ideology, examinationfocused system, large class sizes and limited access to an English-speaking environment.

\section{Adaptation rather than adoption of CLT}

Teachers in East Asian contexts may have doubts about the effectiveness of CLT, however, CLT is still viewed as one of the most effective approaches to English as foreign language teaching (Jigme, 2017; Farsia, 2016; Lixin, 2011; Moon, 2014; Ngoc \& Iwashita, 2012). Although this requires adapting CLT for teaching in East Asian contexts (Littlewood, 2007, 2014), CLT approaches have the potential to be sufficiently flexible "to suit various contexts of language teaching across the world 
and across time" (Kumaravadivelu, 2006, p. 63). This means educators in East Asia should be empowered to customise and integrate new approaches to accommodate their own circumstances. East Asian educators are likely to test out Western teaching techniques and practice, but not necessarily adopt them as a fixed recipe. The values and attributes of the local setting greatly influence the application of communicative approaches in East Asia (Littlewood, 2007, 2014).

CLT requires adaptation rather than adoption in many East Asian settings. Samimy and Kobayashi (2004) suggest that in Japan "English education should embrace CLT in a culturally sensitive and appropriate way, yet maintain its own contextual autonomy" (p. 258). In Hong Kong, Carless (2004) demonstrates how EFL teachers filtered and interpreted the use of communicative tasks in line with their own understanding and practical challenges within their classrooms. In China the implementation of CLT is described as "an extensive cross-breeding of elements drawn from different EFL techniques, methods, and approached from a localized methodology that supports the effective teaching and learning of English" (Ho \& Wong, 2004, p. 464).

Much comprehensive empirical research has been conducted in the Vietnamese context (Bui, 2006; Nguyen, Terlouw, \& Pilot, 2005a; Nguyen, 2010; Pham, 2007; Sullivan, 2000; Tomlinson \& Dat, 2004) as educators search for ways to adopt pedagogies that are appropriate to the context. For example, research suggests the use of technologies could provide resources for authentic communication and collaborative activities (Bui, 2006; Nguyen, 2010). The use of playful resources and activities such as laughter, wordplay, and oral narratives (telling stories) could promote spontaneous learning and communicative classroom activities (Sullivan, 2000). Literature also records the application of cooperative learning in Vietnam. This happened at three levels: administratively, across the curriculum, and in lessons (Nguyen, Terlouw, \& Pilot, 2005a). Pham (2007) proposes that EFL teachers believed in and attempted to promote CLT for the sake of learners rather than because the teachers wanted to please policy-makers. Even so, teachers were largely unaware of what their students felt and thought. Tomlinson and Dat (2004) indicated that it was necessary to provide students with chances to contribute to decisions about classroom methodology. Research suggests that there is scope for CLT in Vietnam to be 
redefined to be both "culturally attuned and culturally accepted" (Ngoc \& Iwashita, 2012, p. 29).

To sum up, this section has focused on the communicative approach, including the background of CLT, some frameworks such as Richards' principles for evaluating CLT, and the recommendation to adapt CLT for East Asia contexts. I illustrated how communicative approaches are widely applied in second language teaching, though there is variation in how they are modified to suit cultural context in Vietnam.

\section{Questioning}

The concept of questioning used throughout this study refers to the process by which teachers and students use questions to stimulate interaction among classroom participants. This section provides an overall understanding of questioning by addressing the different turns that make up the construct of questioning (such as asking, answering, and following-up); and reviewing commonly used questioning sequences within the foreign language classroom.

\section{The construct of questioning}

Questioning in this study is defined as a speaking process, consisting of turns shared between teacher and students. Therefore, this part will identify the function of different turns in a questioning sequence. Basic questioning routines consist of three turns: initiation-response-feedback (IRF) (Dalton-Puffer, 2007; Gibbons, 2007; Jiang, 2014; Sharpe, 2008; Tan, 2007).

\section{Initiation}

Questioning interactions are initiated by a question. This part will review initiating questions by providing the definition of questions, characteristics of quality questions, the purpose of questions, and a classification of questions.

Shomoossi (2004) characterises a question as an utterance with a particular illocutionary force (the interrogative intention of speaker's utterance). Shomoossi also defines a question as a semantic class used to seek information on a specific subject. Research on teacher and student talk claims that teacher questions are utterances 
classified either syntactically or functionally (Heritage \& Heritage, 2013; Lee, 2006; Jiang, 2014; Wang \& Wang, 2013). My study looks at questions that function to elicit responses from students and initiate interaction between teachers and students.

Quality questions are theorised as being "purposeful, engaging, and consequential" (Walsh \& Sattes, 2016 p. 23). Quality questions possess definite atrributes. They help to deliver teaching/subject content and serve instructional purposes, and they initiate a focus on significant content. They may also promote conceptual knowledge, procedural knowledge, and meta-cognitive knowledge, and they have the potential to develop students' cognition.

Initiating questions may serve various functions or purposes (Farahian \& Rezaee, 2012; Ur, 2000). Ur (2000) suggests that teacher questions can be used to lead learners to express their opinions, or to check students' learning progress. Furthermore, they can engage learners to take an active part in learning. Teachers also use questions to provoke learners' thinking and retrieve examples or applications of what has been taught. These pedagogical motives for a teacher's questions promote communication and learning in the classroom.

Literature proposes other classifications of questions. For example, display questions $(D Q)$ ask for known information, while referential questions (RQ) for unknown information (Long \& Sato, 1983). Procedural questions help organise classroom activities and convergent/divergent questions focus on subject content (Farahian \& Rezaee, 2012; Richards \& Lockhart, 1994). Wajnryb (1992) adds other types such as short answer/retrieval-style questions, that stimulate learners to recall predictable factual information from textbooks; and open-ended/display questions, that elicit an unpredictable response. These categories overlap at certain points, hence my study employed the classification proposed in Cotton's taxonomy (2001), which divides questions into two: firstly, lower cognitive questions (LCQ), consisting of closed/display questions, convergent questions, short answer/retrieval-style questions that require learner's retrieval of factual information. Secondly, higher cognitive questions (HCQ), involve open questions, divergent questions or referential questions that require learners to answer with analysis, synthesis, or reasoning. The table below summarises the classification of questions: 
Table 3

Question Classification (adapted from Cotton, 2001)

Two broad levels: $\quad$ Explanation/definition

Sub-type entailed in:

\begin{tabular}{|c|c|c|}
\hline $\begin{array}{l}\text { Higher cognitive } \\
\text { questions (HCQ) }\end{array}$ & $\begin{array}{l}\text { Questions place high } \\
\text { cognitive demands on the } \\
\text { person who answers, and } \\
\text { require critical thinking. }\end{array}$ & $\begin{array}{l}\text { Open questions, } \\
\text { divergent questions or } \\
\text { referential questions. }\end{array}$ \\
\hline $\begin{array}{l}\text { Lower cognitive } \\
\text { questions (HCQ) }\end{array}$ & $\begin{array}{l}\text { Lower Cognitive Questions } \\
\text { contrast with High Cognitive } \\
\text { questions. Lower Cognitive } \\
\text { questions place limited } \\
\text { cognitive demands on the } \\
\text { person who answers, and } \\
\text { require factual recall of } \\
\text { known information (Cotton, } \\
\text { 2001). }\end{array}$ & $\begin{array}{l}\text { Closed/display } \\
\text { questions, convergent } \\
\text { questions, short } \\
\text { answer/retrieval-style } \\
\text { questions. }\end{array}$ \\
\hline
\end{tabular}

Response

A number of studies have examined the response turn (Dalton-Puffer, 2007; Jiang, 2014; Ko, 2014; Wright, 2016).

According to Jiang (2014), there are four common student response patterns to initiating questions posed by their teachers. The first is where there is no response, the second where the teacher answers his/her own question, the third where students answer in chorus, and lastly where an individual student answers. Jiang (2014) interpreted no answer to reflect a gap in students' knowledge. Jiang also found that the teacher answering their own questions can prevent students' opportunities to exhibit thinking and make them more dependent on the teacher. Answering in chorus is students replying in a group or whole class. In contrast, individual answering is a reply from an individual student (Jiang, 2014). However, other researchers may interpret the responses in different ways. 
Ko (2014) explores the concept of multiple responses. This refers to answers in chorus. Multiple responses also means different replying turns to one question. This term captures responses when "the number of turns is sometimes built up by a number of students, who together construct the answer for a single question" (Ko, 2014, p. 49). Ko also contrasts display questions, which often receive multiple responses in chorus, with referential questions, which encourage a variety of responses.

Dalton-Puffer (2007), and Wright (2016) add an explanation of how these types of questions can affect the length and complexity of student answers. Display questions often require short and known answers, which narrows down the possible answers to a limited number of choices. This makes it likely that students will share a common answer in groups or as a whole class. Referential questions are open and encourage different opinions. Therefore, referential questions are likely to elicit long and complex answers (Wright, 2016).

In addition, Dalton-Puffer (2007) suggests that the teacher also can "decide whether responses will be individual or in chorus and how the students can bid for turns at talk (volunteer or nomination)" (p. 31). Dalton-Puffer identifies two ways that teachers can monitor who answers: either the teacher can invite students to volunteer (by raising hands to ask for a turn, or shouting out an answer), or the teacher can nominate/invite a particular student(s) by name to answer the question.

My investigation, based on the above research, distinguishes between individual and chorus answers and teacher nomination or volunteered answers.

\section{Feedback/Following-up}

Feedback turns are often taken by the teacher. By offering an evaluation or acknowledgement, feedback turns can finish the sequence. Alternatively, feedback can open a new interactional sequence (new initiation-response-feedback) if it raises another question or prompts students to talk more when they cannot answer. Therefore, there are two kinds of feedback: feedback after students answer, and a follow-up turn if students struggle to answer. 
Feedback performs a variety of functions but previous research (Chin, 2006; Jiang, 2014; Nassaji \& Wells, 2000) commonly identifies three categories of teacher feedback in the third turn. The teacher may use this turn to affirm or accept students' responses. The teacher may reformulate or repair any problems with the answer; and finally the teacher may encourage learners to develop their answers by asking further questions or exploring further perspectives and dimensions of the issue.

In addition, the literature suggests a type of feedback or follow-up of teacher to no answer or to student's difficulties to respond. For example, teachers might use modification techniques to prompt non-respondents, such as simplifying, restructuring, repeating, exemplifying (Kao, Carkin, \& Hsu, 2011; Meng, Zhao, \& Chattouphonexay, 2012; Yaqubi \& Mozaffari, 2011). Teachers also could manage a lack of student response by offering more wait-time, or inviting an open discussion in pairs or groups (Fagan, 2014; Jiang, 2014; Walsh \& Sattes, 2016).

To summarise, the above parts focus on the functions of specific turns in a questioning sequence, which is normally composed of the question, student reaction/ reply, and teacher feedback/follow-up.

The IRF model was developed in a content learning classroom rather than a language classroom (Atkins \& Brown, 2001). The IRF framework enabled the patterns of oral interaction in the class to be visible. However, the IRF model focused on sections but not extended discourse and it did not pay attention to para-linguistic features such as body language or gestures, which may also be part of the discourse in face-to-face communication. My thesis focuses on the question-initiated interactions in English language learning classes, involving but not limited to the three basic turns in IRF. My thesis captures the dynamic nature of language use in practice, including nonverbal elements and additional turns. The next section reviews questioning patterns within interaction and suggests other turns in questioning, such as struggling to answer and prompting by teachers.

\section{Questioning sequence patterns}

The three-part structure initiation-response-feedback (IRF) is the most typical discourse sequence used in an EFL classroom to stimulate the interaction between 
teacher and student(s), or among students (Tuan \& Nhu, 2010). In practice though, teachers may adopt variations of this questioning sequence. Waring (2009, p. 797) acknowledges that "IRF is not the only interaction that takes place in the classroom; neither is it a single sequence type". The interaction in classroom can take a variety of forms, initiated by both teachers and students for a wide variety of functions and options.

The teacher has a much wider range of options available, particularly in the third turn follow-up (Miao \& Heining-Boynton, 2011). This is evident in the following excerpt (Miao \& Heining-Boynton, 2011, p. 69).

\begin{tabular}{|c|c|c|c|c|}
\hline Line & Speaker & Utterance & Turns & Function/purposes \\
\hline 1 & Teacher & $\begin{array}{l}\text { Can you tell me why you } \\
\text { eat food? }\end{array}$ & Initiation (I) & $\begin{array}{l}\text { Requesting } \\
\text { information }\end{array}$ \\
\hline 2 & Pupil & To keep you strong. & Response (R) & Giving information \\
\hline 3 & \multirow[b]{2}{*}{ Teacher } & $\begin{array}{l}\text { To keep you strong. Yes. } \\
\text { To keep you strong. }\end{array}$ & \multirow[b]{2}{*}{ Feedback (F) } & Evaluating \\
\hline 4 & & $\begin{array}{l}\text { Why do you want to be } \\
\text { strong? }\end{array}$ & & $\begin{array}{l}\text { Requesting further/ } \\
\text { Initiating a new } \\
\text { questioning cycle }\end{array}$ \\
\hline
\end{tabular}

Episode 1: An example of an IRF sequence (adaped by Miao \& Heining-Boynton, 2011, p.69)

The example above involves three turns. The teacher's third-turn follow-up consists of utterances that serve two different functions. The first utterance offered feedback and performed an evaluative function on what the pupil said. The second part of the third turn played an initiating function that elicited further information from the pupil. In the feedback turn, the teacher asked another question (line 4) to open another sequence/cycle of questioning for the pupil, who was engaging in the interaction. Also, the question stimulated other learners to think and contribute. The example reveals how teachers can use variations of IRF sequences to open communication and stimulate student engagement and learning.

Nassaji and Wells (2000), in their quantitative study on teacher-whole-class interaction in Toronto, propose that the IRF sequences can "take a variety of forms 
and be recruited by the teacher for a wide variety of functions, depending on the goal of the activity that the discourse serves" (p. 1). They also mention that the Feedback turn can function to "accept/reject", evaluate, comment, exemplify, expand and justify.

Research claims that though IRF is considered the most frequent structure of interaction, there are more complex IRF patterns happening in the real classroom. Also, there may be more than three basic turns between teacher and students. The third turn, teacher feedback, can be used by skilful teachers to create a stronger communicative base (Nassaji \& Wells, 2000).

Another pattern of discourse, the IRFRF chain (Initiation-Response-FeedbackResponse-Feedback), was identified by Mortimer and Scott (2003) as another way to expand on the IRF structure. In the IRFRF chain, elaborative feedback from the teacher is followed by a further response from a student. This form is typical of discourse that supports a dialogic interaction. As part of the feedback, the teacher could repeat a student's comment to encourage the student to continue, elaborate on the comment, or ask for elaboration. By establishing this pattern, the teacher is able to explore students' ideas and engage them more dialogically in the discourse.

Sharpe (2008) analyses variations of IRF in her study of the interaction between teacher and students in History classes. In brief, the three moves: initiation (I), response $(\mathrm{R})$, and feedback $(\mathrm{F})$, were modified by the teacher to elicit more extended and thoughtful responses from their students. For example: IRF, IRFRF, IRIRF. The functions of these three moves were analysed into: giving information, confirming, extending, requesting suggestions, making suggestions, accepting, and reformulation. This study emphasizes that the teacher deliberately used moves in questioning to support thinking skills such as reasoning and recycling ideas about the subject-content (History).

Further questioning sequences have been identified by other researchers (Gibbons, 2007; Marzban, Yaqubi, \& Qalandari, 2010; Mortimer \& Scott, 2003; Shen \& Yodkhumlue, 2012). For instance, teacher question-student response-teacher feedback and question-student response-teacher feedback and question-student response- ... (IRFQRFQ sequences) (Wang \& Wang, 2013) is the sequence in which 
teachers utilise the third turn to initiate a further cycle of interaction. This also can be called embedded IRF.

Marzban et al. (2010), studying EFL classes in Iran, hypothesised that IRF is not a fixed structure, and identified ISRF (Initiation-Struggle-Response-Feedback) as a modified but less productive version of IRF sequences. ISRF consists of a teacher initiation (I), student struggle (S), teacher response (R), and student feedback (F).

For example:

\begin{tabular}{|c|c|c|c|c|}
\hline Line & Speaker & Utterance & Turns & Function/ purposes \\
\hline 1 & Teacher & $\begin{array}{l}\text { You never started to } \\
\text { work? Why? }\end{array}$ & $\mathrm{I}$ & Requesting information \\
\hline 2 & Student: & ...(cannot answer) & $\begin{array}{l}\text { Struggling } \\
\text { (S) }\end{array}$ & Struggling \\
\hline 3 & Teacher & $\begin{array}{l}\text { Because you are a college } \\
\text { student? }\end{array}$ & $\mathrm{R}$ & Giving information \\
\hline 4 & Student: & Yes & $\mathrm{F}$ & Confirming \\
\hline
\end{tabular}

Episode 2: An example of a modified version of the IRF sequence (adapted by Marzban et al. 2010, p.131)

The teacher nominates a specific student in the initiation turn. This is followed by a short second turn in which the teacher does not allow the student to struggle for long. In the third turn, the teacher offers a complete answer to his own initiation. The feedback turn is taken by the student to confirm the answer. However, Marzban et al. (2010) found that ISRF sequences offered very limited learning opportunities, even fewer than IRF sequences could offer. Marzban et al. suggest that the teacher actually robs students of opportunities to participate and appropriates turns for him/herself. It is suggested that teachers avoid applying this ISRF in their classes.

Literature finds other more productive examples of teacher responses to student struggle (Marzban et al., 2010). For example, the teacher might notice that students were struggling (or could not answer teacher questions) when students do not answer, or make a physical gesture (shaking their head). The teacher might persist in the initiation by paraphrasing the original question or giving hints to encourage students to reply. Then, when students can finally answer, the teacher moves to a feedback turn (Walsh \& Sattes, 2016). Therefore, the adapted interaction consists of: Initiation, 
Struggle, Prompt (Hints/help), Respond, Feedback (ISPRF). Meng et al. (2012) offer further techniques, which can be used by the teacher when students struggle to answer the teacher's question, such as simplifying, restructuring, repeating, and exemplifying.

Another sequence has been suggested that can enable peer discussion. This is teacher Initiation-student Discussion-student Response-teacher Feedback (IDRF) (Shen \& Yodkhumlue, 2012). The student discussion phase might take place in pairs or in a group of students, duplicating the interactions among students before the interaction between students and the teacher.

These sequences are considered productive because they give students more chances to speak and opportunities to engage thoroughly with the topic with either teachers or peers. Using these sequences, the teacher can create more time and turns for students to develop and challenge their opinions. Consequently, more students can actively work with the target language, which means that more students are likely to acquire more language.

The table below summarises different types of questioning interaction:

Table 4

Summary of Modified Versions of IRF Found in Research

\begin{tabular}{|c|c|c|c|c|}
\hline No. & $\begin{array}{l}\text { Questioning } \\
\text { sequence }\end{array}$ & $\begin{array}{c}\text { Abbrevi } \\
\text {-ation }\end{array}$ & Definition/explanation & References \\
\hline 1. & $\begin{array}{l}\text { Teacher Initiation - } \\
\text { Student Response - } \\
\text { Teacher Feedback }\end{array}$ & IRF & $\begin{array}{l}\text { Teachers often open classroom } \\
\text { interaction by raising questions, } \\
\text { following by students' answers, } \\
\text { and ending by teachers' } \\
\text { feedback or follow-up. }\end{array}$ & $\begin{array}{l}\text { Gibbons, } \\
2007 \\
\text { Sharpe, } \\
2008\end{array}$ \\
\hline 2. & $\begin{array}{l}\text { Teacher Initiation - } \\
\text { Student Response - } \\
\text { Teacher Feedback }\end{array}$ & IRFRF & $\begin{array}{l}\text { One of the main types of } \\
\text { classroom talk. This pattern } \\
\text { differs the IRF in the potential }\end{array}$ & $\begin{array}{l}\text { Mortimer } \\
\& \text { Scott, } \\
2003\end{array}$ \\
\hline
\end{tabular}


-Student Response

-Teacher Feedback (I), Student

struggle

(S),

Teacher response (R), and Student feedback (F) opportunities for teacher-student interaction because the pattern is IRFRF; and the feedback from the teacher is followed by further responses from students and so on.

ISRF The initiation by the teacher is following by the second turn that Marzban, Yaqubi, \& the student has only short time Qalandari, to struggle. In the third turn, it 2010 contains a complete answer to teacher's initiation at the beginning. The feedback turn is done by the student to confirm the answer.

4. Teacher question ISPRF The idea of Teacher Prompt is suggested from Walsh and Teacher (I), Student struggle (S), Teacher Prompt (P), $\quad$ Student Response

Teacher Feedback

5. Teacher Initiation Student Discussion -Student Response -Teacher Feedback Sattes (2016) when they outline five stages of questioning. In particular they state that teacher can prompt a response by giving a waiting time and assisting the non-respondent.

IDRF

Another sequence is teacher

Shen Initiation - student Discussion $\&$ student Response - teacher Yodkh Feedback, which can enable umlue, forums for peer discussion, and 2012 might be in pair or in group of students, duplicating the interactions among students 
before the interaction between

students and the teacher. These

sequences are considered

productive because they give

students chances to speak more

and thoroughly about the topic

with either teachers or peers.

Through these, the teacher can

create more time and turns for

students to develop and

challenge their opinions.

Consequently, the more students

can work with the target

language, the more they can

acquire.

The variety of moves in the extended IRF above reveals that: question-initiated interactions are unexpected and dynamic in a real classroom. This raises the issue of whether the three basic turns in IRF interaction is the frequent routine in practice. In a single turn, especially Feedback, the teachers employed different techniques to encourage students to engage more. The table provides examples of extended IRF patterns, and suggests further turns. It also identifies the dynamic of questioning patterns, including the notion of embedded structure or multiple cycles of questioning. It also reveals that the questioning interaction is productive if students can engage more and answer in depth.

There is a distinction between questioning patterns in content teaching and questioning in language teaching. For example, in content teaching, questioning patterns were used to develop critical thinking (Sharpe, 2008); while questioning patterns in language learning often forcused on extended interaction for promoting language learning. The engagement of a language student in asking and answering questions creates opportunities to practice the target language (Shen \& Yodkhumlue, 2012). However, as mentioned before, there is a connection between cognitive 
development and language learning, especially communicative competence. The connection between cognitive development and language learning is an important dimension for the investigation.

To summarise, this section viewed the construct of questioning, and identified variations on the common three-part questioning sequence of initiation, response and follow-up turns. Additional turns were identified in literature consisting of: student's struggle (S), teacher's prompts (P) and discussion among students (D). Teachers and students in the classroom modify these turns to create a variety of questioning patterns.

\section{Summary and research question}

This chapter has five sections. To begin with, it reviews the theoretical frameworks of the study, sociocultural theory and the teaching and learning map (T-L map) by Hall and Kidman (2004). The first section discusses the main premises of sociocultural theory and the key concepts embedded in the theory, which are particularly relevant to this study. This section also described how SCT framework was used in studies in L2 contexts, especially in question-answer interaction contexts.

The second section presents the T-L map proposed by Hall and Kidman (2004) as a framework for my study. This framework focuses on how contextual factors, including the classroom context, institutional context and international and national context influence teaching and learning activities.

This is followed by the outlines of second language acquisition (SLA) and communicative language teaching (CLT) as contextual frameworks. The third section focuses on second language acquisition, including interaction, input and output hypotheses. These theories formed the basis of analysis of question-answer interaction in EFL classrooms in research. This section also reviewed studies about questioning from the perspectives of SLA.

The fourth section illustrates the specific context of my study, CLT. Firstly, it presented a number of cultural factors and pedagogical issues in English education in Asia and Vietnam. The second important element that was considered was the 
position of CLT in higher education in Vietnam. Key information about the approach and how it had been applied in Vietnamese English education was provided.

The final section specified about questioning, including the analysis of previous studies that had addressed questioning. Some ideas discussed were the components of questioning and questioning sequences. The components of questioning consisted of teachers' questions, students' answers, teachers' feedback, students' hesitance within the questioning and teacher re-elicitation, which should be separated from what teachers can do in the feedback turn. Research on questioning in discourse sequences was reviewed to outline questioning within the IRF sequence and variations of IRF, with discourse analysis as a tool to analyse the interaction.

The literature establishes the relevance of looking at second language acquisition, sociocultural perspectives, Hall and Kidman's theory about contextual factors, the particular research context to understand questioning. Therefore, my study asks, "How do Vietnamese tertiary educators use questioning to promote language teaching and learning in EFL classes?"

The following sub-questions will help answer this question:

1. How is questioning understood in Vietnamese tertiary EFL classes?

2. How do Vietnamese EFL teachers and students perceive the role of questioning?

3. How do Vietnamese EFL teachers and students perceive the influences on questioning?

4. How do Vietnamese EFL teachers and students apply questioning in the classroom?

5. How does questioning compare between classes where English is taught as a major subject at university and classes where English is taught as a non-major?

In summary, this chapter reviews literature surrounding the topic of questioning in EFL classrooms. Reviewing this literature helps situate the current study, which uses SCT and SLA to frame instances of how teachers and students use questioning in tertiary EFL classes in Vietnam. 


\section{CHAPTER 3: METHODOLOGY}

\section{Introduction}

This chapter presents the research approach and the rationale for the methodological choices made. It starts by presenting the research design and justifying the choice of case study. After that, it describes the research site, participants, data collection, data analysis, and the use of Vietnamese and English in data collection and analysis. It explains how the methods will address the research questions. The last part of the chapter gives details of my role as the researcher, as well as trustworthiness and ethical considerations.

\section{Research paradigm}

Research designs need to be based on a philosophical worldview, and include an inquiry strategy, and specific methods to conduct research (Cohen, Manion, \& Morrison, 2013; Creswell, 2014). Developing a research framework involves three main interconnected components of ontology, epistemology and methodology (Denzin \& Lincoln, 2008).

Ontology accounts for the nature of existence, which is often divided into two major approaches: positivism and interpretivism (or constructivism) (Lincoln, Lynham, \& Guba, 2011). On the one hand, positivists believe that reality is objective, universal, and singular; on the other hand, interpretivists assume that reality is subjective, context-dependent, and allows multiple perspectives (Creswell, 2014; Hays \& Singh, 2012; Lincoln et al., 2011; Rubin \& Rubin, 2012).

Epistemology refers to the researcher's general orientation about the world and the nature of research (Creswell, 2014). It determines how a researcher conducts research to obtain knowledge (Burton \& Bartlett, 2009). The researcher selects either a positivist or interpretivist/constructivist paradigm. These correspond to the two main types of research, quantitative and qualitative research respectively (Burton \& Bartlett, 2009; Denscombe, 2002). The former type is often described as objective because researchers aim to prevent or minimise human bias, while the latter does not aspire to objectivity and involves active construction and co-creation of understanding 
between the researcher and participants (Lincoln et al., 2011; Spencer, Pryce, \& Walsh, 2014).

Methodology refers to the practical methods that a researcher selects that are consistent with their beliefs about truth and knowledge (Lichtman, 2012; Schensul, 2012). According to Creswell (2013), methodology involves an alignment of specific selections of interpretive paradigms, research questions, and data collection methods.

Each of the above components contributed to the framework for this study.

This study explored English as a foreign language (EFL) tertiary educators' and students' perceptions of teacher questioning, and their beliefs about how questioning contributes to a communicative approach to teach language. Sociocultural theory, as the framework of my study, allowed me to highlight the Vietnamese context of my investigation. Given this social constructivist worldview, this study valued the participants' subjective interpretations of their experiences, which were formed through interactions with others. The views of the participant EFL teachers and students, as well as observations of the interactions between them, were the main sources of data for my study.

A qualitative study was the best inquiry strategy for my study, because it allowed me to investigate the participants' thoughts, beliefs, knowledge, reasoning and feelings about questioning (Johnson \& Christensen, 2014). Thus, it fitted with my aim to understand educators' perceptions about the role of questioning.

In qualitative research, inquirers focus on depth rather than breadth in the belief that there are multiple versions of reality (Rubin \& Rubin, 2012). This study drew on multiple sources of information to investigate the picture of questioning in EFL classrooms from the perspective of multiple participants. This study gained data from observations of classroom practice, from interviews with teachers, and from focus group interviews with students. These techniques are commonly used in qualitative research (Minichiello, Aroni, \& Hays, 2008).

Detailed information on how to collect and analyse data through these methods is discussed in the following sections. 
The research design can be summarised as shown in the table below:

Table 5

Research Design of the Study

\begin{tabular}{cll}
\hline Philosophical worldview & Inquiry strategy & \multicolumn{1}{c}{ Specific methods } \\
\hline Social constructivism & Qualitative methods & Classroom observation \\
& & $\begin{array}{l}\text { Teachers' interviews using } \\
\text { stimulated recall }\end{array}$ \\
& Student focus groups \\
\hline
\end{tabular}

\section{Case study}

The research design used case study. Case study is a method that enables exploration of a phenomenon through extensive data collection (Creswell, 2015). In particular, case study is most widely used in research in education because it affords researchers opportunities to collect detailed, in-depth data by the use of multiple methods and multiple data sources within a particular context (Johnson \& Christensen, 2014).

Yin (2013) proposes two reasons for using case study. These informed my proposed data-gathering methods, and aligned with my research questions. Firstly, the inquirer seeks answers to exploratory or descriptive questions. In my study, most research questions begin "How", which is typical of exploratory questions. Secondly, the inquiry is context dependent. In my study, the phenomenon of questioning would not have meaning outside the context, which was tertiary-level EFL classes in Vietnam. It was in these settings that teachers conducted their questioning within a communicative teaching approach.

In this study, the unit of analysis or "what the case is" (Baxter \& Jack, 2008, p. 545) is the phenomenon of questioning. Bounding a case is necessary to avoid too broad or too many objectives (Stake, 1995; Yin, 2013) and to stay within a reasonable scope (Baxter \& Jack, 2008). This study was bounded by the phenomenon of questioning that was initiated by the teacher or student to promote classroom communication. Non-communicative questioning routines typically involve three moves or turns: initiated questions-responses-follow up feedback, and I wanted to see whether 
Vietnamese educators extended these routines as recommended in a communicative teaching approach. In other words, the study focuses on how teacher and student used questioning to promote learners' communicative competence.

The study followed an embedded multiple-case study design (Yin, 2013), as illustrated below:

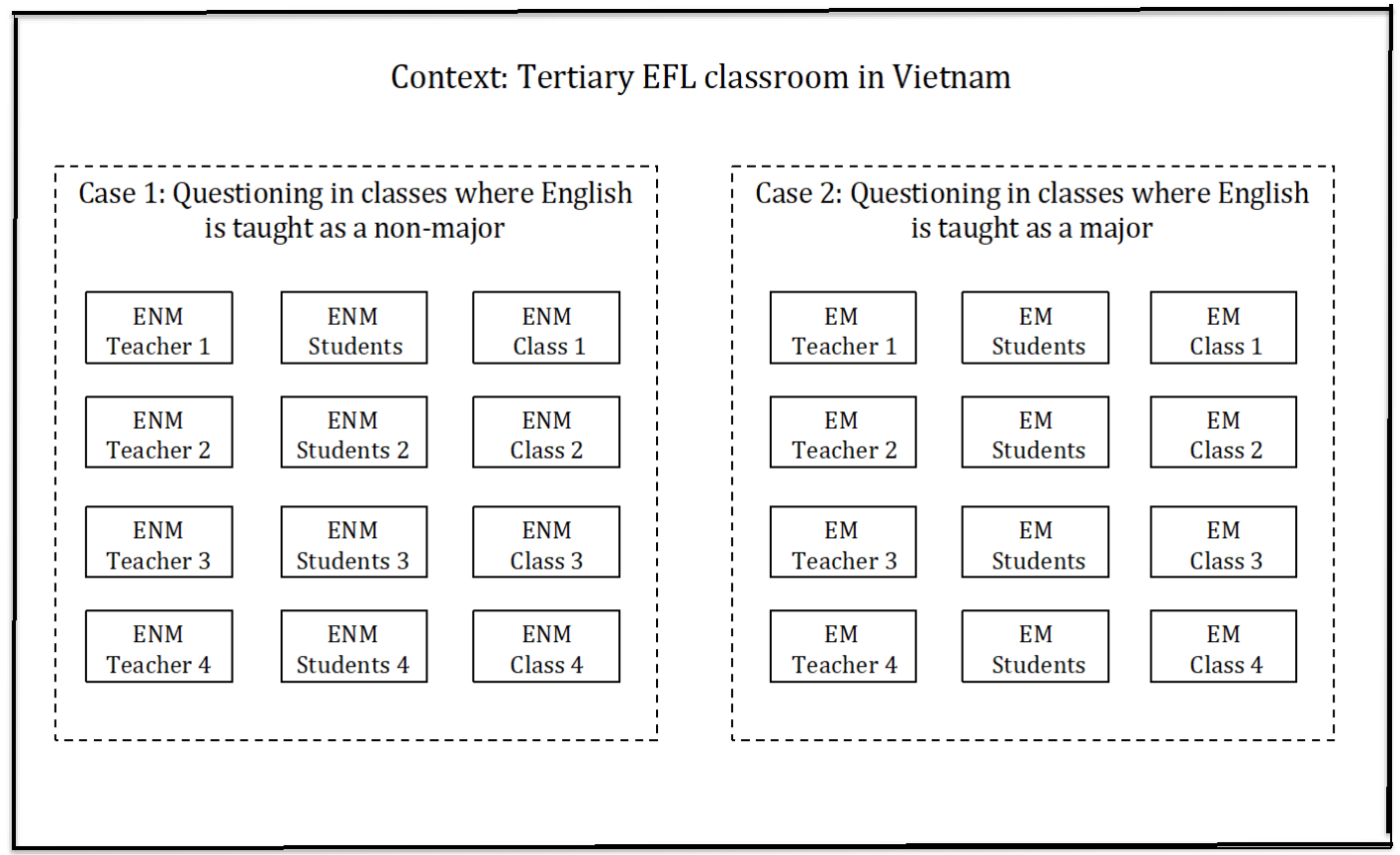

Figure 2. Embedded-multiple case design of the study, adapted from Yin $(2013$, p.50)

Two cases of questioning were investigated. Case one was the questioning in classes where English was taught as a non-major subject, and case two was in classes where English was taught as a major. In each case, there were 12 embedded units, including four teachers, four students and four classes. This enabled insight into and comparison between different sources of data collected (Yin, 2011). It allowed me to examine whether questioning was conducted differently in classes where English was taught as a major and those where English was taught as a non-major.

The embedded multiple-case design of my study can be justified in two ways (Yin, 2013). Firstly, "Analytic conclusions independently arising from two cases, as with two experiments, will be more powerful than those coming from a single case (or a single experiment) alone" (p. 64). Therefore two cases of teacher questioning promotes credibility. Secondly, the selection of two groups of teachers in two contexts, teaching English as a major and as a non-major offers "contrasting 
situations" (Yin, 2013, p. 64), which means findings could be strengthened by comparing cases. The diversity across contexts of the cases enabled me to draw conclusions about how questions were used when teaching English as a major compared to teaching English as a non-major. Furthermore, 12 embedded units in each case strengthened the interpretation of data, because the different levels of analytic units illuminated the case through analysis "within the subunits separately (within case analysis), between the different subunits (between case analysis) or across all of the subunits (cross-case analysis)" (Baxter \& Jack, 2008, p. 550).

\section{Research site}

This study was conducted in eight EFL classes at The University (a pseudonym) - a public university in the capital city of Vietnam. The University provided undergraduate and postgraduate programmes in business-related degrees, preparing graduates to gain employment in international businesses. The University prioritised the teaching and learning of English to equip the labour workforce with adequate language skills to participate in the global economy. English had been introduced and used as instructional medium in most classes.

The University is recognised as a prestigious higher education institution because it has produced English-speaking graduates since the mid-1980s, when the country started its renovation policy to boost its international trade with the world.

My study recruited participants from two English faculties in The University; one taught English as a major subject within a degree (English major faculty) and the other taught English as a non-major subject (English non-major faculty). The English major students had to sit and pass the university entrance exam, consisting of English/French, Mathematics and Literature tests, while English non-major students took Mathematics, Physics, and Chemistry tests for the exam. The English competence for English major students was higher than for English non-major students. In the English major faculty, English subjects were major components of their study and included English language skills and the theories of English. English major students after graduation usually gained jobs as teachers, translators and/or interpreters or researchers either in English linguistics or in English-language teaching methodology. Students in the English non-major faculty were required to 
learn English as a compulsory subject as a minor component of their studies, and English non-major students had to pass a number of English tests to obtain their degree in their specialist discipline. English was used as the medium of instruction in both faculties. The investigation was carried out in EFL classes in both faculties to explore how questioning was used in classes where English was taught for different purposes.

I selected this university because I had worked here as an English teacher, which enabled me to approach potential participants. However, selecting this institution was more than a convenience. Like other major state tertiary institutions in Vietnam, The University operated two types of EFL classes: English was taught as a non-major for students and English was taught as a major. The University was thus typical of the public tertiary level in Vietnam in that it teaches English as a foreign language for different purposes. This may allow other researchers and teachers of EFL classes in other Vietnamese tertiary institutions to identify comparable contextual features.

Particular ethical considerations arose because I had been an English teacher in The University. These are addressed in detail in a later section of this chapter.

\section{Participants}

I recruited eight teachers; four teachers from each faculty, and students from their eight classes. Teachers, student groups, and class observations were three units of investigation. I used three methods to recruit participants: purposive sampling, snowball sampling, and convenience sampling (see figure 9).

Below is the summary of strategies related to select participants for this study:

\section{Table 6}

Summary of sampling strategies

\begin{tabular}{cccc}
\hline Participants & Teachers & Classes & Students \\
\hline $\begin{array}{c}\text { Number of } \\
\text { participants }\end{array}$ & 8 & 8 & 8 groups (four to six \\
students in each) \\
Selection & Purposive sampling & Snowball sampling & Convenience sampling \\
\hline
\end{tabular}




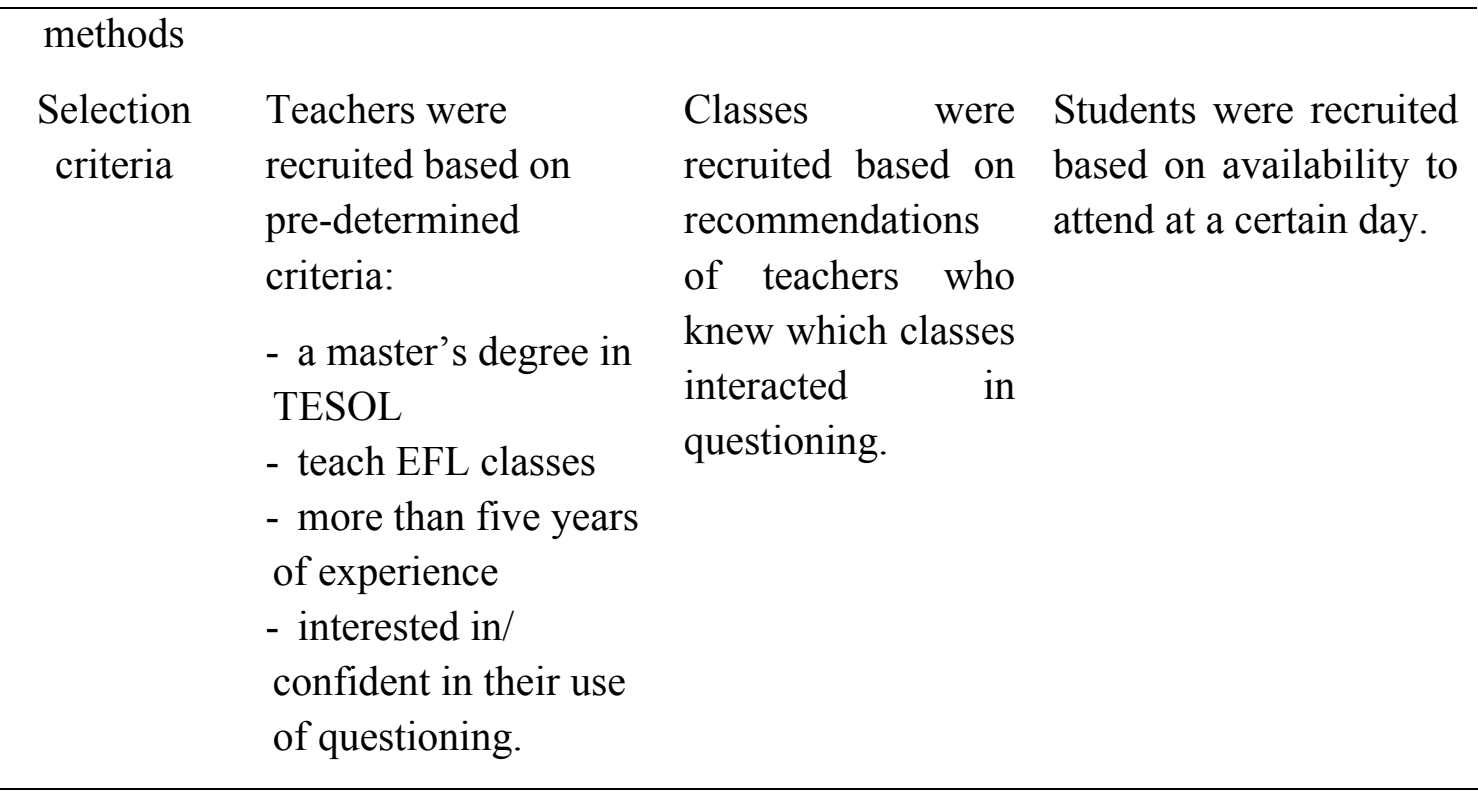

I used a different approach and different selection criteria to select each group of participants. Selection criteria were set to choose the participants who would be available and could contribute rich information for the study. The details of how each group of participants was selected in this thesis, are explained in the following subsections.

\section{Teachers}

I sent invitation emails to approximately 60 teachers in the two chosen faculties. The emails included information sheets and consent forms (Appendix C), to enable the teachers to understand the investigation objectives, their roles if they agreed to participate in the investigation, and my commitment to protect their identities in keeping with the standard Victoria University of Wellington ethical procedures.

In line with a qualitative methodology, the study employed purposive sampling (Johnson \& Christensen, 2014) to select the first four EFL teachers from two faculties who were interested in using questioning and the communicative approach. To do that, the invitation emails included questions that narrowed the selection (based on the criteria in Table 5 above) to those EFL teachers who had a master's degree in TESOL (Teaching English to Speakers of Other Languages) and more than five years of teaching experience. Also, the emails asked teachers to allow me to observe one of their class sessions, and invited them to participate in an interview after the classroom observation. 
Table 7

Profile of Teacher Participants

\begin{tabular}{|c|c|c|c|c|}
\hline No. & Participants & Faculty & Degree & $\begin{array}{l}\text { Teaching } \\
\text { experience }\end{array}$ \\
\hline 1. & EM Teacher 1 & \multirow{4}{*}{$\begin{array}{l}\text { English major } \\
\text { faculty }\end{array}$} & Master in UK & 5 years \\
\hline 2. & EM Teacher 2 & & Master in VN & 6 years \\
\hline 3. & EM Teacher 3 & & Master in VN & 6 years \\
\hline 4. & EM Teacher 4 & & Master in UK & 7 years \\
\hline 5. & ENM Teacher 1 & \multirow{4}{*}{$\begin{array}{l}\text { English non-major } \\
\text { faculty }\end{array}$} & Master in NZ & 8 years \\
\hline 6. & ENM Teacher 2 & & Master in VN & 10 years \\
\hline 7. & ENM Teacher 3 & & Master in VN & 9 years \\
\hline 8. & ENM Teacher 4 & & Master in US & 8 years \\
\hline
\end{tabular}

Classes

I observed one EFL class session taught by each teacher. Eight classes were selected, based on the recommendation of teachers who knew which classes were rich in interaction between teacher and students (snowball sampling) (Patton, 2015). These would offer rich data capturing questioning interaction for the study.

Table 8

Profile of Class Participants

\begin{tabular}{|c|c|c|c|c|c|c|}
\hline No. & Classes & Faculty & Level & $\begin{array}{c}\text { Number } \\
\text { of } \\
\text { students }\end{array}$ & Subject & Course book \\
\hline 1. & EM Class 1 & $\begin{array}{c}\text { English } \\
\text { maior }\end{array}$ & Year 1 & 37 & Pronunciation & Pronunciation \\
\hline 2. & EM Class 2 & faculty & $\begin{array}{l}\text { Year 2, } \\
1^{\text {st }} \text { term }\end{array}$ & 52 & Semantics & $\begin{array}{c}\text { Semantics } \\
\text { (unit 16-20) }\end{array}$ \\
\hline 3. & EM Class 3 & & $\begin{array}{l}\text { Year } 1, \\
1^{\text {st }} \text { term }\end{array}$ & 35 & $\begin{array}{l}\text { Listening and } \\
\text { speaking }\end{array}$ & $\begin{array}{l}\text { All clear, Unit } \\
2\end{array}$ \\
\hline 4. & EM Class 4 & & Year 3, & 46 & Speaking & Cambridge \\
\hline
\end{tabular}




\begin{tabular}{|c|c|c|c|c|c|c|}
\hline & & & $1^{\text {st }}$ term & & (interviewing) & $\begin{array}{l}\text { English for } \\
\text { job-hunting }\end{array}$ \\
\hline 5. & $\begin{array}{c}\text { ENM Class } \\
1\end{array}$ & $\begin{array}{l}\text { English } \\
\text { non- } \\
\text { major } \\
\text { faculty }\end{array}$ & $\begin{array}{c}\text { Year 2, } \\
1^{\text {st }} \\
\text { term- } \\
\text { high } \\
\text { quality } \\
\text { class }\end{array}$ & 28 & $\begin{array}{l}\text { English for } \\
\text { business- } \\
\text { integrating } \\
\text { skills }\end{array}$ & $\begin{array}{l}\text { Business } 2.0 \\
\text { upper (unit } 3 \text {, } \\
\text { p. } 36 \text { ) }\end{array}$ \\
\hline 6. & $\begin{array}{c}\text { ENM Class } \\
2\end{array}$ & & $\begin{array}{l}\text { Year } 1, \\
1^{\text {st }} \text { term }\end{array}$ & 31 & $\begin{array}{l}\text { English for } \\
\text { Business- } \\
\text { integrating } \\
\text { skills }\end{array}$ & $\begin{array}{c}\text { Market leader, } \\
\text { elementary, } \\
\text { Unit } 1\end{array}$ \\
\hline 7. & $\begin{array}{c}\text { ENM Class } \\
3\end{array}$ & & $\begin{array}{c}\text { Year 2, } \\
1^{\text {st }} \\
\text { term- } \\
\text { high } \\
\text { quality } \\
\text { class }\end{array}$ & 33 & $\begin{array}{l}\text { English for } \\
\text { Business- } \\
\text { integrating } \\
\text { skills }\end{array}$ & $\begin{array}{c}\text { Business } 2.0 \\
\text { upper (unit } 4 \text {, } \\
\text { p. } 54, \\
\text { coaching) }\end{array}$ \\
\hline 8. & $\begin{array}{c}\text { ENM Class } \\
4\end{array}$ & & $\begin{array}{c}\text { Year 2, } \\
\text { normal } \\
\text { class }\end{array}$ & 15 & $\begin{array}{l}\text { English for } \\
\text { Business, } \\
\text { integrating } \\
\text { skills }\end{array}$ & $\begin{array}{c}\text { Market Leader, } \\
\text { Pre- } \\
\text { intermediate }\end{array}$ \\
\hline
\end{tabular}

\section{Students}

To select students for the focus group, I firstly sent emails to all the members of classes nominated by participating teachers, to ask permission to observe their activities in one class session, and inviting them to participate in a group focus discussion after the observation. The selection of four to six students was based on their availability (convenience sampling) (Patton, 2015). This selection, based on the researcher's convenience, might cause bias in choosing the participants (Mackey \& Gass, 2016). To avoid the bias, I selected the first six students who wished to participate. 
Table 9

Profile of Focus Groups

\begin{tabular}{|c|c|c|c|c|}
\hline No. & $\begin{array}{l}\text { Student } \\
\text { Groups }\end{array}$ & Faculty & Level & $\begin{array}{c}\text { Number of } \\
\text { students }\end{array}$ \\
\hline 1. & EM Group 1 & \multirow{4}{*}{$\begin{array}{l}\text { English-major } \\
\text { faculty }\end{array}$} & Year 1 & 6 \\
\hline 2. & EM Group 2 & & Year $2,1^{\text {st }}$ term & 6 \\
\hline 3. & EM Group 3 & & Year $1,1^{\text {st }}$ term & 5 \\
\hline 4. & EM Group 4 & & Year $3,1^{\text {st }}$ term & 6 \\
\hline 5. & ENM Group 1 & \multirow{4}{*}{$\begin{array}{l}\text { English non-major } \\
\text { faculty }\end{array}$} & $\begin{array}{l}\text { Year } 2,1^{\text {st }} \text { term- } \\
\text { high quality class }\end{array}$ & 4 \\
\hline 6. & ENM Group 2 & & Year $1,1^{\text {st }}$ term & 6 \\
\hline 7. & ENM Group 3 & & $\begin{array}{l}\text { Year } 2,1^{\text {st }} \text { term- } \\
\text { high quality class }\end{array}$ & 6 \\
\hline 8. & ENM Group 4 & & $\begin{array}{l}\text { Year 2, normal } \\
\quad \text { class }\end{array}$ & 6 \\
\hline
\end{tabular}

\section{Recruitment}

Before carrying out data collection, I obtained permission from the President of The University, and the Deans of the EM faculty and ENM faculty. Information sheets and consent forms (Appendices A and B) asking for permission to conduct the research and collect data at The University were emailed to the President and the Deans. After receiving their consent, I started to contact teachers in these two faculties using one of three contact methods: email, phone, or in person. Through this communication process, the information sheets and consent forms were sent to all potential participants. After the first eight teachers consented to participate, I sent emails to each of classes suggested by the teachers. The emails asked students in the classes to allow me to observe a class session and invited them to focus group discussions. When the arrangements were completed, data were collected. 
Table 10

Stages of Participant Recruitment

\begin{tabular}{|c|c|c|c|c|c|}
\hline Stages & $\begin{array}{l}\text { Researcher's } \\
\text { role }\end{array}$ & Timing & Participants & Aims & $\begin{array}{l}\text { Techniqu- } \\
\text { es }\end{array}$ \\
\hline $\begin{array}{l}\text { Recruitment/ } \\
\text { gaining } \\
\text { permission } \\
\text { from } \\
\text { authorities } \\
\text { and sending } \\
\text { invitation } \\
\text { emails }\end{array}$ & Recruiter & $\begin{array}{l}\text { Three } \\
\text { weeks }\end{array}$ & $\begin{array}{l}\text { - The head of } \\
\text { the Universities } \\
\text { and the deans of } \\
\text { two faculties } \\
\text { - } 60 \text { teachers }\end{array}$ & $\begin{array}{l}\text { - Ask for permission } \\
\text { to carry out the } \\
\text { research in the } \\
\text { setting } \\
\text {-Ask teachers' } \\
\text { permission to } \\
\text { observe and record } \\
\text { one lecture, and } \\
\text { invite them to } \\
\text { interviews } \\
\text { - Ask students' } \\
\text { permission to } \\
\text { observe, and invite } \\
\text { them to focus group } \\
\text { discussions }\end{array}$ & $\begin{array}{l}\text { Email, } \\
\text { phone or in } \\
\text { person }\end{array}$ \\
\hline
\end{tabular}

\section{Data collection}

Data were collected and triangulated using three collection methods: classroom observations, teacher interviews and focus group discussions. Using multiple sources of data enhanced the trustworthiness of the study and allowed me to identify and describe the issues in comprehensive and in-depth ways (Creswell, 2013).

The collection procedure involved three distinct stages. The table below summarises information about the participants, specific strategies, aims and techniques at each stage. 
Table 11

Stages of Data Collection

\begin{tabular}{|c|c|c|c|c|c|}
\hline Stages & $\begin{array}{c}\text { Researcher } \\
\text { s role }\end{array}$ & Timing & Participants & Aims & Techniques \\
\hline $\begin{array}{c}1 . \\
\text { Classroom } \\
\text { observation }\end{array}$ & $\begin{array}{l}\text { Non- } \\
\text { participant } \\
\text { observer }\end{array}$ & $\begin{array}{c}45 \\
\text { minutes } \\
\text { each } \\
\text { class }\end{array}$ & $\begin{array}{l}\text { Eight EFL } \\
\text { classes (each } \\
\text { class is taught } \\
\text { by one of the } \\
\text { participating } \\
\text { teachers) }\end{array}$ & $\begin{array}{c}\text { Obtain data in } \\
\text { practice }\end{array}$ & $\begin{array}{l}\text {-Video } \\
\text { recording } \\
\text { - Field notes }\end{array}$ \\
\hline $\begin{array}{c}\mathbf{2 .} \\
\text { Interviews } \\
\text { (Semi- } \\
\text { structured } \\
\text { interview } \\
\text { and video- } \\
\text { stimulated } \\
\text { recall) }\end{array}$ & Interviewer & $\begin{array}{c}\text { From } \\
45 \\
\text { minutes } \\
\text { to one } \\
\text { hour }\end{array}$ & $\begin{array}{l}\text { Eight } \\
\text { teachers }\end{array}$ & $\begin{array}{l}\text { - Obtain data for } \\
\text { teachers' belief } \\
\text { and perspectives. } \\
\text { - Cross-check } \\
\text { observation's } \\
\text { transcription }\end{array}$ & $\begin{array}{l}\text { Audio } \\
\text { recordings }\end{array}$ \\
\hline $\begin{array}{l}\text { 3. Students' } \\
\text { focus group } \\
\text { (Semi- } \\
\text { structured) }\end{array}$ & Moderator & $\begin{array}{c}\text { About } \\
\text { one and } \\
\text { half } \\
\text { hours }\end{array}$ & $\begin{array}{l}\text { Eight groups } \\
\text { of four to six } \\
\text { students }\end{array}$ & $\begin{array}{c}\text { Collect data from } \\
\text { students' } \\
\text { perspectives }\end{array}$ & $\begin{array}{l}\text { Audio } \\
\text { recordings }\end{array}$ \\
\hline
\end{tabular}

\section{Stage 1: Classroom observation}

Classroom observation was one data collection method used in this study. Observation is a data-gathering technique where the researcher can watch, listen and record to gain a first-hand experience of the participants' behaviours that naturally occur within the research setting (Creswell, 2013; Nunan \& Bailey, 2009). Data gained from observation is "live" and "taking place in situ rather than relying on second-hand accounts" so the data are valid or authentic (Cohen et al., 2013, p. 456).

Through the eight observations, I could gather data about teachers' and learners' activities in the classroom to examine how EFL teachers used questioning to promote a communicative approach in practice. 
Observations were used in this study for two reasons. Firstly, this enabled me to collect data about the practice of participants, which might differ from what the participants said they did (Robson, 2002). Observations provided holistic information on the interactive environment around the participants (Cohen et al., 2013). My observations revealed how teachers asked questions and students answered, and how the rest of the class responded. Furthermore, the method was useful to compare with or to supplement other sources of data (Sapsford \& Jupp, 2006). This aligned with my intention to gather different perspectives by using complementary techniques such as field notes and video recordings. The reasons for incorporating these additional techniques are presented below.

Firstly, field notes taken during or immediately after the observation allowed me to record my immediate impressions and maintain reflexivity (Johnson \& Christensen, 2014). Second, video recording provided opportunities to review the practice a number of times and complement my field notes with further details about non-verbal behaviours. In addition, the video episodes relating to questioning were used for stimulated recall during the interviews at a later stage (Mackey \& Gass, 2016).

On the other hand, one risk of the method was that observational data might not accurately represent their natural behaviour, because participants knew they were being observed and they might change the way they behaved (Sapsford \& Jupp, 2006). To mitigate against this limitation, I built positive rapport with participants before the observations with a brief introduction about myself at the beginning of the session, and let them understand that their identity was kept confidential and the observational data were used only for my research but not for evaluating their performance. During the observations I tried to be unobtrusive and silently observed from the back.

\section{Stage 2: Semi-structured and stimulated interviews with teachers}

The goal of this method was to understand about the teachers' perceptions of their questioning. Interviews are a very common technique in qualitative research to collect in-depth information about the participants' perceptions, (Johnson \& Christensen, 2014; Hesse-Biber \& Leavy, 2011). 
Depending on the researcher's need to balance "flexibility available to the researcher" against "lack of structure", interviews are categorised into three types: structured, semi-structured, and unstructured (Edwards \& Holland, 2013, p. 4). Structured interviews are more used in a quantitative approach because the questions are often closed-ended and answers are standardised to be used for measuring data, while semistructured and unstructured interviews are prominently adopted by qualitative researchers because they ask open-ended questions and may elicit answers expressing different views and in-depth information (Minichiello et al., 2008). Furthermore, semi-structured interviews allow researchers to focus on particular research issues more than can be obtained from an unstructured interview (Rubin \& Rubin, 2012). For this reason, I chose a semi-structured technique for the interviews, so that the eight teacher participants could develop and elaborate their ideas.

In the first part of the interviews, the eight teachers were asked about their viewpoints on questioning, and any challenges as well as facilitators affecting their questioning. This was possible because the researcher was face to face with the interviewees, able to ask questions, explore participants' responses, offer probes or prompts, and ask follow-up questions to get greater clarity or depth. The later part of the interviews used the stimulated recall method.

Selected parts of the video recordings of classroom observation were shown to the teachers as stimulus to recall the purposes for their questioning in particular situations. This method is a valuable mechanism for studying cognitive processes and is commonly used in educational research (Lyle, 2003).

Stimulated recall (Gass \& Mackey, 2000) prompted interviewees to recall the decisions they made in class so they could clarify and explain particular situations in depth. According to Mackey and Gass (2016), the choice of video stimulation is advantageous because it can effectively activate memory by audio and video. Around 48 hours after the events took place is viewed as an optimum period to ensure $95 \%$ accuracy of participants' recollections (Henderson \& Tallman, 2006). Therefore, the video-stimulated interviews were held within two days of the classroom observations so that the decisions were fresh in the teachers' minds. This was the key to reliable data. 
I selected stimulus episodes to focus on what appeared to be the most meaningful interactions (Mackey \& Gass, 2016; Reitano, 2005). In preparing to carry out the stimulated recall interview, I watched the video recordings right after the observations and decided which segments of video would be used. The criteria for choosing the video segments were whether the questioning created an extended interaction, resulted in no interaction, showed an interesting or unusual way of using questioning, and/or whether the teacher chose different types of questions. I cut these video extracts from the whole recordings and saved them in separate files used for the interviews. I chose about five segments for each interview, to provide the interviewees with chances to deeply review each questioning decision. During the stimulated discussion, I played the video segments to the participants so that they could focus on watching. Each segment was played twice or three times to assure that the participants could better recall the incident. Furthermore, beside actively selecting and controlling the stimulus episodes, I also asked the teachers if they needed to watch the segment again, or if there were other classroom questioning situations they would like to comment on.

Gass and Mackey (2000) raise two potential limitations of stimulated recall. If the recall is carried out a long time after the moment the actual event occurs, the shortterm memory may not directly relate to the event that just occurred. The second threat is possible changes of participants' perceptions because they may have experienced some interference during the period from when the event took place and when the stimulated recall takes place. In this research, the stimulated recall interviews occurred one or two days after the observations, and the video recordings that were shown to them during the interview seemed to prompt the interviewed teachers to recall the events easily.

The combination of semi-structured interviews with stimulated recall enabled me to modify the line of interviewing questions to examine participants' perspectives (Rowe, 2009). I could flexibly emphasise or add particular matters so that I collected useful data. Furthermore, the video stimulation also allowed participants to reflect more deeply on the first part in the interviews.

Each interview lasted about one hour. Interviews were audio-recorded so that I could focus on engaging with interviewees (Johnson \& Christensen, 2014). The interviews 
were conducted in Vietnamese to allow teachers to express their ideas comprehensively and freely. Later, the interview transcripts were transcribed and sent back to them so that they could check whether the transcription was accurate (Shenton, 2004).

\section{Stage 3: Student focus groups}

The purpose of the focus groups was to elicit answers about students' perspectives on questioning and what might encourage or discourage them to respond to teacher questions.

A focus group is a useful form of interview that enables researchers to collect qualitative data about feelings and perceptions through the interaction within groups of participants (Morgan, 1997). This research tool was chosen for two reasons. I hoped that being part of a group would generate a feeling of security so that the student participants would be open and honest in expressing their opinions (Langford \& McDonagh, 2003). In addition, by its nature, the discussion process was likely to sharpen and clarify participants' responses so their contributions were able to reach deeper and more considered levels (Schensul, 2012). The students in my research could potentially add more details or debate their peers' opinions.

The limitation was that running a focus group was demanding for me. There was a danger that the discussion process might prompt participants to share extreme attitudes (if members followed the previous opinions expressed by others) or be biased by a more dominant participant in the group (Stewart \& Shamdasani, 2014). Therefore, I had to assume the responsibilities of a moderator and attempt to create a comfortable atmosphere, offer interview prompts for the discussion, try to maintain a focus on the topic, encourage all members' interaction, and ensure that there was no harm or abuse within the group (Denscombe, 2014). To do that, I designed a detailed protocol for focus group discussion, which consisted of predetermined questions, various prompts and clear agenda (Appendix F). Further strategies were used to ensure that the focus groups were safe/open and effective. For example, the discussions took place in Vietnamese so that students felt more comfortable and confident to express opinions. Furthermore, each focus group was scheduled for about 
an hour to give participants enough time to take full part in discussion without the discussion becoming too time-consuming.

In this study, eight groups (one from each class) of six students from the same class were interviewed. In practice, one or two individuals dropped out of some of the groups. This still allowed the focus group (of four to five students) to remain viable. Each focus group lasted up to one-and-a-half hours to give participants enough time to take full part in discussion.

I used audio-recording and open-ended questions to gather data. Audio-recordings allowed me to concentrate on the discussion and later listen to the same recording repeatedly. Prompts and open-ended questions elicited detailed answers and explanations from the students.

\section{Data analysis}

Research data in the study were in the forms of:

- transcripts of stimulated interviews and semi-structured interviews with teachers

- transcripts of focus group discussions with students

- transcripts of audio-recordings of class observations

- class observation notes.

The analysis of teacher interviews and the analysis of the students' focus group discussions were the main sources of data to show teachers' and students' beliefs about questioning. Data from beliefs contributed to answering the research questions about definitions of questioning, roles of questioning and influences on questioning.

Transcripts of audio-recordings of class observations were analysed to answer research question about how questioning was exercised in practice. Also, my classobservation notes and data from the stimulated interviews with teachers complemented an analysis of the questioning sequences in observations. 


\section{Analysis procedure}

The process of data analysis is presented in two stages. The first stage was a detailed coding to find the themes within each case, followed by analysis across the two cases. The figure below summarises the data analysis procedure.

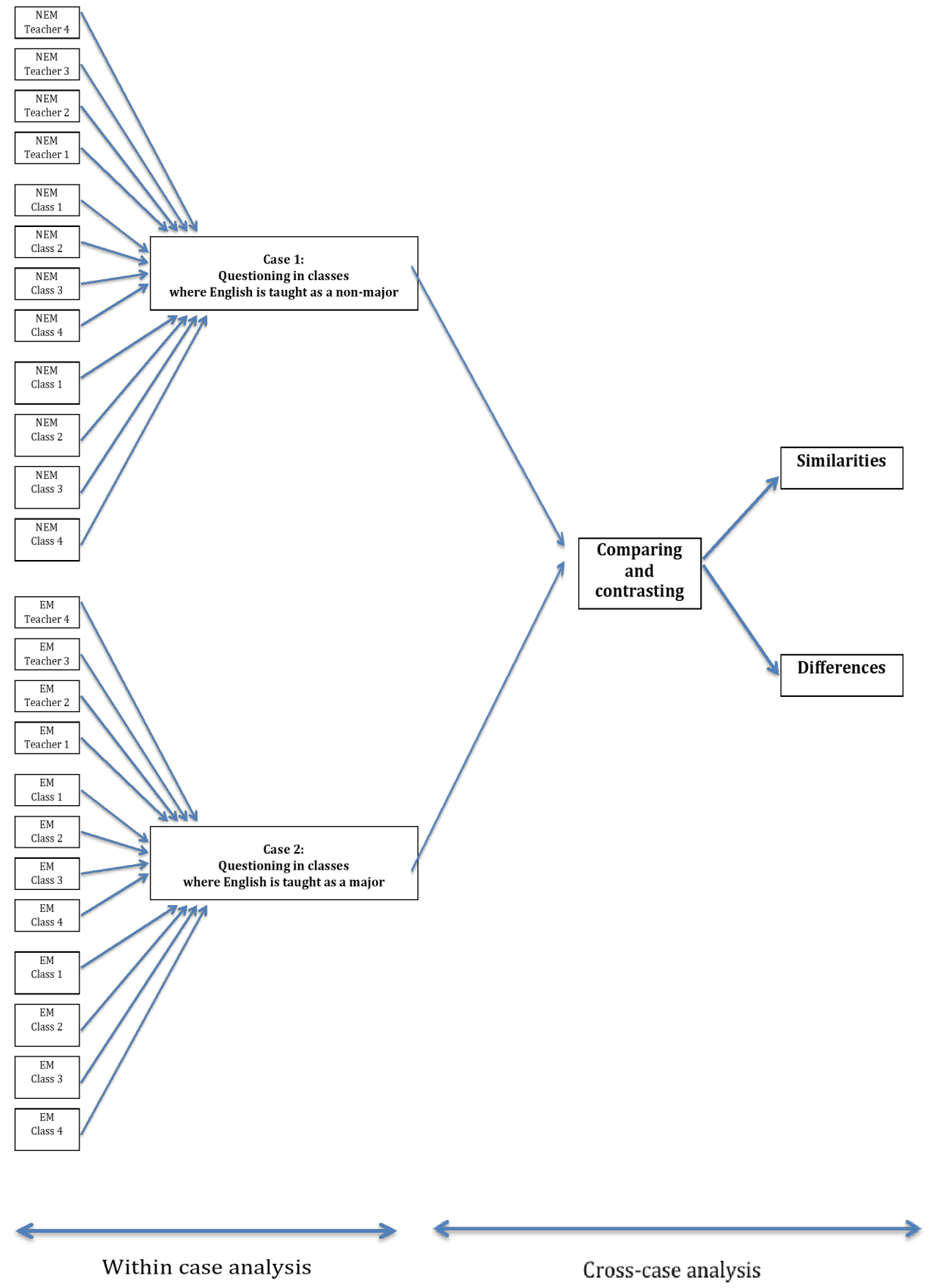

Figure 3. Analysis procedure 


\section{Within-case analysis}

The analysis of each case followed the same procedure, starting at the level of the embedded units, then coding across the 12 embedded units to draw cross-unit conclusions for the case. I began by analysing data in 12 units in the English nonmajor case, including four interviews of four teachers, four focus groups of students and four observations of classes. I applied the same steps to the 12 units in the English major setting. The results of these analyses were two separate sets of coding about questioning in an English non-major context and that in an English major context.

\section{Cross-case analysis}

Johnson and Christensen (2014) state that cross-case analysis is conducted to search for similarities and differences. My purpose in conducting a cross-case analysis was to find explanations for the similarities in or variation between teacher questioning practices in the two different settings.

\section{Analysis techniques}

Certain analysis techniques are particularly recommended for qualitative and case studies (Creswell, 2013; Stake, 2006; Yin, 2013). Most data were analysed using thematic analysis. In addition, discourse analysis, inductive and deductive analysis contributed to thematic analysis.

Thematic analysis is widely used in qualitative research (Grbich, 2012; Johnson \& Christensen, 2014), because it is viewed as an accessible and theoretically flexible approach (Boyd, 2015). Thematic analysis aims to find out the themes, which are words or sets of words "denoting an important idea that occurs multiple times in your data" (Johnson \& Christensen, 2014, p. 600).

According to Braun and Clarke (2006), thematic analysis involves a six-phase process where the researcher moves back and forth as needed throughout the phases. Because this study involved observational data, I added another phase using discourse analysis for observational data to understand the moves and functions of talk in questioning interactions. The flow chart below adapted from Braun and Clarke (2006) summarises the process of thematic analysis used in my study. 


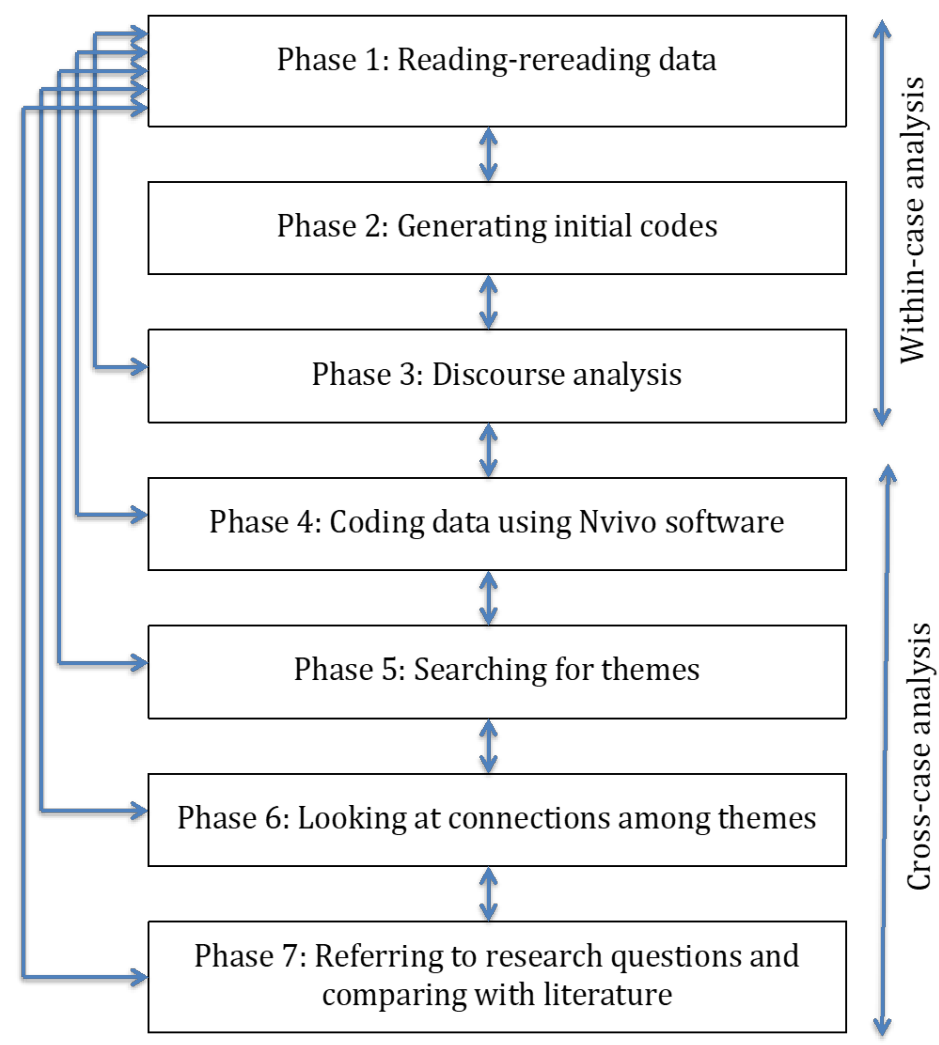

Figure 4. Thematic analysis of the study, adapted from Braun \& Clarke (2006)

Phases 1, 2 and 3 often happened concurrently in the within-case analysis phases, to establish the themes in each case.

I first read and re-read transcripts of classroom observations, teachers' interviews and student focus group interviews. This familiarised me with these data, and I then noted down my initial ideas. Secondly, I coded interesting aspects of data by writing notes on and highlighting potential items in the transcripts. This step helped to generate initial codes. Initial coding needed to be open-ended (avoiding preconceived concepts) and the best fitted for the data (Charmaz, 2014).

Thirdly, working with observation transcripts, data were analysed both inductively (themes were drawn from the data) and deductively (themes were drawn from existing theories) (Joffe \& Yardley, 2004). Discourse analysis was used to analyse the data deductively. In observation analysis, this study addressed some aspects of classroom discourse by using literature on variation of IRF sequences (sequences using three turns: initiation-response-feedback) (Marzban et al., 2010; Waring, 2009) 
and functions or purposes of discourse turns (Gibbons, 2007; Sharpe, 2008). This analysis provided codes to add to the later inductive analysis about questioning interaction. Below is an example of how I used discourse analysis in transcripts of observations (the underlined are questions).

\begin{tabular}{|c|c|c|c|c|}
\hline Line & Speaker & $\begin{array}{c}\text { Utterance and } \\
\text { non-verbal data }\end{array}$ & Turns & Function/ purposes \\
\hline 21 & \multirow{3}{*}{ T: } & Come on, boy. & \multirow{3}{*}{$\mathrm{I}$} & Nominating \\
\hline 22 & & $\begin{array}{l}\text { Tell me what you know about } \\
\text { this topic? }\end{array}$ & & Requesting information \\
\hline 23 & & What is coach or coaching? & & Reformulating \\
\hline 24 & S1: & $\begin{array}{l}\text { A person who guide or achieve } \\
\ldots \text { people... activities } \ldots . \\
\text { (inaudible) }\end{array}$ & $\mathrm{S}$ & $\begin{array}{l}\text { Giving information } \\
\text { (incomplete answer) }\end{array}$ \\
\hline 25 & \multirow[b]{2}{*}{ T: } & Ok. & \multirow[b]{2}{*}{$\mathrm{F}$} & Acknowledging, \\
\hline 26 & & $\begin{array}{l}\text { Have you talked a little bit } \\
\text { about sport? }\end{array}$ & & $\begin{array}{l}\text { Requesting confirming/ } \\
\text { clarifying }\end{array}$ \\
\hline 27 & S1: & Yes & $\mathrm{R}$ & Confirming \\
\hline 28 & \multirow[t]{2}{*}{ T: } & $\begin{array}{l}\text { Coach in this case is very much } \\
\text { like a trainer, in sport. }\end{array}$ & \multirow[t]{2}{*}{$\mathrm{F}$} & Evaluating \\
\hline 29 & & Thank you so much & & Acknowledging \\
\hline 30 & \multirow{2}{*}{$\mathbf{T}:$} & Thank you, Thanks anyway & \multirow{2}{*}{$\mathrm{F}$} & \multirow{2}{*}{ Acknowledging } \\
\hline 31 & & Sit down, please & & \\
\hline
\end{tabular}

Episode 3: An example of how discourse analysis was used in observations

I then used the codes from discourse analysis to complement the coding from stimulated recall interviews. This allowed a contrast between what I had observed in the classroom, with the perceptions/explanation shared by teachers in their interviews. Themes emerged inductively from what participants (teachers and students) said and did in the classroom and in stimulated recall interviews. Also, some themes aligned with the literature about interactional sequences and classroom discourse. For instance, both literature and teachers' beliefs agreed that there were different purposes in their feedback turns, such as correcting student's mistakes, summarising key information or asking for further information.

The next phase was categorising codes to keep the most significant or frequent codes. I used NVivo software as a tool to code, retrieve and present data in sequences (Cohen et al., 2013). NVivo helped me analyse among cases. Cross-case analysis occurred from this phase to figure out the themes across the whole data. 
After this coding, I continued to analyse data but at a wider level to identify themes, and classified different codes into potential themes (Denscombe, 2014). Next, in phase 6 , I reviewed the potential themes and checked if the themes worked in relation to the coded extracts and also in relation to the entire set of data, before working on a thematic map of the analysis (Braun \& Clarke, 2006). Lastly, I discussed how the data informed the research questions and compared to existing literature.

The figure below shows an example of the process of theming (from phase 5 to 7 ) in a cross-case analysis and how the themes were reported in this thesis. 


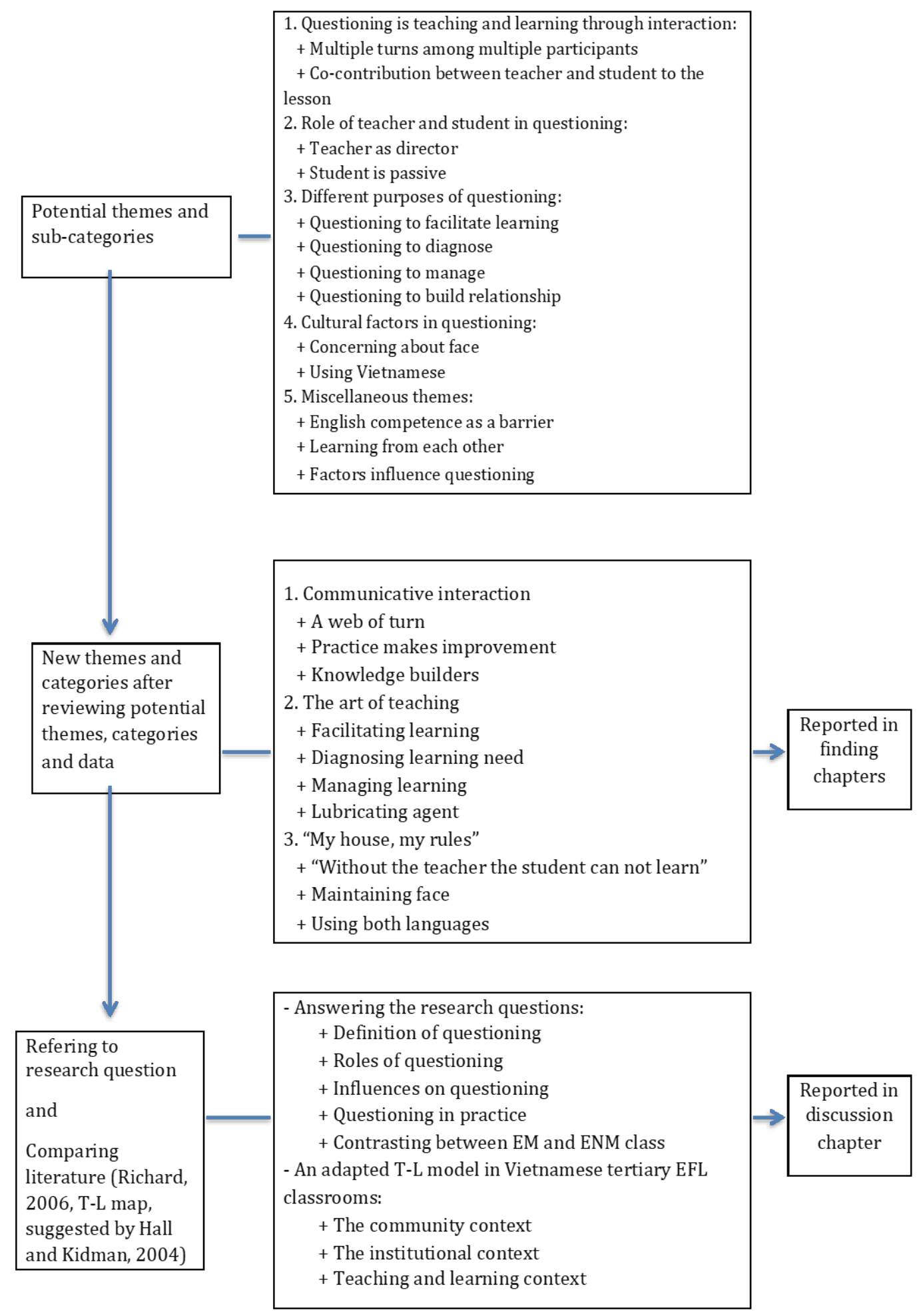

Figure 5. An example of theming and how themes were reported

After coding data in NVivo, I identified potential themes, for example, (1) Questioning is teaching and learning in interaction, (2) The role of teacher and students in questioning: teacher is active and student is passive, (3) Different purposes 
of questioning, (4) Cultural factors in questioning. There were some codes that failed to fit in any of the main themes, such as using Vietnamese in questioning. I then put them into a (5) Miscellaneous theme, because they might be helpful later (Braun \& Clarke, 2006). After that, I reviewed these themes and checked if the themes worked in relation to coded extracts and also in relation to all transcripts.

Continuing analysing data at wider and deeper level, I reread data (transcripts from teacher and student interviews as well as observations) and reviewed all themes and categories I had. I recalled that themes could be "metaphors and analogies" (Ryan \& Bernard, 2003), therefore I used some metaphors to name the themes, for instance "A web of turns" rather than "Multiple turns among multiple participants". I also named the themes after proverbs used by participants such as "Without the teacher, students cannot learn".

I noticed evocative expressions in the interviews such as "Without the teacher, students cannot learn". These all helped me to see a connection with themes "Teachers are the director" and "Students are passive". I decided the theme "Without the teacher, students cannot learn" should consist of two sub-categories "Teachers are directors" and "Students are passive". This theme reveals a traditional relationship between teachers and students in Vietnam classroom.

Furthermore, I began to see codes in the miscellaneous category, such as, "Using Vietnamese to promote questioning". I renamed it to "Using both languages". The categories "Without the teacher, students cannot learn", "Using both languages" and "Concerning about face" all refer to typical happening in local context. Therefore, I put these into the group: "My home, my rules" ("nhập gia tuỳ tục", a vietnamese proverb), referring to the fact that questioning was situated in local context.

From this, I formed the foundation of my Findings chapters, which consisted of three main topics: (1) Communicative interaction, (2) The art of teaching, and (3) My home, my rules. In findings chapters, I did not report two cases (in English major context and in English non-major context) separately, but focused on the themes in cross-case analysis because there were mainly/significant similarities of the use of questioning in two different contexts. However, some contrasts about the use of questioning in two different contexts were mentioned within the themes. 
The last phase was reported in the discussion chapter. I referred to four research questions to discuss the roles of questioning, what influences questioning, and how questioning was revealed in classroom practice. The answers to research questions were discussed with literature about communicative language teaching (CLT) (Richards, 2006) to conclude about how questioning promoted CLT in the tertiary EFL classroom in Vietnam. Furthermore, I used the T-L map by Hall and Kidman (2004), as a theoretical framework to explain how the local contexts influenced CLT application and questioning in the English major class and English non-major class. Referring to the T-L map also illustrates the relationship between different aspects of teaching and learning (such as teacher, learner, content and context). Based on the TL map of Hall and Kidman, I created a modified version of the teaching and learning map, which involved a new element—questioning.

\section{Using Vietnamese or English during data collection and data analysis}

The choice of whether to use Vietnamese or English for data collection and data analysis was made after considering the participants' convenience, the best way to elicit authentic meaningful data, and to be consistent with research ethics.

\section{Using Vietnamese in data collection}

Li (2011b) raised a concern about ethical issues inherent in working with two languages, and translating stories and lives from one to the other and how this might affect the research participants' lives as well as the research process. The author mentions two reasons to choose L1 as the medium for interviewing participants; transcribing and for member checking.

Firstly, the English competence of student participants was possibly inadequate to allow them to "contain the complex and sophisticated ideas, thoughts, and feelings" (Li, 2011b, p. 27) that they wished to convey. This was the main reason that I decided to use Vietnamese when conducting interviews and discussion with teachers and students. I found that our interactions in Vietnamese allowed the participants, especially student participants, to communicate freely and deeply. 
Second is the concern about member checking if the transcripts were translated into English. In my research, the participants responded differently to Vietnamese and English transcriptions. I sent participants the transcripts of both Vietnamese and English for member checking. The participants added more thoughts and clarification to the Vietnamese version; they rarely corrected or refined the English translation.

\section{Using Vietnamese or English in data analysis}

After data collection, I first transcribed then translated interviews into English to prepare for member checking and data analysing. Through listening, transcribing and translating data, I had the chance to get familiar with and think about the participants' beliefs about questioning.

After that, I sent participants the transcripts both in Vietnamese and English. I told them to feel free to check my translation and make some comments or add some more thoughts. Few participants responded to my English translation. They just told me that the English translations were fine. However, to my surprise, the participants sent back the Vietnamese transcripts with lots of comments and ideas added. Three of them explained that reading the transcripts in the L1 was much faster and less timeconsuming than reading in English, because they were quite busy with other work; and one said that they felt more confident to add more thoughts in the mother tongue.

These comments are consistent with Li's (2011b) findings that participants might feel reluctant to correct the English of the researcher, or they might have difficulties in processing the foreign language transcription. Participants seemed to relate better to reading the transcript in their $\mathrm{L} 1$.

Of the 16 groups of participants, three of them confirmed the accuracy of the transcripts with minor changes; while 13 of them answered questions that I had highlighted or asked more detailed questions. Most of the comments were made on the Vietnamese transcripts. For this reason, I found that using the L1 was a good way to collect more meaningful data even after the data collection at the research site.

The next issue is how I came to the decision of whether to analyse Vietnamese rather than English transcripts. I agree with the notion that a translation is always an 
interpretation (Dusi, 2010). This may be because of the difference in ways of expressing the mood, tenses or subjective form between the source or target language (Helin, 2006); and interpretation is always a violation of the original message (Barokass-Emanuel, 2001). From this perspective, no translation can maintain the authentic meaning, and analysis of a translated transcription seems to be an interpretation of the interpretation. In other words, the translation may add another layer to a researcher's interpretation. So data from interview and focus group sources were coded directly in Vietnamese to ensure their original meanings.

\section{Translating in data reporting}

In reporting data in finding chapters, I was aware of issues arising from translating into the L2 (English).

It is difficult to translate directly from one Vietnamese word to one English word and maintain exactly the same meaning. For example, participants stated "động não" which was translated into "brainstorming" (by Vietnamese-English dictionary, Bui, 2010), but is closer in meaning to "critical thinking". Another difficulty was translating collocations in English and Vietnamese. For example, in Vietnamese we have different collocations with the word "face"; "Mất thể diện" (lose face) and "giữ thể diện" (save face), while in English "lose face" and "save face" may not have the same cultural meaning or impact as in Vietnam. It was difficult to translate the collocation attached to the word.

It was difficult to translate participants' beliefs at some points, particularly around the ideas of knowledge, subject matter, content, intelligence, thinking, and brainstorming. The participants provided their own subjective perspectives about these concepts, about which there had been extensive literature and different controversial arguments, and these were difficult to translate exactly. For example, some students mentioned that answering teacher questions made them more intelligent, while the literature argues that IQ was something that we were born with and we can't do much to change it (Buschkuehl \& Jaeggi, 2010). Another example was that students used the terms thinking and brainstorming in L1 interchangeably, without noticing the difference between them thinking (act of reflecting, judging or reasoning) and brainstorming (the technique used in classroom for creative problem solving (Rawlinson, 2017)). 
If I had chosen to translate participants' oral language directly, especially the mentioned controversial terms, I would have had to provide or discuss research around the concepts. This might have overloaded the participants and moved beyond the scope of the study. Therefore, while translating, I chose to keep the essential meaning of the original utterance.

To ensure the trustworthiness of the translation, back-translation was used (Chen \& Boore, 2010). Specifically, a colleague who is an EFL teacher in Vietnam and is fluent in both languages translated the English version back into Vietnamese to compare the language, tone, and voice of the two versions to make sure that they matched each other.

The process I used to decide how to manage L1 and L2 in the study is summarised in following table.

Table 12

The Use of Vietnamese and English in this Study

\begin{tabular}{|c|c|c|}
\hline Time & Things to do & Reasons/results \\
\hline Collecting data & Use L1 & $\begin{array}{l}\text { The mother tongue was used to } \\
\text { facilitate participants, especially } \\
\text { student participants, to communicate } \\
\text { freely and deeply. }\end{array}$ \\
\hline \multirow{3}{*}{ Analysing data } & $\begin{array}{l}\text { - Transcribe data } \\
\text { - Translate data into } \\
\text { English }\end{array}$ & $\begin{array}{l}\text { To prepare for member checking and } \\
\text { analysing. }\end{array}$ \\
\hline & $\begin{array}{l}\text { - Send both L1 and L2 } \\
\text { transcripts to } \\
\text { participants }\end{array}$ & $\begin{array}{l}\text { - For English translation, most of } \\
\text { participants did not write anything. } \\
\text { They just told me that the English } \\
\text { translations were fine. } \\
\text { - For Vietnamese transcripts, } \\
\text { participants added lots of comments } \\
\text { and ideas. }\end{array}$ \\
\hline & $\begin{array}{l}\text { Use L1 transcripts to } \\
\text { code }\end{array}$ & $\begin{array}{l}\text { - The translation may add another } \\
\text { layer to researcher's interpretation. }\end{array}$ \\
\hline
\end{tabular}


- That data were coded directly from

Vietnamese language to ensure their original meanings.

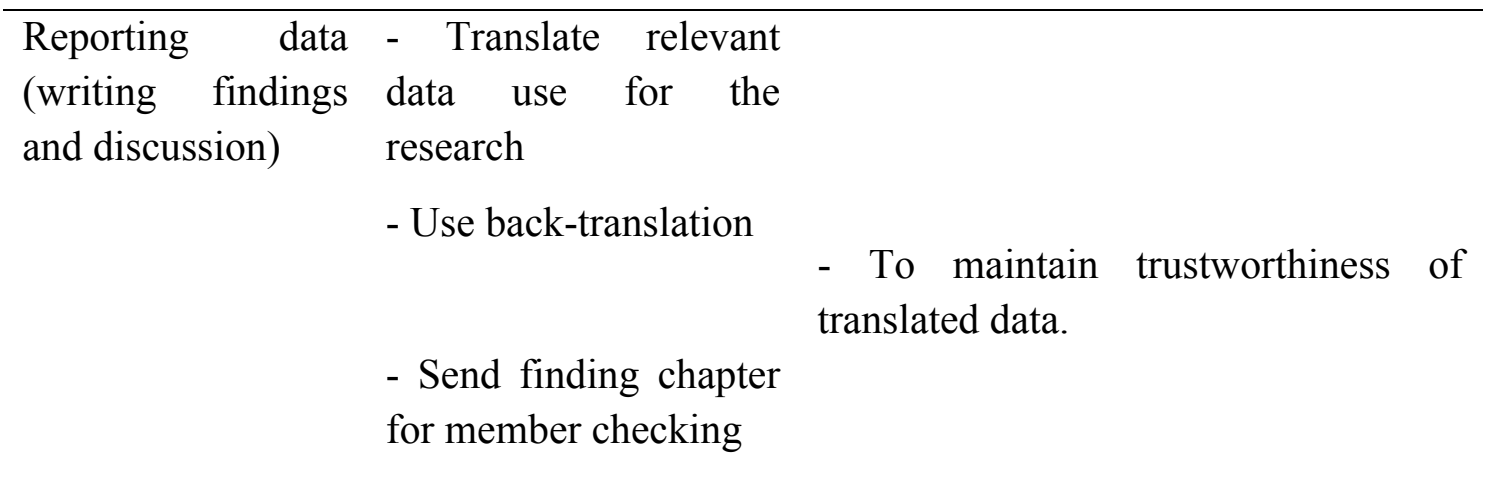

\section{The role of the researcher}

According to Stake (1995) the case researcher may play different roles. I acted as a non-participant observer during class time but took the position of interviewer and moderator in face-to-face stimulated recall interviews and focus group discussion.

Creswell (2014) mentions that the researcher's bias, values and personal background may shape the interpretation, yet qualitative researchers are the primary instrument for data collection and analysis (Merriam, 2002). With this in mind, I acknowledge that my past experience, and my connection with the participants and the research sites could have an influence on the data I gathered and how I analysed them. Firstly, having worked as an EFL teacher for many years, I bring my own perceptions of tertiary education and my own understanding of the field, setting and participants. However, to balance this, my previous experiences also had the potential to enhance my vision and sensitivity towards the participants (Creswell, 2014).

This study was carried out in my own organisation and with some of my colleagues. Although this made the data collection convenient, there was the potential that I might find it difficult to report data objectively. For example, it might not be easy to report negatively on participants and risk our personal relationship. The following section will discuss a number of strategies I used to establish the trustworthiness of the study. 


\section{Trustworthiness}

Credibility, transferability, dependability and confirmability are essential for trustworthy qualitative research (Guba, 1981; Lincoln \& Guba, 1986). To meet these standards, this study applied triangulation, reflexivity, member checking, peer examination, and dense description (Krefting, 1991, p. 217; Shenton, 2004).

\section{Credibility}

Credibility is defined as the truth value or the accuracy of the representation of subjective experiences (Guba, 1981). In quantitative studies this is known as internal validity (Lincoln \& Guba, 1986). My study promoted truth by using triangulation of data sources to explore the phenomenon of questioning through multiple perspectives (classroom observation, stimulated recall during teacher interviews, and student focus groups). It also used reflexivity, member-checking and peer examination.

Reflexivity refers to the influence of the researcher's personal perceptions or background on the research process (Krefting, 1991). Shenton (2004) suggests that information about the background, qualification and experience of the researcher should be made explicit in the research report. During this study, I kept a study journal to reflect on my thoughts and ideas. This enabled me to capture my preconceived assumptions.

Member-checking allows participants to check the researcher's records and translation of participants' words (Lincoln \& Guba, 1986). In my study, the teachers and students had a chance to review and correct the transcriptions. After transcribing data, I sent the transcription back to participants. Another means of establishing the credibility included peer examination-my $\mathrm{PhD}$ supervisors oversaw the research process and the coding process.

\section{Transferability}

Transferability in qualitative research indicates the fit of the research findings into contexts outside the study situation (Guba, 1981; Shenton, 2004). 
A case study relies on analytical applicability rather than generalisation (Yin, 2013). This means the results may be applied to a broader context. To do that, thorough documentation of the qualitative procedure is important to allow other researchers to repeat the procedures of a case study in a new context. I kept detailed notes of the protocols and procedures from selecting participants, data collection to data analysis. These may then be applied by other researchers in new settings.

I also provided a description of background information about participants and context (figures 10,11, and 12) to allow others to judge how transferable the findings may be (Krefting, 1991; Shenton, 2004).

\section{Dependability}

Lincoln and Guba (1986) relate dependability in qualitative research to the consistency or reliability of the findings. It means the same results should be gained if the investigation were repeated (in the same context, with the same methods and with the same participants). However, Guba (1981) argues that qualitative research is variable. Even with the same researcher and participants, variability can result from, for instance, the increasing insight on the part of researcher or changes in participants' life situations.

Strategies such as dense description, triangulation, peer examination, and an iterative coding procedure (Krefting, 1991; Shenton, 2004) provide dependability in this study. Dense description of contexts, methods of data collection and analysis were given (in this chapter) so that others can judge the dependability of the findings. Multiple methods triangulated and supplemented the findings. I conducted an iterative coding procedure to assure meaningful themes and supplemented this procedure with peer examination of the coding by my supervisors.

\section{Confirmability}

Guba (1981) refers to neutrality meaning the degree to which the findings are free from bias, motivation and the researcher's perspectives. To enhance the confirmability, I provided documentation from at least two sources to support and triangulate the findings (Krefting, 1991). Teacher questioning was investigated from 
different perspectives (to reveal beliefs and practices), from the perspectives of teachers and students, and between two contexts, where English is a major and English is a non-major. Reflexivity and awareness of my influence on the data through a reflective diary and discussions with supervisors were another means of establishing confirmability.

The following table summarises the strategies I used to establish trustworthiness in this study.

Table 13

Strategies with Which to Establish Trustworthiness

\begin{tabular}{|c|c|c|}
\hline $\begin{array}{c}\text { Criteria of } \\
\text { trustworthiness }\end{array}$ & $\begin{array}{l}\text { Strategies to establish } \\
\text { trustworthiness }\end{array}$ & Detailed description \\
\hline \multirow[t]{4}{*}{ Credibility } & Triangulation & $\begin{array}{l}\text { Classroom observations, teacher } \\
\text { interviews, and student focus group } \\
\text { discussions. }\end{array}$ \\
\hline & Reflexivity & $\begin{array}{l}\text { Study diary to reflect my thoughts and } \\
\text { ideas. }\end{array}$ \\
\hline & Member checking & $\begin{array}{l}\text { Lecturers and students (participants) } \\
\text { checked the transcriptions and } \\
\text { translations. }\end{array}$ \\
\hline & Peer examination & $\begin{array}{l}\text { My } \mathrm{PhD} \text { supervisors oversaw the } \\
\text { research process and coding process. }\end{array}$ \\
\hline \multirow[t]{2}{*}{ Transferability } & Procedure documentation & $\begin{array}{l}\text { Detailed notes of the protocols and } \\
\text { procedures from participant selecting, } \\
\text { collecting data and analysing data. }\end{array}$ \\
\hline & Dense description & $\begin{array}{l}\text { Detailed description of background } \\
\text { information about participants and } \\
\text { context. }\end{array}$ \\
\hline \multirow[t]{2}{*}{ Dependability } & Dense description & $\begin{array}{l}\text { Detailed description of context, methods } \\
\text { of data collection and analysis. }\end{array}$ \\
\hline & Triangulation & $\begin{array}{l}\text { Classroom observations, teacher } \\
\text { interviews, and student focus group } \\
\text { discussions. }\end{array}$ \\
\hline
\end{tabular}




\begin{tabular}{lll}
\hline Peer examination & $\begin{array}{l}\text { My PhD supervisors oversaw the } \\
\text { research process and coding process. }\end{array}$ \\
\hline Confirmability & Triangulation & $\begin{array}{l}\text { Multiple sources of data from different } \\
\text { perspectives between belief and practice, } \\
\text { among perspectives of teachers and } \\
\text { students, and between two contexts, } \\
\text { where English was a major and English } \\
\text { as a non-major. }\end{array}$ \\
& $\begin{array}{l}\text { Awareness of my influence on the data } \\
\text { through a reflective diary and } \\
\text { discussions with supervisors. }\end{array}$ \\
\hline
\end{tabular}

\section{Ethical considerations}

Victoria University of Wellington's Human Ethics Policy (2007) requires ethical research. It indicates the right of participants to be well-informed about the research and to be protected in terms of privacy, confidentiality, anonymity and withdrawal from the project. To guarantee these rights, I addressed the key ethical and legal issues as follows.

To conduct the investigation in The University in Vietnam, I composed a formal letter to ask for permission from the university and individual faculties (Appendices A and B). I guaranteed to not disclose identities of the university, teachers, students, and faculties. There was also a detailed account of the ethical protocols I followed to carry out the research after approval had been given by Victoria University of Wellington and the university.

The participants who agreed to take part in this study received an information sheet and consent form to clarify the study aim, research procedure, and participants' roles (Appendices C, D, and E). This explained that they could withdraw from the project at any time during the data collection process. For example, I invited four to six students from each class after inviting all the class members by email. The emails were to ask permission to record their responses in one class. Their freedom to withdraw from the investigation without giving a reason before data analysis took place was also clarified in the emails. It was explained that their participation (or not) 
would not affect their grades. I selected the first six students who wished to participate.

The principle of confidentiality was assured. I used pseudonyms to protect the identities of participants. It was clear to participants that all information and data provided by them would be kept confidential, only accessible to my supervisors and me, and would be destroyed after a period of three years.

In the next part will be three findings chapters. As mentioned, though this multiple case study expected a comparison between two contexts (in English major classes and English non-major classes), there was not much difference between these two cases. Therefore, the findings will present three major themes cross the whole data. The data/findings were organised under three themes: Communicative interaction, The art of teaching, and My home, my rules; and the comparison and contrasts between the two cases are included in each theme. 


\section{CHAPTER 4: COMMUNICATIVE INTERACTION}

\section{Introduction}

Participants of this study perceived questioning as a means of creating meaningful interaction through which teachers and students could communicate in the target language. Firstly, teacher and student participants perceived questioning as a web of turns among multiple participants. They also considered questioning brought about opportunities to practice and improve communicating. Lastly, the participants believed that through questioning, teachers and students worked together to develop learning. Observational data supported the participants' beliefs.

\section{A web of turns}

Findings from the interviews and observations showed that questioning was perceived to be a two-way conversation, consisting of multiple turns between teachers and the students.

\section{A two-way interaction}

The teacher participants believed questioning was an interaction, consisting of multiple turns shared between the teacher and the students. Teachers thought questioning was a process in which both teachers and students built learning through "two-way communication" (English non-major/ENM Teacher 1), and the teacher and student could "co-construct the lesson" (English major/ EM Teacher 3). Students also wanted to learn through interaction. Furthermore, both teachers and students agreed that questioning created a "conversation in [the] targeted language" (ENM Teacher 3) and benefited the students' communicative competence.

\section{Multiple turns}

Teacher and student participants found that questioning achieved interaction when the teacher asked questions and students answered (ENM group 2, EM group 1, ENM Teacher 2). Teachers added: 
"Questioning interaction is not just the turns of asking or answering. The teacher can ask more than one question, more than one student can be involved in answering... It can be long and involve further turns [for example giving feedback]" (EM Teacher 4)

The observation data revealed that there were many questioning interactions that were more than three basic turns (Initiation-Response-Feedback). Questioning interactions across the research site were flexible and contained multiple turns among teachers and students. For example, the episode below shows how questioning involved multiple turns in one class, where English was taught as non-major (ENM Class 3).

\begin{tabular}{|c|c|c|c|c|}
\hline Line & Speaker & $\begin{array}{c}\text { Utterance and } \\
\text { non-verbal data }\end{array}$ & Turns & Function/purposes \\
\hline 18 & \multirow{2}{*}{$\mathrm{T}$} & What is coach and coaching? & \multirow{2}{*}{ I } & $\begin{array}{l}\text { Requestioning } \\
\text { information }\end{array}$ \\
\hline 19 & & $\begin{array}{l}\text { What do you know about coach } \\
\text { and coaching? }\end{array}$ & & Repeating \\
\hline 20 & Ss & (Silence) & $\mathrm{S}$ & $\begin{array}{l}\text { Struggling to answer/ } \\
\text { No answer }\end{array}$ \\
\hline 21 & \multirow{3}{*}{$\mathbf{T}:$} & Come on, boy. & \multirow{3}{*}{ I } & Nominating \\
\hline 22 & & $\begin{array}{l}\text { Tell me what you know about } \\
\text { this topic? }\end{array}$ & & $\begin{array}{l}\text { Requesting } \\
\text { information }\end{array}$ \\
\hline 23 & & What is coach or coaching? & & Reformulating \\
\hline 24 & S1: & $\begin{array}{l}\text { A person who guide or achieve } \\
\text {... people... activities... }\end{array}$ & $\mathrm{S}$ & $\begin{array}{l}\text { Giving information } \\
\text { (Incomplete) }\end{array}$ \\
\hline 25 & \multirow[b]{2}{*}{$\mathbf{T}:$} & Ok. & \multirow[b]{2}{*}{$\mathrm{F}$} & Acknowledging \\
\hline 26 & & $\begin{array}{l}\text { Have you talked a little bit } \\
\text { about sport? }\end{array}$ & & $\begin{array}{c}\text { Requesting } \\
\text { confirming/ clarifying }\end{array}$ \\
\hline 27 & S1: & Yes & $\mathrm{R}$ & Confirming \\
\hline 28 & \multirow[t]{2}{*}{$\mathbf{T}:$} & $\begin{array}{l}\text { Coach in this case is very much } \\
\text { like a trainer in sport. }\end{array}$ & \multirow[t]{2}{*}{$\mathrm{F}$} & Evaluating \\
\hline 29 & & Thank you so much & & Acknowledging \\
\hline 30 & \multirow[b]{2}{*}{$\mathbf{T}:$} & (nominates another student) & \multirow[b]{2}{*}{ I } & Nominating \\
\hline 31 & & How about you please, girl? & & $\begin{array}{l}\text { Requesting } \\
\text { information }\end{array}$ \\
\hline 32 & S2: & (stands up and be silent) ... & $\mathrm{S}$ & Struggling to answer \\
\hline 33 & $\mathbf{T}:$ & $\begin{array}{l}\text { Is there any idea about Coach } \\
\text { and coaching? }\end{array}$ & $\mathrm{F}$ & Reformulating \\
\hline 34 & S2: & (keeps silent) & $\mathrm{S}$ & Struggling to answer \\
\hline 35 & $\mathbf{T}:$ & $\begin{array}{l}\text { For instance, in this context, I } \\
\text { am the teacher, I am the } \\
\text { instructor, and I am also a } \\
\text { coach. }\end{array}$ & $\begin{array}{l}\text { F/ } \\
\text { Prompt } \\
\text { (P) }\end{array}$ & Exemplifying \\
\hline
\end{tabular}




\begin{tabular}{|c|c|l|l|l|}
\hline 36 & & Is that right? & & Asking for confirming \\
\hline 37 & S2: & (keeps silent) & S & Struggling to answer \\
\hline 38 & T: & Thank you, Thanks anyway & F & Acknowledging \\
\hline 39 & Sit down, please & $\begin{array}{l}\text { OK, then, I want you to discuss } \\
\text { with your partner in a couple of } \\
\text { minutes and then tell me what } \\
\text { do you know about coaching... }\end{array}$ & D & Offering discussion \\
\hline
\end{tabular}

Episode 4: Multiple turns in questioning

The above episode starts with an overall question "What is coach and coaching?" and the students did not answer. Therefore, the teacher had to nominate two particular students (S1 and S2). Within the overall interaction, there were two embedded questioning patterns: one with S1 (from line 21 to 29) and another with S2 (from line 30 to 39 ). Neither student could answer and the teacher offered the students a chance to discuss in pairs at last (line 40).

The questioning pattern with S1, consisting of ISFRF, began by the question in line 22. Students responded (in line 27). Examples of a student's struggle to answer are evident in line 24 and 32. In line 24, S1 tried to speak but this answer was not comprehensible or completed.

The questioning pattern with S2, forming ISFSFSF, was from line 29. In lines 32, 34 and 37, students S2 could not answer the teacher's question either. The teacher prompted by exemplifying (line 35 ) to encourage students to answer. The teacher also gave feedback at the end of the interaction (line 38 and 39).

The situation above involved more than two participants and more than three turns. In particular, there were three participants involved: the teacher and two students (S1 and S2). There were at least six different turns among them such as the initial question, student response, student struggle to answer, teacher prompt, teacher feedback, and discussion.

In brief, participants perceived that a questioning sequence consists of more than three turns between teacher and student. The teachers' questioning in practice also revealed that questioning sequences were more complex than simply a response to the teacher's initial questions, students' answers and teacher's feedback. Observational 
data showed turns with a range of purposes, such as students' struggles to answer and the teacher's prompt to help them. There were several questioning patterns, and some were embedded within others. There was no fixed pattern of turns, but it depended on the situations, and questioning became a web of turns among the teacher and students.

\section{Practice makes improvement}

Both teachers and students pointed out that questioning in the class provided them with chances to practise the target language in authentic communication and with more competent speakers (communicating meaningfully in English). The participants also suggested that the questioning interaction could encourage students to communicate fluently in contrast to the teacher giving grammatical correction (focusing on fluency).

\section{Communicating meaningfully in English}

Both teachers and students pointed out that questioning in the class created an opportunity for authentic communication for students. When students answered the teacher's questions in the target language, they were pushed to produce language and practise their communicating skills. While answering and making themselves understood, students had to convey their ideas, negotiate for meaning, and ask questions to clarify or solve problems (ENM Teacher 2 and EM Teacher 4).

According to students, the interaction that occurred during questioning could help students to practise responding in the target language. The students described "reaction in English" as:

"When standing up to answer many questions consecutively from the teacher, we have to think and verbalize at the same time. This can sharpen our spontaneous and fluent reactions in English" (EM group 4)

One of the teachers remembered an example that was meaningful for a weaker student, who, at first, could not answer the teacher's question. The teacher tried to encourage the student to start using simple words or phrases in English. The teacher corrected the student's expression and pronunciation, and at last, the student made several meaningful utterances. The teacher thought that: 
"The student started by saying nothing to making meaningful sentences ... interacting with the teacher gave him a chance to practise speaking and to be taught speaking." (EM Teacher 1)

In addition, students acknowledged that outside the classroom they did not have an authentic environment to speak English. They stated that:

"Only in the class, we can practise speaking the language with English teachers. English teachers are the best English speakers that we have." (EM group 2)

They emphasised that:

"We can practise speaking in English not only with the teacher but also in front of many others, the whole class." (EM group 1)

Both students and teachers stated that answering the teachers' questions created authentic interaction in the second language.

\section{Focusing on fluency}

Participating in questioning required the teachers and students to take turns to speak, so they paid more attention to fluency and they were more tolerant of grammatical errors that did not affect understanding.

ENM Teacher 1 said that:

"The most important is students can express something in English. It is not so important that the student has to make an excellent answer."

ENM Teacher 3 stated that:

"I said to students that they didn't need to worry about making the wrong answer. It didn't matter ...; students should just try to say something in English fluently."

The ENM Teacher 3 added: 
"I care more about students speaking fluently and confidently; I don't focus much on the grammar."

Teachers believed students were likely to engage more if students did not worry about making a mistake.

"I don't judge much about errors, I want students feel free to speak their talk" (EM Teacher 1)

To encourage students to communicate effectively, teachers believed that they should make students feel confident and this would be achieved when teachers focused on fluency, rather than accuracy. The situation (EM Class 3) in the episode below was used in a stimulated recall interview. This situation revealed how the teacher chose to ignore a student's mistakes to facilitate the conversation. The questioning sequence was about the topic “What make you stay till late?". After some students had answered, the teacher asked another opinion. (Some parts are in bold for emphasis purposes.)

\begin{tabular}{|c|c|c|c|c|}
\hline Line & Speaker & $\begin{array}{c}\text { Utterance and } \\
\text { non-verbal data }\end{array}$ & Turns & Function/ purposes \\
\hline 6 & \multirow{3}{*}{$\mathrm{T}:$} & $\begin{array}{l}\text { Now, everybody, do you want to } \\
\text { add any information? }\end{array}$ & \multirow{3}{*}{ I } & $\begin{array}{l}\text { Requesting information } \\
\text { (by a yes/no question) }\end{array}$ \\
\hline 7 & & $\begin{array}{l}\text { Or is your opinion same or } \\
\text { different with them? }\end{array}$ & & Reformulating \\
\hline 8 & & (Nominates) You, please & & Nominating \\
\hline 9 & S3: & My opinion different. I often ... & $\mathrm{R}$ & Giving information \\
\hline 10 & $\mathrm{~T}:$ & $\begin{array}{l}\text { With whom? The first or the } \\
\text { second student? }\end{array}$ & $\mathrm{F}$ & $\begin{array}{l}\text { Asking for clarification } \\
\text { (interrupting) }\end{array}$ \\
\hline 11 & S3: & The second & $\mathrm{R}$ & Clarifying \\
\hline 12 & \multirow[b]{2}{*}{$\mathrm{T}:$} & OK. Good! & \multirow[b]{2}{*}{$\mathrm{F}$} & Acknowledging \\
\hline 13 & & Tell me & & $\begin{array}{l}\text { Requiring further } \\
\text { information }\end{array}$ \\
\hline 14 & S3: & $\begin{array}{l}\text { I think Vietnamese students not } \\
\text { stay up late study }\end{array}$ & $\mathrm{R}$ & $\begin{array}{l}\text { Providing further } \\
\text { information. }\end{array}$ \\
\hline \multirow{2}{*}{15} & \multirow{2}{*}{$\mathrm{T}:$} & $\begin{array}{l}\text { Students don't stay up late to } \\
\text { study? }\end{array}$ & \multirow{2}{*}{$\mathrm{F}$} & \multirow{2}{*}{$\begin{array}{l}\text { Correcting "to study"/ } \\
\text { Requesting } \\
\text { confirmation. }\end{array}$} \\
\hline & & $\begin{array}{l}\text { (Raising voice to make question } \\
\text { to ask for confirmation) }\end{array}$ & & \\
\hline 16 & S3: & $\begin{array}{l}\text { Yes, they don't stay up late } \\
\text { study }\end{array}$ & $\mathrm{R}$ & $\begin{array}{l}\text { Confirming (Repeating } \\
\text { same mistake) }\end{array}$ \\
\hline 17 & $\mathrm{~T}:$ & Ok. So what do they do? & $\mathrm{F}=\mathrm{Q}$ & $\begin{array}{l}\text { Requiring further } \\
\text { information }\end{array}$ \\
\hline
\end{tabular}




\begin{tabular}{|c|c|c|c|c|}
\hline 18 & S3: & $\begin{array}{l}\text { They stay up late for playing } \\
\text { games, }\end{array}$ & $\mathrm{R}$ & $\begin{array}{l}\text { Providing further } \\
\text { information. }\end{array}$ \\
\hline 19 & $\mathrm{~T}:$ & Uhuh (nods head) & $\mathrm{F}$ & Acknowledging \\
\hline 20 & S3: & Watching television... & $\mathrm{R}$ & $\begin{array}{l}\text { Providing further } \\
\text { information. }\end{array}$ \\
\hline 21 & T: & Uhuh (nods head) & $\mathrm{F}$ & Acknowledging \\
\hline 22 & S3: & Search internet & $\mathrm{R}$ & $\begin{array}{l}\text { Providing further } \\
\text { information. }\end{array}$ \\
\hline 23 & $\mathrm{~T}:$ & Uhuh (nods head) & $\mathrm{F}$ & Acknowledging \\
\hline 24 & S3: & $\begin{array}{l}\text { I think they don't need to eat } \\
\text { anything to stay awake because } \\
\text { you know games really } \\
\text { interesting }\end{array}$ & $\mathrm{R}$ & $\begin{array}{l}\text { Providing further } \\
\text { information. }\end{array}$ \\
\hline 25 & $\mathrm{~T}:$ & $\begin{array}{l}\text { Ah ha. That's good idea (smiles } \\
\text { and nods head) }\end{array}$ & $\mathrm{F}$ & Acknowledging \\
\hline 26 & \multirow[b]{2}{*}{ S3: } & $\begin{array}{l}\text { And the guys are interested in it } \\
\text { all the time and they do not } \\
\text { need... they just stay awake }\end{array}$ & \multirow[b]{2}{*}{$\mathrm{R}$} & \multirow{2}{*}{$\begin{array}{l}\text { Providing further } \\
\text { information. }\end{array}$} \\
\hline 27 & & $\begin{array}{l}\text { For me, when I feel interesting } \\
\text { and I feel I can stay awake all } \\
\text { night just watch them, do not } \\
\text { need to eat. }\end{array}$ & & \\
\hline 28 & $\mathrm{~T}:$ & $\begin{array}{l}\text { So what happens when the exams } \\
\text { come? }\end{array}$ & $\mathrm{F}=\mathrm{Q}$ & $\begin{array}{l}\text { Requiring further } \\
\text { information; }\end{array}$ \\
\hline 29 & S3: & $\begin{array}{l}\text { When the exam comes I think I } \\
\text { will skip watching } T V \text {. }\end{array}$ & $\mathrm{R}$ & Providing information \\
\hline 30 & $\mathrm{~T}:$ & $\begin{array}{l}\text { Will you stay up late to study for } \\
\text { the exam? }\end{array}$ & $\begin{array}{l}\mathrm{F}=\mathrm{Q} \\
\text { closed }\end{array}$ & $\begin{array}{l}\text { Requiring further } \\
\text { information }\end{array}$ \\
\hline 31 & S3: & Just a little bit, not much & $\mathrm{R}$ & Providing information \\
\hline 32 & $\mathrm{~T}:$ & Really? & $\mathrm{F}=\mathrm{Q}$ & $\begin{array}{l}\text { Asking for } \\
\text { confirmation, showing } \\
\text { some wondering }\end{array}$ \\
\hline 33 & S3: & $\begin{array}{l}\text { When you stay up late all night } \\
\text { you just can't concentrate on your } \\
\text { study tomorrow so I think study is } \\
\text { important, you need to be } \\
\text { (inaudible) to concentrate on it... }\end{array}$ & $\mathrm{R}$ & $\begin{array}{l}\text { Explaining why not stay } \\
\text { late but not really clear }\end{array}$ \\
\hline 34 & $\mathrm{~T}:$ & $\begin{array}{l}\text { So you mean you don't need to } \\
\text { stay up late to study for the exam? }\end{array}$ & $\mathrm{F}=\mathrm{Q}$ & $\begin{array}{l}\text { Asking for confirmation } \\
\text { of not staying late }\end{array}$ \\
\hline 35 & S3: & Not too late & $\mathrm{R}$ & Giving information \\
\hline 36 & $T_{\text {. }}$ & Ah, not too late. & Г & $\begin{array}{l}\text { Acknowledging by } \\
\text { repeating }\end{array}$ \\
\hline 37 & 1. & $\begin{array}{l}\text { And you say you can stay up late } \\
\text { to play games or listen to music? }\end{array}$ & 1 & Asking for confirmation \\
\hline
\end{tabular}




\begin{tabular}{|c|c|l|c|c|}
\hline 38 & S3: & Yeah it is & $\mathrm{R}$ & Confirming \\
\hline 39 & $\mathrm{~T}:$ & Oh. Yes. Interesting. & $\mathrm{F}$ & $\begin{array}{c}\text { Acknowledging. } \\
\text { Evaluating }\end{array}$ \\
\hline 40 & & Thank you very much. & & \\
\hline
\end{tabular}

\section{Episode 5: Focusing on fluency in questioning}

The teacher said that initially she noticed the student's mistake in the answer "I think Vietnamese students not to stay up late study" (line 14), so she tried to correct the error by emphasising "to study" (line 15), but the student still repeated the error (line 13). The teacher thought that the student might not have noticed that the teacher was trying to correct him. The teacher decided to ignore the error. The teacher added that she noticed errors in all the student's answers (for example, lines 9, 16, 24, and 27) but she ignored all the errors because:

"It was more important that the student could speak his opinions. If I stopped the student whenever he made a mistake, he would not continue speaking" (EM Teacher 3)

In that example, it seemed that the student felt comfortable about the process and kept speaking and adding more thoughts.

In brief, teachers and students agreed that questioning involves teaching and learning communicative skills through interaction. This was because questioning created chances for students to practise the L2 in meaningful communication with a more competent speaker. Also, questioning could develop into meaningful conversation if teachers did not focus too much on errors. Observation data supported the idea that teachers prefer fluency rather than accuracy.

\section{Knowledge builders}

Both teacher and students in this study cooperated to build the lesson by questioning and answering. Firstly, teachers used questioning to support students to co-construct knowledge and as an alternative to lecturing. Knowledge learning here focused on content knowledge rather than language knowledge. Secondly, questioning offered the chance for participants in the questioning process to learn from each other. In this case, both content and language learning were distinguished by the participants. 


\section{An alternative to lecturing}

Teachers believed that questioning and answering was more effective than teacher lecturing:

"Teacher questions are to elicit and answering helps students to think about and absorb the content. This two-way communication is more valuable than only teacher lecturing." (ENM Teacher 1)

They also mentioned that:

"Without questioning, the lesson is only one-way lecturing. If the teacher did not ask, students would not speak" (EM Teacher 3)

Similarly, students said they preferred learning through interaction:

"If the teacher lectured without any interaction with students, it would be very boring and make us sleepy; we would just listen and listen.” (EM group 4)

In addition, teachers also believed that questioning could create chances for students to contribute to the lesson.

"Teachers ask questions to encourage students to cooperate to build the lesson." (EM Teacher 1)

Both teachers and students saw questioning made teaching and learning engaging. Observational data also supported this idea.

The below episode was about the topic "what is the purpose of "just in time supplying materials' to producing process?". This was an example of how questioning and answering could support students and the teacher co-construct the lesson (ENM Class $1)$. 


\begin{tabular}{|c|c|c|c|c|}
\hline Line & Speaker & $\begin{array}{l}\text { Utterance and } \\
\text { non-verbal data }\end{array}$ & Turns & Function/ purposes \\
\hline 1 & $\mathrm{~T}:$ & $\begin{array}{l}\text {...A system when materials are } \\
\text { supplied to producing process } \\
\text { just in time when they are } \\
\text { needed. So what's the purpose } \\
\text { of just in time? Or what is the } \\
\text { advantage of this system? Can } \\
\text { anyone explain it for me? Why } \\
\text { do we have just in time } \\
\text { (materials)? }\end{array}$ & $\mathrm{I}=\mathrm{Q}$ & Requesting information \\
\hline 2 & S1: & To keep the cost down & $\mathrm{R}$ & Giving information \\
\hline 3 & $\mathrm{~T}:$ & $\begin{array}{l}\text { So how can it keep the cost } \\
\text { down? }\end{array}$ & $\mathrm{F} / \mathrm{I}=\mathrm{Q}$ & $\begin{array}{l}\text { Requesting further } \\
\text { information }\end{array}$ \\
\hline 4 & S1: & (keeps silent) & $\mathrm{S}$ & Struggling to answer \\
\hline 5 & \multirow{3}{*}{$\mathrm{T}:$} & $\begin{array}{l}\text { How can just in time help us to } \\
\text { keep the cost down? }\end{array}$ & \multirow{3}{*}{$\mathrm{F} / \mathrm{I}=\mathrm{Q}$} & Requesting information \\
\hline 6 & & $\begin{array}{l}\text { How can it help to keep the cost } \\
\text { down? }\end{array}$ & & Repeating question \\
\hline 7 & & Any more explain to us? & & Refomulating \\
\hline 8 & S2: & $\begin{array}{l}\text { Because the cost for storage of } \\
\text { the product is reduced. }\end{array}$ & $\mathrm{R}$ & Giving information \\
\hline 9 & \multirow{4}{*}{$\mathrm{T}:$} & $\begin{array}{l}\text { Um hu. Alright. (writes on } \\
\text { board 'storage'). }\end{array}$ & & Acknowledging. \\
\hline 10 & & $\begin{array}{l}\text { We know that when we store } \\
\text { product, definitely we need } \\
\text { money, we need time and } \\
\text { worker labour to maintain. So } \\
\text { when we limit the time of } \\
\text { product being kept in } \\
\text { warehouse, the cost will go } \\
\text { down. }\end{array}$ & $\mathrm{F}$ & Explaining \\
\hline \multirow[b]{2}{*}{11} & & $\begin{array}{l}\text { One more reason? Storage is } \\
\text { just one reason. }\end{array}$ & \multirow[b]{2}{*}{$\mathrm{I}=\mathrm{Q}$} & Requesting information \\
\hline & & $\begin{array}{l}\text { One more important reason? } \\
\text { (emphasis on "more } \\
\text { important") }\end{array}$ & & Repeating questions \\
\hline 12 & S3: & $\begin{array}{l}\text { We can reduce the } \\
\text { transportation }\end{array}$ & $\mathrm{R}$ & Giving information \\
\hline 13 & \multirow[t]{2}{*}{$\mathrm{T}:$} & $\begin{array}{l}\text { Yes, transportation. Well done. } \\
\text { (writes "transportation" on } \\
\text { board) }\end{array}$ & $\mathrm{F}$ & Acknowledging \\
\hline 14 & & One more thing? & I & $\begin{array}{l}\text { Requesting further } \\
\text { information }\end{array}$ \\
\hline 15 & Class: & (keeps silent) & $\mathrm{S}$ & Struggling to answer \\
\hline 16 & $\mathrm{~T}:$ & $\begin{array}{l}\text { As crucial as deposit they have } \\
\text { to keep .... (looks around) }\end{array}$ & $\mathrm{P}$ & Prompting \\
\hline
\end{tabular}




\begin{tabular}{|c|c|c|c|c|}
\hline 17 & Class & (keeps silent) & $\mathrm{S}$ & Struggling to answer \\
\hline 18 & $\mathrm{~T}:$ & $\begin{array}{l}\text { And just in time make it } \\
\text { possible. It is about money. }\end{array}$ & $\mathrm{P}$ & Prompting/ eliciting \\
\hline 19 & S4: & $\begin{array}{l}\text { We can sell it cheaper price if } \\
\text { we can reduce the cost. }\end{array}$ & $\mathrm{R}$ & Giving information \\
\hline 20 & $\mathrm{~T}:$ & $\begin{array}{l}\text { That's a good idea. I mean } \\
\text { different idea about money. But } \\
\text { it is a good idea. (writes } \\
\text { "cheaper price" on board) }\end{array}$ & $\mathrm{F}$ & Acknowledging \\
\hline 21 & & Another idea? & I & Requesting information \\
\hline 22 & & $\begin{array}{l}\text { Also about money and It starts } \\
\text { with letter C....? }\end{array}$ & $\mathrm{P}$ & Prompting/eliciting \\
\hline 23 & S5: & Capital. $\quad$ n & $\mathrm{R}$ & Giving information \\
\hline 24 & & $\begin{array}{l}\text { Thank you (writes the word } \\
\text { "capital" on board). }\end{array}$ & & Acknowledging \\
\hline 25 & $\mathrm{~T}:$ & $\begin{array}{l}\text { We know that when we don't } \\
\text { store materials, the assets can } \\
\text { be sold in market without } \\
\text { affecting the price. It's easier, } \\
\text { the liquidity of the fund. It is } \\
\text { easier. If we store a lot of } \\
\text { things, we don't have capital or } \\
\text { money to buy CL products or } \\
\text { invest into anything else. } \\
\text { Right? So this is the benefit of } \\
\text { just in time. }\end{array}$ & $\mathrm{F}$ & Explaining/Evaluating \\
\hline
\end{tabular}

Episode 6: Using questioning as an alternative to lecturing

By asking a lot of questions (lines 1, 3, 5, 6, 7, 11, and 14), and prompts (lines 16,18, and 22), this teacher could elicit from students the notion of the benefit of providing material "just in time". The teacher asked students to think more deeply by explaining (line 10) and students were pushed to keep thinking when the teacher repeated the question “one more reason? Another idea? One more thing?" (lines 11, 14, and 21) until they could answer the questions. Instead of providing the information, the teacher could use questioning to encourage students to discover different ideas about the business concept (providing materials "just in time" could keep the cost down by reducing the storage cost of the product, reducing the transportation, and selling it cheaper price if we can reduce the cost).

In this part, teachers and student participants said that questioning was more likely to promote knowledge learning through interaction more effectively than a teacher 
lecturing. Participants often talked about business content learning. However, learning of the subject content was embedded in language leaning. In other words, the language learning in these classes involved business content. Also, language learning consisted of learning critical thinking and learning how to communicate in the target language.

\section{Learning from each other}

Both teachers and students thought that questioning could create interaction among students, in which students could help and learn from each other. They also believed questioning could benefit both students who answered and also those who observed. Furthermore, teachers stated that they could learn from students through questioning.

Firstly, both teachers and students believed that teachers often created collaborative activities among students.

"The teacher often assigned students to work in pairs or groups before responding to the teacher" (ENM group 2, EM group 1, EM group 2)

Teachers stated that encouraging group work or pair work was useful for developing "questions about different viewpoints" (ENM Teacher 1) or "questions about controversial matters" (ENM Teacher 2) or "difficult questions" (ENM Teacher 4 and EM Teacher 4).

Teachers and students believed that group work or pair work could encourage students to learn from each other:

“We [students] can create a pool of knowledge.” (EM group 4, EM Teacher 4)

"Students can see answers from different viewpoints" (ENM Teacher 1 and ENM Teacher 2)

Teachers described some of the benefits of the interaction were that "the more competent could help the weaker" (EM Teacher 1 and EM Teacher 2); students could formulate well-prepared answers (ENM Teacher 3, ENM Teacher 4); and even that questioning created longer interaction among students (EM Teacher 2) 
"They can teach and correct each other. This helped them, especially quiet and weaker students, feel more confident to stand up and answer the teacher" (ENM Teacher 3)

"After discussing even criticizing and justifying, the groups could build an appropriate answer to teacher questions" (ENM Teacher 4)

"During the discussion, students could practise asking and answering more questions with their partners... to create more questioning interaction among them" (EM Teacher 2)

Similarly, many students said that collaborative work could facilitate answering because:

"The answers would be stronger because it is the thoughts of many heads" (ENM group 2)

"I can ask my friends' opinion about my answer to see if I am right or anything needs to be fixed... After discussion, I will feel more confident to stand up and answer teacher questions." (EM group 1)

Both teachers and students said that by using questioning, teachers could create interaction among students. In this interaction, students could learn from each other because they could see the answers from different perspectives, they could practise and help each other to prepare the right response.

Secondly, students believed that teacher questioning could benefit students who were participating in answering, and the other students who were observing. Students provided details of how questioning could help them learn from the teacher and learn from each other.

For instance, students believed that students who answered the questions were able to obtain immediate and useful feedback on their answers (ENM group 2, ENM group 4, EM group 2 and EM group 3).

“The teacher could correct my answer directly and quickly.” (ENM group 4) 
Students said further what they could benefit from teacher feedback.

"Our answers would be commented both in ideas and expression." (ENM group 2)

"Thanks to teacher feedback, I know the good and bad in my answer. This is the way I can learn the English language.” (EM group 2)

ENM group 2 and ENM group 4 had the same opinion that if they responded to the teacher, the teacher could use their answers to clarify any confusion or misunderstanding.

"Standing up to interact with the teacher, we have the chance to raise our concern to the teacher, and the teacher can clarify and clear it up immediately." (ENM group 4)

EM group 3 pointed out that:

"For open questions, there are different answers. I suppose standing up and raising ideas with the teacher is the only way to know whether my opinion is right or not." (EM group 3)

A student in EM group 3 added that:

"The teacher does not only point to the good or bad aspects of our answers. The teacher also corrects or suggests ways to improve or develop the answers." (EM group 3)

The students thought that participating in questioning was a chance to receive feedback, raise concerns and get corrections from the teacher.

According to the students, even students who did not participate in an interaction could also learn while listening to the questions and answers.

"Students answering have the chance to express themselves and receive feedback; the teacher is happy when students are engaging; while other students could learn from the questions and answers." (EM group 4) 
Students gave details of what non-participating students could learn from the questions and answers. For example, the teachers modelled question forms:

"We can learn the ways of asking from teacher questions.... We can learn new words and expressions from the questions" (ENM group 2)

The rest of class was able to gain ideas:

"Especially for open questions with many different answers, students can gain and see the matter from different viewpoints" (EM group 2)

EM group 4 agreed that all students could learn from teachers' feedback about the answers of their classmates:

"Listening to teacher feedback, I also learn a lot, because I also make the same mistakes [as the answerer]." (EM group 4)

In addition, students thought other students could learn the skills of asking and answering through observation:

"The chance to listen to the teacher asking questions helps us to learn how to make questions, and express questions. Teacher questions are question samples." (EM group 1)

The students added:

"Listening to friends' answers, I can learn how to express myself and collect more ideas from other angles, which sometimes are similar or different from mine." (EM group 1)

Students reported that they could learn by answering themselves, or listening to the teacher asking and their classmates answering.

Conversely, teachers stated that the teachers also could learn something from students' answers. For example: 
"I think I learn many good ideas from students. They are smart and full of good ideas. " (EM Teacher 3)

"Students sometimes answer better than I expect, they suggest [ways] to think [about] the matter from different perspectives" (ENM Teacher 1)

One example about how the teacher learned from a student was evident while the teacher was eliciting students to learn about the benefits of "just in time" (ENM Class $1)$.

\begin{tabular}{|c|c|l|c|c|}
\hline Line & Speaker & $\begin{array}{c}\text { Utterance and } \\
\text { non-verbal data }\end{array}$ & Turns & Function/ purposes \\
\hline 18 & $\mathrm{~T}:$ & $\begin{array}{l}\text { and just in time make } \\
\text { possible. It is about money. }\end{array}$ & $\mathrm{P}$ & Prompting/eliciting \\
\hline 19 & $\mathrm{~S} 4:$ & $\begin{array}{l}\text { We can sell it cheaper price if } \\
\text { we can reduce the cost. }\end{array}$ & $\mathrm{R}$ & Giving information \\
\hline 21 & $\mathrm{~T}:$ & $\begin{array}{l}\text { That's a good idea. I mean } \\
\text { different idea about money. But } \\
\text { it is a good idea. (writes } \\
\text { "cheaper price" on board) }\end{array}$ & $\mathrm{F}$ & Acknowledging \\
\hline $\begin{array}{l}\text { Another idea? } \\
\text { Also about money and it starts } \\
\text { with letter C...? }\end{array}$ & $\mathrm{P}$ & Prompting/eliciting \\
\hline
\end{tabular}

Episode 7: Teacher could learn from student's answer

When teacher suggested an idea about money, a student answered that "just in time" could make the price of materials cheaper. In the teacher's turn, she acknowledged this was a good idea, which was different from hers. It showed that teacher could learn something new from student's answers.

To summarise this section, according to teachers, students, and observations, questioning was an interaction consisting of asking and answering turns between the teacher and students. The participants said the interaction provided chances for twoway conversation, which was more beneficial than teacher lecturing only. Askinganswering communication could develop learning for the teachers and students involved. The interaction also provided chances for meaningful conversation in the target language. 
Furthermore, both teachers and students found the process of asking-answering benefited even those not directly involved in the exchange. The student who answered questions could receive feedback from the teacher. Other students could learn from the teacher's questions and the student's answers. In contrast, teachers said that they found questioning beneficial for them because they could learn new and diversified ideas from the students. Observational data also illustrated questioning as a process where teachers could get ideas from the learner.

\section{Summary}

The section proposes that questioning was the process of teaching and learning communication through interaction. There were no significant differences between ENM and EM teachers and students. They shared the same ideas.

Questioning was considered to be a sequence, consisting of multiple turns. The most common three turns were teacher-asking, student-answering, and teacher-feedback. Additionally, I noticed further optional turns in observations, for example when students struggled to answer, teachers provided prompts to elicit the answer. The observations revealed that questioning interactions in the classroom occurred not only between the teacher and a student. It could be between the teacher and many students, and the turns taken during the questioning were flexible. Because teachers varied their questioning techniques according to particular purposes and contexts, the teachers were able to encourage extensive interactions where the quality of the questioning sequence could be evaluated not by the number of turns but by the length of students' answers. Also, questioning was considered by the participants to offer chances for students and teachers to learn. These included chances for students to develop communicative competence in a meaningful context with a more competent speaker, the teacher. In addition, through questioning, teachers and students worked together to build the lessons. Questioning, therefore, enabled students to learn from each other and teachers to learn from students. 


\section{CHAPTER 5: THE ART OF TEACHING}

\section{Introduction}

Findings show that questioning was useful to fulfil a variety of pedagogical purposes. The interview data indicate that for some aspects, the teachers and the students in different faculties saw things differently. For example, English-non-major (ENM) teachers and students identified how business-content language was involved in questioning, while those in English major (EM) classes identified about content of linguistics within questioning. However, participants in both faculties agreed that teachers have to be skilled and talented to use questioning successfully in teaching. Both participants' interview and observational data mentioned common purposes for questioning, such as: facilitating learning, diagnosing learning needs, managing learning and lubricating classroom relationship.

\section{Facilitating learning}

The participants often mentioned how the teachers used questioning to facilitate learning. They used questioning to encourage the students to learn English language content as well as business English/ subject-specific matter embedded in the language, as opposed to transferring knowledge to students. Also, both teachers and students were aware that teachers often used questioning to promote cognitive development. Furthermore, according to teacher participants, the questioning was to scaffold and teach students to work more independently.

\section{Eliciting learning of the content}

Participants thought that teacher questioning facilitated both language and subjectspecific content acquisition. Teachers and students mentioned that the main purpose of teacher questions was to develop language learning but this learning also involved the subject matter or content (ENM Teacher 2, ENM Teacher 3, EM Teacher 1).

Students also agreed that they were able to learn the target language and subject matter: 
"Teacher questions helps us to practise expressing and building sentences in English.” (ENM group 2)

"Teachers always encourage us to talk more and reason deeply so that we can understand the content to a higher level" (EM group 3)

ENM Teacher 2 said that teachers used sets of questions mainly to deliver the lesson content. If students could answer, it meant that the students had learned the subject matter. She said that teachers in higher education were facilitators, who prompted their students:

"The teacher asks, and students answer: this is such an effective teaching method to promote students to discover knowledge; asking questions raises the problem and orients students to focus on particular knowledge." (ENM Teacher 2)

Furthermore, teachers agreed that the purposes of a particular subject could govern the questioning. In particular, the requirement of the lesson significantly influenced the focus of the questions. Teachers in English non-major agreed that:

"Students are majoring in business, so many questions have business-based content." (ENM Teacher 3, ENM Teacher 4)

In contrast, in English major classes, EM Teacher 1 said:

"questions are often difficult and academic relating to linguistic concepts."

EM Teacher 2 stated:

"Depending on what that I am teaching, I could make questions to promote language skills [for example, speaking, pronouncing] or questions for language knowledge acquisition [for instance "what are vowels and consonants?]."

Similarly, students said the aims of teacher questioning depended on the subject matter, which could be business-related content or linguistic content. For example, ENM group 2 stated that in their class: 
“Teacher's questions were about business content to teach us the businessrelated ideas.” (ENM group 2)

While EM group 2 talked about how their teacher used questioning to teach semantics:

“Teacher questions often go around the subject [semantics]....” (EM group 2)

Some examples in observational data revealed that teachers used questioning to teach language content and subject-specific knowledge. For example, questions aiming to teach aspects of language, such as grammar knowledge:

"What tense is used when we talk about an action that happened yesterday?" (ENM Teacher 3)

Questions could be about semantic understanding, for example:

"What is the definition of postulate?" (EM Teacher 1)

Questions might be about teaching business ideas, for instance:

"What are the qualities of a good coach?" (ENM Teacher 2)

Data from the interviews and observations revealed that the critical purpose of questioning was to promote language acquisition, and knowledge about the language, as well as knowledge about business.

In addition, participants believed teachers used feedback to guide students to learn. Teachers believed feedback was significant and useful to teach because:

"Giving feedback is teaching. Students learn much from teacher feedback” (EM Teacher 2)

Students also agreed with that:

"The teacher spends much time for feedback .... I find a lot of information and new thing to learn from teacher's feedback." (ENM group 3) 
Teachers and students said teachers used feedback with a particular purpose:

"I often try to comment on all aspects such as speaking skills, grammar, vocabulary or the content. But it depends on the purpose and outcome of the lesson; I can focus more on some of the particular aspects" (ENM Teacher 4)

"Teachers try to give comments, which are very detailed; for example, about our pronunciation, vocabulary, and content. So we can improve and avoid making the same mistakes in future." (EM group 3)

Teachers talked about different ways to give constructive and straightforward feedback that would support learning.

They tried directly pointing out the weakness in a constructive way. Some paid attention to critical errors "which are basic or repeated" (ENM Teacher 3) or when "many students make the error" (ENM Teacher 3, EM Teacher 3). Others took a comprehensive approach to feedback:

"I will try to mention all the mistakes. I pay attention to ideas and skills and how to improve then answers." (ENM Teacher 1)

EM Teacher 4 agreed:

"I both comment on the good and bad of the answer in a constructive way. For the weakness of the answer, I would be very straightforward, but not aggressive, to point out the mistakes to the whole class."

However, teachers tended to focus on giving feedback on language learning rather than business content because:

"Students may know more about Business [than teachers] because they have learned in their major classes" (ENM teacher 2)

"We are English teachers. The business content is not the main purpose." (EM teacher 4) 
The teachers believed that feedback was important. The teachers also reported ways of giving positive and constructive feedback.

In the episode below (ENM Class 3), the teacher tried to teach by eliciting student answers about coaches and coaching. The situation involved some followup/feedback turns. There were a variety of ways teachers used these turns to promote learning (Some parts are in bold for emphasis purpose):

\begin{tabular}{|c|c|c|c|c|}
\hline Line & Speaker & $\begin{array}{c}\text { Utterance and } \\
\text { non-verbal data }\end{array}$ & Turns & Function/ purposes \\
\hline 56 & \multirow[t]{2}{*}{$\mathrm{T}$ : } & $\begin{array}{l}\text { Now, tell me, tell me, what do } \\
\text { they [coaches] do every day in } \\
\text { their team? }\end{array}$ & \multirow[t]{2}{*}{ I } & Requesting further info, \\
\hline 57 & & What do they do? & & Repeating \\
\hline 58 & S4: & (soft voice) They train & $\mathrm{R}$ & Providing information \\
\hline 59 & $\mathrm{~T}:$ & They ...? & $\mathrm{F}=\mathrm{Q}$ & Eliciting \\
\hline 60 & S4: & (louder) They train & $\mathrm{R}$ & Repeating \\
\hline 61 & \multirow{3}{*}{$\mathrm{T}:$} & Ok. & $\mathrm{F}$ & Acknowledging \\
\hline 62 & & What's else? & \multirow{2}{*}{ I } & Requiring further info \\
\hline 63 & & They...? & & Eliciting \\
\hline 64 & S5: & $\begin{array}{l}\text { They inspire (mispronounces } \\
\text { "inspire") }\end{array}$ & $\mathrm{R}$ & Providing further info \\
\hline 65 & \multirow[t]{2}{*}{$\mathrm{T}:$} & $\begin{array}{l}\text { They inspire (emphasises } \\
\text { pronouncing 'inspire'). }\end{array}$ & \multirow[t]{2}{*}{$\mathrm{F}$} & $\begin{array}{c}\text { Correcting } \\
\text { (pronunciation) }\end{array}$ \\
\hline 66 & & Alright. & & Acknowledging \\
\hline 67 & S6: & They connect. & $\mathrm{R}$ & Giving further info \\
\hline \multirow[t]{2}{*}{68} & \multirow{3}{*}{$\mathrm{T}:$} & $\begin{array}{l}\text { They connect, connect every } \\
\text { member. }\end{array}$ & \multirow[t]{2}{*}{$\mathrm{F}$} & $\begin{array}{l}\text { Re-contexting } \\
\text { (expression), }\end{array}$ \\
\hline & & Alright. & & Acknowledging, \\
\hline 69 & & What else? & I & Requesting further info \\
\hline 70 & S7: & They take care of member. & $\mathrm{R}$ & Giving information \\
\hline 71 & \multirow{3}{*}{$\mathrm{T}:$} & They take care of the team. & $\mathrm{F}$ & $\begin{array}{c}\text { Correcting } \\
\text { (vocabulary) }\end{array}$ \\
\hline 72 & & You are right. You are right & & Acknowledging \\
\hline 73 & & $\begin{array}{l}\text { (talks to the last table) How } \\
\text { about you, guys? }\end{array}$ & $\mathrm{I}$ & Requesting info \\
\hline 74 & $\begin{array}{l}\text { Ss in the } \\
\text { table: }\end{array}$ & (keep silent) & $\mathrm{S}$ & Struggling to answer \\
\hline 75 & \multirow[b]{2}{*}{$\mathrm{T}$ : } & How about techniques? & $\mathrm{F}$ & $\begin{array}{l}\text { Reformulating } \\
\text { (specific question) }\end{array}$ \\
\hline 76 & & $\begin{array}{l}\text { Regarding to how do they deal } \\
\text { with each situation during the } \\
\text { match? }\end{array}$ & $\mathrm{P}$ & Exemplifying \\
\hline
\end{tabular}




\begin{tabular}{|c|c|c|c|c|}
\hline 77 & $\begin{array}{l}\text { Ss in the } \\
\text { table: }\end{array}$ & (keep silent) & $\mathrm{S}$ & Struggling \\
\hline 78 & \multirow[b]{2}{*}{$\mathrm{T}:$} & What else? & \multirow[b]{2}{*}{$\mathrm{F}$} & Reformulating \\
\hline 79 & & $\begin{array}{l}\text { (points to a student at the table) } \\
\text { You, please. }\end{array}$ & & Nominating \\
\hline 80 & S8: & Manage & $\mathrm{R}$ & Giving information \\
\hline 81 & \multirow{4}{*}{$\mathrm{T}:$} & Manage. Yeah, right & \multirow{4}{*}{$\mathrm{F}$} & Repeating \\
\hline 82 & & Manage, I need this word & & Acknowledging \\
\hline 83 & & $\begin{array}{l}\text { They manage procedure, } \\
\text { timetable and positions of } \\
\text { member in the match }\end{array}$ & & $\begin{array}{l}\text { Recontextualising } \\
\text { (vocabulary/ } \\
\text { expression), }\end{array}$ \\
\hline 84 & & They are also managers. & & Expanding \\
\hline
\end{tabular}

Episode 8: Different ways to elicit learning

Observing teacher follow-up/feedback, there were difference pieces of evidence of a variety of ways teachers used to promote learner acquisition.

For example, the teacher prompted students to answer by asking fill-in-blank questions "They....?" (raising voice) (line 59 and 63). Second, the teacher used reformulating by modifying or paraphrasing the question to encourage the student to answer or to make the question more understandable. "How about techniques?" and "what else?" (Lines 75 and 78), for instance, were reformulations of the main question "what do they [coaches] do every day in their team?" (line 56). Thirdly, the teacher used feedback turns to exemplify (by illustrating or clarifying by giving an example) and make the main question more. In line 76 of the above episode, the teacher mentioned "Regarding to how do they deal with each situation during the match?" as an example (of the technique that coaches use with their team).

Furthermore, the teacher noticed and repaired some mistakes in students' responses. For example, she corrected the pronunciation of the word "inspire" (line 65) through recasting. The teacher improved the student's answer constructing a more meaningful phrase or sentence (re-contextualising). For instance, in line 68, when a student answered, "they connect"; the teacher, in the follow-up turn, improved the answer by using the whole phrase "they connect every member". Similarly, in line 83, the teacher added more objects after the verb "manage" to make more meaningful sentences ("They manage procedure, timetable and positions of member in the match.”). 
In the episode, the teacher and students asked and answered questions about a business topic. However, much of the teacher's feedback focused on the language learning, for example, pronunciation, expression, and vocabulary (lines 65, 68, 71, and 83). In addition, as stated by the teachers, the questioning aimed to encourage students to think critically and speak in the target language. These show a connection between language learning and business content learning. Learning was primarily about the target language, and business content was a means to teach the language.

The questioning above illustrated how ENM students struggled to answer, and answered by short words or phrases. The teacher elicited students' answers. Especially, in follow-up/feedback turns, the teacher used some techniques such as asking further questions, reformulating questioning, exemplifying, and correcting the mistake. The students could not only learn about language (for example, pronunciation, phrases, and structures), but also subject-specific (business) content. Business content was a vehicle to teach language.

This situation also reveals that ENM students in this situation responded with short words and phrases. They did not involve much critical thinking in their answers. One of the teachers explained that:

"There are different levels of English competence [in ENM class]. Most of students follow A block [their major at high school are Mathematics, Physics, Chemistry] so they are not good at English.” (ENM teacher 4)

This explanation reveals a distinction between critical thinking in the two types of classes as a result of the different English proficiency of the students. In the next section, there is further analysis and comparison.

In brief, data from participants' beliefs and classroom observations revealed that teachers used questioning to elicit learning. Teachers often asked questions to help students to notice the target language, for instance, pronunciation, new vocabulary, and structures. Learning subject-specific content was a part of learning the target language. English major participants paid attention to academic English (such as semantics and phonetics), while English non-majors were concerned about business English. In addition, according to teachers and students, teachers gave constructive 
and straightforward feedback to teach learners. In observational data, teachers used different techniques in follow-up/feedback turns, such as further eliciting or specific questions or correcting student's mistakes.

\section{Promoting higher level thinking}

Teachers and students stated that another purpose of teacher questioning was to promote cognitive development, and teachers used questioning to guide students to think. Students thought teachers preferred cognitively demanding questions to activate student critical thinking, whereas teachers indicated that they use different types of questions to target different levels of cognition.

First of all, findings showed that teachers used questions to promote thinking at different cognitive levels. Both teachers and students reported that teachers asked different types of questions; and they categorised questions for two purposes: challenging questions for higher cognition and easy questions for lower levels.

Both teachers and students reported that teachers often used the highly cognitively demanding questions to drive students to think critically (ENM Teacher 3, EM Group 2).

ENM Teacher 3 said:

"[I] spend more time creating questions that students have to give opinions, compare, and critique."

Therefore, teachers aimed to ask open questions, for example, "why" or "how" questions, questions about comparison and contrast (EM group 2); questions about opinion and experience, questions seeking same or different perspectives from different students. (ENM Teacher 4, EM group 4).

For example, both teachers and students perceived teachers to prefer using whquestions because:

"Wh-questions such as why or how can make students think most crucially to give clear and specified answer" (EM Teacher 4). 
"Teachers asked more why-questions than what-questions. Why-questions often require more thinking, and we could learn more from why-questions." (ENM group 1)

Students reported that teachers often drove students to think critically and learn to justify their answers.

"Many difficult questions make us debate or criticize. These questions force us to see the matter from different perspectives." (EM group 4)

"The teacher often asks us to answer with reasons and argument." (EM group 2)

In contrast, the participants believed teachers used less cognitively challenging questions to target low-level students. In particular, teachers believed that less cognitively demanding questions, such as yes/no questions were "easy and not beneficial" (EM Teacher 3). However, they sometimes used these questions for a particular purpose. For example, EM teacher 1 and ENM teacher 2 reported that they used less demanding questions to target students with lower levels of English competence:

"I start by yes/no questions to make them feel comfortable to answer, then, may ask more detailed questions of where, what, when or who. These are mainly regarding information in the textbook." (ENM Teacher 3)

"Sometimes I use yes/no questions for less competent students to encourage them to be able to answer." (EM teacher 1)

Similarly, some students who considered themselves as "less-competent learners", meaning "not good at speaking English", agreed that:

"The teacher asked many answerable questions I could answer and I feel capable and engage into the lesson" (EM group 2)

However, teachers said that they were aware of cultivating deeper thinking so yes/no questions were always followed by why or how questions to elicit an explanation from 
the students (ENM Teacher 1, EM Teacher 1), and prompt more extended and more detailed answers (ENM Teacher 2).

Furthermore, to promote critical thinking, teachers argued that they used questioning to teach students to solve difficult problems and work independently. In particular, teachers reported that they used questioning as a scaffold, framework or outline, or the system of questions to help student critical thinking.

Teachers said they could use questioning to help students work more independently. For example, teachers reported using sets of detailed questions (for example, what, where, when, how, with whom) to "build a scaffold for students" to speak about general topics. The teacher emphasised that she used these wh-questions a couple of times to show students the way to deal with any broad topic:

"At last, the teacher gives another topic and teacher does not need to suggest detailed questions because students have already had a habit of talking about the topic basing on a similar system of questions." (ENM Teacher 2)

Teachers believed breaking a complicated question (open questions) into simple questions (closed) could enable students to answer. ENM Teacher 4 specified that when students had difficulty in answering an abstract question, she would simplify the questions and:

"create detailed questions like what, when, who, whom. Students could then have a framework to follow to solve the abstract questions."

Teachers said they planned to use questions systematically to promote thinking. For example, ENM Teacher 2 and ENM Teacher 3 explained that they considered making different types of question for pre-, during- and after- reading or listening activities.

"some lead-in questions for pre-listening or pre-reading are to give students general ideas about the topic.... Questions for detailed information [occur] during the task .... More critical thinking questions come later to make students discuss and reflect” (ENM Teacher 2) 
Consider questioning interactions below (EM Class 4). This was a task in the course book, relating to two companies, Potuko and Golden. The students were asked to express their opinions about the companies.

\begin{tabular}{|c|c|c|c|c|}
\hline Line & Speaker & $\begin{array}{l}\text { Utterance and } \\
\text { non-verbal data }\end{array}$ & Turns & Function/purposes \\
\hline 1 & $\mathrm{~T}:$ & $\begin{array}{l}\text { What do you think about two } \\
\text { companies? }\end{array}$ & I & Requiring information \\
\hline 2 & S: & (keeps silent) & $\mathrm{S}$ & Struggling to answer \\
\hline 3 & $\mathrm{~T}:$ & $\begin{array}{l}\text { Now, tell me what do you think } \\
\text { about them? }\end{array}$ & $\mathrm{F}$ & Repeating/formulating \\
\hline 4 & S: & (keeps silent) & $\mathrm{S}$ & Struggling to answer \\
\hline 5 & $\mathrm{~T}:$ & Are they same or different? & $\mathrm{P}$ & Requiring information \\
\hline 6 & S: & (answers in chorus): different & $\mathrm{R}$ & Giving information \\
\hline 7 & $\mathrm{~T}:$ & $\begin{array}{l}\text { Which company do you want to } \\
\text { apply for to work for? }\end{array}$ & $\mathrm{F}=\mathrm{Q}$ & $\begin{array}{l}\text { Requiring further } \\
\text { information }\end{array}$ \\
\hline 8 & S: & (answers in chorus): Potuko & $\mathrm{R}$ & Giving information \\
\hline 9 & $\mathrm{~T}:$ & Why do you choose Potuko? & $\mathrm{F}=\mathrm{Q}$ & $\begin{array}{l}\text { Requiring further } \\
\text { information }\end{array}$ \\
\hline 10 & S: & (keeps silent) & $\mathrm{S}$ & Struggling to answer \\
\hline 11 & \multirow{3}{*}{$\mathrm{T}:$} & Can you tell us what it offers you? & \multirow{3}{*}{$\mathrm{F}=\mathrm{Qs}$} & Reformulating \\
\hline 12 & & $\begin{array}{l}\text { And what is better at Potuko than } \\
\text { Golden make you choose to work } \\
\text { for Potuko Company? }\end{array}$ & & Reformulating \\
\hline 13 & & $\begin{array}{l}\text { You please (chooses S1, who is } \\
\text { raising hand) }\end{array}$ & & Choosing volunteer \\
\hline 14 & S1: & $\begin{array}{l}\text { The company works for a lot of } \\
\text { projects. I am interested in working } \\
\text { in or involving in different projects. }\end{array}$ & $\mathrm{R}$ & Giving information \\
\hline 15 & \multirow{3}{*}{$\mathrm{T}:$} & Great! & $\mathrm{F}$ & Acknowledging \\
\hline 16 & & $\begin{array}{l}\text { I agree that. The more project can } \\
\text { bring you more profit. }\end{array}$ & & Evaluating \\
\hline 17 & & $\begin{array}{l}\text { What about your opinion? (chooses } \\
\mathrm{S} 2 \text {, who is raising hand) }\end{array}$ & I & $\begin{array}{l}\text { Choosing another } \\
\text { volunteer }\end{array}$ \\
\hline \multirow[t]{2}{*}{18} & \multirow[t]{2}{*}{ S2: } & $\begin{array}{l}\text { Potuko company is bigger because } \\
\text { they have more employees and } \\
\text { projects. }\end{array}$ & \multirow[t]{2}{*}{$\mathrm{R}$} & \multirow[t]{2}{*}{ Giving information } \\
\hline & & I think they can offer better salary. & & \\
\hline 19 & \multirow{3}{*}{$\mathrm{T}:$} & Good idea! & \multirow{3}{*}{$\mathrm{F}$} & Acknowledging \\
\hline 20 & & $\begin{array}{l}\text { We all consider about salary when } \\
\text { apply to a company. }\end{array}$ & & Evaluating \\
\hline 21 & & Thank you & & Acknowledging \\
\hline
\end{tabular}

Episode 9: Using questioning to promote thinking 
The situation showed how the teacher enabled students to answer the question "what do you think about the two companies?" (line 1), which was a general question requiring a high level of cognition. After asking the question twice (lines 1 and 3), the teacher noticed the students struggled to answer, and used more detailed questions such as "Are they [the] same or different?" (line 5), and "Which company do you want to apply for?" (line 7).

These questions required students to choose between two options or asked students to state just the company name. Both questions were low-level in terms of cognition and asked students to retrieve predictable information. Therefore, students easily answered, and answered in chorus (in lines 6 and 8).

After that, the teacher asked another cognitively demanding question "Why do you choose Potuko?" (line 9). This why-question required opinion and reasoning, so students found it difficult to answer. Therefore, they kept silent (line 10). Once again, the teacher broke the difficult questions into the closed question "Can you tell us what it offers you?" (line 11) and more specifically "What is better at Potuko than Golden to make you choose to work for Potuko Company?" (line 12). These specific questions were answerable for the students because they referred directly to some information in the textbook.

Two students (S1 and S2) who answered, provided opinions and reasons for their choice to work for a company (lines 14 and 17). Observational data often recorded that students in EM classes could answer with lengthy answers, critical thinking and more complicated structures. This is in contrast with students in ENM classes, mentioned previously (Episode 8). These situations were the typical examples in EM and ENM, that illustrate that English major students demonstrate ability to answer longer and involve more critical thinking than English non-major students. This could have been because of their higher language proficiency which enabled the English major students to express complex ideas in English.

I observed that simple or closed questions required a short and one-correct answer. However, the open questions in the situation were more difficult and required a more thoughtful and reasoned answer. Furthermore, the teachers used closed and detailed questions to build a framework helping students to answer the difficult and open 
questions. These observations showed that teachers used different types of questions to activate different types of knowledge. For example, closed questions helped students to recall the previous experience. However, open questions were often used to prompt students to give opinions or draw on knowledge outside the course book.

In summary, both data from interviews and observations indicated that the important purposes of teacher questioning were to promote learners' knowledge acquisition and critical thinking. Both teachers and students also found teacher feedback could teach a lot. Regarding critical thinking, both groups thought that teachers preferred to cultivate deeper thinking by using high cognitive questions. However, teachers reported that they took account of different levels of cognition. For example, they used the less cognitively demanding questions to encourage low-level students. Teachers added that they used questions as scaffolding or framework to shape critical thinking. The observational data revealed that this was evident in their teaching practice. Moreover, a cross case analysis between English majors and English nonmajors identified some differences in language learning and critical thinking.

\section{Diagnosing learning needs}

Both teachers and students thought that teachers asked questions to evaluate learning progress. They both agreed that teachers used questioning as a diagnosis to make decisions about the next steps for teaching. Teachers added that questioning also supported students to self-assess their learning. This could make the students aware of any problem and motivate them to learn harder.

\section{Tailoring teaching}

Questioning helps teachers diagnose learning progress to tailor teaching. Using questioning enabled the teachers to diagnose their students' learning gaps, so that the teachers could offer discussion and more wait-time for extra self learning or choose the suitable questions for different levels of proficiency.

When questions were used for teacher assessment of student progress and competence, teachers and students said that teachers cared about students' learning 
progress and had strategies to encourage the students to engage in questioning. Teachers stated that:

"To have good questioning teachers need to understand students and their proficiency. So that teacher can make proper questioning." (ENM Teacher 2)

"After teaching a part of the lesson, the teacher often stops and asks some questions, for instance, 'do you understand?' or 'do you want to make any question about the part?',' (EM group 1)

In addition, teachers believed that:

"The teacher can raise various questions to understand students learning progress." (ENM Teacher 2)

These could be questions asking the student to recall prior knowledge to check whether students had finished their homework, or to check if students remembered what had been taught (ENM Teacher 4, EM Teacher 2). They could be questions to test whether students could understand what the teacher was saying, or had just been taught (ENM Teacher 1). It could be questions to check if students could apply new knowledge in practice (ENM Teacher 4). ENM Teacher 3 pointed out details of how a teacher could diagnose student competence when they engaged questioning.

"Listening to student's answers helps me to know whether students understand the lesson. Through student's pronunciation, vocabulary, or fluency, the teacher can diagnose student's English proficiency."

EM Teacher 1 also mentioned adjusting the type of question to assess the different proficiency levels of students in class:

"Not all students are at the same level. The teacher can make challenging questions to help to identify which students are more competent."

The teacher thought that answers to the questions enabled her to gather data on what the students knew so the teachers could tailor their teaching to the needs of the 
students. Teachers agreed about the importance of understanding the students' processes, since this helped them adjust their teaching.

"I ask questions to check, and if more than one student fails to answer my questions, I know that I need to go back and offer further teaching." (ENM Teacher 1).

"I make questions to know the current levels of students and based on that to deliver the lesson. If the teacher doesn't ask, the teacher may not choose an effective teaching method" (ENM Teacher 3)

Similarly, students believed that one of the reasons for teacher questioning was to understand students' learning and target their teaching.

ENM group 4, EM group 1 and EM group 4 mentioned that questioning played a role for the teacher too.

"The teacher asks questions also to see if students understand the lesson, to adjust her teaching." (ENM group 4)

"Based on student answers, the teacher can decide to teach the same part again or move on" (EM group 4)

EM group 1 had the same opinion, and added more thoughts about how teacher questioning gave insights to the teacher:

"They [teacher questions and student answers] help teacher know the attitude and psychology of students, whether the class is active, whether students love the lesson." (EM group 1)

In practice, I observed how the teachers used questioning to diagnose learning progress. The example below, in EM Class 2, illustrates how the teacher used questioning to check a student's understanding of the previous lesson. 


\begin{tabular}{|c|c|c|c|c|}
\hline Line & Speaker & $\begin{array}{c}\text { Utterance and } \\
\text { non-verbal data }\end{array}$ & Turns & Function/purposes \\
\hline \multirow{2}{*}{1} & \multirow{2}{*}{$\mathrm{T}:$} & What is postulate meaning...? & \multirow{2}{*}{ I } & \multirow{2}{*}{ Requesting information } \\
\hline & & (writes the question on board) & & \\
\hline 2 & S: & (keeps silent) & $\mathrm{S}$ & Struggling to answer \\
\hline 3 & $\mathrm{~T}:$ & $\begin{array}{l}\text { Tell me any idea about } \\
\text { postulate meaning? }\end{array}$ & $\mathrm{F}$ & Repeating question \\
\hline 4 & S: & (keeps silent) & $\mathrm{S}$ & Struggling to answer \\
\hline 5 & \multirow[b]{2}{*}{$\mathrm{T}:$} & $\begin{array}{l}\text { Have you prepared the lesson } \\
\text { today? }\end{array}$ & $\mathrm{F}$ & $\begin{array}{l}\text { Checking if students } \\
\text { prepared for lesson }\end{array}$ \\
\hline 6 & & $\begin{array}{l}\text { You can answer it if you, at } \\
\text { least, look at the heading of the } \\
\text { lesson today. }\end{array}$ & $\mathrm{P}$ & $\begin{array}{l}\text { Offering hints of where } \\
\text { students could find the } \\
\text { answer }\end{array}$ \\
\hline 7 & S: & (keeps silent) & $\mathrm{S}$ & Struggling to answer \\
\hline 8 & \multirow{4}{*}{$\mathrm{T}:$} & $\begin{array}{l}\text { If you haven't read the part. It } \\
\text { will be difficult for you to } \\
\text { understand the lesson today. }\end{array}$ & & Evaluating \\
\hline 9 & & Ok. So another question. & $\mathrm{F}$ & Changing the topic \\
\hline \multirow[t]{2}{*}{10} & & $\begin{array}{l}\text { What is the different between } \\
\text { meaning in dictionary and in- } \\
\text { context meaning? }\end{array}$ & \multirow[t]{2}{*}{ I } & \multirow[t]{2}{*}{ Requiring information } \\
\hline & & (writes the question on board) & & \\
\hline 11 & S: & (keeps silent) & $\mathrm{S}$ & Struggling to answer \\
\hline 12 & \multirow{2}{*}{$\mathrm{T}:$} & $\begin{array}{l}\text { Come on, you learnt it in } \\
\text { previous lesson. }\end{array}$ & \multirow[t]{2}{*}{$\mathrm{F}$} & Offering hints \\
\hline 13 & & Do you still remember it? & & $\begin{array}{l}\text { Asking for } \\
\text { confirmation }\end{array}$ \\
\hline 14 & S: & (keeps silent) & $\mathrm{S}$ & Struggling to answer \\
\hline 15 & \multirow{3}{*}{$\mathrm{T}:$} & $\begin{array}{l}\text { I guess we need to spend some } \\
\text { minutes to read the part again. } \\
\text { So I will give you } 10 \text { minutes to } \\
\text { read the chapter. }\end{array}$ & \multirow{3}{*}{$\begin{array}{l}\mathrm{F} / \\
\mathrm{D}\end{array}$} & Offering wait-time \\
\hline 16 & & $\begin{array}{l}\text { You can discuss this with your } \\
\text { partner after reading. }\end{array}$ & & Offering discussing \\
\hline 17 & & $\begin{array}{l}\text { I will invite some of you to } \\
\text { answer later. }\end{array}$ & & $\begin{array}{l}\text { Informing about } \\
\text { nomination }\end{array}$ \\
\hline
\end{tabular}

Episode 10: Using questioning to check students' preparation/readiness

In this situation, teachers asked some questions about how students had prepared for the new lesson (from lines 1 to 8 ) and what had been learned before (from lines 9 to 17). Based on the silence of students and the struggle of a nominated student, the teacher knew that students might not be well-prepared for the new lesson, and there might be a gap of the knowledge in previous lesson. Therefore, the teacher decided to 
offer some wait-time and pair work for students (lines 16 and 17). The teacher also informed about the nomination after the discussion (line 17), which might be a way to encourage the students to work harder.

In another situation (ENM Class 3), the teacher used questions to get to know about learner competence. She used different questioning for different learners (bold for emphasis purpose).

\begin{tabular}{|c|c|c|c|c|}
\hline Line & Speaker & $\begin{array}{c}\text { Utterance and } \\
\text { non-verbal data }\end{array}$ & Turns & Function/purposes \\
\hline 1 & \multirow{2}{*}{$\mathrm{T}$ : } & $\begin{array}{l}\text { Through this video, what do } \\
\text { you think about coach and } \\
\text { coaching? }\end{array}$ & \multirow{2}{*}{$\mathrm{I}$} & $\begin{array}{l}\text { Requesting } \\
\text { information }\end{array}$ \\
\hline 2 & & $\begin{array}{l}\text { You please? (nominates a } \\
\text { student) }\end{array}$ & & Nominating \\
\hline 3 & $\begin{array}{l}\text { Nominated } \\
\text { S1: }\end{array}$ & Coach ... play in football ... & $\mathrm{S}$ & $\begin{array}{l}\text { Struggling to answer } \\
\text { (incomplete) }\end{array}$ \\
\hline 4 & $\mathrm{~T}$ : & $\begin{array}{l}\text { Ok. who is the coach and who } \\
\text { is player here? }\end{array}$ & $\mathrm{F}$ & Eliciting \\
\hline 5 & $\begin{array}{l}\text { Nominated } \\
\text { S1: }\end{array}$ & He is coach. & $\mathrm{R}$ & Giving information \\
\hline 6 & $\mathrm{~T}$ : & $\begin{array}{l}\text { Who? The man in black or } \\
\text { the people playing football? }\end{array}$ & $\mathrm{F}$ & Asking clarification \\
\hline 7 & $\begin{array}{l}\text { Nominated } \\
\text { S1: }\end{array}$ & Man ...in black & $\mathrm{R}$ & Giving information \\
\hline \multirow{3}{*}{8} & \multirow{6}{*}{ 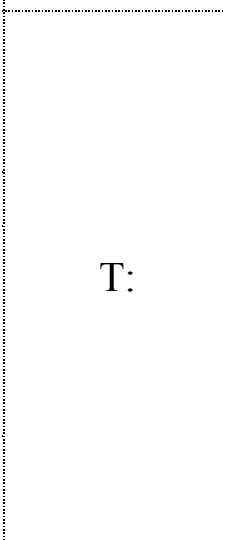 } & That's right. & \multirow{3}{*}{$\mathrm{F}$} & Acknowledging \\
\hline & & He looked funny right? & & Evaluating \\
\hline & & Thank you. & & Acknowledging \\
\hline & & $\ldots \ldots$ & & \\
\hline 9 & & $\begin{array}{l}\text { Now, another student tell me } \\
\text { about what the coach, the man } \\
\text { in black do with the team? } \\
\text { Anybody? }\end{array}$ & I & $\begin{array}{l}\text { Requesting } \\
\text { information }\end{array}$ \\
\hline 10 & & $\begin{array}{l}\text { How about you? (nominates } \\
\text { another student) }\end{array}$ & & Nominating \\
\hline 11 & $\begin{array}{l}\text { Nominated } \\
\text { S2: }\end{array}$ & $\mathrm{He}$ is training the players. & $\mathrm{R}$ & Giving info \\
\hline 12 & & Great! & $\mathrm{F}$ & Acknowledging \\
\hline 13 & $\mathrm{~T}$ : & $\begin{array}{l}\text { So do you know to be a good } \\
\text { trainer, good coach, what } \\
\text { qualities for a good coach? }\end{array}$ & $\mathrm{I}$ & Requiring further info \\
\hline 14 & $\begin{array}{l}\text { Nominated } \\
\text { S2: }\end{array}$ & $\begin{array}{l}\text { I think the coach needs some } \\
\text { knowledge about football. They } \\
\text { are good at football. }\end{array}$ & $\mathrm{R}$ & Giving information \\
\hline
\end{tabular}




\begin{tabular}{|c|c|c|c|c|}
\hline 15 & \multirow{3}{*}{$\mathrm{T}:$} & Agreed. & \multirow[b]{2}{*}{$\mathrm{F}$} & Acknowledging \\
\hline 16 & & $\begin{array}{l}\text { Good coach has to be } \\
\text { knowledgeable. }\end{array}$ & & Confirming/evaluating \\
\hline 17 & & What else? & I & $\begin{array}{l}\text { Requiring further } \\
\text { information }\end{array}$ \\
\hline 18 & $\begin{array}{l}\text { Nominated } \\
\text { S2: }\end{array}$ & $\begin{array}{l}\text { Good coach has good plan for } \\
\text { the team }\end{array}$ & $\mathrm{R}$ & $\begin{array}{l}\text { Giving further } \\
\text { information }\end{array}$ \\
\hline 19 & & Uhhuh, Right. & $\mathrm{F}$ & Acknowledging, \\
\hline 20 & $\mathrm{~T}:$ & Why? Tell me & I & $\begin{array}{l}\text { Requesting further } \\
\text { information }\end{array}$ \\
\hline 21 & $\begin{array}{l}\text { Nominated } \\
\text { S2: }\end{array}$ & $\begin{array}{l}\text { A coach should know who is } \\
\text { the good player, which position } \\
\text { is suitable. }\end{array}$ & $\mathrm{R}$ & $\begin{array}{l}\text { Giving further } \\
\text { information }\end{array}$ \\
\hline 22 & $\mathrm{~T}$ & Yeah. Well done... & $\mathrm{F}$ & Acknowledging \\
\hline
\end{tabular}

Episode 11: Using questioning according to students' competence

The questions in this sequence explored what the students understood about a coach or coaching. Two students were nominated to engage in the questioning. The teachers directed different types of questions to each of them, closed and optional questions for the first student, and open questions for the second one. In the stimulated recall interview, the teacher explained why she used different questioning for students of different levels. Listening to the answers, she discerned that the first students nominated might be at a lower level, so she decided to ask some simple questions such as optional questions (lines 4 and 6) to enable the students to answer. For the second student, the teacher guessed this student would be more competent. Therefore she adjusted questioning by asking further high-cognitive questions, which encouraged reasoning (lines 13, 17 and 20) to cultivate the student's thinking.

\section{Self-assessing learning}

According to teachers, questioning was not only a tool for a teacher to assess student's learning progress, but it was also a tool for students to self-assess their learning. Questioning for self-assessment might promote student learning (ENM Teacher 3 and ENM Teacher 4).

ENM Teacher 2 noticed that through answering questions students were able to assess their competence and learning progress. If students found it difficult to answer, students could realise that there was a gap in their knowledge. It could be lack of 
vocabulary, or poor pronunciation or some mistake. This self-recognition was meaningful for students because it could motivate them to study harder. ENM Teacher 3 proposed some questions that could push the student to think about their proficiency seriously.

"Sometimes I make some questions to let students self-assess. For example: Are you happy with your answer? Do you think your answer is good enough? I want students to know and self-assess their own answer so that they can self-correct or have the chance to clarify their difficulties."

The teachers said they used questioning to help students assess their own learning process. The teachers thought that for students, understanding their own strengths and weaknesses could motivate them to learn.

Both teachers and students perceived that teachers used questioning to enrich their understanding of students' learning in order to better teaching. Furthermore, the teachers believed that questioning provided a diagnosis for students to understand learning progress.

To sum up, another role of questioning that most teachers mentioned was that it helped teachers assess student learning progress or competence. Also, teachers thought that the questioning could help students assess their own progress. Observational data supported the premise that teachers used questioning to understand learners' progress to better inform their teaching in the future.

\section{Managing learning}

One of the main purposes the participants often mentioned was how the teachers acted in managing the classroom by using questioning. Teachers stated that they used this kind of questioning to organise classroom activities. In addition, both teacher and students were aware that teachers often used questioning to improve the students' attitudes towards learning. The questioning for management, sometimes, did not primarily aim to foster learning. However, this questioning type was useful to improve student performance and their attitude towards learning. 


\section{Organising classroom activities}

Teachers believed that they used questions to manage classroom activities. The teachers said one of the common aims of questioning was to direct group work. ENM Teacher 2 stated that:

"The teacher needs to control group work, because students might not effectively work in groups or pairs." (ENM Teacher 2)

Therefore, the teachers often approached each group and asked questions to make sure that students focused on their work. ENM Teacher 4 explained the importance of the teacher in monitoring student group work. She said that teachers needed to observe the group and use questions, firstly, to orient the group discussion and ensure that it followed the right track. Secondly, to check for understanding (such as "Do you understand? Are there any questions?') to see if students needed any help. Thirdly, to guide students to prepare for presentations.

"Students don't know how to delegate roles to each other, so I need to make some questions like 'who will be the presenter? who is the secretary noting down ideas when you discuss?"' (ENM Teacher 4)

These kinds of questions, according to the teacher, were used to direct the task:

"these questions are to make them work efficiently and reduce passing responsibility to others to go to the board and make a presentation" (ENM Teacher 4)

Inviting students to work in groups and pairs was one of the most useful techniques for EFL classes according to the teachers. They believed that creating teamwork provided students with more time to think and students could help each other to prepare a better answer.

The situations in this part focus on how teachers use questions to monitor students in teamwork and the pedagogical motivation behind this kind of questioning. 
In the following situation (ENM Class 3), the teacher used questions to get to know the topic the group was discussed.

\begin{tabular}{|c|c|c|c|c|}
\hline Line & Speaker & $\begin{array}{l}\text { Utterance and } \\
\text { non-verbal data }\end{array}$ & Turns & Function/purposes \\
\hline 1 & $\mathrm{~T}$ : & What are you talking about? & $\mathrm{I}=\mathrm{Q}$ & $\begin{array}{l}\text { Requiring } \\
\text { information }\end{array}$ \\
\hline 2 & S1: & $\begin{array}{l}\text { Question 2, what make good } \\
\text { coaches. We talk about good } \\
\text { coach should have much special } \\
\text { knowledge. }\end{array}$ & $\mathrm{R}$ & Giving information \\
\hline 3 & $\mathrm{~T}:$ & $\begin{array}{l}\text { What do you mean by special } \\
\text { knowledge? }\end{array}$ & $\mathrm{F}=\mathrm{Q}$ & $\begin{array}{c}\mathrm{F} \text { (Requiring further } \\
\text { explanation) }\end{array}$ \\
\hline 4 & S2: & $\begin{array}{l}\text { It means suitable knowledge or } \\
\text { understanding. }\end{array}$ & $\mathrm{R}$ & Providing information \\
\hline 5 & \multirow[t]{2}{*}{$\mathrm{T}:$} & $\begin{array}{l}\text { Uhhum. I know what you mean } \\
\text { but can you find another way to } \\
\text { explain it? }\end{array}$ & \multirow{2}{*}{$\mathrm{F}=\mathrm{Q}$} & $\begin{array}{l}\text { Requiring further } \\
\text { explanation, }\end{array}$ \\
\hline 6 & & $\begin{array}{l}\text { For example...? give example } \\
\text { of special knowledge? }\end{array}$ & & $\begin{array}{l}\text { Suggesting giving } \\
\text { exemplification }\end{array}$ \\
\hline 7 & S2: & $\begin{array}{l}\text { Managing skill, communicative } \\
\text { skill. }\end{array}$ & $\mathrm{R}$ & Giving examples \\
\hline 8 & $\mathrm{~T}:$ & Good. Let's continue. & $\mathrm{F}$ & $\begin{array}{l}\text { Acknowledging and } \\
\text { encouraging }\end{array}$ \\
\hline
\end{tabular}

Episode 12: Using questioning to check and direct group work

In Episode 12, the teacher started the discussion by asking a general question about what the students were discussing (line 1). The next follow-up turn (line 3), was a question to encourage the students to clarify a point that the student did not clearly state. Especially, in lines 5 and 6, "I know what you mean but can you find another way to explain it? For example...? Give example of special knowledge?" The teacher suggested students gave exemplification to make their points clear. These questions, for students, functioned as information requests, which helped their thinking.

However, the teacher also used the questions to check how the group was working and to direct the students to work more effectively. Another example of the teacher communicating with a group is below (EM teacher 2). 


\begin{tabular}{|c|c|c|c|c|}
\hline Line & Speaker & $\begin{array}{c}\text { Utterance and } \\
\text { non-verbal data }\end{array}$ & Turns & Function/purposes \\
\hline 1 & $\mathrm{~T}$ & How are you now? & $\mathrm{I}=\mathrm{Q}$ & $\begin{array}{c}\text { Requesting } \\
\text { information } \\
\text { (Managing reason) }\end{array}$ \\
\hline 2 & S: & We are still working. & $\mathrm{R}$ & Giving information \\
\hline 3 & $\mathrm{~T}:$ & $\begin{array}{l}\text { What have you discussed about } \\
\text { the topic? }\end{array}$ & $\mathrm{F}$ & $\begin{array}{l}\text { Requesting } \\
\text { information }\end{array}$ \\
\hline 4 & Ss: & (keep silent) & S & Struggling to answer \\
\hline 5 & $\mathrm{~T}$ : & $\begin{array}{l}\text { Ok. Who write down ideas you } \\
\text { discuss? }\end{array}$ & $\mathrm{F}$ & $\begin{array}{c}\text { Requiring } \\
\text { information } \\
\text { (Managing reason) }\end{array}$ \\
\hline 6 & Ss: & (keep silent) & $\mathrm{S}$ & Struggling to answer \\
\hline 7 & $\mathrm{~T}:$ & $\begin{array}{l}\text { Who will be the presenter? Have } \\
\text { you decided yet? }\end{array}$ & $\mathrm{F}$ & $\begin{array}{c}\text { Requiring } \\
\text { information } \\
\text { (Managing reason) }\end{array}$ \\
\hline 8 & S: & No & $\mathrm{R}$ & Giving information \\
\hline 9 & & You have to choose. & & Suggesting \\
\hline 10 & $\mathrm{~T}$ : & $\begin{array}{l}\text { Now, discuss more and later I'll } \\
\text { call one of you come to talk in } \\
\text { front of the class }\end{array}$ & $\mathrm{F}$ & $\begin{array}{l}\text { Informing about } \\
\text { nomination }\end{array}$ \\
\hline
\end{tabular}

Episode 13: Using questioning to organise group members

In this situation, the teacher started by asking a management question (line 1) to know how students were doing, and later in every follow-up turn (in lines 5 and 7) the teacher asked other managerial questions to organise how members worked in the group. However, the main purpose of these questions was "to help students to share the mission in the team and make one of representative ready to talk in front of the class" (EM Teacher 2). In the last follow-up turn, the teacher informed about nomination also to encourage the students to work more effectively in the group (line $10)$.

Observation data reveals other examples of questioning aiming at organising. The following episode occurred after the teacher gave students numbers to decide the order of their turns. 


\begin{tabular}{|c|c|c|c|c|}
\hline Line & Speaker & $\begin{array}{c}\text { Utterance and } \\
\text { non-verbal data }\end{array}$ & Turns & Function/ purposes \\
\hline 1 & $\mathrm{~T}:$ & $\begin{array}{l}\text { Please let me know which } \\
\text { number do you have? }\end{array}$ & I & $\begin{array}{l}\text { Requesting } \\
\text { information }\end{array}$ \\
\hline 2 & S1: & Number two. & $\mathrm{R}$ & Giving information \\
\hline 3 & \multirow[b]{2}{*}{$\mathrm{T}:$} & Ok. & $\mathrm{F}$ & Acknowledging \\
\hline 4 & & $\begin{array}{l}\text { (talks to another) What about } \\
\text { you? }\end{array}$ & I & $\begin{array}{l}\text { Requesting } \\
\text { information }\end{array}$ \\
\hline 5 & S2: & We are number three. & $\mathrm{R}$ & Giving information \\
\hline 6 & $\mathrm{~T}:$ & $\begin{array}{l}\text { (talks to the last group) And } \\
\text { you? You must be number } 1 ? \\
\text { Right? }\end{array}$ & I & $\begin{array}{l}\text { Requesting } \\
\text { information }\end{array}$ \\
\hline 7 & S3: & 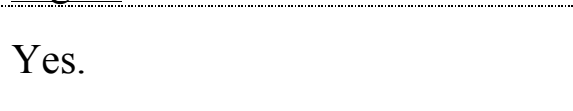 & $\mathrm{R}$ & $\begin{array}{l}\text { Confirming/Giving } \\
\text { information }\end{array}$ \\
\hline 8 & \multirow[b]{2}{*}{$\mathrm{T}:$} & Ok. & \multirow[b]{2}{*}{$\mathrm{F}$} & Acknowledging \\
\hline 9 & & $\begin{array}{l}\text { So now it is your order. Group } \\
\text { number one will answer first, } \\
\text { then group } 2 \text { and the last is } \\
\text { group } 3 .\end{array}$ & & Directing \\
\hline
\end{tabular}

Episode 14: Questioning to manage classroom activities

In Episode 14, the teacher, in the initiation in line 1, requested the students to tell her which number they had to decide the students' turn to do a task. In short, the initial question was an information request for a managerial reason.

In addition, I frequently observed teachers using questions to give students directions or instructions. An example from ENM Class 1 is below.

\begin{tabular}{|c|c|l|c|c|} 
Line & Speaker & $\begin{array}{c}\text { Utterance and } \\
\text { non-verbal data }\end{array}$ & Turns & Function/ purposes \\
\hline 1 & $\mathrm{~T}:$ & $\begin{array}{l}\text { How about the last table? Could } \\
\text { you move to this side? }\end{array}$ & $\mathrm{I}$ & Directing \\
\hline 2 & $\mathrm{~S}:$ & $\begin{array}{l}\text { (at last table, stand up and } \\
\text { move) }\end{array}$ & $\mathrm{R}$ & Doing \\
\hline 3 & $\mathrm{~T}:$ & Good! Thank you. & $\mathrm{F}$ & Acknowledging \\
\hline
\end{tabular}

Episode 15: Using questioning as direction or instruction

These questions giving directions typically had the structures of suggestions such as 'How about...?' or 'Could/can you....?' (line 1). The questions often indicated a command despite the question-form. In the above example, the teacher question was to ask students to move to manage the proper position of the whole class. The reaction 
from the students was a non-verbal response; they moved following the teacher direction. This questioning focused on organizing student seating to prepare for learning activities.

\section{Improving learning behaviour}

To encourage learning behaviour and attitude, teachers used questioning to grab students' attention and make students more accountable for their learning, and gave bonus marks to motivate engagement.

Firstly, managing student behaviours was achieved by attracting students' attention. Both teachers and students stated that teachers sometimes used questions to make students stay focused on the lesson:

"I was very sleepy, and I think the teacher knew that so she asked me questions to wake me up." (ENM group 1)

This strategy was confirmed by the teachers.

"When someone seems to be sleepy or losing interest, I could make questions like 'what do you think about... [the topic]' or 'do you agree with the previous answer"" (ENM Teacher 2)

Teachers, for the same purpose, used the technique of nominating any student that they thought was not paying attention to the lesson.

"if students are chatting privately, I will call the students to answer some simple questions instead of saying 'stop talking privately.' It is a gentle way to remind them and make them focus on the lesson" (ENM Teacher 3)

Furthermore, both teacher and student participants said teachers used questioning to motivate students and make them more accountable for learning. Teachers and students believed that the teachers' questioning was intended to make the students responsible for contributing to the lesson. For example, students noticed that teachers asked questions to stir-up the atmosphere in class: 
"We notice that when the classroom is quiet, the teacher often asks questions. Indeed, the teacher asking questions makes us involved and excited and willing to contribute to the lesson." (EM group 4)

Teachers suggested that asking questions made students prepare themselves to respond.

"Students often work harder to find at least an answer because they know that it is a sign that someone is being called to stand up." (EM Teacher 3)

They felt that this tactic worked best when they asked the question unexpectedly or loudly:

"I have a habit of asking questions suddenly and nominating students randomly. My students are familiar with that. It teaches them to have a quick reaction, and it keeps students alert and fully concentrated on the lesson." (ENM Teacher 1)

Students revealed how questions made them take responsibility for their learning:

"The teacher asks more than one student to answer one question. Therefore, I have to focus and listen to what the teacher asks, what other students answer. Just because I may be the next person answering the question” (ENM group 3)

Teachers would repeat questions to encourage students to answer. For instance, in the situation in ENM Class 1 the teacher asked a lot of questions, raising three or four questions at once.

\begin{tabular}{|c|c|c|c|c|}
\hline Line & Speaker & $\begin{array}{c}\text { Utterance and } \\
\text { non-verbal data }\end{array}$ & Turns & Function/purposes \\
\hline 1 & $\mathrm{~T}:$ & $\begin{array}{l}\text {...A system when materials are } \\
\text { supplied to producing process } \\
\text { just in time when they are } \\
\text { needed. So what's the purpose } \\
\text { of just in time? Or what is the } \\
\text { advantage of this system? Can } \\
\text { anyone explain it for me? Why } \\
\text { do we have just in time } \\
\text { (materials)? }\end{array}$ & $\mathrm{I}=\mathrm{Q}$ & $\begin{array}{l}\text { Requesting } \\
\text { information }\end{array}$ \\
\hline 2 & S1: & To keep the cost down. & $\mathrm{R}$ & Giving information \\
\hline 3 & $\mathrm{~T}:$ & $\begin{array}{l}\text { So how can it keep the cost } \\
\text { down? }\end{array}$ & $\mathrm{F} / \mathrm{I}=\mathrm{Q}$ & $\begin{array}{l}\text { Requesting further } \\
\text { information }\end{array}$ \\
\hline
\end{tabular}




\begin{tabular}{|c|c|c|c|c|}
\hline 4 & S1: & (keeps silent) & $\mathrm{S}$ & Struggling to answer \\
\hline 5 & \multirow{3}{*}{$\mathrm{T}:$} & $\begin{array}{l}\text { How can just in time help us to } \\
\text { keep the cost down? }\end{array}$ & \multirow{3}{*}{$\mathrm{F}=\mathrm{Q}$} & $\begin{array}{l}\text { Requesting } \\
\text { information }\end{array}$ \\
\hline 6 & & $\begin{array}{l}\text { How can it help to keep the cost } \\
\text { down? }\end{array}$ & & Repeating question \\
\hline 7 & & Any more explain to us? & & Reformulating \\
\hline 8 & $\mathrm{~S} 2:$ & $\begin{array}{l}\text { Because the cost for storage of } \\
\text { the product is reduced. }\end{array}$ & $\mathrm{R}$ & Giving information \\
\hline 9 & \multirow{3}{*}{$\mathrm{T}$ : } & $\begin{array}{l}\text { Um hu. Alright. (writes on } \\
\text { board "storage"). }\end{array}$ & $\mathrm{F}$ & Acknowledging. \\
\hline 10 & & $\begin{array}{l}\text { We know that when we store } \\
\text { product, definitely we need } \\
\text { money, we need time and } \\
\text { worker labour to maintain. So } \\
\text { when we limit the time of } \\
\text { product being kept in } \\
\text { warehouse, the cost will go } \\
\text { down. }\end{array}$ & & Explaining \\
\hline 11 & & $\begin{array}{l}\text { One more reason? Storage is } \\
\text { just one reason. One more } \\
\text { important reason? (emphasis on } \\
\text { "more important") }\end{array}$ & $\mathrm{I}=\mathrm{Q}$ & Repeating questions \\
\hline 12 & S3: & $\begin{array}{l}\text { We can reduce the } \\
\text { transportation. }\end{array}$ & $\mathrm{R}$ & Giving information \\
\hline 13 & \multirow[t]{2}{*}{$\mathrm{T}:$} & $\begin{array}{l}\text { Yes, transportation. Well done. } \\
\text { (writes "transportation" on } \\
\text { board) }\end{array}$ & $\mathrm{F}$ & Acknowledging \\
\hline 14 & & One more thing? & I & $\begin{array}{l}\text { Requesting further } \\
\text { information }\end{array}$ \\
\hline 15 & Class: & (keeps silent) & S & Struggling to answer \\
\hline 16 & $\mathrm{~T}:$ & $\begin{array}{l}\text { As crucial as deposit they have } \\
\text { to keep .... (looks around) }\end{array}$ & $\mathrm{P}$ & Prompting \\
\hline 17 & Class & (keeps silent) & $\mathrm{S}$ & Struggling to answer \\
\hline 18 & $\mathrm{~T}:$ & $\begin{array}{l}\text { And just in time make it } \\
\text { possible. It is about money. }\end{array}$ & $\mathrm{P}$ & Prompting/ eliciting \\
\hline 19 & S4: & $\begin{array}{l}\text { We can sell it cheaper price if } \\
\text { we can reduce the cost. }\end{array}$ & $\mathrm{R}$ & Giving information \\
\hline 20 & \multirow{3}{*}{$\mathrm{T}$ : } & $\begin{array}{l}\text { That's a good idea. I mean } \\
\text { different idea about money. But } \\
\text { it is a good idea. (writes } \\
\text { "cheaper price" on board) }\end{array}$ & $\mathrm{F}$ & Acknowledging \\
\hline 21 & & Another idea? & I & $\begin{array}{l}\text { Requesting } \\
\text { information }\end{array}$ \\
\hline 22 & & $\begin{array}{l}\text { Also about money and It starts } \\
\text { with letter C...? }\end{array}$ & $\mathrm{P}$ & Prompting/eliciting \\
\hline 23 & S5: & Capital. & $\mathrm{R}$ & Giving information \\
\hline
\end{tabular}




\begin{tabular}{|c|c|c|c|c|}
\hline 24 & & $\begin{array}{l}\text { Thank you (writes the word } \\
\text { "capital" on board). }\end{array}$ & & Acknowledging \\
\hline 25 & $\mathrm{~T}:$ & $\begin{array}{l}\text { We know that when we don't } \\
\text { store materials, the assets can be } \\
\text { sold in market without affecting } \\
\text { the price. It's easier, the } \\
\text { liquidity of the fund. It is easier. } \\
\text { If we store a lot of things, we } \\
\text { don't have capital or money to } \\
\text { buy CL products or invest into } \\
\text { anything else. Right? So this is } \\
\text { the benefit of just in time. }\end{array}$ & $\mathrm{F}$ & $\begin{array}{l}\text { Explaining/ } \\
\text { Evaluating }\end{array}$ \\
\hline
\end{tabular}

Episode 16: Questioning for engagement

The teacher asked a series of questions that referred to same points.

"So what's the purpose of just in time? Or what is the advantage of this system?

Can anyone explain it for me? Why do we have just in time (material)?" (line 1)

"How just in time help us to keep the cost down? How it help to keep the cost down? Any more explain to us? " (lines 5, 6 and 7)

"One more reason? Storage is just one reason. One more important reason?" (line 11)

The ENM Teacher 1 explained that these rapid questions helped students concentrate on the lesson. She asked a lot of questions, raised three or four questions at once, or posed provocative questions to inspire students to answer. The teacher said that she repeated questions to urge the students answer when the classroom was quiet:

"I repeated the question, said it, again and again, to warm up the atmosphere, and to encourage students to respond" (ENM Teacher 1)

Furthermore, I observed that, in questioning, teachers often used statements with some discourse markers with such as "OK?" "Right?" "Alright?" with a rising tone which made them become questions. The teacher used this type of question in EM Class 2.

"Try to discuss all exercises with your friend, ok?" 
"she has the word /piza/ in Vietnamese, right?"

"You pronounce the word wrongly, you recognize the word wrongly. You identify the word wrongly, you focus on the word wrongly, right?"

Or teacher in ENM Class 4 said:

"What does "breakthrough" mean? Dot pha! Dot pha! Right? Creating something new. Is it right? To make an important discovery, OK?

So have you got all of these, right? Understand? OK. Any question?"

The teachers were aware that they sometimes added these discourse markers at the end of statements with a questioning intonation. The teachers thought that these statements in question form sent the message that the teachers were calling for attention from students.

Teachers and students agreed that teachers often used questioning including nominating students to maintain students' concentration when the students were distracted. In practice, teachers used other techniques too, such as using discourse markers to make statement become questions, posing many questions and repeating questions to keep students alert.

Furthermore, participants believed grading students' participation in questioning routines was another way to motivate learning engagement. Teachers and students reported that EFL teachers often used grading to reward or punish/fine/penalise. Grades and rewards, in this study, were used by the teachers to foster engagement. The teachers had a clear plan of the method and proportion of the bonus points that were given:

"The teacher could grade students with 20\% for contribution and engagement in the classroom. I use this proportion for allocating bonuses to students." (ENM Teacher 3)

Teachers said grading was a reward for good answers: 
"I use bonuses to encourage students to answer high cognitive questions. If students have good answers, they deserve to have a bonus." (EM Teacher 4)

Penalty points were also used with recall questions about the content that teachers thought students should remember:

"Those questions were about their homework. I give them minus to remind them to review the old lessons before going to the class" (EM Teacher 1)

The situations below showed how teachers used grading within questioning. The first example was a teacher grading as a reward to encourage engagement.

\begin{tabular}{|c|c|c|c|c|}
\hline Line & Speaker & $\begin{array}{c}\text { Utterance and } \\
\text { non-verbal data }\end{array}$ & Turns & Function/purposes \\
\hline 1 & $\mathrm{~T}$ : & So who arrived late? & I & $\begin{array}{c}\text { Requesting } \\
\text { information } \\
\text { (managing reason) }\end{array}$ \\
\hline 2 & S: & (Some students raise hands) & $\mathrm{R}$ & $\begin{array}{l}\text { Giving information } \\
\text { (non-verbal) }\end{array}$ \\
\hline 3 & \multirow{5}{*}{$\mathrm{T}:$} & $\begin{array}{l}\text { Some of you will get an } \\
\text { attendance check if you can } \\
\text { answer my questions........ }\end{array}$ & $\mathrm{F}$ & $\begin{array}{l}\text { Offering } \\
\text { bonus/attendance } \\
\text { mark }\end{array}$ \\
\hline 4 & & $\begin{array}{l}\text { Listen to the first part of the } \\
\text { conversation and tell me where } \\
\text { they might be }\end{array}$ & \multirow{4}{*}{$\mathrm{I}$} & Introducing the task \\
\hline & & (Plays the recording) & & \\
\hline 5 & & Ok? Tell me where are they? & & Requiring information \\
\hline 6 & & $\begin{array}{l}\text { You, please. (invites a student } \\
\text { raising hand) }\end{array}$ & & $\begin{array}{l}\text { Choosing } \\
\text { volunteering student }\end{array}$ \\
\hline 7 & S1: & They are at the airport & $\mathrm{R}$ & Giving information \\
\hline 8 & $\mathrm{~T}:$ & Why do you think so? & $\mathrm{F}$ & $\begin{array}{l}\text { Requiring further } \\
\text { information }\end{array}$ \\
\hline 9 & S1: & $\begin{array}{l}\text { They said they have done } \\
\text { check-out and wait for luggage }\end{array}$ & $\mathrm{R}$ & $\begin{array}{l}\text { Providing further } \\
\text { information }\end{array}$ \\
\hline 10 & \multirow[b]{2}{*}{$\mathrm{T}:$} & That's correct. & \multirow[b]{2}{*}{1} & Acknowledging \\
\hline 11 & & Did you arrive late today? & & $\begin{array}{l}\text { Requiring information } \\
\text { (managing reason) }\end{array}$ \\
\hline 12 & S1: & Yes. & $\mathrm{R}$ & Giving information \\
\hline 13 & \multirow[t]{2}{*}{$\mathrm{T}:$} & $\begin{array}{l}\text { It is your lucky day. I will } \\
\text { forgive and you got the } \\
\text { attendance check today. }\end{array}$ & \multirow[t]{2}{*}{$\mathrm{F}$} & \multirow[t]{2}{*}{$\begin{array}{l}\text { Offering bonus/ } \\
\text { attendance mark }\end{array}$} \\
\hline 14 & & Now, the second question.... & & \\
\hline
\end{tabular}

Episode 17: Teacher's grading as a reward 
The second was how teachers used grading as punishment for poor preparation.

\begin{tabular}{|c|c|c|c|c|}
\hline Line & Speaker & $\begin{array}{c}\text { Utterance and } \\
\text { non-verbal data }\end{array}$ & Turns & Function/ purposes \\
\hline 1 & $\mathrm{~T}:$ & $\begin{array}{l}\text { So what was the homework I } \\
\text { gave you last time? }\end{array}$ & I & $\begin{array}{c}\text { Requesting } \\
\text { information } \\
\text { (managing reason) }\end{array}$ \\
\hline 2 & Ss: & (keeps silent) & $\mathrm{S}$ & Struggling to answer \\
\hline 3 & \multirow[b]{2}{*}{$\mathrm{T}:$} & $\begin{array}{l}\text { What was the homework I gave } \\
\text { you last time? }\end{array}$ & $\mathrm{F}$ & $\begin{array}{l}\text { Repeating to request } \\
\text { information }\end{array}$ \\
\hline 4 & & $\begin{array}{l}\text { (talks to one of student) Where } \\
\text { is your course book? }\end{array}$ & I & $\begin{array}{c}\text { Requesting } \\
\text { information } \\
\text { (managing reason) }\end{array}$ \\
\hline 5 & The S: & I don't have. & $\mathrm{R}$ & Giving information \\
\hline 6 & $\mathrm{~T}:$ & Why? & $\mathrm{F}=\mathrm{Q}$ & $\begin{array}{l}\text { Requesting further } \\
\text { information }\end{array}$ \\
\hline 7 & The S: & I forgot it at home. & $\mathrm{R}$ & Giving information \\
\hline 8 & $\mathrm{~T}:$ & So what's your name? & $\mathrm{F}=\mathrm{Q}$ & $\begin{array}{l}\text { Requesting further } \\
\text { information }\end{array}$ \\
\hline 9 & The S: & Linh. & $\mathrm{R}$ & Giving information \\
\hline 10 & \multirow{3}{*}{$\mathrm{T}$ : } & Linh. OK. & $\mathrm{F}$ & Confirmation \\
\hline \multirow[t]{2}{*}{11} & & $\begin{array}{l}\text { (talks to the whole class) One of } \\
\text { the requirements is that you } \\
\text { have to bring your course book } \\
\text { along with you. And you have to } \\
\text { finish homework. }\end{array}$ & \multirow[t]{2}{*}{ I } & \multirow[t]{2}{*}{$\begin{array}{c}\text { Requesting } \\
\text { information } \\
\text { (managing reason) }\end{array}$} \\
\hline & & Otherwise I will give you a...? & & \\
\hline 12 & Ss: & (in chorus) Minus & $\mathrm{R}$ & Giving information \\
\hline \multirow{2}{*}{13} & \multirow{3}{*}{$\mathrm{T}:$} & Minus.Minus from your mark. & & Confirming \\
\hline & & remember that. & $\mathrm{F}$ & \\
\hline 14 & & Remember? & I & $\begin{array}{l}\text { Asking for } \\
\text { confirmation }\end{array}$ \\
\hline 15 & Ss: & (loudly in chorus) Yes. & $\mathrm{R}$ & Confirming \\
\hline 16 & \multirow[b]{2}{*}{$\mathrm{T}$ : } & $\begin{array}{l}\text { So the homework I give you last } \\
\text { time in lesson two. }\end{array}$ & $\mathrm{F}$ & Adding information \\
\hline 17 & & Have you completed it? & I & $\begin{array}{c}\text { Requesting } \\
\text { information } \\
\text { (managing reason) }\end{array}$ \\
\hline 18 & Ss: & (in chorus) Yes & $\mathrm{R}$ & Giving information \\
\hline 19 & $\mathrm{~T}:$ & Yes. Good. & $\mathrm{F}$ & Acknowledging \\
\hline
\end{tabular}

Episode 18: Teacher using grades as a punishment

The teacher took away points to remind students to bring the course book and do their homework. 
Data revealed that the teachers used rewarding or grading, within questioning, as a tactic to foster students' performance. However, teachers and students had different opinions about whether using grading could effectively promote engagement. According to teachers, bonuses and penalty marks were useful to motivate the students' learning attitudes and engagement. The teachers said that:

"when the teacher promises to give a grading bonus for the questions, students become excited to volunteer and raise hands. " (ENM Teacher 3)

"I use bonus marks to stir-up the atmosphere. It could create a healthy competition among students. They compete to take turns to answer." (EM Teacher 1)

They agreed that this strategy worked well because most of the students cared greatly about grades:

"Students always want to get good grades. If they know that the questions have a bonus, they will use all their ability, searching, discussing, thinking, to answer as well as they can." (EM Teacher 4)

There were two alternative attitudes towards teacher rewards, as students had different opinions about grading as motivation or demotivation. Some students such as ENM group 1, and ENM group 4 stated:

"Many students, especially who highly think about the grade, want questions with a bonus. I think it is necessary if my exam grade is low, good performance in classroom can improve my grade. I think it is a good motivation." (ENM group 1)

"The questions are often to review previous lessons. We all want to obtain the high marks, and all are afraid of losing marks." (ENM group 4)

EM group 2 gave reasons why they prefer questions with bonus points: 
"The teacher marking us for what we perform in class is fair and even assesses exactly our ability. Because sometimes, we had the bad luck to receive low marks in the final examination."

EM group 3 and EM group 4 also agreed that they become more active and volunteered to respond whenever the teacher promised to give a bonus,

"We often like questions with bonus and compete to respond.” (EM group 3)

"Whenever the teacher states that the questions are with bonus, the class becomes exciting. The teacher doesn't need to nominate students; we volunteer to answer." (EM group 4)

Whereas some others said:

"Promising bonus makes learning too competitive and extrinsically motivated: (ENM group 1)

"Teachers may threaten or warn students if they don't respond. This makes me upset, and I don't want to answer teacher's question." (ENM group 3)

A student stated how he felt after the teacher gave him a minus point when he could not answer the question well enough:

"The teacher criticized and gave me a minus grade. The teacher assumed that I did not prepare for the lesson or review the old lesson. This makes I feel not fair and don't want to contribute to the lesson." (EM group 1)

Because some thought answering to receive a reward was not always effective, some students suggested that:

"The way of giving bonus should be considered. For example, after students answer, the teacher gives bonus; the teacher shouldn't mention about the bonus before students answer." (ENM group 1)

Some students had different opinions about whether using bonuses was a type of extrinsic motivation (ENM group 1 and ENM group 3), or threats could make 
students uncomfortable (EM group 1). However, teachers and the majority of students agreed that students cared a great deal about grades, therefore, these bonuses and threats worked to motivate students to engage in answering teacher questions.

Teachers and students viewed questions as a way to push students to engage and become more accountable for their own learning. Data in interviews and observations indicated that teachers encouraged learning behaviour by using nomination, repeating questions, and giving students a bonus or minus mark for their answers. Sometimes participants held different opinions about whether these techniques could be motivation or pressure for students. Both teachers and students agreed that students became more alert and engaged through the use of questions.

In brief, according to the teachers and students, questioning was a managerial tool helping to organise classroom activities and learning attitudes and behaviours. In particular, both agreed that the teachers used questions to make students focus on the lesson. Bonus mark questions also made students engage and take responsibility for learning. When managing students in group work, teachers reported that teacher questions could help them to orient students and manage member responsibility. I observed that teachers often used questioning to direct group work. Furthermore, observational data showed teachers using questioning to organise, for example, student position or speaking turns.

\section{Lubricating agent}

According to teachers and students, building relationships was another common reason for using questioning. Good relationships could facilitate teaching and learning like the lubricating agent for an engine. Participants believed in the importance of developing rapport and respect between teacher and student.

\section{Building rapport}

Teachers and students mentioned how teachers used question-answering interactions to create a harmonious relationship between the teacher and the students. In particular, teachers and students agreed that good relationships meant they understood each other: 
"the teacher becomes closer to and more friendly with students. The teacher understands student more” (EM group 1)

In ENM Teacher 4's opinion, teacher questions could provide a chance for teacher and students to develop relationships:

"asking and answering make the teacher and students emotionally closer to each other."

Even if:

"the questions are not necessarily related to the lesson content" (ENM Teacher 4)

Teachers gave some examples of such non-content-related questions such as "How is your day today? Are you happy with the final exam?", and these sorts of questions often happened at the beginning of the lesson to build harmony or to make the students feel relaxed after the previous lessons and prepared for the new one. The teachers emphasised that:

"sometimes I use fun questions to entertain students. I am not so severe to only make academic and content-based questions. I just aim to make a happy and comfortable atmosphere” (EM Teacher 3)

The below episode (ENM Class 4) was used in stimulated recall interview, as an example of how the teacher used questioning to build rapport.

\begin{tabular}{|c|c|c|c|c|}
\hline Line & Speaker & $\begin{array}{c}\text { Utterance and } \\
\text { non-verbal data }\end{array}$ & Turns & Function/ purposes \\
\hline 1 & $\mathrm{~T}:$ & How is everyone today? & $\mathrm{I}$ & $\begin{array}{c}\text { Requesting } \\
\text { information }\end{array}$ \\
\hline 2 & $\mathrm{~S}:$ & $\begin{array}{l}\text { It is hot. } \\
\text { Giving information }\end{array}$ \\
\hline 4 & & $\begin{array}{l}\text { It is like summer today, right? } \\
\text { It is hotter and hotter. }\end{array}$ & $\mathrm{R}$ & Acknowledging \\
\hline 5 & $\mathrm{~T}:$ & $\begin{array}{l}\text { But I hope that you will get } \\
\text { familiar with it, and it doesn't } \\
\text { affect your learning. }\end{array}$ & $\mathrm{F}$ & Evaluating \\
\hline
\end{tabular}

Episode 19: Questioning to build rapport 
This was at the beginning of the lesson. The teacher said that she asked the question to greet students and make the students feel comfortable before the lesson (for emotional/social reasons). The teacher also added:

“Some conversations about students' life, health or recent examination are good to make a good relationship with them” (ENM Teacher 4)

Both teachers and students agreed that a good relationship could promote teaching and learning.

Teachers (EM teacher 2, EM Teacher 4) reported that questions were a "stone that kills two birds" (EM teacher 2), to establish a connection with students, and this then would positively influence learning:

"Ask about their daily life or something that interests students. It is a good way to understand and make friends with students. A good relationship between teacher and students can motivate students to learn" (EM Teacher 4)

Both teachers and students explained how a good relationship could help learning and teaching. A good relationship between teacher and students could make the students feel like engaging and contributing more; thereby acquiring the language and gaining more knowledge.

The teachers also felt that positive relationships motivated them to teach better. For instance, teachers believed that if they used questioning to make students "feel involved or connected" (ENM Teacher 1) or "feel close to the teacher" (ENM Teacher 4) or "feel a happy atmosphere" (EM Teacher 3), the students would more actively participate in the lesson.

Students agreed that harmony could benefit both the teaching and students' engagement:

"I think when the teachers are happy they often teach more enthusiastically." (ENM group 2) 
"[If] we like the teacher, we feel more confident and want to answer more." (EM group 2)

One of the teachers admitted that she was sometimes tempted to lecture and talk, but when she noticed students becoming bored and distant, she posed questions as a way to interact and connect with students. She observed that through answering her questions, students became more engaged and closer to her (EM Teacher 1).

In brief, both teachers and students agreed that teachers asked questions as a way to build a relationship with students. Furthermore, the relationship-building questioning could make students and teacher emotionally closer. They believed that a good relationship was valuable because it could boost both the teacher and students to engage in classroom interaction.

\section{Respecting students}

Teachers believed that to build a relationship, they must show that they respect their students. Through questioning, teachers showed their respect by asking polite questions, recognising/welcoming students' opinions, and offering feedback.

According to the teachers, when students were shy, they tended to be quiet and not to answer. Therefore, teachers needed to use questions to engage students respectfully. Because:

"If students feel they are respected and their answers are acknowledged they feel stimulated to engage more." (ENM Teacher 2)

Teachers mentioned that they felt responsible for making students comfortable and confident in class. EM Teacher 1 talked about the fact that teachers made many utterances functioning as commands but in question form (for example, "Could you please move to the first row?" (ENM Teacher 1)).

"when I give a demand, it sounds like I impose this on students. So I use question forms to somehow show my respect to students. It is because I consider students are my customers." 
ENM Teacher 1 believed that the requests in question form:

"were instructions and students had to follow, but ... reduced the feeling of giving an order and forcing students into doing something."

The teachers reported that when using questioning, teachers tried to raise the students' status by using friendly and respectful language. Furthermore, both teachers and students felt that encouraging questions worked to engage students. Encouraging questions were open:

"The teacher asked open questions, the ones that did not involve right or wrong. This made us feel confident to answer, not scared of making wrong answers.” (ENM group 2)

Or asked for the students' points of view:

"I answered because the questions involved the personal experience of students..." (ENM group 1)

Another habit that was shared by many teachers was asking questions in Vietnamese and using the ' $a$ ' ending (a Vietnamese marker used by the younger or senior to the older or superior to show courtesy). The teachers explained that:

"It is partly because I feel that the mother tongue can make a better connection with the student. I just want to make the students feel less pressure ...I guess I say the word ' $a$ ' just to show that I am polite and I respect them very much." (ENM Teacher 1)

ENM Teacher 2 considered that since university students were adult, they deserved her respect.

"The teacher should not have a pre-fixed answer, especially for open questions. We all respect students' opinions, even if the answer may be opposite to the teacher's answer."

ENM Teacher 3 had a strategy to deal with opposing viewpoints: 
"I respect students' answers, but I can suggest students think more. My way is stating my own opinion and suggesting they think about it in different ways or for reference."

However, some students disagreed with this. Students talked about how the teacher did not always welcome different ideas, but they showed politeness by not arguing and accepting the teacher's answer:

"I felt my answer made sense and was reasonable but teacher kept asking me and orient me to follow her opinion. I think the teacher did not like student's idea that was different from hers" (EM group 4)

Both teachers and students agreed that respecting the student's viewpoints would make students engage more. However, while teachers said that they respected students' different opinions, the students felt that some teachers did not welcome the students' ideas if they differed from the teacher's.

For example in ENM class 1:

\begin{tabular}{|c|c|l|c|c|}
\hline Line & Speaker & $\begin{array}{c}\text { Utterance and } \\
\text { non-verbal data }\end{array}$ & Turns & Function/ purposes \\
\hline 19 & $\mathrm{~S} 4:$ & $\begin{array}{l}\text { We can sell it cheaper price if } \\
\text { we can reduce the cost. }\end{array}$ & $\mathrm{R}$ & Giving information \\
\hline 20 & $\mathrm{~T}:$ & $\begin{array}{l}\text { That's a good idea. I mean } \\
\text { different idea about money. But } \\
\text { it is a good idea. (writes } \\
\text { "cheaper price" on board) }\end{array}$ & $\mathrm{F}$ & Acknowledging \\
\hline 22 & $\mathrm{l}$ & $\mathrm{I}$ & $\begin{array}{l}\text { Another idea? } \\
\text { information }\end{array}$ \\
\hline
\end{tabular}

Episode 20: Teacher welcomed new idea from student

In teacher feedback turn (line 20), the teacher stated that the answer of students was not what she expected, but although it was different from her suggestion, she considered it "a good idea". By writing the student's idea on the board the teacher showed her acceptance of the idea.

In another situation (ENM Class 3), a student answered questions "what are good qualities of a coach?" 


\begin{tabular}{|c|c|l|c|c|} 
Line & Speaker & \multicolumn{1}{c}{$\begin{array}{c}\text { Utterance and } \\
\text { non-verbal data }\end{array}$} & Turns & Function/purposes \\
\hline 2 & S: & $\begin{array}{l}\text { They are rich. } \\
\text { Ok. May be, may not. Ok. }\end{array}$ & & Riving information \\
\hline 3 & T: & $\begin{array}{l}\text { Coach are often rich, I guess. } \\
\text { But I am asking about the } \\
\text { quality of a coach. }\end{array}$ & $\mathrm{F}$ & $\begin{array}{c}\text { Rejecting and } \\
\text { explaning }\end{array}$ \\
\hline
\end{tabular}

Episode 21: Polite rejection to student answer

The question was open enough to enable students to have different opinions. But the teacher's feedback was equivocal ("May be may not") and later the teacher rejected the answer with an explanation that the answer did not focus on the question. I observed that when teachers disagreed, they often offered a reason and explanation for their rejection.

Teachers thought that they were open to students' questions and students' feedback. They mentioned some ways they used to encourage active learning/autonomy for the students like 'empowering' students into questioning and answering, creating question and answer (Q \& A) sections, and welcoming students' questions.

For example, ENM Teacher 3 proposed that students learnt by giving feedback to each other:

"I empowered students to give feedback to each other. If students could recognize the good and mistake, and correct themselves, it was very effective learning, I suppose. I just gave feedback after students' feedback.” (ENM Teacher 3)

ENM Teacher 2 encouraged students to question each other:

"After the presentation of students, I asked others to ask some questions to the presenter. The presenter then had to answer the questions. I want to create a habit of asking and criticizing for students. It is also to create questioning interaction between student and student.” (ENM Teacher 2)

Whereas EM Teacher 4 stated that students enjoyed nominating each other. 
"when a student finishes answering the questions, I let him choose the next group to answer the next questions. Students like the feeling of having a chance to nominate others" (EM Teacher 4)

All the teachers showed in these ways that they welcomed questions from students.

Some teachers (ENM Teacher 2, EM Teacher 1) mentioned how they spent time creating a section of questions and answers (Q\&A) to sum up the lesson. For instance:

"I often had 4 to 5 minutes, called the $Q \& A$ section, after each part to let students ask, share or criticize. I tried to keep this routine for every part." (ENM Teacher 2)

In observations, for example in ENM Class 1, EM class 2, EM Class 3, I noticed questions intended to invite students' questions:

"Do you understand? Any opinion about the part?” (ENM Class 1)

"Do you have any question?" (EM class 2)

"Do you agree or want to add anything?" (EM Class 3)

However, other teachers (EM Teacher 1, ENM Teacher 4) admitted that time pressure could present a barrier to students asking questions to teacher:

"I felt regret that because of time pressure to complete the lesson, I could not be patient and energetic enough to deal with all student questions" (ENM Teacher 4)

EM Teacher 4 visited each group of students to invite students' questions:

"Students often feel shy they tend not to make questions in public. So I often come into each group and invite them to make questions... Students often make many questions to me when I come near them." (ENM Teacher 4)

Teachers believed that making students understand that teachers welcome questions could encourage students to ask more questions. 
"Our students feel afraid to challenge the teacher, so they don't ask questions. Therefore, I always clearly state that making questions means they are contributing to the lesson and teachers expect them to ask more" (EM Teacher 1)

They also suggested how teachers could welcome questions by all means:

"They [students] can ask questions directly or write questions on a piece of paper or send email to me." (EM Teacher 2)

In contrast, students (ENM group 1 and ENM group 4) said that they were reluctant to interrupt the teacher in order to ask questions:

"Teachers often teach nonstop, so it is not convenient for us to stop to make question" (ENM group 1)

In short, teachers believed that they tried to empower students to become active and autonomous through giving feedback, encouraging students to ask questions, and creating Q\&A sections. However, some were concerned that time pressure prevented this from happening. Some students also reported that sometimes teachers focused on lecturing and this prevented them from interacting with their teacher.

Teachers and students agreed that good relationships could facilitate teaching and learning. Teachers stated that they tried to build rapport and show respect for their students by making open and polite questions. Teachers believed that they welcomed students' different opinions, questions and feedback. However, students reported that some teachers were not really open to different opinions offered by students. Questioning, in this sense, performed like a lubricating agent that promoted more effective teaching and learning.

To summarise this section, the teachers and students identified many purposes of questioning. Firstly, questioning could help teacher fulfil their pedagogical goals of eliciting learning and improving attitude to learning. Questioning inspired students to formulate an answer, students had to think, talk, and therefore learn. Secondly, both teachers and students believed that questioning enabled teachers and students to understand their learning progress and therefore allowed them to refine teaching or 
learning. Thirdly, they viewed questioning as a guiding tool to promote developing cognition/thinking and organising learning activities. Finally, participants thought teachers used questions to build a good relationship with students. They believed that teachers tried to establish rapport and show respect for students and this could improve student participation. Generally, both participants' beliefs and practice showed that teachers were aware of their purposes and the teachers used different techniques to motivate engagement.

\section{Summary}

Findings identified that questioning was always purposeful. There were four reasons teachers used questioning: facilitating learning, diagnosing learning needs, managing learning, and building relationships.

Teachers used questioning to facilitate learning content and critical thinking. Teachers used questioning to diagnose what students know, to tailor future teaching. Students engaging in questioning could self-assess their learning, to find motivation to try harder. Teachers could use questioning to organise classroom activities and improve learning attitude and behaviours. Questioning was also seen a lubricant, building good relationships between teacher and students, which would facilitate learning and teaching. Therefore, questioning was always targeted, and the underlying/ultimate goal of questioning was to promote teaching and learning.

Observational data revealed a variety of techniques that teachers used in questioning for different purposes. However, while teachers thought that they used questioning effectively to fulfil their pedagogical aims, students did not always appreciate this and sometimes perceived the questioning as stressful and they felt demotivated by it.

Also, there were a variety of ways students could respond to questions: individually or in chorus, by volunteering, or by being nominated. These significantly influenced the students' participation. When selecting volunteers to answer, or nominating students, both teachers and students had the same opinions. Volunteering meant students were active and felt competent. Teachers often used nomination when no student was willing to answer. Nomination often made students feel stressed; therefore, nominated students often felt unable to answer well. Some teachers added 
that nomination was a good technique that could grab students' attention and encourage students to make more effort to learn. Observational data also revealed that teachers were skilled in the use of questioning.

In summary, findings, especially from observational data, show teachers, like artists of speaking, used questioning to encourage learning, grab learners' attention, direct learners, and gain learners' respect. There were some differences/distinctions between participants in two faculties. For instance, ENM participants reported business matter was part of the content in questionings, while EM participants said their questioning involved linguistic contents. Observational data reveals that EM participants demonstrated the ability to produce longer and more critical thinking in questioning than ENM students. Except for these distinctions, participants in two faculties both agreed that teachers and students used questioning for different reasons, but the underlying purpose of questioning was to promote teaching and learning. 


\section{CHAPTER 6: "MY HOME, MY RULES"}

\section{Introduction}

One of themes emerging from data was "my home, my rules" (a Vietnamese proverb, "nhập gia tuỳ tục"). This proposes that questioning was contextually situated. This section looks at some of the factors, relating to the local context in Vietnam, that influenced questioning, such as the traditional role of teacher and student, questioning with a concern for face or status, and the use of Vietnamese in English classes.

\section{"Without the teacher, students cannot learn"}

"Without the teacher, students cannot learn" (Khong thay do may lam nen) is a proverb in Vietnam. Some participants referred to this idea when they reported that traditionally the EFL students were seen as passive or subservient in Vietnamese classrooms. They also reported that the teachers were viewed as having a superior status.

\section{The students as passive participants}

Both participants' reported beliefs and my observations indicated that students tended to be too shy or modest to answer questions, and they rarely asked questions. If they asked questions, the questions were often for limited purposes, like asking permission or clarification. Questions about content were infrequent.

Teachers and students reported that students were shy and modest. They believed this affected how students answered.

"Many students are shy and quiet. They just want to listen to the teacher and others." (ENM group 4)

"I waited for an answer, but students kept quiet, and I had to nominate someone to make them speak." (ENM Teacher 3)

However, teachers and students, especially in English major classes, believed that students were able to answer but did not want to show off. 
"We were not shy but we did not answer that question because we did not want to show off." (EM Group 1)

"Students can answer, maybe because they are modest, they don't raise their hand to answer. However, if the teacher nominates them, they answer well." (EM teacher 3)

According to teachers and students, the reason why Vietnamese students were shy and quiet was cultural (ENM Teacher 1, ENM Teacher 2, ENM Teacher 4, and EM Teacher 2). There were cultural expectations from teachers that:

"Vietnamese students rarely ask questions because they don't have that habit." (EM Teacher 2)

"They are first-year students; they are uncomfortable to speak in front of many people." (ENM Teacher 1)

Similarly, students thought culture played a role in answering:

"Eastern culture appreciates being modest. I really admire students in the western country who are very active in expressing what they believe. However, Vietnamese students are passive and feel ashamed to show off." (EM group 3)

Furthermore, they did not think it was appropriate for students to argue with or challenge the teacher:

"They do not have the habit of arguing because the teacher is considered always to be right, so they will not challenge the teacher." (EM Teacher 2)

In short, the participants acknowledged students' shyness and passivity, and believed that these became barriers to questioning. The participants believed that if students asked questions, their questions were often merely to ask for clarification or to ask permission. Both teachers and students stated that:

"Student questions are often to ask clarification." (ENM Teacher 3, EM Teacher 3) 
Questions from students were not as frequent as questions from the teacher. However, there were several examples of students initiating interaction by asking managerial questions of the teacher and their peers.

The first situation was when a student was about to go to the blackboard and make a brief presentation (EM Class 3). The student actively asked the teacher:

\begin{tabular}{|c|c|c|c|c|}
\hline Line & Speaker & $\begin{array}{c}\text { Utterance and } \\
\text { non-verbal data }\end{array}$ & Turns & Function/purposes \\
\hline 1 & S: & Can I use my notes? & I & Asking for permission \\
\hline 2 & \multirow{2}{*}{$\mathrm{T}:$} & Yes. & \multirow{2}{*}{$\mathrm{R}$} & Accepting \\
\hline 3 & & Be sure that you speak not read. & & Clarifying \\
\hline
\end{tabular}

\section{Episode 22: Student questions for permission}

In the situation, the structure of "Can I...?" refers to a suggestion-function with question form. In particular, the student wanted to get permission from the teacher to use notes while presenting. Therefore, the question did not create interaction for learning. The interaction ended with a response from the teacher.

The following sequence, in EM Class 4, was also initiated by the students:

\begin{tabular}{|c|c|c|c|c|}
\hline Line & Speaker & $\begin{array}{l}\text { Utterance and } \\
\text { non-verbal data }\end{array}$ & Turns & Function/ purposes \\
\hline 1 & \multirow{2}{*}{$\mathrm{S}:$} & $\begin{array}{l}\text { When will you send the topics } \\
\text { to us? }\end{array}$ & \multirow{2}{*}{$\mathrm{I}$} & \multirow{2}{*}{$\begin{array}{l}\text { Requesting } \\
\text { information }\end{array}$} \\
\hline 2 & & $\begin{array}{l}\text { How long before the } \\
\text { examination? }\end{array}$ & & \\
\hline 3 & $\mathrm{~T}:$ & $\begin{array}{l}\text { Just two or three days before the } \\
\text { exam day. }\end{array}$ & $\mathrm{R}$ & Giving information \\
\hline 4 & \multirow{2}{*}{ S: } & Oh, no. & \multirow{2}{*}{$\mathrm{F}$} & Disagreeing \\
\hline 5 & & Could you send it to us sooner? & & Polite requesting \\
\hline 6 & \multirow[t]{2}{*}{$\mathrm{T}:$} & $\begin{array}{l}\text { All of the topics you already } \\
\text { learned in the textbook. I just } \\
\text { send you to facilitate... You } \\
\text { don't really need them. }\end{array}$ & \multirow[t]{2}{*}{$\mathrm{R}$} & $\begin{array}{l}\text { Explaining and } \\
\text { rejecting }\end{array}$ \\
\hline 7 & & No more bargaining. & & $\begin{array}{l}\text { Killing the } \\
\text { conversation }\end{array}$ \\
\hline
\end{tabular}

Episode 23: Student questions for request 
In Episode 23, the initial questions ("When will you send the topics to us? How long before the examination?") (lines 1 and 2) functioned as an information request. The initiation was not for a cognitive reason, but students wanted to get information to prepare for the exam.

The students tried to open the interaction by asking one more question ("Could you send it to us sooner?"), which was a polite request (line 5). The question was a command-function with question form. However, it was rejected by the teacher, and the interaction was ended by the teacher.

In general, the interviews and observations indicated that students were passive. The participants explained that Vietnamese students' passiveness might result from the fact that they were not accustomed to be assertive by initiating questions and there was a reluctance to express themselves. Observations showed some evidence of students' questions. However, these questions were for clarification or requesting rather than for cognitive reasons.

\section{The teacher as the director or superior}

Teachers were seen as more powerful by both teachers and students. They agreed that the teacher should control questioning and orient how students participate in the questioning. They believed teachers held this power because "Teachers are like [movie] directors" (ENM Teacher 3) and “teachers are superior” (EM Group 1).

Firstly, teacher and student participants perceived that teachers directed by manipulating/leading questioning. Teachers perceived that teachers should take control.

"Teachers have to be powerful to make students listen" (ENM Teacher 4)

"Students need the teacher's direction to work effectively" (ENM Teacher 2)

Teachers described how they controlled questioning sequences: 
"Teacher is the person who opens the questioning, encourages students to answer and decide whether to close the questioning-asking interaction" (EM Teacher 1)

Teachers believed that they used questions for the following pedagogical purposes.

"Teachers rule questioning....We ask any questions and as many as we should, but we always use questions to serve a particular plan." (ENM Teacher 3)

Teachers said that they used questioning flexibly to suit different purposes and for particular students. For example, using questioning ENM Teacher 2 decided the content:

"I choose questions for my plan. These could be questions in a textbook or questions about reality; questions for content or questions for practising skills. It depends on my plan" (ENM Teacher 2)

ENM Teacher 3 discussed her decision-making in terms of the difficulty of questions:

"I decide whether there should be easy questions or difficult questions. Students are at a lower level are for easier questions and more proficient students can be assigned to answer the difficult questions.' (ENM Teacher 3)

Teachers also said they adjusted the questioning by repeating questions, paraphrasing, or breaking down questions, to fulfil their goals of encouraging students to answer and learn (ENM Teacher 2).

Students agreed that teachers were the people who "control questioning and answering interaction" (EM Group 4). They said that they trusted their teachers' knowledge and decision:

“Teachers' answers are the best" (ENM Group 2)

and

“We will follow whatever the teacher asks us to do" (EM Group 4). 
Even if they were uncomfortable about the situation they agreed with the teacher:

"I don't like to be nominated.... but if being nominated, I have to stand up and try to say something” (EM Group 3)

Teachers said they adapted their questioning according to their particular teaching purposes, context, and learners. Students stated that they believed in cooperating with the teacher's direction.

In addition, teachers and students believed that teachers could control the engagement of students through skilful questioning. For instance, teachers could assign roles to students in groups to regulate student interaction.

"I suggest different roles of performers: secretary, team leader, presenter or who will represent the group to answer. Like a director choosing actors and scenes, I assign students to do their roles.” (ENM teacher 3)

Teachers and students shared the same opinion that teachers controlled the turns and ways that students could answer the questions. For example, when considering how to ask questions of the teacher, the students might choose to ask questions about the language because the English teacher preferred only questions about English, not specific business-related content.

"We asked about the concepts of supply and need. But the teacher refused to answer and suggested we asked the teachers in the field.... I just asked the English questions about English not business.” (ENM group 2)

Students also perceived the teachers had the power to refuse certain answers.

“Answering 'I don't know' for questions about homework is not accepted by the teacher" (EM Group 3)

Some students mentioned how teachers specified the kinds of answers they would accept.

"The teacher requires us to answer with reasons and details" (EM Group 4) 
"Teachers always ask us to give qualified answers, which are good both in content and speaking skill.” (EM group 2)

Teachers also stated that they set a standard for answering. For instance, they expected third year English majors to show their reasoning:

"Student answers have to be specific and well-supported with evidence, reasons and strong argument" (EM Teacher 4)

Teachers decided how students should answer by nominating particular students, allowing answering in chorus, or inviting volunteers. Also, teachers could ask students for written answers or spoken answers.

Teachers shared their reasons for choosing how students could answer. For example, the teacher would nominate students when students were quiet (ENM Teacher 1 and ENM Teacher 3), invite the volunteering student to stand up to answer difficult questions because the volunteers were often competent (ENM Teacher 2 and EM Teacher 2), or create excitement by requesting answers in chorus for short answer questions (EM Teacher 3).

Besides, teachers could combine different ways of choosing answers such as encouraging students to answer in chorus or individually, answering in writing or aloud, answering by volunteering or by teacher nomination.

"I try to exercise alternative ways of selecting answering [nomination, volunteering, in chorus] depending on the situations.... Sometimes, I ask different individual students to stand up in turn for the same question to cultivate deep and different thoughts." (EM Teacher 4)

EM Teacher 3 stated the advantages of choosing different modes of answering by directing students to write down answers or speak in front of the whole class:

"Sometimes, I ask the groups to write answers to questions on paper so that they can practise writing also.... Sometimes, I ask students to come to the board and face the whole class; I stand at the far end. I ask the students to answer 
loudly. I aim to make the students feel confident and practise speaking in front of an audience." (EM Teacher 3)

The teachers believed that mixing the modes of inviting students to answer illustrated flexible questioning. They believed that this variety encouraged students to respond.

In brief, teachers and students believed that teachers had the responsibility of directing questioning. Teachers decided the content and types of questioning, based on their pedagogical purpose. Students perceived the teacher were superiors whose answers were the best and students should follow their teachers' direction. Both teachers and students agreed that teachers directed and delegated students to answer. Teachers added that they could select different ways for students to answer, like nomination, volunteering and in chorus.

The following is the quotation in EM Class 3, mentioned before. In this part, it was analysed to show the roles of the teacher in directing questioning. In this situation, the teacher required a student (S3) to compare and contrast S3's opinion with the two previous answers.

\begin{tabular}{|c|c|c|c|c|}
\hline Line & Speaker & $\begin{array}{c}\text { Utterance and } \\
\text { non-verbal data }\end{array}$ & Turns & Function/purposes \\
\hline 6 & \multirow{3}{*}{$\mathrm{T}:$} & $\begin{array}{l}\text { Now, everybody, do you want } \\
\text { to add any information? }\end{array}$ & \multirow{3}{*}{$\mathrm{I}$} & $\begin{array}{c}\text { Requesting } \\
\text { information (by a } \\
\text { yes/no question) }\end{array}$ \\
\hline 7 & & $\begin{array}{l}\text { Or is your opinion same or } \\
\text { different with them? }\end{array}$ & & Reformulating \\
\hline 8 & & $\begin{array}{l}\text { (Nominates a student) You, } \\
\text { please. }\end{array}$ & & Nominating \\
\hline 9 & S3 & My opinion different. I often .... & $\mathrm{R}$ & Giving information \\
\hline 10 & $\mathrm{~T}$ & $\begin{array}{l}\text { With whom? The first or the } \\
\text { second student? }\end{array}$ & $\mathrm{F}$ & $\begin{array}{l}\text { Asking for } \\
\text { clarification } \\
\text { (interrupting) }\end{array}$ \\
\hline 11 & S3 & The second. & $\mathrm{R}$ & Clarifying \\
\hline 12 & \multirow[b]{2}{*}{$\mathrm{T}$ : } & OK. Good! & \multirow[b]{2}{*}{$\mathrm{F}$} & Acknowledging \\
\hline 13 & & Tell me. & & $\begin{array}{l}\text { Requiring further } \\
\text { information }\end{array}$ \\
\hline 14 & S3: & $\begin{array}{l}\text { I think Vietnamese students not } \\
\text { stay up late study. }\end{array}$ & $\mathrm{R}$ & $\begin{array}{l}\text { Providing further } \\
\text { information. }\end{array}$ \\
\hline 15 & $\mathrm{~T}:$ & $\begin{array}{l}\text { Students don't stay up late to } \\
\text { study? }\end{array}$ & $\mathrm{F}$ & $\begin{array}{l}\text { Correcting "to study"/ } \\
\text { Requesting }\end{array}$ \\
\hline
\end{tabular}




\begin{tabular}{|c|c|c|c|c|}
\hline & & $\begin{array}{l}\text { (Raising voice to make question } \\
\text { to ask for confirmation) }\end{array}$ & & confirmation. \\
\hline 16 & S3: & $\begin{array}{l}\text { Yes, they don't stay up late } \\
\text { study. }\end{array}$ & $\mathrm{R}$ & $\begin{array}{l}\text { Confirming } \\
\text { (Repeating same } \\
\text { mistake) }\end{array}$ \\
\hline 17 & $\mathrm{~T}:$ & Ok. So what do they do? & $\mathrm{F}=\mathrm{Q}$ & $\begin{array}{l}\text { Requiring further } \\
\text { information }\end{array}$ \\
\hline 18 & S3: & $\begin{array}{l}\text { They stay up late for playing } \\
\text { games, }\end{array}$ & $\mathrm{R}$ & $\begin{array}{l}\text { Providing further } \\
\text { information. }\end{array}$ \\
\hline 19 & $\mathrm{~T}:$ & Uhuh (nods head) & $\mathrm{F}$ & Acknowledging \\
\hline 20 & S3: & Watching television... & $\mathrm{R}$ & $\begin{array}{l}\text { Providing further } \\
\text { information. }\end{array}$ \\
\hline 21 & T: & Uhuh (nods head) & $\mathrm{F}$ & Acknowledging \\
\hline 22 & S3: & Search internet. & $\mathrm{R}$ & $\begin{array}{l}\text { Providing further } \\
\text { information. }\end{array}$ \\
\hline 23 & T: & Uhuh (nods head) & $\mathrm{F}$ & Acknowledging \\
\hline 24 & S3: & $\begin{array}{l}\text { I think they don't need to eat } \\
\text { anything to stay awake because } \\
\text { you know games really } \\
\text { interesting. }\end{array}$ & $\mathrm{R}$ & $\begin{array}{l}\text { Providing further } \\
\text { information. }\end{array}$ \\
\hline 25 & $\mathrm{~T}:$ & $\begin{array}{l}\text { Ah ha. That's good idea (smiles } \\
\text { and nods head). }\end{array}$ & $\mathrm{F}$ & Acknowledging \\
\hline 26 & \multirow[b]{2}{*}{ S3: } & $\begin{array}{l}\text { And the guys are interested in it } \\
\text { all the time and they do not } \\
\text { need... they just stay awake. }\end{array}$ & \multirow[b]{2}{*}{$\mathrm{R}$} & \multirow{2}{*}{$\begin{array}{l}\text { Providing further } \\
\text { information. }\end{array}$} \\
\hline 27 & & $\begin{array}{l}\text { For me, when I feel interesting } \\
\text { and I feel I can stay awake all } \\
\text { night just watch them, do not } \\
\text { need to eat. }\end{array}$ & & \\
\hline 28 & $\mathrm{~T}:$ & $\begin{array}{l}\text { So what happens when the } \\
\text { exams come? }\end{array}$ & $\mathrm{F}=\mathrm{Q}$ & $\begin{array}{l}\text { Requiring further } \\
\text { information; }\end{array}$ \\
\hline 29 & S3: & $\begin{array}{l}\text { When the exam comes I think I } \\
\text { will skip watching TV. }\end{array}$ & $\mathrm{R}$ & Providing information \\
\hline 30 & $\mathrm{~T}:$ & $\begin{array}{l}\text { Will you stay up late to study } \\
\text { for the exam? }\end{array}$ & $\begin{array}{l}\mathrm{F}=\mathrm{Q} \\
\text { closed }\end{array}$ & $\begin{array}{l}\text { Requiring further } \\
\text { information }\end{array}$ \\
\hline 31 & S3: & Just a little bit, not much. & $\mathrm{R}$ & Providing information \\
\hline 32 & $\mathrm{~T}:$ & $\underline{\text { Really? }}$ & $\mathrm{F}=\mathrm{Q}$ & $\begin{array}{l}\text { Asking for } \\
\text { confirmation, } \\
\text { showing some } \\
\text { wondering }\end{array}$ \\
\hline 33 & S3: & $\begin{array}{l}\text { When you stay up late all night } \\
\text { you just can't concentrate on } \\
\text { your study tomorrow, so I think } \\
\text { study is important, you need to } \\
\text { be (inaudible) to concentrate on } \\
\text { it ... }\end{array}$ & $\mathrm{R}$ & $\begin{array}{l}\text { Explaining why not } \\
\text { stay late but not really } \\
\text { clear }\end{array}$ \\
\hline
\end{tabular}




\begin{tabular}{|c|c|c|c|c|}
\hline 34 & $\mathrm{~T}:$ & $\begin{array}{l}\text { So you mean you don't need to } \\
\text { stay up late to study for the } \\
\text { exam? }\end{array}$ & $\mathrm{F}=\mathrm{Q}$ & $\begin{array}{l}\text { Asking for } \\
\text { confirmation of not } \\
\text { staying late }\end{array}$ \\
\hline 35 & S3: & Not too late. & $\mathrm{R}$ & Giving information \\
\hline 36 & \multirow[b]{2}{*}{$\mathrm{T}$ : } & Ah, not too late. & \multirow[b]{2}{*}{$\mathrm{F}$} & $\begin{array}{l}\text { Acknowledging by } \\
\text { repeating }\end{array}$ \\
\hline 37 & & $\begin{array}{l}\text { And you say you can stay up } \\
\text { late to play games or listen to } \\
\text { music? }\end{array}$ & & $\begin{array}{l}\text { Asking for } \\
\text { confirmation }\end{array}$ \\
\hline 38 & S3: & Yeah it is. & $\mathrm{R}$ & Confirming \\
\hline 39 & \multirow{2}{*}{$\mathrm{T}:$} & Oh. Yes. Interesting. & \multirow{2}{*}{$\mathrm{F}$} & \multirow{2}{*}{$\begin{array}{l}\text { Acknowledging. } \\
\text { Evaluating }\end{array}$} \\
\hline 40 & & Thank you very much. & & \\
\hline
\end{tabular}

\section{Episode 24: Teacher's directing roles in questioning}

The roles of the teacher were revealed in a number of ways, outlined below.

Teachers firstly could nominate a student to answer the questions (line 8). Then, when the student S3 said "My opinion is different. I often...." (line 9), the student was about to give more details of his opinion. However, the teacher interrupted the student's turn "With whom? The first or the second student?" (line 10) to clarify who S3 was referring to.

During the interaction, the teacher could command students to talk more (line 13) and extend the questioning by eliciting more information (line 17). The teacher also could correct the student's mistake (line 15), though the student did not notice the error (line $13)$.

In line 28, the teacher oriented the student (S3) to shift the answer from "what students do when they stay till late?" to "So what happens when the exams come?" (line 28). The teacher showed the power to monitor or orient the students to open the topic and develop ideas.

However, from line 30 to 40 , the teacher encouraged students to answer and clarify teacher concerns. In line 32, the teacher seemed to show some curiosity about S3's answer by asking "Really?" This encouraged the student to explain. S3 tried to explain and could produce a long answer (line 33). The explanation might be that the student did not stay up late to study because the student wanted to be alert for the lesson the next morning. However, the teacher, in line 34, seemed to ignore the reason 
why the student would not stay up late, but chose to focus and ask for another confirmation "So you mean you don't need to stay up late to study for the exam?" The teacher, once again, chose the focus of the conversation. In line 37, the teacher asked for another confirmation, "And you say you can stay up late to play game or listen to music?" Which was later confirmed by the student S3 in line 38. Several requests for confirmation, for example, "Really?", "So you mean you don't need to stay up late to study for the exam?", and "You say you can stay up late to play game or listen to music?" might show that the teacher had some concerns. However, the teacher, at last in line 39 and 40 accepted and evaluated the student answers.

Throughout this sequence, I observed that the teacher directed questioning. The teacher could choose a particular student to participate. The teacher could open and end the questioning. The teacher could extend, shift the topic, or choose to focus on a particular idea. The situation revealed the directing role of the teacher.

\section{Maintaining face}

The student and teacher participants both reflected that answering and questioning was influenced by concerns about gaining respect, losing face and saving face.

\section{Making a good impression}

Teachers believed that gaining respect from students was important. They thought that competent teachers could conduct effective questioning or show off their expertise.

“Good teachers make good questioning” (EM Teacher 1)

"Sometimes, I ask difficult questions and if students cannot answer I will give a good explanation" (ENM Teacher 3)

This made "Students believe in the teacher" (EM Teacher 1), the teachers "feel good" (ENM Teacher 1) and "feel being respected" (ENM teacher 3).

ENM Teacher 2 made a comparison about her teaching practices. When she was young and inexperienced, she felt that: 
"Students sometimes didn't engage and answer my questions, maybe because I did not know how to call them to answer."

While she now has more experience, she felt more confident, students respected her and engaged more in questioning. She added:

"Now I make more questions, more critical questions, and more open questions. I require students to be more active, answer my questions. I just guide and answer when necessary."

Teachers perceived that they had good competence in English when they had the linguistic expertise to impress students and enhance their confidence to teach:

"Students admire and wish to learn from teachers' model of English" (ENM Teacher 4)

"English competence of teacher contribute to the teacher's confidence to communicate and engage in questioning” (EM Teacher 2)

In the teachers' opinions, it was important to gain the respect of students through good questioning in their teaching.

Similarly, students said that they wanted others, the teacher and their peers, to be impressed by their answers. They said this motivated them to engage in questioning.

Many students stated that they were stimulated to answer because they considered answering questions was a way to impress the teacher and friends:

"For me, I try to raise hand to make a good impression on the teacher" (ENM group 1)

“I volunteered to answer to make teacher pay attention to me." (EM group 4)

ENM group 1 even considered that students asking questions could greatly impress the teacher. 
"I think asking a question can make a better impression on the teacher than volunteering to answer teacher question."

Both teachers and students believed that gaining respect or making a good impression encouraged them to use questioning.

\section{Avoiding losing face}

Several students mentioned their fear of losing face if they were not able to answer. They viewed this as a motivation. Students found it stressful to answer questions:

"If we stand up and cannot answer teacher's questions, we are afraid of losing face in front of the teachers and peers. Therefore, we have to try to learn more." (ENM group 1)

ENM group 4 also stated that they tried hard to get ready to answer because they didn't want to lose face:

"I tried to read the lesson before the class, concentrate on the lecture, then I could answer the questions, avoid being losing face if I could not answer."

Other students chose not to participate in questioning the teacher because they were too afraid of losing face. ENM group 1 and ENM group 4 agreed that asking for clarification might suggest incompetence.

"Making an intelligent question is not an easy job, and making a simple question might make others think that you are an idiot or incompetent." (ENM group 1)

Students also decided not to ask questions partly because they were afraid that other students might think that they were incapable or slow.

"This is the psychology of uncovering ignorance." (ENM group 4)

Students were concerned about losing face themselves if they could not answer or ask questions. Therefore, some students said that they tried harder to learn, while some others said they tried to avoid asking a silly question. 
Students reflected that they might not answer or criticise to save the face of others. EM group 2 and EM group 3 stated that students who were more competent noticed the gap between different levels in the class, so:

"The competent students don't raise hands, to give turns or chances for others who are less competent to answer." (EM group 2)

and

"Better students may not answer easy questions because they think these questions should be saved for the other students who are slower." (EM group 3)

Students also said that they wanted to avoid embarrassing their teachers:

"Sometimes, I have a different answer to the teacher. But I don't debate with the teacher because I don't want to make the teacher have a negative feeling." (EM group 4)

Students believed that they avoided loss of face for other students and the teacher by giving turns to other students. They also did not want to criticise teachers to save the teacher's face.

Some other students reported that engaging in questioning could be a way to save the face of others. ENM group 2, EM group 2 and EM group 4 shared that they might answer a question because they wanted to prevent either the teacher or classmates from losing face. In particular, ENM group 2 said:

"Sometimes the teacher kept asking questions, and no student raised his hand. The atmosphere was too quiet, and the teacher felt awkward and embarrassed. We try to raise a hand to save the whole class and the teacher."

EM group 2 expressed that they felt sorry and uncomfortable when the teacher tried to be enthusiastic while students were unresponsive:

"The teacher kept asking and waiting for a hand. She kept waiting and looking around to seek for an answer. She looked unhappy. I, though not very sure 
about my answer, felt responsible for answering, just speak something to make the lesson move on."

EM group 4 recalled a time when the teacher got angry when no one could answer questions about their homework.

"The teacher got angry, and things became bad. She asked us to read a book by ourselves until we could answer the questions. I, before that, hadn't wanted to answer. I volunteered to answer the question to save the class."

Some students mentioned about what they often did when giving feedback to another student's answer:

"I just wanted to raise the student's status then I said that it was excellent and I agreed with them.” (EM Group 1)

The students who did not intend to answer because they were not sure (EM group 2) or who were not willing (EM group 4) to respond, became more active and involved in answering teachers' questions to maintain the learning relationship.

In the same way, teachers said that they cared about students' face when using questioning.

Teachers talked about helping students on occasions when students might get embarrassed.

"When nominating a student of the lower level, I often asked questions that students could answer easily because I didn't want to embarrass the students." (ENM Teacher 1)

Besides, teachers believed that good feedback should be positive.

"Positive comments on their answer can save student's face, and this makes students feel comfortable and keep trying answer next time." (ENM Teacher 3)

Students also agreed that teacher positive feedback could save their face: 
"It doesn't matter if she comments on bad or good points but the way teacher talk could make students feel comfortable to accept." (EM group 2)

In short, to avoid losing face, students said they tried not to place themselves or others in embarrassing situations. To save the face of others, students and teachers tried to make students feel positive and competent.

To summarise, both teachers and students were concerned about their own face and that of others. Teachers believed good questioning was important to win students' respect and show their competence. Students also wanted to impress their teacher and classmates, so they tried harder to learn and participate in the questioning. Both teacher and students acknowledged that they were concerned about face and took this into account when deciding whether to participate in asking-answering interactions. Students made decisions to avoid losing face themselves and to save face for peers and the teacher. Teachers stated that they were concerned about saving face of students, so they gave positive comments and posed answerable questions. Therefore, gaining good impression, avoiding losing face, or saving face, could be the motivation or demotivation of teachers and students to engage in questioning.

\section{Using both languages}

Participants used both English language and Vietnamese in questioning sequences. This bilingual approach was underpinned by the following ideas. Firstly, both teachers and students acknowledged English was an important subject, which could motivate student engagement. However, they believed the foreign language caused some difficulties for students, and the first language could be helpful in learning in a new language.

\section{English proficiency as a barrier}

The participants believed that English was an important subject for their future careers, so students were encouraged to participate actively. For example, teachers and students recorded:

"We need English to find a good job after graduation” (ENM group 2 and ENM group 3) 
"Students know English is the international language to communicate with the world" (ENM Teacher 1)

Therefore, both English major and English non-major students considered they were motivated to learn English, and they made a strong effort to engage in questioning.

"Engaging in answering the teacher is to show that we have the good attitude to learn the subject" (ENM group 3)

"We want to communicate with the teacher to improve our English." (EM group 2)

However, some teachers believed that students who were not good at English struggled to understand their questions and had difficulty in answering in the target language.

"if the teacher asks questions containing complex English vocabulary, weak students are often silent." (ENM Teacher 4)

"The question was difficult. Some new words prevented me from understanding the question. Also, I was not sure that I had enough vocabulary to answer in English.” (EM Group 4)

ENM Teacher 4 described a situation where a low-level student dealt with a difficult question.

"it was quite time-consuming and kept others waiting. The student looked uncomfortable."

ENM Teacher 3 also believed that teachers should pay attention to each student when asking questions because of varying levels of English proficiency in one class.

Students agreed that confidence to answer related to their English proficiency. They said that English proficiency could be an enabler or be a barrier to students when answering teacher questions. For example: 
"students who are competent in English often actively engage in answering. In contrast, students whose English is not their strength, are often quiet." (EM group 2)

ENM group 1 also viewed how students with different language proficiency levels responded to teacher questions.

"I think volunteering to answer is often done by more language competent students, while the less language competent students often feel afraid, afraid of speaking out and standing up in front of others."

Students mentioned difficulties using the target language to answer teacher questions.

"Not all students are good at English; sometimes it is difficult to express our ideas in English. I think it is also one of the reasons making us reluctant to answer teacher questions." (ENM group 1)

"I was afraid of standing up and embarrassing myself by making silly mistakes or mispronunciation. It was the reason why I did not raise my hand though I wanted to answer. " (EM group 2)

Both teachers and students found that English competence could affect students' participation in questioning.

\section{Using Vietnamese to promote questioning}

In addition, because of the challenge for students to speak in the target language, some teachers allowed the use of L1:

"I have to translate the questions in mother tongue to make them understand." (ENM Teacher 4)

The L1 provided a scaffold for learning in English.

"The student can answer in Vietnamese first, and I will help him/her to answer again in the target language." (ENM Teacher 2) 
Some students also preferred that the teacher used L1, especially for terminology in questioning.

"For deeply understanding the questions, especially the difficult questions with technical terms, I prefer being asked in Vietnamese, or both English and Vietnamese." (ENM group 1)

Also, students thought that L2 to answer was recommended, but some L1 when necessary could help, especially for beginning levels:

"I have good ideas for the questions, but when expressing into English, I cannot make my answers clear enough to understand. I don't have enough vocabulary. I would love to answer in Vietnamese and teacher can help me to say it in English.” (ENM 4)

Below are some examples of how teachers and students used L1 to support questioning. The first situation, in ENM Class 3, was when a student asked the teacher to provide a word in English.

\begin{tabular}{|c|c|c|c|c|}
\hline Line & Speaker & $\begin{array}{c}\text { Utterance and } \\
\text { non-verbal data }\end{array}$ & Turns & Function/purposes \\
\hline 1 & \multirow{2}{*}{ S: } & $\begin{array}{l}\text { Cô ơi, từ mạnh thường quân } \\
\text { tiếng anh là gì ạ? }\end{array}$ & \multirow{2}{*}{ I } & \multirow{2}{*}{ Requiring information } \\
\hline 2 & & $\begin{array}{l}\text { (What is the English word for } \\
\text { 'manh thường quân'?) }\end{array}$ & & \\
\hline \multirow[b]{2}{*}{3} & \multirow[b]{2}{*}{$\mathrm{T}:$} & Em có thế dùng từ "sponsor" & \multirow[b]{2}{*}{$\mathrm{R}$} & \multirow[b]{2}{*}{ Giving information } \\
\hline & & $\begin{array}{l}\text { (You can use the word } \\
\text { 'sponsor') }\end{array}$ & & \\
\hline \multirow{2}{*}{4} & \multirow{2}{*}{$\mathrm{S}:$} & Cô viết ra cho em với ạ? & \multirow{2}{*}{$\mathrm{F}$} & \multirow{2}{*}{$\begin{array}{l}\text { Requesting } \\
\text { information }\end{array}$} \\
\hline & & (Can you write it down please?) & & \\
\hline \multirow{2}{*}{5} & \multirow{2}{*}{$\mathrm{T}$} & (Writes down) & \multirow{2}{*}{$\mathrm{R}$} & \multirow{2}{*}{ Giving information } \\
\hline & & Here it is. & & \\
\hline 6 & $\mathrm{~S}$ & Thank you. & $\mathrm{F}$ & Acknowledging \\
\hline
\end{tabular}

Episode 25: Questioning using Vietnamese for new word

One questioning sequence was initiated by the student (line 1). The student also extended the conversation by asking another question to request more support (line 4). However, both the teacher and student used Vietnamese to ask and answer. 
The second situation, in EM Class 2, showed how a teacher and students used L1 to support understanding of a difficult subject.

\begin{tabular}{|c|c|c|c|c|}
\hline Line & Speaker & $\begin{array}{c}\text { Utterance and } \\
\text { non-verbal data }\end{array}$ & Turns & Function/ purposes \\
\hline 46 & $\mathbf{T}$ & Are you alright? & I & $\begin{array}{l}\text { Checking learning } \\
\text { progress }\end{array}$ \\
\hline 47 & S: & $\begin{array}{l}\text { Em vẫn chưa hiêu cái này lắm } \\
\text { cô à (I still don't really } \\
\text { understand this)(points to the } \\
\text { book) }\end{array}$ & $\mathrm{R}$ & $\begin{array}{l}\text { Giving information/ } \\
\text { Asking for help }\end{array}$ \\
\hline 48 & \multirow{3}{*}{ T: } & $\begin{array}{l}\text { Postulate meaning hả? } \\
\text { (Postulate meaning?) }\end{array}$ & \multirow{3}{*}{$\mathrm{F}$} & Confirming \\
\hline 49 & & $\begin{array}{l}\text { Cac em hiểu nó nghĩa là môt câu } \\
\text { được chấp nhận là đúng cho } \\
\text { mục đích tranh luận và nghiên } \\
\text { cứu khoa học? (It means } \mathrm{A} \\
\text { statement accepted as true for } \\
\text { the purposes of argument or } \\
\text { scientific investigation) }\end{array}$ & & Giving information \\
\hline 50 & & $\begin{array}{l}\text { Thử lấy ví dụ nào? (Can you } \\
\text { give me some example?) }\end{array}$ & & $\begin{array}{l}\text { Requesting } \\
\text { Exemplifing }\end{array}$ \\
\hline 51 & S: & $\begin{array}{l}\text { Khó quá cô ạ. (It is very } \\
\text { difficult.) }\end{array}$ & $\mathrm{S}$ & Struggling to answer \\
\hline 52 & \multirow{3}{*}{ T: } & $\begin{array}{l}\text { Nghữ nghĩa mà em. (It is } \\
\text { difficult because it is semantics.) }\end{array}$ & \multirow{3}{*}{$\mathrm{F}$} & $\begin{array}{l}\text { Acknowledging the } \\
\text { difficulty }\end{array}$ \\
\hline 53 & & $\begin{array}{l}\text { Anyway, please discuss further } \\
\text { in your group. }\end{array}$ & & Offering discussion \\
\hline 54 & & $\begin{array}{l}\text { We will explain it later for the } \\
\text { whole class. OK? }\end{array}$ & & $\begin{array}{l}\text { Delaying giving } \\
\text { feedback }\end{array}$ \\
\hline
\end{tabular}

Episode 26: Questioning using Vietnamese to facilitate understanding

In this situation, the teacher initiated the interaction with the group by asking a question to offer an explanation “Are you alright?" (line 46). This question provided a chance for students to state any difficulty and ask the teacher to explain a term (line 47). This suggested that the student might feel more comfortable to ask in the L1 (line 47). In the teacher's turns (lines 48 to 50), the teacher answered the student's question and asked the student to give an example to check whether the student understood. The teacher said that she chose to explain in L1 because it was difficult for the student to understand the term in the target language. 
"The definition of the word is in the textbook. The student still doesn't understand, so I think it would be better for translating in Vietnamese" (EM Teacher 1)

However, the student still struggled to answer (line 51). In the final follow-up turn (lines 52 to 54) the teacher delayed offering an answer. The teacher encouraged the group to find the answer before providing the answer to the whole class.

In short, students perceived English as an important subject, and this provided motivation for them to engage in interaction in the target language. However, teachers and students reported that language competence was a concern for students participating in questioning. They agreed that English could be a barrier for students to understand and answer questions. Also, teachers and students said that it could be helpful to use Vietnamese to promote questioning. Teaching practice revealed that students used their L1 to ask questions to teachers. In some difficult subjects, for example, semantics, teachers and students used L1 quite often to facilitate understanding.

To summarise, questioning in an EFL classroom in Vietnam revealed some matters relating to particular cultural or local traits. Firstly, findings from beliefs and observations showed that Vietnamese students took a passive role and respectfully deferred to their teachers. These were traditional roles. Secondly, both teachers and students stated that they were concerned about face when engaging in questioning. In particular, gaining respect and making a good impression were important for them; for this reason saving face or avoiding losing face could influence their engagement. Finally, English was a foreign language for these participants, and was considered important for their graduation or future career. Finally, participants believed English competence affected student participation. The data from beliefs and observations reported that the participants used L1 to support questioning.

\section{Summary}

There were significant similarities between participants in English major classes and those in English non-major classes about the influences in questioning. Participants in both contexts indicated that questioning, in this study, was influenced by traditional 
and cultural factors. Firstly, questioning sequences reflected the asymmetrical power relationship between the Vietnamese teachers and students. The teachers held a more powerful position than the students, because the teachers often talked more, and could direct the questioning interaction. The observation data showed more teacher talk than student talk. It was evident in the questioning sequences I observed that on average teacher's talk time was about three times more than students' talk time. The dominant teachers' turns consisted of eliciting the students' knowledge and prompting their thinking. The students' replies were brief, particularly when the teacher used closedended questions or elicited one-word answers. Furthermore, students did not often ask questions to teachers and peers. However, a lot of evidence from this study shows that teachers tried to encourage students to talk more. Teachers gave chances for students to ask questions to teacher and peers. Teachers also made provision for teamwork or discussion among students to allow students to talk more. The teamwork and discussion also allowed students to have more time to prepare before answering some difficult questions.

Another traditional feature in questioning was that participants cared greatly about face while using questioning. Both teachers and students thought about losing face, saving face and giving face while questioning and answering. Teachers said that they were concerned about saving face of students. Teachers sometimes avoided making students embarrassed or in difficult/stressful positions if the student could not answer. Therefore, teachers positively encouraged students to talk more by focusing on fluency rather than accuracy. Teachers also gave face to students when they raised students' status in questioning. The teachers revealed that they respected students and considered students as "customers". For example, the teachers used very polite language. Similarly, students thought carefully about the matter of face in questioning. Students were afraid of losing face if they could not answer. They cared about the judgment of peers and teacher, so they sometimes felt demotivated to answer, or responded by making more effort to answer and learn. Students also said they sometimes volunteered to answer to save the face of their classmates. They thought the teacher might get angry and the atmosphere would become very stressful when no students answered the teacher. They also answered to save the teacher from an embarrassing situation or losing power/authority when the class became quiet and unresponsive. 
Finally, findings show that the choice of English or/and Vietnamese language also facilitated questioning. The English language was viewed as the purpose for and means of communication in the classroom. However, participants found that students' competence in the language varied. This sometimes made questioning in English challenging for students. Therefore, the participants used their mother tongue especially, in lessons of specific-subject content like semantics and business technical terms. 


\section{CHAPTER 7: DISCUSSION AND CONCLUSION}

\section{Introduction}

This chapter consists of seven main sections.

To begin, I provide the summary of this thesis. Then, I answer the research questions, referring to how questioning promoted language teaching and learning in these tertiary EFL classrooms in Vietnam.

Next, I discuss how questioning interactions are embedded within teaching and learning contexts. To do this, I discuss English teaching and learning in EFL classrooms in Vietnam and present a modified framework for questioning interaction based on Hall and Kidman's (2004) Teaching-learning map (T-L map).

In the next part I examine the implications, limitations of this study and suggest recommendations for further research. A conclusion ends this chapter.

\section{Summary of the study}

This study explores how Vietnamese tertiary educators use questioning to promote language teaching and learning in tertiary EFL classes in Vietnam. This section summarises the previous chapters.

In the introduction, I captured the prominent features of English education in Vietnam. In the context of economic renovation and the open-door policy, English has become the dominant foreign language in schools. There has been a shift from traditional methods to a communicative approach to promote learners' communicative competence. However, after three decades of the changes, there are still concerns about the quality of English education in Vietnam. From my own teaching experience and previous research about questioning in EFL, I was motivated to investigate how questioning could promote language learning in Tertiary EFL classes in Vietnamese cultural context.

In the literature review I signalled a sociocultural perspective to understand questioning in a Vietnamese context. The T-L map by Hall and Kidman (2004) 
provided a framework to discuss teaching and learning in class, and the different contextual features beyond the class. Theories and empirical studies of second language acquisition informed an understanding of learning English as a foreign language. The chapter also addressed more specifically the research context, especially the application of CLT, which is the dominant and recommended approach for English language learning and teaching in many EFL classes in East Asia and Vietnam.

My investigation used a qualitative, embedded multiple case study. The data for my study came from three sources: teachers' beliefs, students' perceptions, and classroom practice. Data were collected and triangulated using three collection methods: classroom observations, teacher interviews, and focus group discussions. In data analysis, I used thematic analysis for beliefs and perceptions from participants. I also combined discourse analysis and stimulated recall interviews with teachers to explain and clarify about what was happening in situations.

The first findings chapter, Communicative interaction, presented themes about questioning. The participants perceived that questioning was a important tool used by teachers to promote communicative learning and teaching through interaction. Questioning was viewed as a web of turns between teacher and students. Questioning provided opportunities for practising the target language in authentic communication. Questioning enabled learning through cooperation between teacher and student.

In chapter 5, The art of teaching, the second theme revealed that questioning was always purposeful. Teacher and students used questioning for different reasons: facilitating learning, diagnosing learning need, managing learning, and building classroom relationships. Questioning was seen as an effective tool to help teachers fulfill various pedagogical purposes.

In chapter 6, My home, my rules, the last theme reflected questioning in relation to cultural and traditional features, such as the unequal relationship between teacher and students, the concern about face/status, and the disparate English proficiency of participants. These features greatly influenced teachers' and students' perceptions and practices of questioning. Questioning, therefore, was situated in the local cultural context. 
The findings providing the answers for research questions are discussed in the following section.

\section{Addressing the research questions}

In the context of EFL classes in a Vietnamese university, five research questions framed and guided this study:

1. How is questioning understood in Vietnamese tertiary EFL classes?

2. How do teachers and students perceive the role of questioning?

3. How do teachers and students perceive the influences on questioning?

4. How do teachers and students apply questioning in the classroom?

5. How does questioning compare between classes where English is taught as a major subject at university and classes where English is taught as a non-major?

This section presents key findings responding to the five questions above, under the headings: understanding about questioning, roles of questioning; influences on questioning; applying questioning in the classroom; and questioning between Englishmajor classes and English non-major classes. Together these five sections provide a holistic answer to the main question of my research "How do Vietnamese tertiary educators use questioning to promote language teaching and learning in EFL classes? 
A summary of key findings responding to these research questions is presented in table below.

Table 14

Answers to Research Questions

\begin{tabular}{|c|c|c|}
\hline Questi & & Key findings \\
\hline $\begin{array}{l}\text { 1. How } \\
\text { questioning } \\
\text { understood } \\
\text { Vietnamese } \\
\text { tertiary } \\
\text { classes? }\end{array}$ & $\begin{array}{l}\text { is } \\
\text { in }\end{array}$ & $\begin{array}{l}\text { - Questioning is a web of turns, consisting of multiple turns } \\
\text { between teacher and students. } \\
\text { - Questioning is a way of communicating meaningfully in } \\
\text { the target language. } \\
\text { - Questioning is a process of building knowledge. }\end{array}$ \\
\hline
\end{tabular}

2. How do Four significant roles of questioning are reported. The Vietnamese EFL underlying purpose is consistently to promote teaching and teachers and learning students perceive the role of questioning?

- Questioning facilitates learning

○ In making their answers clear and meaningful, or listening to the teacher and other students, students have multiple chances to practise language skills.

- Students can learn the target language and the subjectspecific content in the target language as they constructe answers.

- Questioning helps diagnose learning needs

- Students' answers can be used to assess what the students know and are finding difficult so the teachers can tailor their teaching to the needs of the students.

- Answering teacher questions enables students to selfassess and recognise gaps in their knowledge. This motivates students to study harder.

- Questioning helps to manage learning and learning behaviour

○ Questions allows teachers to organise the classroom to implement their teaching purposes and direct learning activities.

- Teachers use questions strategically to gain the students' attention; reorient students towards learning; and allocate responsibilities in group work.

- Questioning supports a positive relationship between 
teacher and students:

- Questioning help teachers to gain respect because they can demonstrate their expertise when giving feedback, and show their respect for students' opinions.

$\circ$ Participating in questioning makes teachers and students open to sharing ideas and closer in their relationship with each other.

- A good relationship between teacher and students can encourage them to like and engage in classroom activities and contribute more.

3. How do Three main influences were identified by teacher and students, Vietnamese EFL including traditional teaching methods, the matter of face, and teachers and students' English proficiency.

students perceive the influences on

- Traditional roles of teacher and students significantly influence their questioning interactions.

questioning?

- The teachers take the role of director and controller of the questioning.

○ In response, students are passive and cooperate with teachers.

- Concern about losing face, saving face, and giving face is a barrier or an enabler to their questioning.

$\circ \quad$ At times losing face, saving face, and giving face can place students in a stressful position, making them afraid to engage in questioning.

- At other times students are motivated to engage in questioning when they care about saving face of classmates or the teacher.

- Student engagement and their English proficiency has the greatest impact on questioning.

- If students cooperate, teachers often feel encouraged and more prepared to construct deeper questions. Poor engagement of students is a barrier to teachers constructing high-level questions.

- Teachers ask different kinds of questions to students at different levels of English: more critical questions for students with higher levels of English proficiency, and less cognitively challenging questions for students with lower levels.

4. How do - Observational data show some alignments with teachers Vietnamese EFL and students' beliefs: 


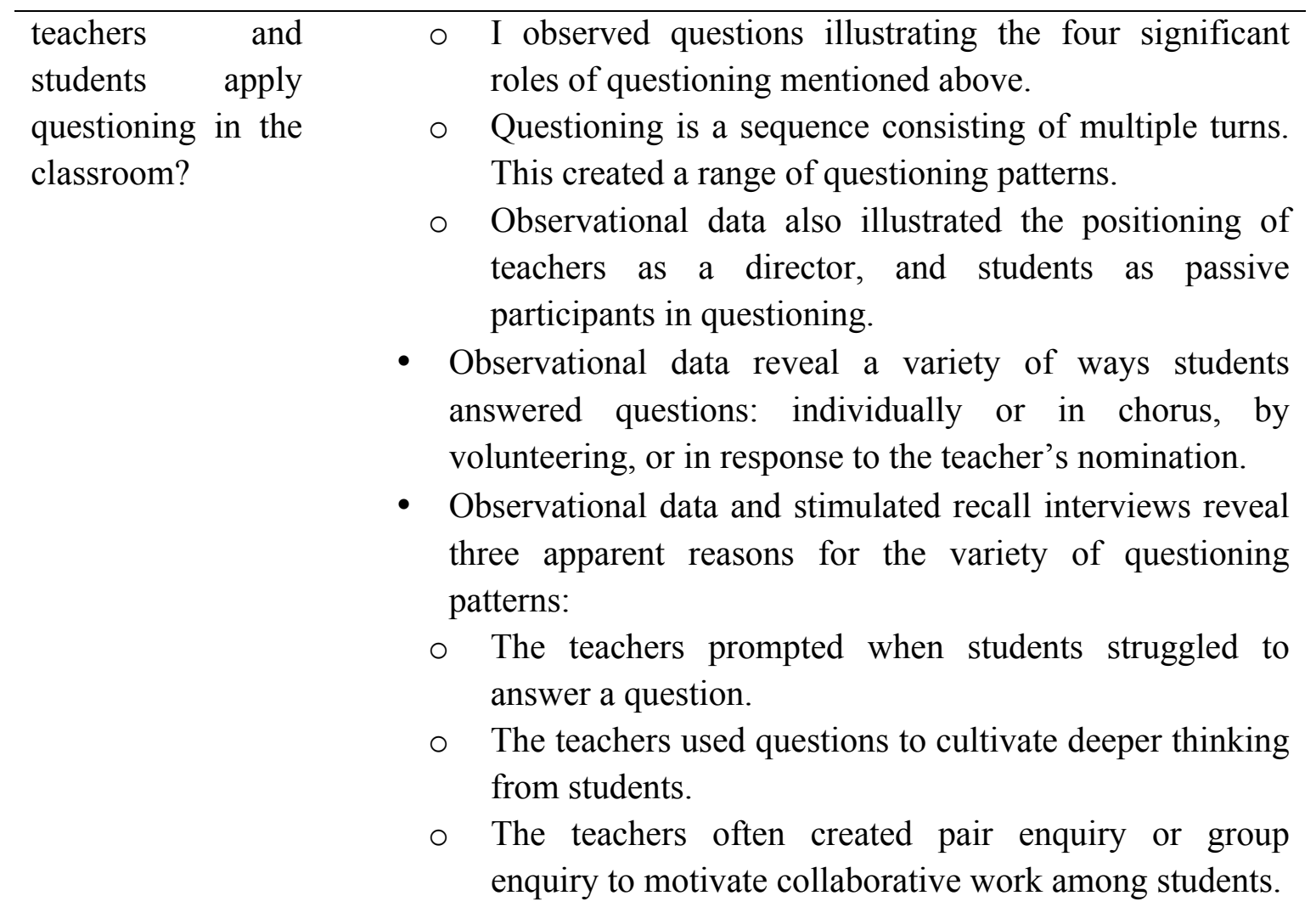

5. How does questioning compare between classes where English is taught as a major subject at university and classes where English is taught as a non-major?
There were some differences between English major and English non-major classes, such as:

- English major students were expected to articulate more critical thinking when participating in questioning; while English non-major students often struggled to respond at length and in depth to questions posed by the teacher.

- English major teachers and students were interested in English as a language of communication, whereas, English non-major teachers and students were interested in learning English specifically for business.

- Teacher questions in the two different cases were designed differently. English non-major teachers did not ask many critical questions, mainly because they feared revealing that they did not have a deep knowledge of business content. English major teachers, in contrast, expected to cope with in-depth thinking in the foreign language. 


\section{Understanding about questioning}

In my study, questioning was understood in three ways: questioning involved webs of turns, questioning was seen as meaningful communication in target language, and questioning was a process where learning was co-constructed by the participants. Chapter 4 of this thesis viewing questioning as communicative interaction provides the evidence for how teachers and students defined questioning.

Firstly, my study used a discourse perspective to reveal questioning as a sequence constructed from different turns among teachers and students. Both perceptional and observational data show that there were more than three basic turns (InitiationResponse-Feedback (IRF)), and more than two participants engaged in the questioning sequence. My data illustrate that questioning was a web of turns. Questioning did not follow fixed patterns. Teachers and students rarely engaged in the three IRF turns. Instead they extended questioning and involved complex and multiple turns. Additional turns such as student struggle, student discussion or teacher prompt were revealed. This is in line with research claiming that a variety of questioning sequences are used in EFL classroom; especially when teachers use the third turn to expand the sequence (Miao \& Heining-Boynton, 2011; Waring, 2009).

Secondly, my study illustrated how questioning in the EFL classroom provides opportunities for authentic communication in the target language. Questioning developed into meaningful conversation when teachers did not focus on errors. When students answered the teacher's questions in the target language, they were pushed to produce language, and to interact with a more competent speaker (see Communicating meaningfully in English on pages 93). This is reminiscent of the Output hypothesis (Swain, 2000), which argues that a learner's language acquisition can be enhanced if the learners are pushed to produce output and use the target language in meaningful ways (Shomoossi, 2004).

Thirdly, questioning was a process of interactive learning as an alternative to the lecture format. Participants saw questioning as learning, which was coconstructed by both teachers and students rather than students experiencing a one-way lecture. Also, questioning was a collaborative activity in that participants learned from each other; students learned from peers, both students who answered and also those who observed 
could learn, and teachers could learn from students. The output of the student who is answering can also become input for the other students who are observing the question-answer interaction (Swain, 1995). This supports studies in Second language acquisition (SLA) theory illustrating that interaction provides opportunities for both participants and observers to notice the language (Ko, 2014).

Research about questioning involves an understanding of what the concept of questioning means. Some researchers focus on the functions and forms of questions (Heritage \& Heritage, 2013; Lee, 2006). Some studies view questioning as a discourse sequence (Sharpe, 2008; Shen \& Yodkhumlue, 2012). My study contributes to a definition of questioning as a form of interaction that is central to learning and teaching. The notion that questioning offers opportunities for meaningful communication in the target language reveals that questioning is a useful means to promote students' communicative competence.

\section{Roles of questioning}

Questioning played a significant role in student learning as well as in teaching. Four main roles of questioning emerged from the data, mainly in Chapter 5: facilitating learning, diagnosing learning needs, managing learning and learning behaviour, and building relationships.

First of all, data reveal that questioning developed students' language learning and critical thinking (see Facilitating learning on p.107). Language learning in this study, refers to the target language (language skills and language content) and subject content embedded in the target language learning. Language learning consisted of language skills that were developed through questioning, such as pronouncing words comprehensibly. In making their answers clear and meaningful, or listening to the teacher and other students, students had multiple chances to practise these skills. Language learning could also be language content, for example, in constructing answers, students learned how to use new vocabulary or structures in the target language. In addition, language learning in my study also involved learning business content. Business was the topic of questioning. The negotiating of business content helped develop the language skills needed to process and express complex ideas. In addition, questioning promoted cognitive development. My findings supported earlier 
studies in that teachers used different types of questions to target different levels of cognition, which was a common theme in previous studies (Pham \& Hamid, 2013; Wang \& Wang, 2013). In addition, teachers in my study were aware of and adept in encouraging critical thinking by using questioning to scaffold and teach students to work more independently (see Promoting higher level thinking, p.114). Teacher questioning was used to challenge cognition, connect knowledge with real life, and move students to think critically at a higher level.

Another important role of questioning was helping teachers and students to diagnose learning needs (see Diagnosing learning needs on p. 119). Teachers used students' answers to assess students' learning or language proficiency level. Teachers thought that answers to their questions provided useful data on what the students knew and were finding difficult, so the teachers could tailor their teaching to the needs of the students. Answering teacher questions enabled students to self-assess and recognise gaps in their knowledge. Both teacher and student participants agreed that this selfassessment could push the students to think about their proficiency seriously, and it motivated them to study harder when they could see their own progress and gaps in their knowledge. My study provides further evidence supporting the noticing hypothesis that second language learning takes place when learners notice about the mismatches between what they do not know or know only partially (Gass, 2013; Swain, 1995).

Thirdly, most teachers believed that questioning was a tool that helped teachers manage learning and learning behaviour (see Managing learning on p. 125). Teachers believed that such classroom management was important for teaching and learning, and questions allowed teachers to organise the classroom to implement their teaching purposes and direct learning activities. Teachers also used questions strategically to gain the students' attention when the students were not focusing on the lesson. Teachers reported that their questions reoriented students towards learning, and they also used questions to allocate responsibilities in group work. My study was congruent with Cohen, Manion, Morrison and Wyse's (2010) findings that teachers asked questions for managerial purposes and used questioning to arrange learning activities and encourage positive learning attitudes. 
Questioning supported a positive relationship between teacher and students to facilitate teaching and learning like the lubricating agent for an engine (see Lubricating agent on p. 139). Through questioning, teachers were able to gauge, not only students' level of proficiency but also students' preferences and feelings. Questioning helped teachers to gain respect and build a relationship with students because they could demonstrate their expertise when giving feedback, and at the same time show their respect for students' opinions. Students stated that they felt closer in their relationship with their teachers when they engaged in the questioning process. Few studies mention the role of questioning in building relationships in EFL classrooms. My study shows how questioning acted as a lubricating agent to facilitate learning and teaching relationships. Both teachers and students perceived that a good relationship between teacher and students could make the students feel like engaging and contributing more, thereby acquiring new language and gaining more knowledge.

My study supports other studies in finding that teachers used questioning for different reasons (Farahian \& Rezaee, 2012; Ur, 2000). It suggests that the functions of questioning can be gathered under four common categories: facilitating learning, diagnosing, managing, building relationship. Data show that for some of these reasons, such as managing or building relationships, questioning might not be primarily aimed at teaching content. However, any forms of questioning had the potential to directly or indirectly promote language learning.

\section{Influences on questioning}

Data emerging in the findings, especially chapter 6, My home, my rule on p. 150, record that local contextual influences, such as traditional teaching methods and the matter of face, had an impact on their questioning practices. In addition, teachers also shaped their questions according to the engagement and motivation of students.

Firstly, participants suggested that the traditional roles of teacher and students significantly influenced their questioning interactions (see Without the teacher, students cannot learn on p. 150). The teachers were expected to take the role of director and controller of the questioning. Teachers chose both the topic and the types of questions. They also directed students to answer and could promote or recast the students' answers. Teachers could select how students answered, for example, in 
chorus, by nomination, or by choosing a volunteer. In response, students were passive and cooperated with teachers. According to teachers and students, the positions of teachers and students in questioning were rooted in traditional habits and cultural values. Previous studies in Asian countries also noted the unequal position of power between teachers and students in EFL classrooms. For example, DeWaelsche (2015) illustrates how in Korean traditional EFL classroom, teachers were dominant and the suppliers of information, while students were reluctant to ask and use critical thinking skills. However, my study argues that the teacher's authority was necessary to direct and promote questioning.

Secondly, both teachers and students also mentioned face as a barrier or an enabler to their questioning (see Maintaining face on p. 160). Both teachers and students thought about losing face, saving face, and giving face while questioning and answering. Teachers said that they took care to save the students' face. Teachers tried to avoid embarrassing students or placing them in a difficult/stressful position if the students could not answer. Therefore, teachers would positively encourage students to talk more, and if this did not work, teachers focused on fluency rather than accuracy. Teachers also gave face to students by deliberately trying to raise students' status through questioning. The teachers revealed that they respected students and considered students as "customers".

Similarly, students carefully considered the matter of face in questioning. Students were afraid of losing face if they could not answer. They cared about the judgment of peers and teachers, so at times they felt demotivated to answer or at other times made more effort to answer and learn. My findings were similar to Tan's (2007), which recorded that teachers in China were aware that a fear of losing face or a wish to save face also prevented their students from engaging in questioning. However, my study provides a new perspetive in that an awareness of face encouraged students to engage in questioning. Students said they sometimes volunteered to answer to save the face of the class. They thought the teacher might get angry, and the atmosphere might become very stressful if no students answered the teacher's questions. They also answered to save the teacher from embarrassment or losing power/authority if the class was too quiet and unresponsive. 
In addition, both teachers and students believed that student engagement had the greatest impact on questioning (see Using both languages on p. 165). Students' participation could motivate or demotivate teachers to ask questions, and students to answer. According to the teachers, if students cooperated, teachers often felt encouraged and more prepared to construct deeper questions. In contrast, poor engagement of students was seen as a barrier to teachers constructing high-level questions. Furthermore, the engagement of students appeared to be determined by the students' level of English proficiency. Other literature has found a relationship between learners' participation in questioning and their English proficiency. For instance, Sano (2014) claims that Japanese EFL students were reluctant to respond to teacher questions because of their limited English competence. My study adds another example from another Asian setting. In particular, teachers found that they asked different kinds of questions to students at different levels of English: more critical questions for students with higher levels of English proficiency, and less cognitively challenging questions for students with lower levels.

My study emphasises three influences upon questioning: an asymmetrical power relationship between EFL teachers and students, the matter of face, and students' engagement and level of English proficiency. These influences reflect an essential element in sociocultural theory (SCT); that cultural contexts mediate language learning. The influences on questioning in Vietnamese EFL classroom were similar to those reported in other Asian nations (DeWaelsche, 2015; Sano, 2014; Tan, 2007). However, my study adds that the traditional or cultural factors were not always a barrier to questioning.

My study is congruent with studies suggesting that cultural settings influenced the way teacher and students engage in questioning. My study provides an empirical investigation in a Vietnamese context, and suggests that sociocultural influences play a significant role in language learning in Asian EFL classrooms. Furthermore, these influences disclose some cultural differences between Asian and Western countries in promoting communicative language teaching. 


\section{Applying questioning in the classroom}

Data, especially from the observations, provided insight into how questioning was managed in practice. Also, observational segments used in the stimulated interviews with teachers illustrated teachers' thoughts about their classroom decisions.

Observations, especially those used while interviewing teachers, identified that there was alignment between teachers' beliefs and practices. For example, teachers identified the four main roles of questioning mentioned above that I observed in their classroom questioning (see Episodes 8-21 in Chapter 5).

In addition, data from classroom observations showed some similarities between teachers' and students' beliefs about the position of teachers as a director, and students as passive participants in questioning. There was evidence in practice, for example, in Episode 24 (p.159), about the asymmetrical power relationship between the teachers and the students. The teachers placed themselves in a more powerful position than the students, because teachers talked more, and directed the questioning interaction. Teachers also opened or closed the questioning interaction. The observation data showed more teacher talk than student talk, and the dominant teacher turns consisted of elicitations of the students' knowledge and prompting of their thinking. The students' replies were brief, particularly when the teacher used closed questions that elicited one-word answers. Furthermore, students did not often ask questions to teachers and peers. However, there was considerable evidence showing that teachers were aware of encouraging students to talk more. Teachers gave chances for students to ask questions to the teacher and peers. Teachers also constructed tasks that required teamwork or discussion among students, with the purpose of prompting students to talk more. The teamwork and discussion also allowed students to take more time to prepare before answering difficult questions.

My study acknowledges that teachers' beliefs about the purposes of questioning were consistent with their practice, and there was an unequal relationship between teachers and students in questioning. This adds further evidence to the literature comparing teachers' beliefs and practices (Farrell \& Mom 2015; Pham \& Hamid, 2013). However, my study found alignment between students' perceptions and their performance. For example, students admitted that they were shy and passive in 
response to their teachers' dominant position. My observations of questioning in the classroom illustrated that students rarely initiated, or criticised teachers. This also reveals the consistency between students' beliefs and teachers' beliefs. The comparisons between belief and practice, between teacher and students, were highlighted through the employment of multiple sources of data collection: from teachers, from students and from observations of classroom practice.

Student responses is a common topic in literature (Boyd, 2015; Dalton-Puffer, 2007; DeWaelsche, 2015; Jiang, 2014; Wright, 2016). My observational data revealed a variety of ways students answered questions: individually or in chorus, by volunteering, or in response to the teacher's nomination. This supports DaltonPuffer's (2007) and Jiang's (2014) categories of different ways of answering.

In my study, observational data also revealed a relationship between common question processes and different ways of answering. Closed questions required short answers and allowed students to answer in chorus (see Episode 9 on p.117). The questioning in this case did not appear to focus on language learning but managing the class (see Episode 18, p. 136) or to stir up atmosphere (see Improving learning behaviour, p.130 ). In contrast, if questions were open and required a reasoned response or individual perspective, teachers often selected an individual student or different students in turn (see Episode 11 on p.124). This finding agreed with findings from Dalton-Puffer (2007), and Wright (2016), that suggested how different questions could involve different ways for students to answer.

My study adds an explanation of how teachers and students chose the questions and ways of answering (see Teacher as the director or superior on page 153). Teachers seemed to use nomination when the class did not respond to teacher questions, and no student was willing to answer. Sometimes, teachers nominated students who were not paying attention. Nomination seemed to make students stressed because most nominated students were embarrassed and struggled to answer well. In contrast, when teachers invited students who had raised their hand, the volunteer students seemed to be confident and often demonstrated that they could have good answers in the target language. By drawing upon data from observations and from stimulated recall interviews, my study provides an insight into participants' perceptions, feelings and performance that influenced the answering process. 
Data from classroom observations in this study show that questioning interactions were rarely simple, two or three turns routines between teachers and students. The teacher participants in this study always had strategies to encourage students to respond when they struggled to answer. Instead, there were two extended questioning patterns commonly found. The first pattern was when teachers prompted further answers: teacher question-student struggle to answer/simple answer-teacher prompt/modified questions-student response-teacher feedback and questions-student response-... Teachers used their turn to support students to answer and to initiate a further cycle of interaction. This questioning created longer interactions between the teacher and students. Another questioning pattern witnessed in the study was teacher question-student discussion-student answer... This routine enabled forums for peer discussion, which might be in pairs or groups of students, duplicating interactions among students. This took place before an interaction between students and the teacher. These two extended questioning patterns were seen as productive because they gave students more chances to speak in depth about the topic with either teachers or peers (see Learning from each other on p. 101). By initiating these patterns, the teacher could create more turns for students to develop their opinions.

My study proposes that the reasons for the variety of questioning patterns appeared to arise from three situations: the teachers prompted when students struggled to answer a question, the teachers encouraged deeper thinking, and teachers motivated students to participate in group work discussion.

Firstly, when students struggled to answer teacher questions, teachers could use different techniques such as repeating, paraphrasing, using more specific questions, and providing hints by giving examples. Episode 9 on p. 117, for instance, illustrates how these techniques helped student to be able to answer teacher questions. Other studies also found that EFL teachers used similar techniques in teachers' responses when the students did not answer (Kao et al., 2011; Yaqubi \& Mozaffari, 2011). My study suggests further techniques they used to help students to respond were using the first language and translation, or providing visual aids from videos or pictures. Most teachers were observed to be very patient in facilitating students to answer. Teachers explained that teachers were pushed and aware of making the interaction successful, therefore, they always provided prompts to help students to be able to respond. 
Another questioning sequence illustrated how teachers cultivated deeper thinking from students, which is considered to be an essential aspect of CLT (Jacobs \& Farrell, 2003). I witnessed how teachers often posed further questions after the students' initial answers (for example, in Episode 11 on p. 124). Teachers dug deeper by asking more questions, which usually required higher cognition, for example, asking students to give reasons or provide evidence, or pose hypotheses. Teachers in these situations involved more than one student in answering one question, to open the interaction to include different viewpoints. The teacher feedback afterwards often positively summarised students' answers, or offered further suggestion or development. Teachers claimed that critical thinking was important and benefited learning.

I observed that the teachers often created pair work or group work to motivate students (Episodes 10, 12 and 13 on p. 122, 127, and 128 respectively). According to teachers from the interviews, discussions would allow all students the chance to work and speak, and facilitate students to work out difficult questions together. In these situations, teachers often circulated around each group to direct or offer help in their discussions. Therefore, the questioning sequences became more complicated with multiple participants (teachers and different members in groups) and, according to participating teachers and students, this provided the opportunity for questions initiated by students to teachers because the teachers were more accessible to them. Answers arising from group discussions were often well-prepared and showed high levels of thinking (see Learning from others on p.101 ). This was an example of how questioning can promote collaborative learning, one of the aspects of CLT (Richards, 2006).

Literature identifies that extended questioning sequences result from the teacher's skilful management in feedback turns, and may perform a variety of functions such as affirming, repairing, prompting, and exploring further perspectives (Kao et al., 2011; Meng et al., 2012). My study adds empirical evidence of a variety of questioning patterns. Furthermore, I combined discourse analysis and stimulated recall interviews in observation data. This combination allowed me to illustrate and explain the turns and participants' decisions in questioning. 
In summary, my study identified three extended questioning sequences, which cover how teachers used questioning when students struggled to answer, how teachers used questioning to cultivate deeper thinking, and how the teacher used questioning to promote collaborative work among students. These three sequence types were evident across most interactions in the observational data. They illustrate how flexible and complicated questioning patterns were. In other words, questioning in practice rarely consisted of three basic IRF turns between teachers and students, but turns and participants varied widely. Furthermore, observational data showed that such questioning faciliated communicative interactions in this EFL context. The various questioning patterns emerged from the dynamic of the pedagogical discourse.

\section{Contrasting questioning between English-major and English non-major classes}

Participants in both English major and English non-major shared significant similarities in perceptions and practice about questioning. However, there were a number of differences in expectations and practices of questioning in two classes.

For example, teacher and student participants expected English major students to be able to engage in more critical and high-cognitive questioning. These students were required to answer with more reasoning and evidence. Whereas, in English non-major classes, teachers reported they had to simplify their questions and prompt the answers. The observation data showed that questioning in the English major class often contained longer answers that reflected deeper critical thinking from students, while students in English non-major classes struggled with expressing their ideas in the L2 (see Episodes 8 and 9 on p. 112 and 117 respectively).

Furthermore, the cross-case comparison between participants in the EM class and ENM class also revealed that English major teachers and students were interested in English as a language of communication, whereas, English non-major teacher and students learnt English specifically for business (see Elicting learning of the content on p.107).

Teacher and student participants thought that the type of class (English non-major or English major classes) made a difference to the students' participation. For example, students in English major classes were often reported to have higher English 
proficiency and greater willingness to answer than students in English non-major classes. This enabled English major students to demonstrate their critical thinking while answering in the target language (see Elicting learning of the content on p.107). Teacher participants also clarified why their questions were managed/designed differently. English non-major teachers did not ask many critical questions, mainly because they feared revealing that they did not have deep knowledge of business content. English major teachers, in contrast, expected to foster in-depth thinking in the foreign language (see The teacher as the director or superior on p. 153).

The differences between these two kinds of class, English major or English nonmajor, were revealed teachers and students' interviews and my observations of classroom practice. The later sections will elaborate these differences further.

\section{Summary}

To conclude, this section reviewed findings in relation to the research questions of the study. It indicates five key matters.

- Questioning in EFL classroom was defined by participants as an interaction consisting of a variety of turns shared among participants. Questioning was considered to be communicative interaction in the target language. Questioning was also viewed as a process in which both teachers and students contributed to the learning process.

- Questioning played a significant role in motivating students, co-constructing learning, promoting language competence and cognitive development, managing classroom activities, enhancing teacher and student relationships, and assessing learning.

- Cultural and local contextual factors, such as the dominance of teacher, the concern about status, and the use of the first language could influence questioning.

- The use of questioning in classroom was congruent with teachers' and students' beliefs about the roles of questioning, and positions between teachers and students in questioning. Observational data, especially, illustrated and explained why teachers used a variety of questioning sequences in classroom practice. 
- The cross case analysis reveals differences between questioning practices in English major and English non-major classes, for example, particularly in levels of critical thinking and purposes of using English language.

The five salient points above suggest that questioning is critical for teaching and learning the target language, since it offers learning opportunities to communicate and understand the target language through interaction.

Within a CLT based approach, the asking-answering mechanism can create interaction, encourage collaborative learning, and promote critical thinking. These are the key aspects of CLT (Jacobs \& Farrell, 2003; Nunan, 2004; Richards, 2006; Richards \& Rodgers, 2001). Therefore, my study found that questioning fits within a communicative approach. However, my study also viewed that questioning interaction was significantly influenced by the traditional roles assumed by teachers and students. In tertiary EFL teaching and learning in my study, questioning was situated in Vietnamese culture. This is in line with SCT and SLA theories that language learning is co-constructed between participants, and it is situated in social and cultural contexts. The next section will discuss further the phenomenon of questioning using the literature about the contexts.

An adapted T-L model: Teaching and Learning in Vietnamese Tertiary EFL Classrooms

This section theorises teaching and learning in Vietnamese tertiary EFL classrooms. The use of questioning is discussed in relation to the T-L map proposed by Hall and Kidman (2004).

As noted in the literature review chapter, the T-L map (Hall \& Kidman, 2004) provides a theoretical framework to capture the influences of social and cultural features to the teaching and learning activities in EFL classes.

The T-L map (Figure 7 below) links the three components of the teaching and learning process, students, teacher, and content. The relationships among these components are recognised as expertise (between teacher and content), rapport (between teacher and students) and understanding (between students and content). 
These components and their relationships are situated within three levels, the teaching-learning context in the centre of the map, an institutional context and subcontext at another level, and the community contexts at wider level.

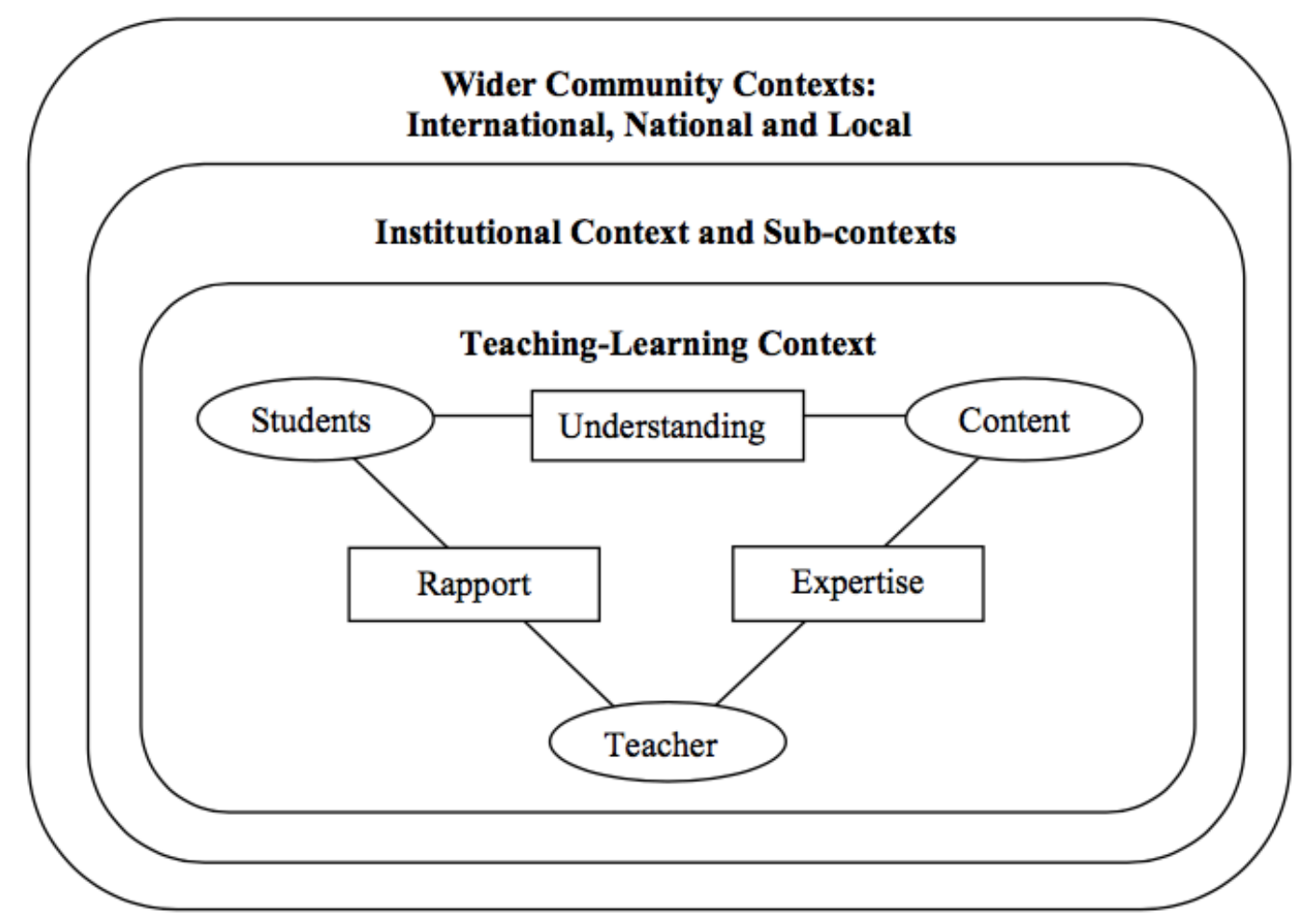

Figure 6: T-L map (Hall \& Kidman, 2004)

Using the T-L map theorises how English education was contextually situated in Vietnam. My study revealed how teachers' and students' questioning behaviours were influenced by factors beyond the classroom. For example, questioning was influenced by contextual factors such as cultural expectations and institutional differences. This model conceptualises influences within the classroom context, specifically the relationships between teacher, students, and language learning (content), and other environmental factors that influence the relationships.

Moreover, the findings of this study suggest that a new aspect, questioning, should be positioned within the teaching-learning context of the T-L map. The significant role of questioning interactions in learning is supported by EFL literature that interaction links all the other contextual elements in the T-L map, teacher, students and content (Meng, Zhao \& Chattouphonexay, 2012; Ozcan, 2010). The data from my study suggest that interaction should take a central position in relation to other key 
elements, teacher, student and content in the context of Vietnamese English language education.

For this reason, I argue that the T-L map of Hall and Kidman (2004), when applied to the teaching and learning of English in a Vietnamese university, should be extended by putting questioning, as a form of interaction, in the centre of the diagram. Furthermore, the relationships among the components also are modified under the influence of questioning. The justification for modifying the map will be discussed in detail.

The new map that describes the learning and teaching in EFL classroom in tertiary education in Vietnam is shown in Figure 7 below.

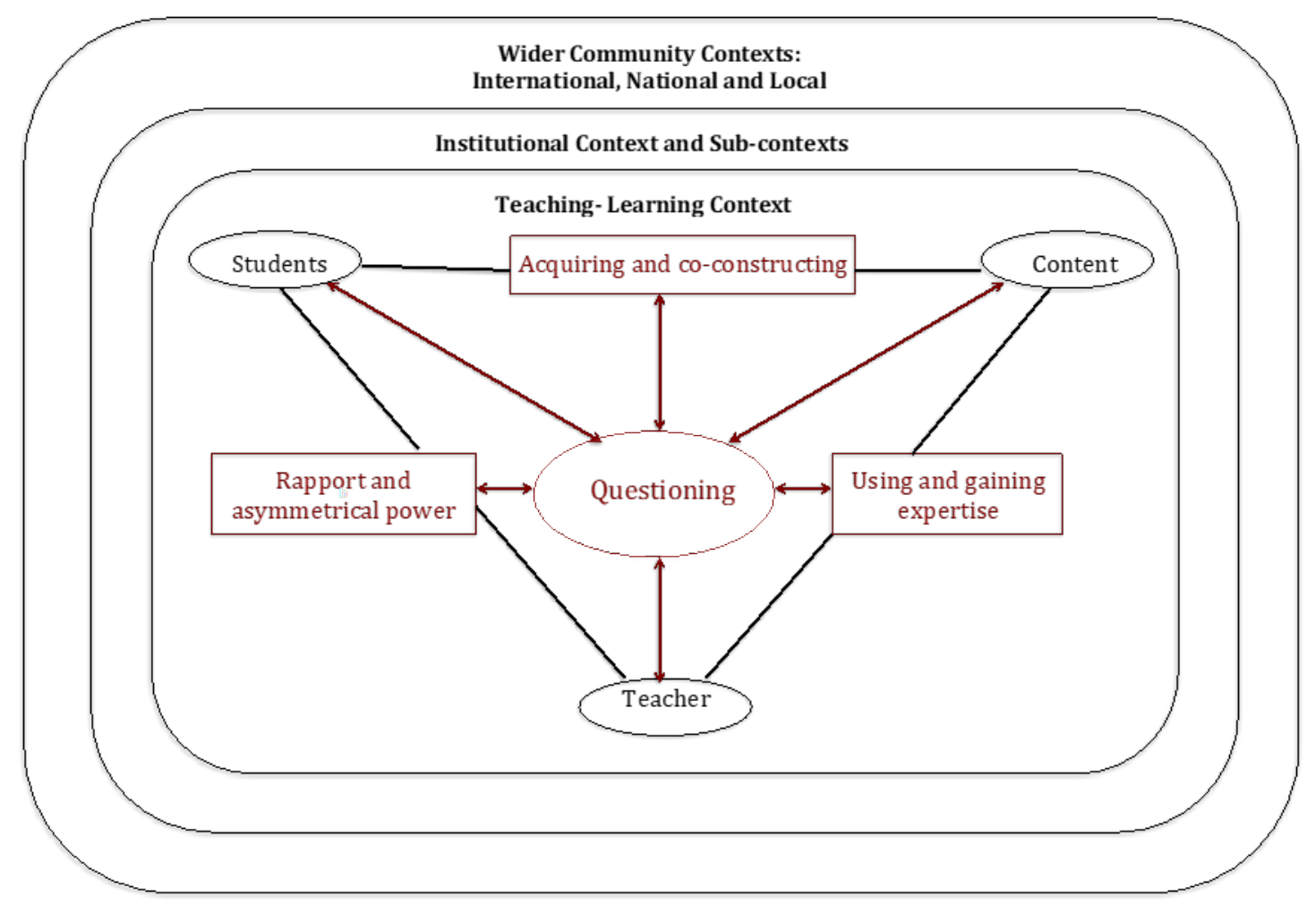

Figure 7: Modified T-L map for teaching and learning in Vietnamese tertiary EFL classrooms

The discussion now considers each of the contexts in turn. I start with the wider community context, which captures the current global and local trends leading to the commitments and tensions in applying the communicative approach in EFL classes in Vietnam. The second part analyses how the institutional context and sub-contexts, 
such as English for different purposes result in distinctions in English learning in the two types of classes, English major and English non-major. Finally, the discussion addresses the immediate classroom teaching and learning context. In this classroom context, the relationship among the elements of teachers, students, and content, will be discussed in relation to the core element: questioning. The red colour in Figure 7 above illustrates the modified features from the original T-L map by Hall and Kidman.

\section{The community contexts: Commitments and tensions in applying the} communicative approach

The wider community context consists of the international context, as well as national and local contexts. The following discussion will address how the contexts led to two significant matters in English education at tertiary level in Vietnam. The first one is how policymakers and educators in EFL classes have committed to promoting English communicative competence. The second matter is in practice; there remains a tension in promoting CLT in EFL classes. These matters will be discussed in the next sections in relation to the findings of this study.

\section{Commitment to improving English communicative competency}

As presented in the introduction chapter, in the context of economic renovation (from 1986) and the subsequent open-door policy, the Vietnamese government prioritises promoting English education. In the history of English education at tertiary level in Vietnam, from the 1990s (Nguyen, 2007), there has been a shift from teacher-centred approaches such as grammar-translation and audio-lingualism to learner-centred approaches, which focus on the development of communicative language ability for learners. The communicative language teaching approach (CLT) has been mandated by the Ministry of Education and training to be widely applied into EFL classrooms to promote learners' communicative competence in English (Hiep, 2007; Ngoc \& Iwashita, 2012).

CLT was introduced in the tertiary curriculum to promote learners' communicative competence in English. In EFL classrooms at tertiary level, teachers and learners also consider learning English important, and they are motivated to apply CLT in teaching 
and learning through questioning in the classroom. However, the success of the application of CLT in Vietnam is still a concern (Bock, 2000; Ngoc \& Iwashita, 2012; Pham, 2004, 2007; Pham \& Hamid, 2013).

In my study, through observing teachers' and students' questioning, I witnessed the transition from traditional methods to a CLT approach in these EFL classrooms. The next section will discuss how teachers and students in this study used questioning to promote key principles of CLT, for example, learning through interaction, learnercentredness, new roles for teachers as facilitators and negotiators of meaning, authentic environment, collaborative learning (Jacobs \& Farrell, 2003; Nunan, 2004; Littlewood, 2007, 2014; Richards, 2006; Richards \& Rodgers, 2001).

Firstly, teachers worked hard to teach through interacting with students, one of the key principles of applying CLT. As stated in the Findings, particularly Chapter 4, the teacher participants perceived questioning as an effective way to teach both language and the subject content. Questioning offered chances for interaction between teacher and students. Teacher participants in my study used questioning as a tool to encourage multiple turns from many students to cultivate higher thinking and discussion in class. Teaching and learning were through interaction rather than teachers reading or providing information to the students and students copying it into textbooks, which was a traditional teaching method in Vietnam (Thanh, 2011). The teachers also used questioning to promote interactions among students, providing chances for them to learn from each other. This is in line with Richards' (2006) view that "learning is not an individual, private activity, but a social one that depends upon interaction with others" (p. 25). My study also illustrates that questioning was a form of interaction that can promote effective learning because students were encouraged to engage with one another to co-construct their understanding.

Furthermore, the motivation of students to learn English encouraged them to become active and autonomous learners. English has become a compulsory subject across the whole higher education system in Vietnam, and English competence is considered an advantage for getting more desirable jobs after graduation, such as jobs with higher pay, jobs in foreign companies or in big cities. Ngo, Spooner-Lane, and Mergler (2017) suggested two types of motivation in EFL classes, extrinsic motivation and intrinsic motivation. In terms of extrinsic motivation, according to Hoang (2010), 
tertiary students are motivated to learn English because a good command of English helps them to find desirable jobs. Also, he categorises two more motivations for learning English. Firstly that English is necessary to pass tertiary examinations, and secondly, proficiency in English opens the door for Vietnamese students to study further in English-speaking countries. My study adds a learning dimension to Hoang's work in that both teachers and students perceived they engaged in questioning to improve their English communicative competence, to achieve a reward (such as receiving bonus marks from teachers), to avoid feeling shame, or to gain respect from others.

Besides, the findings also suggest that students in my study were intrinsically motivated to learn English (see Learning from each other on p. 101). The students were determined to learn English. Both teachers and learners were aware that participating in questioning was an effective way of learning English. Through asking, answering, and receiving feedback, students had multiple chances to use and absorb the language. Teachers in my study stated they tried to create opportunities for students to participate in questioning. The teachers said they wanted to question students, and they also wanted questions from students. On the other hand, though they did not often question teachers, the students said that they wanted to answer teacher questions because they knew it would benefit their English learning. Observational data also demonstrated that students, especially in the English major classes, volunteered to answer teacher questions and tried hard to elaborate on their responses (on Episode 9 on p. 117). This shows that the students desired to engage in questioning because of an intrinsic motivation to learn English (Ngo, Spooner-Lane, $\&$ Mergler, 2017). Vietnamese students in my research were highly motivated to learn English.

The teachers were also aware of encouraging students' engagement by offering opportunities for students to ask questions. Teachers respected and accepted opposing view points from students. Though these attempts were not always successful, they reveal how teachers were concerned about developing student's active engagement (see Respecting students on p. 142).

Furthermore, in these EFL classrooms, teachers and students have the chance to create meaning and communicate in an authentic environment for speaking English 
(see Communicating meaningfully in English and Focus on fluency on p. 93 and 94 respectively). In response to globalisation and the Vietnamese government's action plan to booster English language education, English has been popularly used as the medium of instruction in many EFL classes (Dang, Nguyen \& Le, 2013). In my study, this appeared to positively promote students' communicative competence. Both teacher and student participants used English to communicate for most of each period. The work of teachers and students to use English all the time stimulated abundant questioning sequences in the target language. The questioning sequences conducted by participants in these classes in English were authentic and similar to those used in L1 classrooms, including greetings, phatic communication, and classroom management activities (seating of students, distributing responsibilities to group members). According to Campbell (2004), Richards (2006) and Littlewood (2007), one of the issues in EFL classrooms in East Asian countries was the lack of authentic environments to communicate in English. My study added an example of how Vietnamese EFL teachers could implement CLT by allowing students to communicate in the target language naturally through questioning interactions.

To summarise, in my study the international and national contexts involve the promotion of interaction in teaching English, high motivation for learning English, and the use of English as the medium of instruction. Under the influence of these, policymakers and educators committed to promoting English education and communicative competence. My study also illustrates that teachers and students have been encouraged, and work hard, to apply CLT. However, my study also indicates that there were some aspects of questioning where teachers and students felt tension between the Western concepts and their traditional values when applying CLT. These are discussed in the next section.

\section{Tension between Western concepts and traditional values in applying CLT}

There was a mismatch between teachers' and students' expectations in implementing collaborative and active learning. Teachers were aware that they needed to generate discussion among students, which created more interaction (see Organizing classroom activities on p. 126). In interviews, teachers said they offered time for discussion among students to make students talk more and dig deeper into teacher questions. Both teachers and students considered these discussion forums were 
beneficial because students could learn from peers and help each other. Teachers said that they wanted group work to promote collaborative and active learning among students. This is one example of how teachers tried to promote autonomous learning, one principle of CLT. On the one hand, some of the observational data revealed that after discussion, students could answer at length and demonstrate high-order thinking. On the other hand, my field notes recorded that the teachers' presence influenced the work of students in discussion. If the teacher came to the group, the group tended to talk more and work actively. In contrast, without the teacher's guidance, the group would not discuss the questions but talked privately in their first language, or some members in the group worked actively while others did something in private. The student participants also admitted that, when working in groups, they preferred being told what they needed to know and precisely how they should work together. This is another example of how these Vietnamese students were not independent and autonomous enough to manage their own group learning according to a Western model (Nguyen, Terlouw, \& Pilot, 2005b). However, teachers tried to act as facilitators, guiding the groups by asking eliciting questions to prompt students to work together and solve the problem (see Episodes 12 and 13 on p. 127 and 128 respectively).

Other evidence shows the differences between teachers' and students' perceptions and practices about applying CLT. For instance, while teachers said that they preferred it when students actively asked questions, students appeared passive and rarely initiated questioning interactions (see The students as passive participants on p. 150). Many students hesitated to engage in answering because they felt shy and did not want to express themselves in front of others. Teachers also tried to prompt students to express their opinion, and welcomed opinions and argument from students, though this was not always effective. The students said they were shy and did not feel comfortable to ask questions or argue with teachers. These show that some students found it difficult to participate in CLT classes.

Furthermore, there was evidence that teachers also experienced tensions in using CLT. Though according to the Western model there should be a low power distance between students and teacher (Nguyen, Terlouw, \& Pilot, 2005b), both data from interview and observation revealed that teachers still wanted to maintain their 
authority in the classroom (see The teacher as the director or superior on p. 153). For instance, teachers said they sometimes showed off their expertise by asking highcognitive questions and giving knowledgeable answers. In particular, class observations suggest that there were times when the teacher chose to manage some parts of the students' answer or redirect students' answers for particular purposes, for example, interrupting students talking to ask for clarification, or oriented students to expand on the answer (see Episode 24, p. 159). Data in my findings indicate that teachers considered their authority necessary to gain students' respect and to conduct effective questioning.

To account for the above conflicts in teachers' and students' perceptions and practice, it is worth mentioning that the passiveness of students and the power/authority of teachers in the EFL classroom is rooted in the tradition of Vietnamese society. As stated in the introduction, one challenge seemed to arise from a conflict between the Western concept of CLT and Vietnamese traditional educational values, known as Confucian Heritage Culture (CHC) (Ngoc \& Iwashita, 2012; Nguyen, Terlouw, \& Pilot, 2005a; Sullivan, 2000). CHC applied to classroom practice requires a teachercentred mode of learning underlying knowledge transmission, where students are passive and rarely dare to question the teacher. Many Vietnamese proverbs express this moral lesson: "Không thầy đố mày làm nên" (without the teacher, you cannot do anything), "Một chữ là của thầy, nửa chữ cũng là của thầy" (a word that you know is taught by teacher, half of a word that you know is also taught by teacher). These proverbs state students' perceptions that the teacher is superior, and students should completely follow what a teacher says. Therefore, in questioning, teachers appeared to be very powerful in controlling and orienting the interaction, whereas students were relatively passive and rarely initiated critical thinking.

Also, there were some explanations for teachers' tension about carrying out CLT. It is noticeable that most of the teacher participants in this research had studied in Western countries such as England, New Zealand, and America (see Profile of teacher participants on p. 63). The teachers in this study also stated that they had participated in ELT workshops and seminars and had trained in implementing CLT. According to Lewis and McCook (2002), and Nguyen (2007), teachers who have studied in English-speaking countries often try to implement new ideas from those workshops 
and seminars by combining them with the valued features from traditional educational systems. However, the participant teachers had experienced Confucian learning styles since they were young. This experience gave the teachers the perception that good teachers were knowledgeable and needed to gain respect from students. This study agrees with Ha's (2007) that teachers in Vietnam, despite their global mobility, still hold a strong sense of Vietnamese cultural identity, and this influences the way they teach. My study contributes more examples of teachers' attempts to reconcile their beliefs (what they said) and what they did in questioning interaction.

To sum up, questioning interactions in tertiary EFL classroom show that teachers understood the principles of CLT and worked hard to apply CLT in their classes. Teachers used questioning as an effective way to make teaching interactive rather than a means of conveying knowledge. Instead, teachers encouraged students' coconstruction, authentic communication, collaborative work among students, and encouraged students to participate actively. However, this study also indicates that teachers still faced challenges in the application of CLT. For example, there was evidence of conflicts between teachers' and students' expectations, between perceptions and practice, and between Western concepts and their traditional values. The literature also points out that CLT techniques, which originated in Western countries, were not always culturally attuned to the Vietnamese cultural context, due to differences such as individualism versus collectivism and a small power distance versus a larger power distance (Ellis, 1996; Ngoc \& Iwashita, 2012; Nguyen, Terlouw, \& Pilot, 2005a; Sullivan, 2000). Therefore, there have been challenges in modifying CLT to suit the cultural context. Teachers and students still applied traditional teaching methods and values in performing questioning activities. It is possible that despite 30 years of attempts to apply CLT in English education at the tertiary level, the implementation of CLT have not always been consistent. My study adds a learning dimension to the idea that CLT application in tertiary EFL classroom in Vietnam is locally situated. My study especially contributes that questioning could be an effective tool to promote more interaction, collaboration, and autonomous learning; these are the key factors to promote the application of CLT. 


\section{The institutional context and sub-context: English for different purposes}

In the next level of the T-L map, institutional-context and sub-context refer to the context of The University and the two participating faculties: an English non-major faculty and an English major faculty. The findings indicate that there were certain contextual factors influencing teachers' and students' perceptions and practices of questioning. The following sections will discuss how English was taught in integration with another subject and how English was taught as a major and nonmajor subject. The discussion will also involve how questioning was used in these contexts.

\section{English in integration with other subjects}

English was the target language and the medium for teaching other subject content. The observed EFL classes prioritised language learning (especially communicative skills such as speaking and listening). Additionally, language always was used for a purpose. The purpose of English non-major classes was to use English in a business context, English coursebooks were used by business students where most tasks were about business topics. In English major classes, specific content knowledge such as linguistics was the primary focus. However, because the University prioritised preparing all graduates to gain employment in international businesses, English major students also learned English through business-related contents. The subject matter differed for each class and encompassed an explicit focus on learning the target language, business-specific content, and linguistic content. The main purpose of both types of classes was language learning; but the business content was the vehicle to teach the language.

In my study, both teachers and students agreed that questioning interactions promoted learning both in the target language and of general concepts of business. Data from observations, for example, Episode 8 (p.112), also reveal that teachers asked further high-cognitive questions in English to dig deeper into the specific subject content; and questioning techniques (such as exemplifying, repeating, correcting) to help the students respond and understand particular business concepts. These indicated that content areas and linguistic elements could be taught through appropriate questioning 
techniques in an EFL classroom. In other words, English was taught in integration with other subjects.

Previous research, for example, Kao, Carkin, and Hsu (2011), Lo and Macaro (2015), and Menegale (2008), focused on how teacher questioning was used in content and language-integrated learning classrooms at universities in Taiwan, Hong Kong, and Italy. These studies agreed that questioning was used most in verbal exchanges between teachers and students in the class, and good questioning enhanced their students' learning of both the target language and the subject content.

In my study, English language learning involved business content learning. This supports the idea that English should be studied in integration with other subjects in the curriculum, rather than as a standalone subject. This is one manifestation of the application of CLT in EFL classroom (Richards, 2006). My study adds more evidence that content areas and linguistic elements can be developed through appropriate questioning techniques in an EFL classroom.

\section{English major and English non-major classes}

As stated, data were collected in two faculties, a English non-major faculty and an English major faculty. There were differences in students' English competence in each programme, the amount of time spent studying English, and the status of English learning in each degree. These distinctions between two faculty contexts may explain some of the differences in questioning mentioned before.

It was noticeable that the English proficiency of English major students was higher than that of non-English major students; the focus in the English major curriculum was more English-language specific than that of English non-major curriculum. Therefore, it is possible that the English major teachers asked more cognitively demanding questions because the teachers believed that the students' English competency was higher than that of the English non major students, and these teachers were aware that demonstrating critical thinking was a requirement of the curriculum. Furthermore, teachers in the English non-major faculty did not push challenging questioning about business-related topics, either because the teachers were not confident about their students' English proficiency, or the teachers were not 
expert in the content area of business (see Promoting higher level thinking on p. 114 and Avoid loosing face on p. 162). In literature, there have been a few studies in Vietnam about the differences in questioning between classes where English is taught as a major subject and classes where English is taught as a non-major subject, such as differences in motivation to learn English (Ngo, Spooner-Lane, \& Mergler, 2017), and the differences between practice and belief (Hai, 2011). This study contributes an idea that elements of difference in interactions in English major classes and English non-major classes could be a result of teachers' perceptions about their students' English competence and teachers' confidence in their own expertise.

In brief, this section illustrated how English education and questioning were situated within the institutional context and sub-context of two faculties. Learning was principally about language and language was used for different purposes. My study contributes that teachers and students were able to use questioning to promote teaching English in integration with other subjects, and the faculty contexts also provide an explanation for the differences in questioning in English major and English non-major classes.

The discussion of two levels of contexts above, including wider community context and institutional context as well as sub-contexts, suggests that contextual factors greatly influenced the teaching and learning in EFL classroom in Vietnam. Noticeably, it indicates that the application of CLT in Vietnam was influenced by cultural and traditional values, and English education adapted to contextual factors. This aligns with SCT theory that learning and teaching are dependent on institutions, settings, and cultural artefacts in the social environment (Edwards, 2005; Gibbons, 2007). However, my study reveals that questioning could help teachers and students promote the application of CLT and enhance English language education. The following will discuss the classroom application of questioning in the teaching and learning context.

\section{The teaching and learning context: Questioning as a new element}

At this level Hall and Kidman (2004), identify three aspects of context: the teacher the students, and the content. In the original map (Figure 6, p. 192), the key relationship between teacher and students is rapport, and a relationship between 
teacher and English language (content) is embodied in the notion of expertise. Teachers should possess two kinds of expertise: the expertise of the subject or content (for example, English language and subject content), and expertise about teaching and using pedagogical skills (Hall \& Kidman, 2004). Both rapport and expertise are critically important to support students' understanding and learning achievement; that is, their English competency (Hall \& Kidman, 2004). According to these writers, rapport and expertise also interact to enhance or, if either is lacking, limit, student understanding and learning.

Findings from my study show that questioning is also a significant aspect (Figure 7, p.193). Questioning could connect and support all other elements-the teacher, students, and content; and lead to new relationships among these three elements. In the next part, I will justify these connections and explain the new relationships between them in relation to the literature about EFL.

\section{Teacher-Learners: Rapport and asymmetrical power}

Firstly, in EFL classrooms in this study, teaching and learning activities were achieved through questioning between teacher and students. Questioning promoted the relationship between teachers and students by developing rapport even within asymmetrical power structures. I have added asymmetrical power to the map because, in the context of this study, the power difference between teachers and students facilitated questioning from the teacher and thus contributed to learning.

My findings show that when teacher and students were in a good relationship, they became more engaged in the interaction. Teachers could ask more questions, students felt more responsive, and students could initiate questioning interaction. Some studies, such as Sun (2012), emphasised that Chinese ESL students preferred a democratic relationship with the teacher, and students desired proper and respectful questioning that encouraged them to perform better. My study findings concur with Sun's (2012), that when the students felt comfortable, they became more involved in questioning. Moreover, my findings add the teachers' perspective. When teachers acknowledged the cooperation from students, the teachers themselves also became more motivated in extending questioning interactions. Teachers in my study also perceived that a positive relationship between teacher and student could facilitate 
teaching and learning. Therefore, they intentionally built rapport with the students to promote more interaction.

On the other hand, there was an unequal power relationship between teachers and students. My findings reveal that teachers played dominant roles, as director and superior (see Without the teacher, students can not learn on p.150). Teachers initiated and oriented questioning; teachers controlled how students engaged in questioning. The dominance of the teacher was necessary to promote a positive learning attitude. The strength of the unequal power between teachers and students is a characteristic of traditional education in Vietnam. Some studies view the dominant position of teacher as a barrier that may inhibit students from developing autonomy (DeWaelsche, 2015; Tan, 2007). In contrast, my study suggests that the authority and power of teachers were necessary to promote questioning and guide students in becoming more responsible for their own learning.

To summarize, the relationship between teacher and students, according to Hall and Kidman (2004), focuses on the concept of rapport. However, my study adds that the relationship between teacher and student in an EFL classroom consists of rapport and asymmetrical power. In tertiary EFL classes in Vietnam, these two aspects of the relationship between teacher and student exist together, and contribute to each other, rather being in tension with each other. Questioning benefits the construction of this relationship and promotes English learning and teaching.

\section{Student - Content: Accquiring and co-constructing}

In Hall and Kidman's map, the connection between the students and content is described as understanding. In the context of EFL classroom in this study, questioning provides an effective channel that promotes learning. I argue the relationship between students and content is acquiring and co-constructing learning.

In my study, the content of learning was mainly the target language, and acquiring refers to how students learned the language and developed language skills. For example, student participants stated that when answering teacher questions, they had the chance to practice communicating in the target language, and these questions elicited the development of higher cognition. Through questioning, students had 
opportunities to listen to good modelling from teachers or peers, produce the language, make their answer understood, and clarify further questions (see Learning from each other on p. 10198). This process involved communication modifications such as negotiation of meaning and self-correction. This is reminiscent of the input hypothesis, output hypothesis and interaction hypothesis in SLA, that argue that learners' language acquisition can be enhanced if the learners are pushed to produce output and use the target language in meaningful ways (Swain, 2005). One notable finding was that in the questioning interaction, students received assistance from teachers when they struggled, and students learnt from each other. This fits within SCT theory that the process of learning depends on how teachers and peers provide effective assistance so learners can answer questions at a higher level than they would unassisted.

Furthermore, findings indicate questioning supported the participants to co-construct knowledge. Teachers used questioning as an alternative to lecturing (see $A n$ alternative to lecturing, p. 98). It meant teachers did not convey the knowledge to the students, but students were forced to construct their own knowledge while answering teacher questions. Teachers asked questions, and students contributed their opinions and arguments. By these processes, students engaged in learning with the teacher. Teachers' questioning, especially with high cognitive questions (HCQ) demanded an advanced level of thinking, resulting in open and diversified opinion answers (Jiang, 2014; Shen \& Yodkhumlue, 2012; Shomoossi, 2004). In this study, teachers said they did not have pre-determined answers, and they acknowledged that they led students to think deeply by using strategic questioning (for example detailed questions for scaffolding purposes). Students became active and could co-construct the new knowledge (see Promoting higher level thinking on p. 114). Therefore, questioning promoted students to co-construct the content.

In brief, questioning promoted the acquiring and constructing of a relationship between students and the content. I also argue that a two-sided connection existed between questioning and the relationship. For instance, the data from interviews reveal when students mastered the knowledge; they were more responsive and more motivated to participate in questioning interactions (see Promoting higher level 
thinking on p. 114). Therefore, questioning promoted the acquisition of language and the acquiring relationship also promoted successful questioning.

In summary, learning was mediated by questioning. Questioning interactions created an authentic way for students to engage with subject content. Questioning offered opportunities for students to acquire the language and encouraged them to create new knowledge This suggests that, in EFL classes, the learning process was oriented by the teacher (teachers initiated questioning and guided students to answer), and learning could also be active and responsible (especially when students answered open questions and responded with critical thinking). These findings support SCT principles and SLA theories that learning is co-constructed, and it happens effectively in interaction.

\section{Teacher-Content : Using and gaining expertise}

The concept of expertise suggested by Hall and Kidman's map, in this study refers to teacher expertise in teaching (teaching expertise) or their expertise in knowledgecontent (content expertise). Findings agree that questioning could facilitate teachers to use their expertise to share content with learners. Also, questioning facilitated teachers to gain more expertise in teaching and content. Therefore, I modified the relationship between teacher and content in my study to using and gaining expertise.

Firstly, teaching expertise in these EFL classrooms was seen as a pedagogical skill, or the teachers' ability in delivering the lesson. For instance, the way teachers effectively used questioning to elicit thinking from students rather than conveying the knowledge to students. Observational data illustrated long conversations between teachers and students, in which the teachers prompted students who were struggling to answer, and teachers used questions to cultivate students' thinking (see Promoting higher level thinking, p. 114). Findings of this study are in line with previous literature indicating that teacher pedagogical expertise involves different questioning skills, for example different question types aimed at different levels of cognition (Jiang, 2014; Pham \& Hamid, 2013), teacher content knowledge, preparation, and strategies of questioning to improve learners' English proficiency (Yunus \& Yasin, 2018). 
Apart from questioning skills to teach the language content or subject content, findings of this study acknowledge that questioning was used for different purposes, such as managing classroom activities or diagnosing learning progress (see Chapter 5, p.107). These purposes of questioning could ultimately serve in teaching and learning. For instance, teachers used questioning to diagnose student progress, and adjust proper teaching. Teachers also used questioning as a managerial tool to make students more engaged in and responsible for their learning. Therefore, these questioning skills were elements of teaching expertise to promote learning and teaching.

Secondly, content expertise in this study refers to teacher competence in English language and subject content. This study did not focus on examining this type of expertise. However, data reveals some key points about teachers' content expertise. Teacher participants mentioned that they believed in their English competence, which made them confident to interact with students (see Making a good impression, p. 160). Furthermore, data reveals that most teachers had a couple of years' learning in Western countries for their post-graduate qualification. In contrast, in terms of subject-specific content, some teachers stated that their major was English and business content knowledge was new for them (see Eliciting learning of the content on p. 107). Some teachers stated that if they found some specific knowledge beyond their expertise, they were likely to open the questioning, and welcomed discussion and argument from students. The teachers added that, in this situation, they learned many good ideas from discussing issues with students. Students were majors in business, and they had already learned the subject content in their major classroom.

The fact that teachers acknowledged they could learn more about subject content through interaction with students reveals another important point about teachers gaining expertise. Questioning played an important role in helping teachers to build their content knowledge. Teachers learned new and creative ideas from students' answers. In addition, teachers added that their teaching expertise had a connection with experience. The teachers reflected how as they developed teaching experience, they were able to use questioning more effectively (see Making a good impression, $\mathrm{p}$. 160). Therefore, through questioning interactions with students, teachers bettered their content knowledge and teaching skills. 
In brief, as seen in the map (Figure 7, p. 193), the influence between questioning and expertise is a two-sided arrow. Firstly, questioning facilitated teachers to use and gain expertise in delivering content, sharpening their teaching skills and learning from students. Secondly, expertise also influences questioning interaction. For instance, as discussed above, when teachers felt more experienced or confident in their expertise, they tended to create more questioning.

In conclusion, questioning was seen as an important way of making teachers, students, and content interact with each other. Questioning promoted the relationships among teacher, students, and content. These relationships also greatly influenced questioning interaction.

\section{Summary}

The adapted diagram below again, is followed by a summary of the teaching and learning in this EFL classroom in a university in Vietnam.

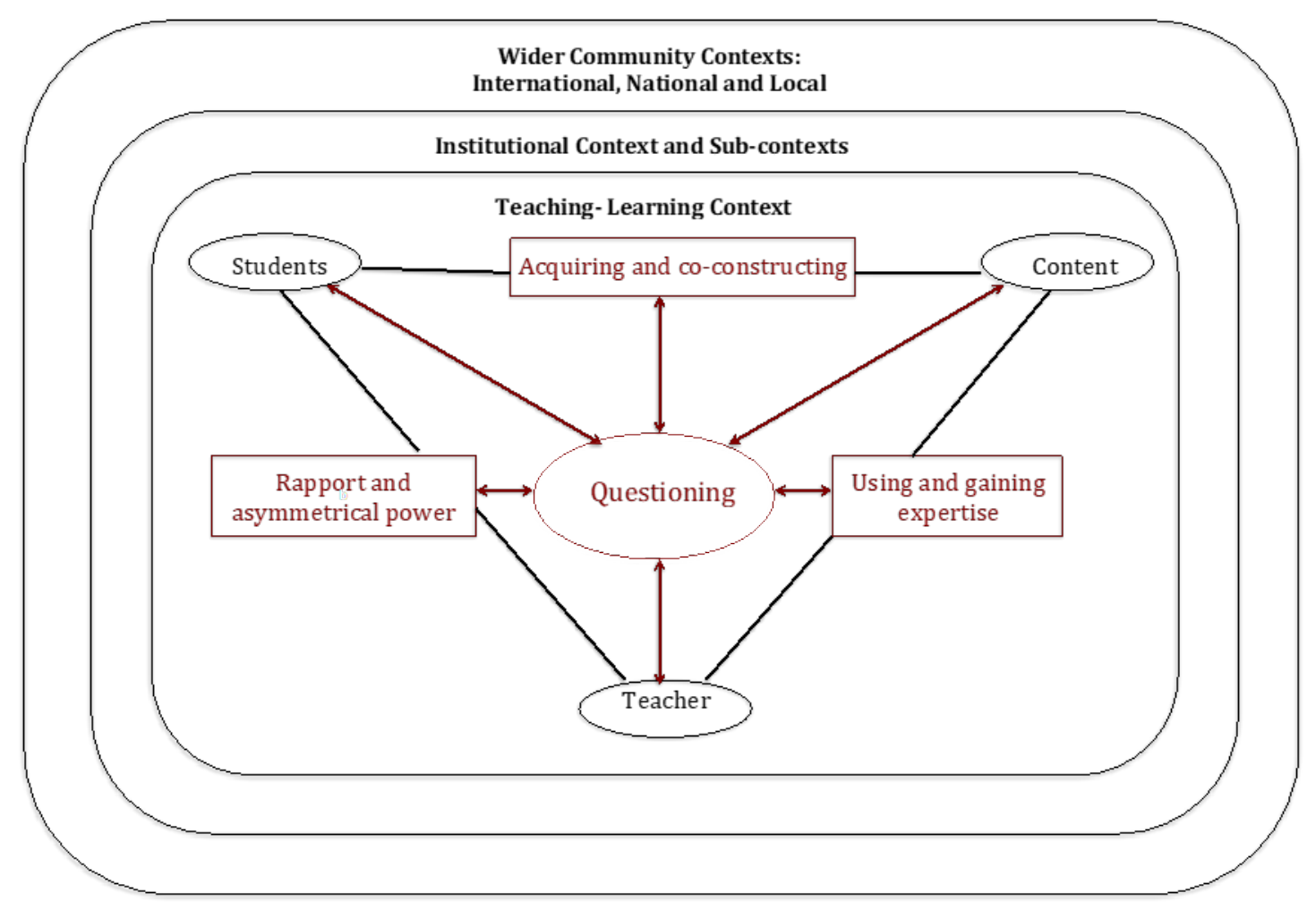

Figure 8: Modified T-L map for teaching and learning in Vietnamese tertiary EFL classrooms (repeated) 
In this study, globalisation has influenced the Vietnamese government to promote communicative language teaching. This is the wider community context in the T-L map. Vietnamese tertiary EFL educators are required to raise their students' English communicative competency. Findings of my study reveal that the teachers used questioning to promote interaction and collabrative learning, the core features of CLT. However, there was tension between the Western concepts and the participants' traditional values. For instance, questioning was still more teacher-centred due to the dominance of teachers and the passive engagement of students.

Institutional contexts and sub-contexts in my study refer to how the specific characteristics of The University and the two Faculties influenced English learning. Firstly, because The University offered business-related degrees to prepare all graduates for employment in international trade. Therefore, business English held an important status in the institution. Business content was embedded in EFL classes. This led to English being taught in integration with other subjects. Secondly, data were collected in two faculties: an English non-major faculty and an English-major faculty. There were the differences in English competence, the range of English subjects, amount of time spent learning in English, and the status of English learning in their degree in these two faculties. These differences affected the way that questioning was managed in these two participant groups.

The teaching and learning contexts indicate three key elements, teacher, students and content, and the relationships among them. Questioning connected all other elements and modified the relationships among them. Questioning connected teacher and students and promoted a respect and asymmetrical power between them. Questioning facilitated students to acquire and co-construct the content. Through questioning, teachers used and gained expertise. The two-headed arrows in the classroom teaching and learning context show the bi-directional relationship of all classroom aspects and questioning interactions. This means all key elements and the relationships among them also greatly influenced questioning.

To conclude, this section has discussed the nature of teaching and learning in particular tertiary foreign classrooms in Vietnam by providing insights into the major issues in tertiary English education in global, national and institutional contexts. In addition, the chapter highlighted how questioning was the means that connected other 
aspects (teacher, students, and content) and supported the relationships among these components. The following part acknowledges the key contributions/implications of my study.

\section{Implications of this study}

There are a number of implications of this study. These relate to how questioning affects communicative competence, cultural influences on questioning, the role of students in language learning, and teacher autonomy.

The study examined how questioning promoted language learning and learners' communicative competence. It revealed how EFL teachers deliberately employed questioning to create meaningful communication in the target language, to encourage collaborative learning, to facilitate teaching and promote critical thinking. These exemplify ways that teachers used questioning effectively to bring about CLT in their EFL classrooms. Through understanding the communicative value of the questioning strategies I observed, other Vietnamese EFL teachers may wish to apply these in their own classroom.

My study identified how Vietnamese cultural and traditional expectations influenced questioning for instance, the dominance of the teacher over the learners, the concerns about status, and the English language proficiency of participants in classroom. These characteristics affected some of the difficulties in using questioning to teach the foreign language, especially when adapting a Western appoach in their EFL classes. There might be a discussion about the influence of cultural and local contexts on English langugage education in which teachers discuss modifications to Western approaches to CLT in Confucian settings.

A challenge faced by teachers in this study was to encourage their students' autonomy. The lack of student initiation in questioning and interaction might result from or lead to the control of teachers. This suggests that if teachers were aware of the impact of their authority, students might take more responsibility for their learning. Teachers may deliberately provide opportunities and encouragement to students to encoutrage their participation in learning. Therefore, my study suggests that students need to learn how to be confident and effective in communicating in English. For 
example, lessons teaching techniques in asking and answering, and skills for discussion or group work. This would allow students to understand their responsibility and actively participate in questioning and interaction.

In addition, this study highlights the role thatVietnamese policy makers may play inthe implementation of CLT in Vietnam. They may need to involve the educators, teachers and students in the adaptation of CLT in their classrooms. Teachers would welcome the opportunity to decide on the application of CLT in their own context. They are in a good position to do this because they understand their students' needs. If teachers were allowed to do this, it would help to reduce the criticism that the adopting CLT is simply the imposition of neo-colonisation.

Furthermore, my study has theoretical implications. The T-L map, proposed by Hall and Kidman (2004), captures the contexts around and key relationships in teaching and learning activities in tertiary education. My study applied the map to tertiary EFL classrooms in Vietnam. The application provided insights into the educational culture and contexts at play in EFL in Vietnam. In addition, my study extended the notion of the T-L map to include questioning — not just as a strategy for content learning but also as a communicative strategy to generate authentic use of the target language. My study suggests questioning, as a from of interaction, is a central component within the teaching and learning context. Questioning as a key interaction provides a means to connect and support all other elements: the teacher, students, and content, and lead to new relationships between these three elements. Few studies have been conducted on questioning in tertiary EFL classrooms in Vietnam. This research adds to the limited literature.

\section{Limitations}

The study used multiple case qualitative design to investigate the research phenomenon through multiple data sources, multiple participant groups, and two different contexts (two types of classes, English major and English non-major). There were, however, a number of methodological limitations. The following will identify and justify them. 
The first limitation of the study was the case-study design; the findings were the result of an in-depth investigation into a single institution, which could limit its transferability. Nevertheless, there was a strong rationale in choosing the site because it had strong similarities with other universities in Vietnam. The University was established and undergoing a range of policies and practices that were mandated in all public universities in Vietnam. Therefore, the findings of this case study have insightful implications that can be applied to other Vietnamese institutions of similar characteristics.

Each class, or each teacher participant's teaching, was observed once, and the observation data provided only a snapshot of what was going on in the EFL classroom. Furthermore, it would have been of more value to organise the second round of observations, interviews and focus groups in which the interview or group discussion topics were divided into more general and more specific each time. The timing of the observations would have been affected by the part of the academic year (e.g. not near examinations). Nevertheless, the high number of interviews and focus groups, and the multiple perspectives gathered from different groups of participants, have contributed to the rich description of data. The case study aims for rich description rather than breadth. Furthermore, the observation sessions were video recorded, creating opportunities for me to assess the data later and use questioning interactions from the observations to analyse the phenomenon in practice.

Finally, while there were not obvious large differences between the cases, English major classes and English non-major classes, there were more similarities than differences. The aspect of contrast and comparison between different contexts has potential for further research in different contexts.

\section{Recommendation for further research}

Future research could use my study as a methodological framework for investigating students' perceptions and practice in questioning, and questioning in different department contexts. Further studies might consider focusing on questioning initiated by students and among students, or in different contexts with different types of classes (for example, English major classes and English non-major classes, beginning classes 
and last year classes, English for speaking and listening and English in writing and reading).

Furthermore, a mixed-method design could add the breadth to the research on the questioning phenomenon in EFL classes. While qualitative data generated from observation, interviews and focus groups such as those methods used in this study provided the platform to investigate the participants' experiences and their inner thoughts, quantitative data could augment this by adding an explanatory angle.

It is noticeable that there has been little research about questioning in Vietnam, especially in tertiary classes. More research is needed on questioning for promoting English medium education in tertiary institutions in Vietnam. This study focused on the use of questioning experienced by a particular group of tertiary teachers and students at a university in the north and capital city in Vietnam. Questioning in EFL classes from other universities and other regions (in the middle and south of Vietnam), or for classes specialising in other disciplines, may be different and thus would be an area for further research.

\section{Conclusion}

This chapter has answered five research questions on how questioning could promote language teaching and learning in EFL classes in Vietnam. The chapter then discussed the nature of teaching and learning in particular tertiary foreign language classrooms in Vietnam by providing insights into the major issues in English education in tertiary education, in the global, national and institutional contexts. The chapter highlighted how questioning was the means that connected other aspects (teacher, students, and content) and supported the relationships among these aspects. After that, a number of implications were provided. Lastly, the chapter outlined some limitations and suggestions for further studies.

To conclude, questioning is the most popular form of interaction in EFL classroom in Vietnam. Questioning is a classroom technique and useful tool for teachers to fulfill pedagogical needs. Especially, this asking-answering mechanism can effectively promote interaction, collaborative learning, critical thinking, key aspects of CLT. This is how questioning could promote communicative competence. In this study, questioning reveals a cultural-responsive version of CLT in EFL learning in tertiary in 
Vietnam.

Questioning is a contextually situated phenomenon. In my thesis, questioning is teacher-centred. Vietnamese teachers perceive and are expected to control and direct questioning and how students participate in questioning. Learning in my study is about acquiring the target language but the learning also involves language for business. Subject content learning is embedded in and also supports language learning.

Different contextual influences of international and national factors, English globalisation, and the Vietnamese government's promotion of English competence, can explain the commitment and tension in applying the communicative approach. Other contexts, such as institutional and sub-contexts, that refer to some specific matters such as English as a major or non-major subject, and Business English or academic English for business.

Finally, my study emphasises the central role of questioning in language teaching and learning in EFL classrooms at tertiary level in Vietnam. Questioning is the key channel that connects and promotes the relationship between teachers, students, and content, the core aspects of teaching and learning. Questioning promotes rapport through traditional asymmetrical relationships between the teacher and students; acquiring and co-constructing learning; and using and gaining content expertise. These relationships also influence questioning interaction.

Through engaging in this study I have learned that questioning is essential for interaction in language learning. I hope that my study will encourage other teachers to think deeply about the impact of their questioning on language learning. 


\section{REFERENCES}

Antón, M. (1999). The discourse of a learner-centered classroom: Sociocultural perspectives on teacher-learner interaction in the second-language classroom. The Modern Language Journal, 83(3), 303-318.

Astuti, S. P. (2015). Teachers' and students' perceptions of motivational teaching strategies in an Indonesian high school context (Unpublished thesis for Master of Education). Victoria University of Wellington, New Zealand.

Atkins, A., \& Brown, H. (2001). Sinclair and Coulthard's 'IRF'model in a one-to-one classroom: an analysis. University of Birmingham, England.

Barokass-Emanuel, N. (2001). Ethics in translation: an exploration through art, dramatization, literary and political texts (Doctoral dissertation). Concordia University, Canada.

Baxter, P., \& Jack, S. (2008). Qualitative case study methodology: Study design and implementation for novice researchers. The Qualitative Report, 13(4), 544-559.

Bock, G. (2000). Difficulties in implementing communicative theory in Vietnam. Teacher's Edition, 2, 24-28.

Bodley, J. H. (1994). Cultural anthropology: Tribes, states, and the global system. Palo Alto, CA: Mayfield.

Boyd, M. P. (2015). Relations between teacher questioning and student talk in one elementary ELL classroom. RELC Journal, 47(3), 370-404.

Braun, V., \& Clarke, V. (2006). Using thematic analysis in psychology. Qualitative Research in Psychology, 3(2), 77-101.

Bronfenbrenner, U. (1979). The Ecology of Human Development: Experiments by Nature and Design. Cambridge, MA: Harvard University Press.

Bruner, J. (1985). Child's talk: Learning to use language. Child Language Teaching and Therapy, 1(1), 111-114. 
Brutt-Griffler, J. (2002). World English: A study of its development. UK: Multilingual Matters.

Bui, P. (2010). Vietnamese-English Dictionary. Hanoi: NXB Phuong Dong.

Bui, T. M. H. (2006). Teaching speaking skills at a Vietnamese university and recommendations for using CMC. Asian EFL Journal, 14(2), 1-19.

Burton, D., \& Bartlett, S. (2009). Key issues for education researchers. London: Sage.

Buschkuehl, M., \& Jaeggi, S. M. (2010). Improving intelligence: A literature review. Swiss Medical Weekly, 140, 266-272.

Campbell, A. P. (2004). Using livejournal for authentic communication in EFL classes. The Internet TESL Journal, 10(9), 64-68.

Carless, D. (2004). Issues in teachers' reinterpretation of a task-based innovation in primary schools. TESOL Quarterly, 38(4), 639-662.

Charmaz, K. (2014). Constructing grounded theory. London: Sage.

Chen, H. Y., \& Boore, J. R. (2010). Translation and back-translation in qualitative nursing research: methodological review. Journal of Clinical Nursing, 19(1-2), 234-239.

Chin, C. (2006). Classroom interaction in science: Teacher questioning and feedback to students' responses. International Journal of Science Education, 28(11), $1315-1346$.

Cohen, L., Manion, L., \& Morrison, K. (2013). Research methods in education (7th ed.). New York: Routledge.

Cohen, L., Manion, L., Morrison, K., \& Wyse, D. (2010). A guide to teaching practice. New York: Routledge.

Corbin, J. M., \& Strauss, A. L. (2015). Basics of qualitative research: Techniques and 
procedures for developing grounded theory $\left(\right.$ Vol. $\left.4^{\text {th }}\right)$. Thousand Oaks, CA: Sage.

Cotton, K. (2001). Classroom questioning. US: North West Regional Educational Laboratory.

Creswell, J. W. (2013). Qualitative inquiry and research design: Choosing among five approaches. Los Angeles: Sage.

Creswell, J. W. (2014). Research design: qualitative, quantitative, and mixed method approaches ( $4^{\text {th }}$ ed.). Los Angeles: Sage.

Creswell, J. W. (2015). Educational research: planning, conducting, and evaluating quantitative and qualitative research $\left(5^{\text {th }}\right.$ ed.). Boston: Pearson.

Cundale, N. (2001). What we preach? Stated beliefs about communicative language teaching and classroom questioning strategies. Language Teacher, (25(5), 4-9.

Dalton-Puffer, C. (2007). Discourse in Content and Language Integrated Learning (CLIL) Classrooms. Philadelphia: John Benjamins Publishing.

Dang, T. K. A., Nguyen, H. T. M., \& Le, T. T. T. (2013). The impacts of globalisation on EFL teacher education through English as a medium of instruction: An example from Vietnam. Current Issues in Language Planning, 14(1), 52-72.

David, O. F. (2007). Teacher's Questioning Behaviour and ESL classroom patterns. Humanity \& Social Sciences Journal, 2(2), 127-131.

Demirezen, M. (2011). The foundations of the communicative approach and three of its applications. Journal of Language \& Linguistics Studies, 7(1), 57-71.

Denscombe, M. (2002). Ground rules for good research: a 10 point guide for social researchers. Buckingham England: Open University.

Denscombe, M. (2014). The good research guide: for small-scale social research projects (5th ed.). UK: McGraw-Hill Education. 
Denzin, N. K., \& Lincoln, Y. S. (2008). Collecting and interpreting qualitative materials. (3rd ed.). Thousand Oaks, California: Sage Publications.

DeWaelsche, S. A. (2015). Critical thinking, questioning and student engagement in Korean university English courses. Linguistics and Education, 32, 131-147.

Do, H.T. (2006, September). The role of English in Vietnam's foreign language policy: A brief history. Paper presented at 19th Annual EA Education Conference 2006, Perth, Australia.

Doan, M. N. (2012). Cambodian and Laotian Students' Experience of Language Barriers, Cultural Differences, and Teacher-Student Rapport in a University in Vietnam: A Grounded Theory Approach (Unpublished thesis for Master of Education). Victoria University of Wellington, New Zealand.

Dorji, J. (2017). Communicative language teaching as conceptualized by Bhutanese English as second language teachers. Indonesian EFL Journal, 3(1), 1-10.

Dusi, N. (2010). Translating, adapting, transposing. ASSA (Applied Semiotics, Sémiotique Appliquée), 24(9), 82-94.

Edwards, A. (2005). Let's get beyond community and practice: the many meanings of learning by participating. Curriculum Journal, 16(1), 49-65.

Edwards, R., \& Holland, J. (2013). What is Qualitative Interviewing? London: Bloomsbury Academic.

Ellis, G. (1996). How culturally appropriate is the communicative approach? ELT Journal, 50(3), 213-218.

Ellis, R., Tanaka, Y., \& Yamazaki, A. (1994). Classroom interaction, comprehension, and the acquisition of L2 word meanings. Language learning, 44(3), 449-491.

Engin, M. (2013). Questioning to scaffold: an exploration of questions in pre-service teacher training feedback sessions. European Journal of Teacher Education, 36(1), 39-54. 
Fagan, D. S. (2014). Addressing Learner Hesitancy-to-Respond Within InitiationResponse-Feedback Sequences. TESOL Quarterly, 52(2), 425-435.

Farahian, M., \& Rezaee, M. (2012). A case study of an EFL teacher's type of questions: An investigation into classroom interaction. Procedia-Social and Behavioral Sciences, 47, 161-167.

Farsia, L. (2016). Re-conceptualizing communicative language teaching through socio-cultural perspective. Englisia, 3(2), 119-128.

Farrell, T. S., \& Mom, V. (2015). Exploring teacher questions through reflective practice. Reflective Practice, 16(6), 849-865.

Frank, J. (2013). Raising cultural awareness in the English language classroom. English Teaching Forum, 51(4), 2-11.

Gass, S. M. (2003). Input and interaction. In C. Doughty \& M. H. Long (Eds.), Handbook of second language acquisition (pp. 224-255). Oxford, England: Blackwell.

Gass, S. M. (2013). Second language acquisition: An introductory course. New York: Routledge.

Gass, S. M., \& Mackey, A. (2000). Stimulated recall methodology in second language research. New York: Routledge.

Gass, S. M., \& Mackey, A. (2007). Input, interaction, and output in second language acquisition. In B. VanPatten \& J. Williams (Eds.), Theories in second language acquisition: An introduction (pp. 175-199). Mahwah, NJ: Lawrence Erlbaum.

Giang, T. (2011). Tren 53\% sinh vien kho dat chuan dau ra [More than 53\% of students find it hard to achieve the exit English level]. The Tuoi Tre. Retrieved from http://tuoitre.vn/Giao-duc/462236/Tren-53-sinh-vien-kho-dat-chuan-daura.html 
Gibbons, P. (2007). Mediating academic language learning through classroom discourse. In J. Cummins \& C. Davidson (Eds.), International handbook of English language teaching (pp. 701-718). New York, NY: Springer.

Grbich, C. (2012). Qualitative data analysis: An introduction. California: Sage.

Guba, E. G. (1981). Criteria for assessing the trustworthiness of naturalistic inquiries. ECTJ, 29(2), 75-91.

Ha, P. L. (2007). Australian-trained Vietnamese teachers of English: Culture and identity formation. Language, culture and curriculum, 20(1), 20-35.

Hai, T. Q. (2011). Dạy-học ngoại ngữ căn bản và chuyên ngành: mâu thuẫn giữa kì vọng và thực tế [Teaching English major and English non-major: Conflict between expectation and practice]. Tạp chí Ngôn ngũ và Đò̀i sống, 12, 24-28.

Hall, C., \& Kidman, J. (2004). Teaching and Learning: Mapping the Contextual Influences. International Education Journal, 5(3), 331-343.

Hays, D. G., \& Singh, A. A. (2012). Qualitative inquiry in clinical and educational settings. New York: Guilford Press.

Helin, I. (2006). Implication of Evidentiality in Translation. A Man of Measure: Festschrift in Honour of Fred Karlsson. Supplement to Sky, 19, 282-290.

Henderson, L., \& Tallman, J. I. (2006). Stimulated recall and mental models: tools for teaching and learning computer information literacy. Lanham, Md: Scarecrow Press.

Heritage, M., \& Heritage, J. (2013). Teacher questioning: The epicenter of instruction and assessment. Applied Measurement in Education, 26(3), 176-190.

Hesse-Biber, S. N., \& Leavy, P. (2011). The practice of qualitative research (2nd ed.). Los Angeles: Sage.

Hiep, P. H. (2007). Communicative language teaching: Unity within diversity. ELT Journal, 61(3), 193-201. 
Ho, W. K., \& Wong, R. (2004). English language teaching in East Asia today. Singapore: Eastern Universities Press.

Hoang, V. V. (2010). The current situation and issues of the teaching of English in Vietnam. 立命館言語文化研究, 22(1), 7-18.

Hofstede, G. \& Hofstede, J. (2005) Cultures and organization-software of the minds (2nd ed.). New York: McGraw-Hill.

Holliday, A. (1994). Appropriate methodology and social context. Cambridge: Cambridge University Press.

Horsburgh, M. (1999). Quality monitoring in higher education: the impact on student learning. Quality in Higher Education, 5(1), 9-25.

Hu, G. (2004). Pedagogical practices in Chinese EFL classrooms. Asian Englishes, $7(1), 42-59$.

Jacobs, G. M., \& Farrell, T. S. (2003). Understanding and implementing the CLT (Communicative language teaching) paradigm. RELC Journal, 34(1), 5-30.

Jiang, Y. (2014). Exploring teacher questioning as a formative assessment strategy. RELC Journal, 45(3), 287-304.

Joffe, H., \& Yardley, L. (2004). Content and thematic analysis. In D. Marks, \& L. Yardley (Eds). Research methods for clinical and health psychology (pp. 5668). London: Sage.

Johnson, K. E. (2006). The sociocultural turn and its challenges for second language teacher education. Tesol Quarterly, 40(1), 235-257.

Johnson, R. B., \& Christensen, L. (2014). Educational research: Quantitative, qualitative, and mixed approaches (5th ed.). Thousand Oaks, California: Sage.

Joskin, A. M. (2013). Investigating the implementation process of a curriculum: A case study from Papua New Guinea (Unpublished thesis for Master of Education). Victoria University of Wellington, New Zealand. 
Kao, S-M., Carkin, G., \& Hsu, L-F. (2011). Questioning techniques for promoting language learning with students of limited L2 oral proficiency in a dramaoriented language classroom. Research in Drama Education, 16(4), 489-515.

Ko, S. (2014). The nature of multiple responses to teachers' questions. Applied Linguistics, 35(1), 48-62.

Krashen, S. (1985). The input hypothesis: Issues and implications. London: Longman.

Krashen, S. (1991). The input hypothesis: An update. In J. Alatis (Ed.), Georgetown University Round Table on Languages and Linguistics 1991. Linguistics and language pedagogy: The state of the art (pp. 409-431). Washington, DC: Georgetown University Press.

Krefting, L. (1991). Rigor in qualitative research: the assessment of trustworthiness. The American Journal of Occupational Therapy: Official Publication of the American Occupational Therapy Association, 45(3), 214-22.

Kumaravadivelu, B. (2006). TESOL Methods: Changing Tracks, Challenging Trends. TESOL Quarterly, 40(1), 59-81.

Langford, J., \& McDonagh, D. (2003). Focus groups: supporting effective product development. New York: Taylor \& Francis.

Lantolf, J. P. (2000). Introducing sociocultural theory. In J. Lantolf (Ed.), Sociocultural Theory and Second Language Learning (pp.1-26). Oxford: Oxford University Press.

Lantolf, J. P. \& Thorne, S. L. (2006). Socio-cultural theory and the genesis of second language development. Oxford: Oxford University Press.

Larsen-Freeman, D., \& Long, M. H. (2014). An introduction to second language acquisition research. New York: Routledge.

Le, Q. X. (2013). Fostering learner autonomy in language learning in tertiary education: an intervention study of university students in Hochiminh City, Vietnam (Doctoral dissertation). University of Nottingham, UK. 
Le, T. T. H. (2011). Hoc sinh khong giao tiep duoc bang tieng Anh [Students cannot communicate in English]. The Tuoi Tre. Retrieved from http://tuoitre.vn/Bandoc/454395/Hoc-sinh-khong-giao-tiep-duoc-bang-tieng-Anh.html

Le, V.C. (1999, October). Language and Vietnamese pedagogical contexts. Paper presented at the meeting of Fourth International Conference on Language and Development, Hanoi, Vietnam.

Lee, Y-A. (2006). Respecifying display questions: Interactional resources for language teaching. TESOL Quarterly, 40(4), 691-713.

Lewis, M., \& McCook, F. (2002). Cultures of teaching: Voices from Vietnam. ELT Journal, 56(2), 146-153.

Li, L. (2011a). Obstacles and opportunities for developing thinking through interaction in language classrooms. Thinking Skills and Creativity, 6(3), 146158.

Li, Y. (2011b). Translating interviews, translating lives: Ethical considerations in cross-language narrative inquiry. TESL Canada Journal, 28(5), 16-30.

Lichtman, M. (2012). Qualitative Research in Education: A User's Guide. Los Angeles: Sage.

Liddicoat, A. J., Papademetre, L., Scarino, A., \& Kohler, M. (2003). Report on intercultural language learning. Canberra, ACT: Commonwealth of Australia.

Lightbown, Patsy M., \& Spada, Nina. (2006). How languages are learned (3rd ed.). New York: Oxford University Press.

Lincoln, Y. S., \& Guba, E. G. (1986). But is it rigorous? Trustworthiness and authenticity in naturalistic evaluation. New directions for program evaluation, (30), 73-84.

Lincoln, Y. S., Lynham, S. A., \& Guba, E. G. (2011). Paradigmatic controversies, contradictions, and emerging confluences, revisited. The Sage Handbook of Qualitative Research, 4, 97-128. 
Littlewood, W. (2007). Communicative and task-based language teaching in East Asian classrooms. Language Teaching, 40(03), 243-249.

Littlewood, W. (2014). Communication-oriented language teaching: Where are we now? Where do we go from here? Language Teaching, 47(03), 349-362.

Lixin, X. (2011). Communicative Language Teaching in a Chinese University Context: Beliefs and Practice. Chinese Journal of Applied Linguistics, 34(2), $44-61$.

Lo, Y. Y., \& Macaro, E. (2015). Getting used to content and language integrated learning: what can classroom interaction reveal?. The Language Learning Journal, 43(3), 239-255.

Long, M. (1983). Native speaker/non-native speaker conversation and the negotiation of comprehensible input. Applied Linguistics, 4(2), 126-141.

Long, M. (1996). The role of the linguistic environment in second language acquisition. In W. C Ritchie \& T. K. Bhatia (Eds.), Handbook of Second Language Acquisition (pp. 413-468). San Diego, CA: Academic Press.

Long, M. H., \& Sato, C. J. (1983). Classroom foreigner talk discourse: Forms and functions of teachers' questions. In H. W. Seliger \& M. H. Long (Eds.), Classroom Oriented Research in Second Language Acquisition (pp. 268-285). Rowley, Massachusetts: Newbury House Publishers.

Lyle, J. (2003). Stimulated recall: a report on its use in naturalistic research. British Educational Research Journal, 29(6), 861-878.

Mackey, A. (1999). Input, interaction, and second language development: An empirical study of question formation in ESL. Studies in Second Language Acquisition, 21(4), 557-587.

Mackey, A., \& Gass, S. M. (2016). Second language research: methodology and design (2nd ed.). New York: Routledge. 
Marzban, A., Yaqubi, B., \& Qalandari, K. (2010). IRF and ISRF sequences and their anti-pedagogical value. Journal of Applied Linguistics, 3(2), 121-144.

McCormick, D., \& Donato, R. (2000). Teacher question as scaffolding assistance in an ESL classroom. In J. K. Hall \& L. Verplaetse (Eds.), Second and foreign language learning through classroom interaction (pp. 183-203). Mahwah, N.J: Lawrence Erlbaum.

McDonough, K. (2005). Identifying the impact of negative feedback and learners' responses on EFL question development. Studies in second language acquisition, 27(1), 79-103.

McNeil, L. (2012). Using talk to scaffold referential questions for English language learners. Teaching and Teacher Education, 28(3), 396-404.

Menegale, M. (2008). Expanding teacher-student interaction through more effective classroom questions: from traditional teacher-fronted lessons to student-centred lessons in CLIL. In C. M. Coonan (ed.). CLIL e l'apprendimento delle lingue. Le sfide del nuovo ambiente di apprendimento, Venezia, Settembre 2008. Venezia: Libreria Editrice Cafoscarina, (pp. 105-128). Venice: Libreria Editrice Cafoscarina.

Meng, J., Zhao, T., \& Chattouphonexay, A. (2012). Teacher questions in a contentbased classroom for EFL young learners. Theory and Practice in Language Studies, 2(12), 2603-2610.

Mercer, N. (2007). Sociocultural discourse analysis: Analysing classroom talk as a social mode of thinking. Journal of Applied Linguistics and Professional Practice, 1(2), 137-168.

Merriam, S. B. (2002). Introduction to qualitative research. San Francisco: JosseyBass.

Miao, P., \& Heining-Boynton, A. L. (2011). Initiation/response/follow-up, and response to intervention: Combining two models to improve teacher and student performance. Foreign Language Annals, 44(1), 65-79. 
Minichiello, V., Aroni, R., \& Hays, T. (2008). In-depth interviewing: Principles, techniques, analysis. Australia: Pearson Education.

MOET. (2006). Instruction on teaching and learning foreign languages No 9893/BGDĐT-GDTrH dated September 6th, 2006.

MOET. (2007). Institute for Educational Strategies and Curriculum Development. English Curriculum. Hanoi: Educational Publishers.

Moon, Woo Lee. (2014). Will communicative language teaching work? Teachers' perceptions toward the new education reform in South Korean. Indonesian Journal of Applied Linguistics, 3(2), 1-17.

Morgan, D. L. (1997). Focus groups as qualitative research (2nd ed.). Thousand Oaks, California: Sage Publications.

Mortimer, E.F., \& Scott, P.H. (2003). Meaning making in secondary science classrooms. Maidenhead, UK: Open University Press.

Nassaji, H., \& Wells, G. (2000). What's the use of 'triadic dialogue'?: An investigation of teacher-student interaction. Applied Linguistics, 21(3), 376406.

Ngo, H., Spooner-Lane, R., \& Mergler, A. (2017). A comparison of motivation to learn English between English major and non-English major students in a Vietnamese university. Innovation in Language Learning and Teaching, 11(2), $188-202$.

Ngoc, K. M., \& Iwashita, N. (2012). A comparison of learners' and teachers' attitudes toward communicative language teaching at two universities in Vietnam. University of Sydney Papers in TESOL, 7, 25-49.

Nguyen, L. V. (2010). Computer mediated collaborative learning within a communicative language teaching approach: A sociocultural perspective. The Asian EFL Journal Quarterly, 12(1), 202-233. 
Nguyen, N. T. (2008). Deputy Prime Minister and Minister of Education and Training conclusion. Paper presented at the Vietnamese National Conference on Higher Education Quality, Hanoi, Vietnam.

Nguyen, P. M., Terlouw, C., \& Pilot, A. (2005a). Cooperative learning vs Confucian heritage culture's collectivism. The analysis in Viet Nam. Asia Europe Journal, 3(3), 1-27.

Nguyen, P. M., Terlouw, C., \& Pilot, A. (2005b). Cooperative learning vs Confucian heritage culture's collectivism: confrontation to reveal some cultural conflicts and mismatch. Asia Europe Journal, 3(3), 403-419.

Nguyen, Q. T. (2013). The Impact of Context on a Vietnamese Tertiary Level English Teacher's Implementation of Pair Work. International Journal of Innovation in English Language Teaching and Research, 2(1), 27-46.

Nguyen, T. M. H. (2007). Developing EFL learners' intercultural communicative competence: A gap to be filled? Asian EFL Journal (Teaching Articles), 2(1), $86-99$.

Nunan, D. (2004). Task-based language teaching. Cambridge: Cambridge University Press.

Nunan, D., \& Bailey, K. M. (2009). Exploring second language classroom research: A comprehensive guide. Boston, MA: Heinle, Cengage Learning.

O’Dwyer. S. (2017). Deflating the 'Confucian Heritage Culture' thesis in intercultural and academic English education. Language, Culture and Curriculum, 30(2), 198-211.

Ozcan, S. (2010). The effects of asking referential questions on the participation and oral production of lower level language learners in reading classes (Unpublished master's thesis). Middle East Technical University, Turkey. 
Pandian, A. (2002). English language teaching in Malaysia today. Asia Pacific Journal of Education, 22(2), 35-52.

Patton, M. Q. (2015). Qualitative research and methods: Integrating theory and practice. London: Sage Publications Ltd.

Pham, H. H. (2004). Trained in the West, teaching in the East: Vietnamese teachers returning from TESOL courses abroad (Unpublished doctoral thesis). University of Melbourne, Australia.

Pham, H. H. (2007). Communicative language teaching: Unity within diversity. ELT Journal, 61(3), 193-201.

Pham, L. N. K., \& Hamid, M. O. (2013). Beginning EFL teachers' beliefs about quality questions and their questioning practices. Teacher Development, 17(2), 246-264.

Phan, L. H. (2004). University classrooms in Vietnam: Contesting the stereotypes. ELT Journal, 58(1), 50-57.

Phan, T. T. T. (2015). Towards a potential model to enhance language learner autonomy in the Vietnamese higher education context (Doctoral dissertation). Queensland University of Technology, Australia.

Pica, T. (1992). The textual outcomes of native speaker-non-native speaker negotiation: What do they reveal about second language learning? In C. Kramsch \& S. McConnell-Ginet (Eds.), Text and Context: Cross-Disciplinary Perspective on Language Study (pp. 198-237). Lexington, MA: D. C. Heath \& Co.

Pica, T. (1994). Research on negotiation: What does it reveal about second-language learning conditions, processes, and outcomes? Language Learning, 44(3), 493527.

Rawlinson, J. G. (2017). Creative thinking and brainstorming. London: Routledge. 
Razzaghi, S., Khonamri, F., \& Yaqubi, B. (2012). The effect of EFL teachers' questioning behavior on the amount of learners' classroom interaction during prereading discussion task. Modern Journal of Language Teaching Methods, 2(4), 147-158.

Reitano, P. (2005, July). Using video stimulated recall and concept mapping in reflective teaching practices: Strengths, limitations and potential threats. Paper presented at the meeting of 33rd annual Australian Teacher Education Association Conference. Brisbane, Australia.

Rezaei, S., Derakhshan, A., \& Bagherkazemi, M. (2011). Critical thinking in language education. Journal of Language Teaching and Research, 2(4), 769777.

Richards, J. C. (2006). Communicative language teaching today. New York: Cambridge University Press.

Richards, J. C., \& Lockhart, C. (1994). Reflective teaching in second language classrooms. New York: Cambridge University Press.

Richards, J. C., \& Rodgers, T. S. (2001). Approaches and Methods in Language Teaching (2nd ed.). Cambridge: Cambridge University Press.

Robson, C. (2002). Real world research: a resource for social scientists and practitioner-researchers (2nd ed.). Oxford: Blackwell Publishers.

Rowe, V. C. (2009). Using video-stimulated recall as a basis for interviews: Some experiences from the field. Music Education Research, 11(4), 425-437.

Rubin, H. J., \& Rubin, I. (2012). Qualitative interviewing: the art of hearing data (3rd ed.). Thousand Oaks, California: Sage.

Ryan, G. W., \& Bernard, H. B. (2003). Techniques to identify themes. Field Methods, 15(1), 85-109. 
Samimy, K. K., \& Kobayashi, C. (2004). Toward the development of intercultural communicative competence: Theoretical and pedagogical implications for Japanese English teachers. Jalt Journal, 26(2), 245-261.

Sano, M. (2014). Critical Thinking Skills and Teachers' Questioning Behavior in a Japanese University EFL Context (Doctoral dissertation). Soka University, Japan.

Sapsford, R., \& Jupp, V. (2006). Data Collection and Analysis (2nd ed.). London: Sage Publications.

Savignon, S.J. \& Wang, C. (2003). Communicative language teaching in EFL contexts: Learner attitudes and perceptions. International Review of Applied Linguistics in Language Teaching, 41(3), 223-249.

Schensul, J. J. (2012). Methodology, methods, and tools in qualitative research. In S. D. Lapan, M. T. Quartaroli, \& F. J. Riemer (Eds.). Qualitative Research: An Introduction to Methods and Designs, (pp. 69-103). San Francisco: Jossey-Bass

Sharpe, T. (2008). How can teacher talk support learning? Linguistics and Education, 19(2), 132-148.

Sheen, Y., \& Ellis, R. (2011). Corrective feedback in language teaching. Handbook of research in second language teaching and learning, 2, 593-610.

Shen, P., \& Yodkhumlue, B. (2012). A case study of teacher's questioning and students' critical thinking in college EFL reading classroom. International Journal of English Linguistics, 2(1), 199-206.

Shenton, A. K. (2004). Strategies for ensuring trustworthiness in qualitative research projects. Education for information, 22(2), 63-75.

Shim, R. J., and Baik, M. J. (2003). English Education in South Korea. In W. K. Ho and R. Y. L. Wong (Eds.), English Language Teaching in East Asia Today: Changing Policies and Practices (pp. 235-256). Singapore: Eastern Universities Press. 
Shomoossi, N. (2004). The Effect of Teachers' Questioning Behavior on EFL Classroom Interaction: A Classroom Research Study. Reading Matrix: An International Online Journal, 4(2), 96-104.

Spencer, R., Pryce, J. M., \& Walsh, J. (2014). Philosophical approaches to qualitative research. In P. Leavy (Ed.), The Oxford Handbook of Qualitative Research (pp. 81-98). New York: Oxford University Press.

Stake, R. E. (1995). The art of case study research. Thousand Oaks: Sage Publications.

Stewart, D. W., \& Shamdasani, P. N. (2014). Focus groups: Theory and practice. Los Angeles: Sage Publications.

Suk-a-nake, R., Heaton, S.L., Dhanan, C., \& Rorex, P.D. (2003). Thai university EFL learners' oral responses to various spoken question types. SLLT, 12, 19-31.

Sullivan, P. N. (2000). Playfulness as mediation in communicative language teaching in a Vietnamese classroom. In J. P. Lantolf (Ed.), Sociocultural Theory and Second Language Learning (pp.115-131). Oxford: Oxford University Press.

Sun, Z. (2012). An empirical study on new teacher-student relationship and questioning strategies in ESL classroom. English Language Teaching, 5(7), $175-183$.

Swain, M. (1985). Communicative competence: Some roles of comprehensible input and comprehensible output in its development. In S. M. Gass \& C. Madden (Eds.), Input in second language acquisition (pp. 235-253). Rowley, MA: Newbury House.

Swain, M. (1993). The output hypothesis: Just speaking and writing aren't enough. The Canadian Modern Language Review, 50(1), 158-164.

Swain, M. (1995). Three functions of output in second language learning. In G. Cook \& B. Seidlhofer (Eds.), Principle and practice in applied linguistics: Studies in honor of H. G. Widdowson (pp. 125-144). Oxford: Oxford University Press. 
Swain, M. (2000). 'The output hypothesis and beyond: mediating acquisition through collaborative dialogue'. In J. Lantolf (Ed.), Sociocultural Theory and Second Language Learning (pp. 97-114). Oxford: Oxford University Press.

Swain, M. (2005). 'The output hypothesis: Theory and research'. In F. Hinkel (Ed.), Handbook on research in second language teaching and learning (pp. 495508). Mahwah, NJ: Lawrence Erlbaum.

Swain, M., \& Lapkin, S. (1995). Problems in output and the cognitive processes they generate: A step towards second language learning. Applied Linguistics, 16(3), 371-391.

Tait, C., Horsley, J., \& Tait, K. (2018). The contextual teaching-learning mapping of academically successful Pasifika students. Asia Pacific Education Review, 19(3), 353-361.

Tan, Z. (2007). Questioning in Chinese university EL classrooms - what lies beyond it? RELC Journal, 38(1), 87-103.

Thanh, P. T. H. (2011). An Investigation of Perceptions of Vietnamese Teachers and Students toward Cooperative Learning (CL). International education studies, 4(1), 3-12.

Tomlinson, B., \& Dat, B. (2004). The contributions of Vietnamese learners of English to ELT methodology. Language Teaching Research, 8(2), 199-222.

Toohey, K, (2000). Learning English at school: Identity, social relations and classroom practice. Clevedon, UK: Multilingual Matters.

Tuan, L. T., \& Nhu, N. T. K. (2010). Theoretical review on oral interaction in EFL classrooms. Studies in Literature and Language, 1(4), 29-48.

Ur, P. (2000). A course in language teaching: Practice and theory. Cambridge, England: Cambridge University Press.

Vietnamese Prime Minister. (2008). Quyết định Phê duyệt Đề án "Dạy và học ngoại ngũu trong hệ thống giáo dục quốc dân giai đoạn 2008-2020" (Decision on 
"The project of teaching and learning foreign languages in the national educational system 2008-2020”). (1400/QĐ-TTg). Hanoi: Vietnam.

Vygotsky, L. S. (1978). Mind in Society. Boston, MA: Harvard University Press.

Wajnryb, R. (1992). Classroom observation tasks: A resource book for language teachers and trainers. Cambridge, England: Cambridge University Press.

Walqui, A. (2006). Scaffolding instruction for English language learners: A conceptual framework. International Journal of Bilingual Education and Bilingualism, 9(2), 159-180.

Walsh, J. A., \& Sattes, B. D. (2016). Quality questioning: Research-based practice to engage every learner. Thousand Oaks, California: Corwin Press.

Wang, K., \& Wang, X. (2013). Promoting knowledge construction and cognitive development: A case study of teacher's questioning. Theory and Practice in Language Studies, 3(8), 1387-1392.

Waring, H. Z. (2009). Moving out of IRF (Initiation-Response-Feedback): A single case analysis. Language Learning, 59(4), 796-824.

Wells, G. (1999). Dialogic Inquiry: Towards a Sociocultural Practice and Theory of Education. Cambridge: Cambridge University Press.

Wright, B. M. (2016). Display and referential questions: Effects on student responses. Nordic Journal of English Studies, 15(4), 160-189.

Yang, C. C. R. (2010). Teacher questions in second language classrooms: An investigation of three case studies. Asian EFL Journal, 12(1), 181-201.

Yang, H. (2006). A report of an ESL classroom observation in two language schools in Auckland. TESL Canada Journal, 23(2), 1-11.

Yaqubi, B., \& Mozaffari, F. (2011). EFL teacher questions to scaffold learning process: A Conversation Analytic Study. Journal of English Language Pedagogy and Practice, 4(8), 228-259. 
Yin, R. K. (2011). Applications of case study research (3rd ed.). Thousand Oaks, California: Sage.

Yin, R. K. (2013). Case study research: design and methods (5th edition.). Los Angeles: Sage.

Yunus, M. M., \& Yasin, M. H. M. (2018). Competencies in Knowledge, Preparation and Questioning Skills: From English Teachers' Perspectives. International Journal of Innovative Research and Development, 7(7).

Zohrabi, M., Yaghoubi-Notash, M., \& Khiabani, S. Y. (2014). Teachers' Use of Display vs. Referential Questions. International Journal of Applied Linguistics and English Literature, 3(2), 96-100. 


\section{APPENDICES}

\section{APPENDIX A: INFORMATION SHEET AND CONSENT FOR THE PRESIDENT OF THE UNIVERSITY}

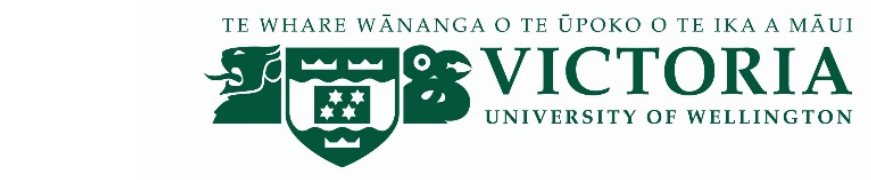

Teacher questioning in English classes in a university in Vietnam

\section{INFORMATION SHEET (FOR PRESIDENT OF UNIVERSITY)}

Thank you for your interest in this project. Please read this information before deciding whether or not to take part.

I am a PhD student in Education at Victoria University of Wellington. As part of this degree I am undertaking a research project leading to a thesis. The project I am undertaking is examining teacher questioning within communicative language teaching. This research project has received approval from the Victoria University Human Ethics Committee (2016).

Lecturers and students in Faculty of English for Specific Purposes and Business English Faculty in Foreign Trade University will be potential participants in this study. I need your permission to contact with the lectures and students. I will ask their permission to undergo the research. Both lecturers and students will be asked to allow me to audio and video record one lesson. After two days, lecturers will be invited to participate in a 30 minute interview where we will discuss parts of the video-recordings. Students will be invited to participate in a separate focus group discussion in one-and-a-half hours.

Participants' responses from interviews, focus group discussion and the recording of the class will form the basis of my research project but their identity will be kept confidential. I will use pseudonyms when referring to each participant and the university so it will not be possible for the participants and the university to be identified personally. No other person besides my supervisors, Dr. Margaret Gleeson and Dr. Carolyn Tait and myself, will see the 
video or transcripts. The translator will commit to treat the information as confidential as well.

Audio and video recordings and transcripts will be kept safe and secure in locked cabinets or password protected files. They will be deleted three years after the end of the project.

The thesis will be submitted for marking to Victoria University of Wellington and deposited in the University Library. It is intended that one or more articles will be submitted for publication in scholarly journals. The university and faculties will not be identified in the published material.

If you do decide to let me do the research in the university, you have the right to:

- ask any questions about the study at any time;

- $\quad$ stop the study without having to give reasons at any time before $1^{\text {st }}$ January 2017 when data analysis will take place;

If you have any further questions or would like to receive further information about the project, please contact me or my supervisors at the School of Education at Victoria University at:

Researcher:

Phan Thi Van Anh

Email: vananh.phan@vuw.ac.nz

\section{Supervisors:}

\section{Dr. Margaret Gleeson}

Phone: : +64 44639502

Email: margaret.gleeson@vuw.ac.nz

\section{Dr. Carolyn Tait}

Phone: +64 4463 9590,

Email: carolyn.tait@vuw.ac.nz

If you have any concerns about the ethical conduct of the research you may contact the Victoria University HEC Convener: Associate Professor Susan Corbett. Email susan.corbett@vuw.ac.nz or telephone +64-4-463 5480. 


\section{Teacher questioning in English classes in a university in Vietnam}

\section{CONSENT TO APPROVE THE RESEARCH IN THE UNIVERSITY (FOR PRESIDENT OF UNIVERSITY)}

Researcher: Phan Thi Van Anh, School of Education, Victoria University of Wellington.

I have been given and have understood an explanation of this research project. I have had an opportunity to ask questions and have them answered to my satisfaction.

I agree for the research study described above to be conducted in Foreign Trade University. I understand that:

- I may stop this project before data analysis takes place on 1 January 2017 without having to give reasons.

- Students and lecturers are permitted to withdraw from the research at any time.

- Any information the participants provide will be kept confidential by the researcher, the supervisors and the person who translates the transcripts in the project.

- The published results will not use university's name, and that no arguments will be attributed to the university in any way that will identify the university.

- The video and audio recordings as well as the transcripts relating to participants and university will be destroyed three years after the end of the project.

Signed:

Name of President:

Date: 


\section{APPENDIX B: INFORMATION SHEET AND CONSENT FOR THE DEANS OF THE FACULTIES}

TE WHARE WĀNANGA O TE ŪPOKO O TE IKA A MĀUI

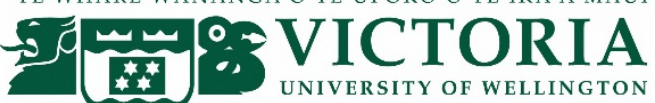

\section{Teacher questioning in English classes in a university in Vietnam}

\section{INFORMATION SHEET FOR DEAN OF FACULTY}

Thank you for your interest in this project. Please read this information before deciding whether or not to take part.

I am a PhD student in Education at Victoria University of Wellington. As part of this degree I am undertaking a research project leading to a thesis. The project I am undertaking is examining teacher questioning within communicative language teaching. This research project has received approval from the Victoria University Human Ethics Committee (2016). It has also received permission from the president of your university.

Lecturers and students in Faculty of Business English in Foreign Trade University will be potential participants in this study. I need your permission to contact with the lectures and students in the faculty. I will ask their permission to undergo the research. Both lecturers and students will be asked to allow me to audio and video record one lesson. After two days, lecturers will be invited to participate in a 30 minute interview where we will discuss parts of the video-recording. Students will be invited to participate in a separate focus group discussion in one-and-a-half hours.

Participants' responses from interviews, focus group discussion and the recording of the class will form the basis of my research project but their identity will be kept confidential. I will use pseudonyms when referring to each participant and the university so it will not be possible for the participants and the university to be identified personally. No other person besides my supervisors, Dr. Margaret Gleeson and Dr. Carolyn Tait and myself, will see the video or transcripts. The translator will commit to treat the information as confidential as well. 
Audio and video recordings and transcripts will be kept safe and secure in locked cabinets or password protected files. They will be deleted three years after the end of the project.

The thesis will be submitted for marking to Victoria University of Wellington and deposited in the University Library. It is intended that one or more articles will be submitted for publication in scholarly journals. The university and faculty will not be identified in the published material.

If you do decide to let me do the research in the university, you have the right to:

- $\quad$ ask any questions about the study at any time;

- $\quad$ stop the study without having to give reasons at any time before $1^{\text {st }}$ January 2017 when data analysis will take place;

If you have any further questions or would like to receive further information about the project, please contact me or my supervisors at the School of Education at Victoria University at:

Researcher:

Phan Thi Van Anh

Email: vananh.phan@vuw.ac.nz

\section{Supervisors:}

\section{Dr. Margaret Gleeson}

Phone: : +64 44639502

Email: margaret.gleeson@vuw.ac.nz

\section{Dr. Carolyn Tait}

Phone: +64 4463 9590,

Email: carolyn.tait@vuw.ac.nz

If you have any concerns about the ethical conduct of the research you may contact the Victoria University HEC Convener: Associate Professor Susan Corbett. Email susan.corbett@vuw.ac.nz or telephone +64-4-463 5480. 


\section{Teacher questioning in English classes in a university in Vietnam CONSENT TO APPROVE THE RESEARCH IN THE FACULTY (FOR DEAN OF FACULTY)}

\section{Researcher: Phan Thi Van Anh, School of Education, Victoria University of Wellington.}

I have been given and have understood an explanation of this research project. I have had an opportunity to ask questions and have them answered to my satisfaction.

I agree for the research study described above to be conducted in The Faculty I understand that:

- I may stop this project before data analysis takes place on 1 January 2017 without having to give reasons.

- Students and lecturers are permitted to withdraw from the research at any time.

- Any information the participants provide will be kept confidential by the researcher, the supervisors and the person who translates the transcripts.

- The published results will not use faculty's name, and that no arguments will be attributed to the faculty in any way that will identify the faculty.

- The video and audio recordings as well as the transcripts relating to participants and faculty will be destroyed three years after the end of the project.

- Signed:

Name of Dean:

Date: 


\section{APPENDIX C: INFORMATION SHEET AND CONSENT FOR TEACHER PARTICIPANTS}

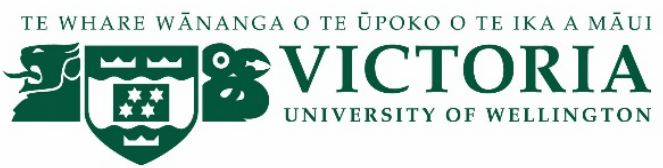

\section{Teacher questioning in English classes in a university in Vietnam}

\section{INFORMATION SHEET FOR LECTURERS}

Thank you for your interest in this project. Please read this information before deciding whether or not to take part.

I am a PhD student in Education at Victoria University of Wellington. As part of this degree I am undertaking a research project leading to a thesis. My project is examining teacher questioning within communicative language teaching. This research project has received approval from the Victoria University Human Ethics Committee (2016). The project has also received the permission from the president of your university and dean of your faculty.

I am inviting teachers and students from tertiary EFL classes at Foreign Trade University to participate in this study. I need your permission to audio and video-record one lesson. After two days, you will be invited to participate in a face-to-face interview where we will discuss parts of the video-recording.

Your responses from the interview and the recording of the class will form the basis of my research project but your identity will be kept confidential. I will use pseudonyms when referring to each participant so it will not be possible for you to be identified personally. No other person besides my supervisors, Dr. Margaret Gleeson and Dr. Carolyn Tait, and me will see the video or transcripts. The translator will commit to treat the information as confidential as well.

Audio- and video-recordings and transcripts will be kept safe and secure in locked cabinets or password protected files. They will be deleted three years after the end of the project.

The thesis will be submitted for marking to Victoria University of Wellington and deposited in the University Library. It is intended that one or more articles will be submitted for publication in scholarly journals. 
You do not have to accept this invitation if you don't want to. If you do decide to participate, you have the right to:

- choose not to answer any question;

- withdraw from the study without question at any time before $1^{\text {st }}$ January 2017 when data analysis will take place;

- ask any questions about the study at any time;

- receive a transcript of your interview;

- be able to read any reports of this research by emailing the researcher to request a copy.

If you have any further questions or would like to receive further information about the project, please contact me or my supervisors at the School of Education at Victoria University at:

Researcher:

Phan Thi Van Anh

Email: vananh.phan@vuw.ac.nz

\section{Supervisors:}

\section{Dr. Margaret Gleeson}

Phone: : +64 44639502

Email: margaret.gleeson@vuw.ac.nz

\section{Dr. Carolyn Tait}

Phone: +64 4463 9590,

Email: carolyn.tait@vuw.ac.nz

If you have any concerns about the ethical conduct of the research you may contact the Victoria University HEC Convener: Associate Professor Susan Corbett. Email susan.corbett@vuw.ac.nz or telephone +64-4-463 5480. 


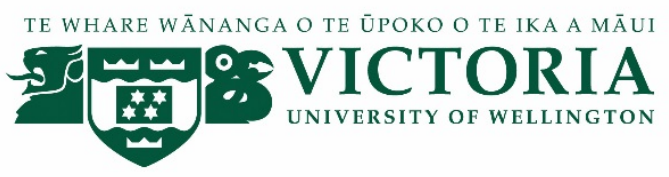

\section{Teacher questioning in English classes in a university in Vietnam}

\section{CONSENT TO PARTICIPATE IN RESEARCH (FOR LECTURERS)}

\section{Researcher: Phan Thi Van Anh, School of Education, Victoria University of Wellington.}

I have been given and have understood an explanation of this research project. I have had an opportunity to ask questions and have them answered to my satisfaction.

I understand that:

- I may withdraw myself (or any information I have provided) from this project before data analysis takes place on 1 January 2017 without having to give reasons.

- Any information I provide will be kept confidential by the researcher, the supervisors and the person who translates the audio-recording of our interview.

- The published results will not use my name, and that no opinions will be attributed to me in any way that will identify me.

- The video and audio recordings as well as the transcripts of the observation and interview will be destroyed three years after the end of the project.

- I will have an opportunity to check the transcripts of the interview before publication.

I consent to the following:

- I agree that the researcher will observe and audio and video record one session of my class

Yes $\square \quad$ No

- I agree to take part in one audio recorded interview to reflect on the video of the class.

Yes $\square \quad$ No

- I would like to have a summary of findings

Yes $\square \quad$ No

Signed:

Name of participant:

Date: 


\section{APPENDIX D: INFORMATION SHEET AND CONSENT FOR STUDENTS (CLASS OBSERVATION)}

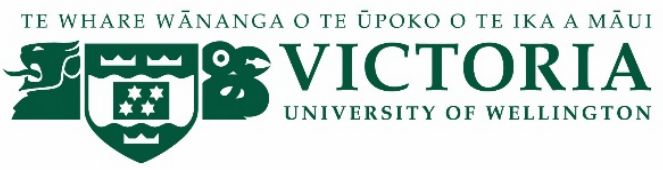

Teacher questioning in English classes in a university in Vietnam

\section{INFORMATION SHEET FOR STUDENTS}

Thank you for your interest in this project. Please read this information before deciding whether or not to take part.

I am a PhD student in Education at Victoria University of Wellington. As part of this degree I am undertaking a research project leading to a thesis. My project is examining teacher questioning within communicative language teaching. This research project has received approval from the Victoria University Human Ethics Committee (2016). The project has also received the permission from the president of your university and dean of your faculty.

I am inviting teachers and students from tertiary EFL classes at Foreign Trade University to participate in this study. I need your permission to audio- and video-record one lesson. After two days, you may be invited to participate in a focus group discussion for about one-and-ahalf hours.

Your responses from the focus group discussion and the recording of the class will form the basis of my research project but your identity will be kept confidential. I will use pseudonyms when referring to each participant so it will not be possible for you to be identified personally. No other person besides my supervisors, Dr. Margaret Gleeson and Dr. Carolyn Tait, and me will see the video or transcripts. The translator will commit to treat the information as confidential as well.

Audio- and video-recordings and transcripts will be kept safe and secure in locked cabinets or password protected files. They will be deleted three years after the end of the project.

The thesis will be submitted for marking to Victoria University of Wellington and deposited in the University Library. It is intended that one or more articles will be submitted for publication in scholarly journals.

You do not have to accept this invitation if you don't want to. It will not affect your academic progress in any way. Your participation or not will not affect your grades. If you do not 
want to participate in the observations, you may sit so that your image will not be captured. Alternatively, your voice or image in the video will be deleted or blocked out. If you have other concerns about attending the class, please discuss this with your teacher.

If you do decide to participate in the observation you have the right to:

- withdraw your appearance in observation recordings from the study without question at any time before $1^{\text {st }}$ January 2017 when data analysis will take place;

- ask any questions about the study at any time;

If you decide to participate in the focus group, you have the right to:

- choose not to answer any question in the focus group;

- leave the focus group discussion at any time;

- receive a transcript of your focus group;

- be able to read any reports of this research by emailing the researcher to request a copy.

However, you cannot withdraw your data from the focus group after your participation.

If you have any further questions or would like to receive further information about the project, please contact me or my supervisors at the School of Education at Victoria University at:

Researcher:

Phan Thi Van Anh

Email: vananh.phan@vuw.ac.nz

\section{Supervisors:}

\section{Dr. Margaret Gleeson}

Phone: : +64 44639502

Email: margaret.gleeson@vuw.ac.nz

\section{Dr. Carolyn Tait}

Phone: +64 4463 9590,

Email: carolyn.tait@vuw.ac.nz

If you have any concerns about the ethical conduct of the research you may contact the Victoria University HEC Convener: Associate Professor Susan Corbett. Email susan.corbett@vuw.ac.nz or telephone +64-4-463 5480. 


\section{Teacher questioning in English classes in a university in Vietnam CONSENT TO PARTICIPATE IN RESEARCH (FOR STUDENTS)}

\section{Researcher: Phan Thi Van Anh, School of Education, Victoria University of Wellington.}

I have been given and have understood an explanation of this research project. I have had an opportunity to ask questions and have them answered to my satisfaction.

I understand that:

- I may withdraw myself (or any information I have provided) from this project before data analysis takes place on $1^{\text {st }}$, January 2017 without having to give reasons. My participation or non-participation will not affect my grades.

- Any information I provide will be kept confidential by the researcher, her supervisors and the person who translates the transcripts of our focus group discussion.

- The published results will not use my name, and that no opinions will be attributed to me in any way that will identify me.

- The video and audio recordings as well as the transcripts of the observation and focus group discussion will be destroyed three years after the end of the project.

- I will have an opportunity to check the transcripts of the discussion and receive a summary of the results of the research when it is completed If I ask for.

I consent to the following:

- I agree to take part in a video recorded classroom observation: $\quad$ Yes $\square$ No

- I agree to take part in an audio recorded focus group discussion: $\quad$ Yes $\square$ No

Signed:

Name of participant:

Contact details: (email/phone)

Date: 


\section{APPENDIX E: INFORMATION SHEET AND CONSENT FOR STUDENT GROUP DISCUSSION}

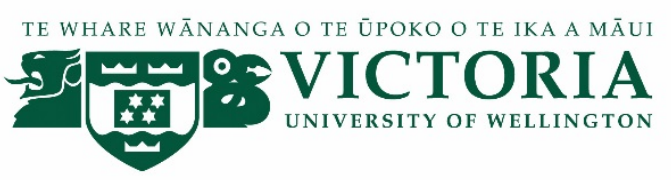

\section{Teacher questioning in English classes in a university in Vietnam}

\section{INFORMATION SHEET FOR STUDENTS (FOCUS GROUP DISCUSSION)}

Thank you for your interest in this project. Please read this information before deciding whether or not to take part.

I am a PhD student in Education at Victoria University of Wellington. As part of this degree I am undertaking a research project leading to a thesis. My project is examining teacher questioning within communicative language teaching. This research project has received approval from the Victoria University Human Ethics Committee (2016). The project has also received the permission from the president of your university and dean of your faculty.

I am inviting teachers and students from tertiary EFL classes at Foreign Trade University to participate in this study. I need your permission to audio- and video-record one lesson. After two days, you may be invited to participate in a focus group discussion for about one-and-ahalf hours.

Your responses from the focus group discussion and the recording of the class will form the basis of my research project but your identity will be kept confidential. I will use pseudonyms when referring to each participant so it will not be possible for you to be identified personally. No other person besides my supervisors, Dr. Margaret Gleeson and Dr. Carolyn Tait, and me will see the video or transcripts. The translator will commit to treat the information as confidential as well.

Audio- and video-recordings and transcripts will be kept safe and secure in locked cabinets or password protected files. They will be deleted three years after the end of the project. 
The thesis will be submitted for marking to Victoria University of Wellington and deposited in the University Library. It is intended that one or more articles will be submitted for publication in scholarly journals.

You do not have to accept this invitation if you don't want to. It will not affect your academic progress in any way. Your participation or not will not affect your grades. If you decide to participate in the focus group, you have the right to:

- choose not to answer any question in the focus group;

- leave the focus group discussion at any time;

- $\quad$ receive a transcript of your focus group;

- be able to read any reports of this research by emailing the researcher to request a copy. However, you cannot withdraw your data from the focus group after your participation.

If you have any further questions or would like to receive further information about the project, please contact me or my supervisors at the School of Education at Victoria University at:

Researcher:

Phan Thi Van Anh

Email: vananh.phan@vuw.ac.nz

\section{Supervisors:}

\section{Dr. Margaret Gleeson}

Phone: : +64 44639502

Email: margaret.gleeson@vuw.ac.nz

\section{Dr. Carolyn Tait}

Phone: +64 4463 9590,

Email: carolyn.tait@vuw.ac.nz

If you have any concerns about the ethical conduct of the research you may contact the Victoria University HEC Convener: Associate Professor Susan Corbett. Email susan.corbett@vuw.ac.nz or telephone +64-4-463 5480. 


\section{Teacher questioning in English classes in a university in Vietnam CONSENT TO PARTICIPATE IN A FOCUS GROUP}

\section{Researcher: Phan Thi Van Anh, School of Education, Victoria University of Wellington.}

I have been given and have understood an explanation of this research project. I have had an opportunity to ask questions and have them answered to my satisfaction.

I consent to take part in an audio recorded focus group discussion.

I understand that:

- My participation or discontinuous participation will not affect my grades.

- Any information I provide will be kept confidential by the researcher, her supervisors and the person who translates the transcripts of our focus group discussion.

- The published results will not use my name, and that no opinions will be attributed to me in any way that will identify me.

- The audio recordings as well as the transcripts of the focus group discussion will be destroyed three years after the end of the project.

- I will have an opportunity to check the transcripts of the discussion and receive a summary of the results of the research when it is completed if I ask for it.

- I may not withdraw data from the focus group after I have participated.

- Signed:

\section{Name of participant:}

Contact details: (email/phone)

Date: 
APPENDIX F: INFORMATION AND SUGGESTED GROUND RULES FOR FOCUS GROUP INTERVIEW ON TEACHER QUESTIONING IN ENGLISH CLASS

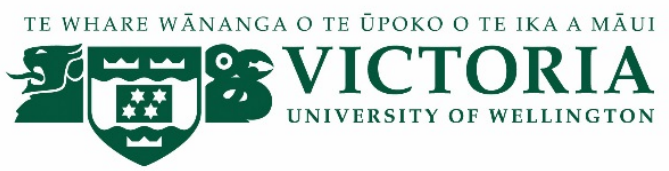

Teacher questioning in English classes in a university in Vietnam

\author{
INFORMATION AND SUGGESTED GROUND RULES FOR \\ FOCUS GROUP INTERVIEW ON TEACHER QUESTIONING IN ENGLISH CLASS
}

\title{
INFORMATION
}

\section{What is a Focus Group?}

A focus group is a relaxed, non-threatening discussion with a number of people, the purpose being to obtain perceptions on a defined topic/area. The group comprises a 'neutral' moderator (interviewer/facilitator) who interacts with the participants, asks the questions and encourages sharing of ideas between the participants. Group members can add to, and respond to others' comments and hence influence the ideas of others. However, participants are often chosen if they share some commonality with regard to the topic as most people feel more comfortable when disclosing material to people who resemble themselves.

\section{Objective of the Meeting}

The objective of this focus group meeting is to identify what students perceive teacher questioning in English class.

\section{The Planning for the Session}

1. A number of questions have been appended to this information sheet. These will form the basis of the discussion between the group members. Members 
can of course raise any other pertinent issues at the end of the discussion when 'any other comments' are called for.

2. It is important that all, participants can readily communicate with each other so being seated in a circle shape is the most useful arrangement.

3. It is important that participants agree upon a number of ground rules for the meeting. A suggested list of ground rules are appended to this information sheet.

4. The interview will be audio-recorded by the moderator and the tape will be transcribed at a later date. The transcriber will be required to sign a confidentiality agreement.

5. Members will receive a copy of the report of findings after the material has been analysed.

\section{SUGGESTED ‘GROUND RULES’ FOR FOCUS GROUP INTERVIEW}

1. It is important that all of your co-participants contribute to the discussion. Do assist others to contribute if you feel this is appropriate.

2. Keep focused on the question that is being asked. Frequently look at the question to keep you on this task.

3. Try to keep the meeting moving by being succinct - but do give all relevant information. The time frame will give you an idea about how much time to spend on each question but, if necessary, another meeting can be convened to gather further information.

4. The moderator will attempt to obtain a closure on each answer to the question - no one should feel that they have important ideas not discussed.

5. All participants need to agree that as a general rule discussion points are confidential to participants. No names or identification of school is to occur in any subsequent discussions. 


\section{APPENDIX G: INDICATIVE QUESTION PROMPTS FOR TEACHER INTERVIEW}

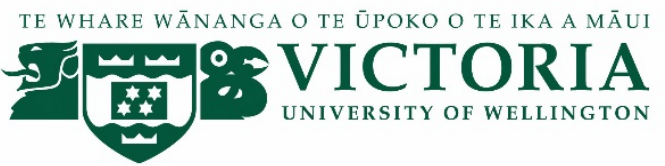

\section{Teacher questioning in English classes in a university in Vietnam}

\section{For general questions:}

Indicative question prompts for teacher interview

1. What role do you think questioning plays in promoting student learning?

a. What areas of student learning are impacted by questioning? (Communicative competency, thinking skill, understanding of lesson content, etc.)

b. What types of questions do you usually ask? Can you give me an example?

c. How do different kinds of questions affect students' language learning?

d. How do you think you can use teacher questioning to assess students' language learning? Could you please tell me more about that?

2. What role do you think that questioning plays in a communicative classroom? Can you think of an example?

a. If students do not respond to your questions, what would you do to encourage them?

b. How can you stimulate students to answer difficult questions?

c. After students answer, what do you do to encourage them to engage in more communication?

3. How do you use questions to encourage interaction between students and students?

a. Who should ask questions - teachers, students or both? Why?

b. How can you encourage students to make questions?

4. English is taught as a major/ non-major in your class, how does the purpose of teaching English influence your questioning (promote communicative language learning)? 
5. Are you satisfied with the quality and quantity of questioning in your class? Why or why not?

a. What encourages you to use questions in class?

b. What discourages you from using questions in class? (students' language proficiency, the major subject, etc.)

6. Have you ever had any professional learning and development about the use of questioning? If so please elaborate. If not would you like some?

\section{For the stimulated recall interview for teachers}

1. I would like you to focus on your question in this section. Why did you ask that question at that point in the lesson?

2. Why did you select that student?

3. How did this question help the student's/students' language learning?

4. Can you tell me a little more about that? 


\section{APPENDIX H: INDICATIVE QUESTION PROMPTS FOR STUDENT FOCUS GROUP}

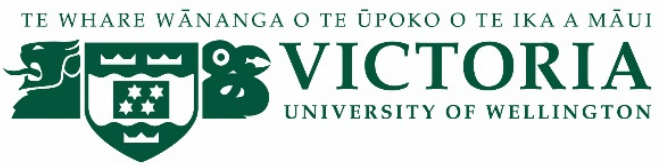

\section{Teacher questioning in English classes in a university in Vietnam}

\section{Indicative questions for student focus groups}

1. What role do you think that teacher questioning plays in your language learning?

a. Why do you think teachers ask questions in class?

b. What types of questions do the teachers usually ask? Can you think of an example?

c. How do the teacher's questions help you to learn? (lesson content, communicative ability, critical thinking, etc.)

2. When the teacher asks questions, do you prefer to answer in chorus, or be nominated by teacher, or volunteer to stand up to respond? Why?

a. Under what circumstances do you volunteer an answer?

b. Can you explain why (if you do not usually answer the questions voluntarily)?

3. Do you ask questions of other students as well as of your teachers? Can you think of an example?

4. English is taught as a major/ non-major in your class. How does it influence your response to teacher questioning?

5. What encourages you to respond to teacher questions? (the teacher offers more wait time or further explanation of questions, working in a pair or a group before giving answers, the teacher is friendly and open, etc.) Can you remember a time when you were encouraged to respond?

6. What may make it difficult for you to respond to teacher questions? (Difficult questions, lack of confidence, don't have enough time to think before answering, etc.) Can you remember a time when you were reluctant to respond?

7. How do you feel about asking the teacher questions?

8. If you ask questions of other students or the teacher what sorts of questions do you ask? Can you remember a time when you asked other students/your teacher a question? 


\section{APPENDIX I: TRANSLATOR CONFIDENTIALITY AGREEMENT}

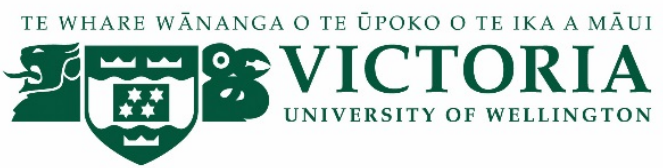

\section{Teacher questioning in English classes in a university in Vietnam}

\section{TRANSLATOR CONFIDENTIALITY AGREEMENT}

I, agree to translate data from Vietnamese into

English for this study. I acknowledge the strict and complete confidentiality of the translation process. I agree to:

1. Keep all research information shared with me confidential by not discussing or sharing the information in any form or format (e.g., disks, tapes, transcripts) with anyone other than Phan Thi Van Anh, the researcher of this study;

2. Keep all research information in any form or format (e.g., disks, tapes, transcripts) secure while it is in my possession. This includes:

- keeping all translation documents and digitized recordings in computer password-protected files;

- closing any translation programs and documents when temporarily away from the computer;

- keeping any printed translations in a secure location such as a locked file cabinet; and

- permanently deleting any e-mail communication containing the data;

3. Give all research information in any form or format (e.g., disks, tapes, transcripts) to the researcher when I have completed the research tasks;

4. Erase or destroy all research information in any form or format that is not returnable to the researcher (e.g., information stored on my computer hard drive) upon completion of the research tasks.

Signed:

Name of translator:

Date: 